UNIVERSIDADE DE SÃO PAULO

INSTITUTO DE FÍSICA

\title{
Aplicação da Teoria de Conjuntos Fuzzy a Problemas da Biomedicina
}

\author{
Neli Regina Siqueira Ortega
}

Tese de Doutoramento submetida ao Instituto de Física da Universidade São Paulo para obtenção do Título de Doutor em Ciências

Orientador: Prof. Dr. Eduardo Massad

Co-orientador: Prof. Dr. Mário José de Oliveira

\section{Banca examinadora:}

Profa. Dra. Dirce Maria Trevizan Zanetta (FM/SJRP)

Prof. Dr. Eduardo Massad (FM/USP)

Prof. Dr. Fernando Gomide (FEE/UNICAMP)

Prof. Dr. Nestor Caticha (IF/USP)

Prof. Dr. Rodney Bassanezi (IMECC/UNICAMP)

Projeto financiado pela FAPESP

São Paulo - 2001 
Á todos que alimentam o amor
e a esperança em seus corações

Ao Eduardo Rissi, por todo o amor que ele me inspira 


\section{Agradecimentos}

No meu modo de ver, nunca realizamos um trabalho solitário pois sempre somos auxiliados, seja com idéias, com compreensão, com conselhos sinceros ou com o silêncio caridoso. Na realização desse trabalho tive muitos colaboradores e recebi apoios diversos, e é com alegria que agradeço:

Ao Eduardo Massad, por ter me proposto um tema tão interessante e com o qual tanto me identifiquei. Por ter confiado em mim e respeitado integralmente o meu modo de pensar e agir, permitindo que eu conduzisse os trabalhos e as colaborações segundo a minha maneira. A sua atitude de orientador contribuiu intensamente para o desenvolvimento da auto-confiança e da autonomia no meu trabalho acadêmico. Agradeço-lhe por termos sido antes parceiros do que professor e aluna, sem se furtar as suas responsabilidadesde orientador. Enfim, pelo seu positivismo contagiante.

Ao Mário José de Oliveira, por ter aceitado co-orientar esteprojeto, contribuindo para o trabalho com sua visão de físico,estando sempre disposto a discutir as minhas idéias e solícito para resolver qualquer problema de caráter burocrático.

Ao Pedro Tonelli do IME-USP, ao Laécio de Barros do IMECC/UNICAMP e a Suzana Abreu, por terem me acolhido de forma tão carinhosa no seu grupo de seminários, cujas discussões são para mim fundamentais. Agradeço particularmente ao Laécio que, pela harmonia dos nossos interesses em epidemiologia, colaborou intensamente com parte dos trabalhos aqui apresentados.

Ao Marcelo Burattini e Paulo Silveira da FMUSP, ao Cláudio Struchiner da FIOCRUZ, ao Luiz Fernando Nascimento da FM/Taubaté, ao José Leal da Costa e Liz Maria de Almeida da FM/UFRJ, ao Galdenoro Botura e Francisco Lotufo da FEE/UNESP de Guaratingueta, a Aglaé Navarrode Magalhães do CBPF e a Marisa Vianna do Museu de Zoologia da USP, pela colaboração presente e futura que caracteriza a interdisciplinariedade dessa tese.

Aos pneumologistas da FMUSP/HC, pelo auxílio no desenvolvimento do sistema especialista para o diagnóstico de doenças pulmonares, fornecendo inclusive propotocolos médicos. A todos os profissionais de saúde envolvidos na campanha de vacinação contra o sarampo do ano de 1997, por terem colaborado como especialistas na elaboração desse modelo.

À Professora Amélia Império Hamburger, por ter sido a primeira aqui no IFUSP a me incentivar a prosseguir nessa pesquisa. Pela lucidez e autenticidade dos seus pensamentos que são como flores a nos convidar à reflexão.

Ao Professor Silvio Salinas por ter me acolhido no Departamento de Física Geral, mostrando-se sempre interessado com o meu desenvolvimento acadêmico. 
À todos os amigos da DIM, Renee, Lopez, Chico, Armando, Sameshima, Ray, Tatico, Jorge, Valtair, enfim, todos que fazem da dim um lugar agradável e bem humorado. Agradeço especialmente a Wilma e a Iracene pelo profissionalismo e boa vontade com que nos ajudam nos nossos trabalhos.

À todos da FGE, em especial as nossas secretárias Silvana, Dirce e Ivone, que fazem com que as coisas funcionem. Ao Jairo pela paciência em me ajudar com as máquinas. Ao Nelson, ao Leonardo e ao Josué por me ajudarem a vencer olatex. Ao Leo, ao Fabiano, a Geraldine, e todos os amigos da Mecânica Estatística que já me deixam saudades.

Aos desenhistas do IFUSP, em especial ao Carlos que me ajudou imensamente com as figuras, demonstrando uma dedicação e uma gentileza sem limites

À FAPESP pelo apoio financeiro e respeito com que recebe os seus bolsistas.

À minha mãezinha e minha irmã Neu, porque não consigo avançar sem me lembrar que devo a elas muito do que sou, que sou parte delas e que elas são parte de mim.

Aos meus amigos mais queridos, Nana, Lele, Jeff, Peluche, Fred e Eide, por me ouvirem tantas e tantas vezes, por confiarem em mim, pela nossa amizade que supera as circunstâncias.

Ao meu doce Du, meu oceano de emoções, meu companheiro de todas as horas, que juntamente com o Pequeninho e a Neguinha preenchem os meus dias com deliciosa simplicidade e bom humor.Por me sentir tão amada e respeitada. Pelo seu esforço hercúleo em colocar algo de método no meu jeitotão fuzzy de ser.

À Deus por me oferecer tantas oportunidades para aprender a amar. 


\section{Resumo}

Sistemas biológicos, médicos e epidêmicos apresentam vários tipos de incertezas inerentes aos seus processos. Muitas dessas incertezas têm sido tratadas de forma eficiente com modelos estatísticos e Bayesianos. Todavia, essas áreas ainda carecem de estruturas matemáticas que possibilitem o tratamento das incertezas não-estatísticas típicas de alguns desses sistemas. Além disso, a utilização de termos lingüísticos para expressar quantitativamente as variáveis é muito comum em algumas dessas áreas. Assim, devido às suas características, a lógica fuzzy se apresenta como uma teoria adequada para tratar alguns desses problemas.

O objetivo dessa tese foi desenvolver aplicações da teoria de conjuntos fuzzy a problemas da biomedicina. O nosso desafio foi propor caminhos, buscar maneiras, de realizar uma junção efetiva dessa teoria com as áreas citadas, principalmente a epidemiologia. Foram elaborados oito trabalhos, onde vários aspectos dessa teoria foram abordados, tais como: modelos lingüisticos fuzzy estáticos e dinâmicos, processos de decisão fuzzy, probabilidade de eventos fuzzy, relações fuzzy e a utilização do princípio de extensão na construção de regras fuzzy.

Concluímos que a teoria de conjuntos fuzzy pode auxiliar no tratamento de muitos problemas de cunho epidemiológico, bem como sistemas diagnóstico. Mostramos também que ela pode trabalhar de forma efetiva em processos de decisão de Saúde Pública. Alguns sistemas podem, potencialmente, ajudar os médicos no diagnóstico e prognóstico de doenças, principalmente na ausência de especialistas. Os modelos lingüísticos estáticos funcionaram muito bem, entretanto, dificuldades quanto aos modelos dinâmicos precisam ainda ser superadas. Discutimos também o papel do especialista na elaboração de modelos fuzzy em epidemiologia e propomos um método para

elaboração de modelos menos dependentes. Todos os trabalhos apresentaram bons resultados, esti-mulando a continuidade das pesquisas nessa área. 


\begin{abstract}
Biological, medical and epidemic systems present several types of inherent uncertainties to its processes. Many of these uncertainties have been treated in an efficient way with statistical and Bayesian models. Though, these areas still lack of mathematical structures that make possible the treatment of the non-statistical uncertainties typical of some of these systems. Besides, the use of linguistic terms to express quantitatively the variables is very common in these areas. So, due to its features, the fuzzy logic comes as an appropriate theory to treat some of these problems.

The aim of this thesis was to develop applications of the fuzzy logic theory to problems of biomedicine. Our challenge was to propose paths, to look for ways, of accomplishing an effective junction off this theory with the mentioned areas, mainly with epidemiology. Eight works were elaborated, where several aspects of this theory were approached, such as: static and dynamic fuzzy linguistic models, fuzzy decision making, probability of fuzzy events, fuzzy relations and the use of extension principle in the construction of fuzzy rules.

We conclude that the fuzzy logic theory can aid in the treatment of many epidemiological problems, as well as diagnostic systems. We also show that it can work effectively in decision making processes of Public Health. Some systems can, pottentially, help the physicians in the diagnosis and prognostic of diseases, mainly in the specialists' absence. The static linguistic models worked well, however, difficulties concerning the dynamic models still need to be overcome. We also discuss the specialist's role in the elaboration of fuzzy models in epidemiology and propose a method for elaboration of less dependent models. All the works presented good results, stimulating the continuity of the researches in this area.
\end{abstract}




\section{Sumário}

\begin{tabular}{lll}
\hline O problema e a teoria & 1
\end{tabular}

$\begin{array}{lll}\mathbf{1} & \text { Introdução } & \mathbf{3}\end{array}$

1.1 O que é a lógica fuzzy . . . . . . . . . . . . . . . . . . . . . . . 4

1.2 Um breve histórico $\ldots \ldots \ldots$. . . . . . . . . . . . . . . . . . . . . . . 7

1.3 Porque aplicar lógica fuzzy em problemas da biomedicina . . . . . . . . 9

1.4 A lógica fuzzy na física . . . . . . . . . . . . . . . . . . . . . . 10

1.5 A teoria de conjuntos fuzzy e a teoria de probabilidade . . . . . . . . . 12

1.6 Sistemas dinâmicos contínuos fuzzy . . . . . . . . . . . . . . . . . 14

1.7 O trabalho de tese $\ldots \ldots \ldots \ldots \ldots$. . . . . . . . . . . . . . . . . 15

$\begin{array}{lll}2 & \text { Alguns conceitos da teoria de conjuntos fuzzy } & 17\end{array}$

2.1 Teoria de medida fuzzy . . . . . . . . . . . . . . . . . . 17

2.2 Conjuntos fuzzy $\ldots \ldots \ldots \ldots$. . . . . . . . . . . . . . . . . 19

2.3 Variáveis lingüísticas . . . . . . . . . . . . . . . . . . . . 26

2.4 Distribuição de possibilidades . . . . . . . . . . . . . . . . . . . . . . . 28

2.5 Regras fuzzy . . . . . . . . . . . . . . . . . . . . . . . . . . . . . . . 29

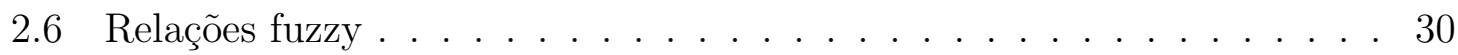

2.6 .1 Composição de Relações Fuzzy . . . . . . . . . . . . . . . . . . 32

2.7 Princípio de extensão . . . . . . . . . . . . . . . . . . . . 33

2.8 Processos de decisão fuzzy . . . . . . . . . . . . . . . . . . . . . . 36

2.9 Probabilidade de eventos fuzzy . . . . . . . . . . . . . . . . . . . . 38

$2.9 .1 \quad$ Probabilidade condicional de eventos fuzzy . . . . . . . . . . . . . 39

2.9 .2 Eventos fuzzy independentes . . . . . . . . . . . . . . . . . . . 40

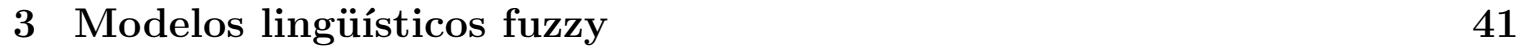

3.1 Modelos lingüísticos (MLs) . . . . . . . . . . . . . . . . . . . . . . . . . . . . . 42

3.2 Modelos lingüísticos tipo Mamdani . . . . . . . . . . . . . . . . . . . . 43

3.3 Modelos lingüísticos com múltiplas variáveis . . . . . . . . . . . . . . . 45

3.4 Métodos de defuzificação . . . . . . . . . . . . . . . . . . . . . . . . . . . . . . . . . . . . .

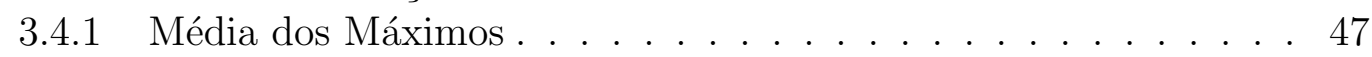

3.4 .2 Centro de Área . . . . . . . . . . . . . . . . . . . . . . . . . . . . . . . . . . . . 48

3.4 .3 Método das Alturas . . . . . . . . . . . . . . . . . . . . . . . . 49

3.5 Modelos lingüísticos dinâmicos fuzzy $\ldots$. . . . . . . . . . . . . . . . . . 49 
3.6 Modelos fuzzy tipo Takagi-Sugeno-Kang (TSK) . . . . . . . . . . . . . 52

II Os trabalhos desenvolvidos 54

4 Uma proposta de estimador de risco fuzzy em epidemiologia $\quad 56$

4.1 Estimadores de risco fuzzy . . . . . . . . . . . . . . . . . . 57

4.2 Simulação do modelo . . . . . . . . . . . . . . . . . . . . . . . . . . . . 59

4.3 Discussão $\ldots \ldots \ldots \ldots 1$

\begin{tabular}{|lll}
5 & Probabilidades de eventos epidemiológicos fuzzy & 62
\end{tabular}

5.1 A primeira questão epidemiológica. . . . . . . . . . . . . . . . . . . . 62

5.2 A segunda questão epidemiológica . . . . . . . . . . . . . . . . . . . 63

5.3 Discussão . . . . . . . . . . . . . . . . . . . . . . 66

6 Processo de decisão fuzzy para escolher uma estratégia de vacinação para o sarampo no Estado de São Paulo $\quad 67$

6.1 Elaborando a estratégia de vacinação . . . . . . . . . . . . . . . . . . . 68

6.2 A epidemia de sarampo em São Paulo. . . . . . . . . . . . . . . . . . . 73

6.3 O impacto da vacinação . . . . . . . . . . . . . . . . . . . . . . . 74

6.4 Discussão . . . . . . . . . . . . . . . . . . . . . . 77

7 Modelos lingüísticos fuzzy estáticos em biomedicina

7.1 Modelo para a inferência da progressão clínica da AIDS em indivíduos HIV soropositivos . . . . . . . . . . . . . . . . . 79

7.2 Modelo para estimativa de risco de morte neonatal . . . . . . . . . . . 86

7.3 Discussão $\ldots \ldots \ldots \ldots$. . . . . . . . . . . . . . . . . . . . . . . 92

8 Modelos dinâmicos fuzzy em epidemiologia $\quad 94$

8.1 Modelo para raiva canina na cidade de São Paulo . . . . . . . . . . . . . 95

8.2 Modelo MIMO para um sistema epidêmico tipo SIR . . . . . . . . . . . 106

8.3 Discussão $\ldots \ldots \ldots \ldots$. . . . . . . . . . . . . . . . . . . . . . . . . 115

9 Aplicação do princípio de extensão em modelos lingüísticos fuzzy 117

9.1 Extraindo a opinião do especialista . . . . . . . . . . . . . . . . . . . 117

9.2 O método . . . . . . . . . . . . . . . . . . . . . . 118

9.3 A aplicação . . . . . . . . . . . . . . . . . . . . . . 120

9.4 Discussão $\ldots \ldots \ldots \ldots$

10 Trabalhos em andamento e perspectivas futuras 124

10.1 Um modelo para a facilitação social entre espécies de cupins que apresentam canibalismo . . . . . . . . . . . . . . . . . . . . . . . . . . . 124

10.1 .1 O experimento . . . . . . . . . . . . . . . . 126

10.1.2 O autômato celular . . . . . . . . . . . . . . . . . . 127 
10.1 .3 Resultados Experimentais . . . . . . . . . . . . . . . . . . . . . 128

10.1 .4 Discussão . . . . . . . . . . . . . . . . . . . . . . . . 130

10.2 Sistema especialista fuzzy para diagnóstico de doenças pulmonares . . . 130

10.3 Fuzzy clustering em epidemiologia . . . . . . . . . . . . . . . . . . . . 135

10.4 Modelos lingüísticos fuzzy . . . . . . . . . . . . . . . . . . . . . 136

$\begin{array}{ll}11 \text { Considerações finais } & 138\end{array}$ 


\section{Parte I}

\section{O problema e a teoria}




\section{Capítulo 1}

\section{Introdução}

\section{"EPISTEMA 0 \\ PARADOXO FUNDAMENTAL}

Enquanto se pergunta sobre a possibilidade de existir a máquina que compreende, vai-se construindo uma.

E sua primeira manifestação será dizer:

Please understand me!"

Amélia Império Hamburger, 1990

O desejo de resolver problemas cada vez mais complexos tem produzido o desenvolvimento dos computadores, e a necessidade de máquinas cada vez mais eficientes e capazes tem, por sua vez, impulsionado o desenvolvimento da Inteligencia Artificial (Luger 83 Stubblefield 1997). Já podemos presenciar máquinas que aprendem por meio de exemplos devido a Teoria de Redes Neurais (Kosko 1992), que são capazes de lidar com sentenças contraditórias com o advento da Teoria da Lógica Paraconcistente (Costa et. al. 1999), que podem além de aprender evoluir com a ajuda da Teoria de Algoritmos Genéticos (Sanchez et. al. 1997) e que são capazes de imitar parte do raciocício humano, através da incorporação da habilidade para lidar com situações imprecisas e incertas, devido aos avanços da Teoria da Lógica Fuzzy (Klir 8$\}$ Yuan 1995). Toda a área de Soft Computing (Aminzadeh 83 Jamshidi 1994) senvolvido rapidamente e o interesse de profissionais e pesquisadores das mais diversas áreas por seu avanço, e por suas perspectivas de aplicação, cresce vertiginosamente.

\footnotetext{
${ }^{1}$ A área de soft computing abrange diversas teorias e tecnologias inteligentes: Inteligência Artificial, Redes Neurais, Sistemas Especialistas, Lógica Fuzzy, Algoritmo Genético, etc.
} 
Não há dúvida, portanto, de que a máquina e o racicíonio humano nunca estiveram tão próximos quanto no momento atual. A Inteligência Artificial avança evoluindo as máquinas, tornando-as mais capazes e propondo soluções cada vez mais realistas a problemas antes somente possíveis ao cérebro humano. A informática médica acompanha esta evolução e o computador auxilia o médico nas mais diferentes atividades. As contribuições da engenharia médica no desenvolvimento de controladores inteligentes no pré e pós operatórios, na tecnologia de exames laboratoriais, no tratamento de imagens, na dosagem de anestesias e mesmo em sistemas diagnósticos, são inegáveis. A lógica fuzzy muito tem participado desse processo. De fato, esta teoria tem demonstrado possuir grande capacidade de aplicação em problemas da biomedicina, dado o tipo de incerteza envolvido nos procedimentos médicos, biológicos e epidemiológicos. No entanto, até então, a maioria dos trabalhos de lógica fuzzy em medicina se devem a aplicações da área de engenharia médica e desenvolvimento de controle de equipamentos médicos (Degani $\&$ Bortolan 1987, Buckley $\& 6$ Siler 1988, Kerre 66 Nachtegael 2000, Kovalerchuk B. et al 1997, Bezdek et al 1997, Lin et al 1996, Ham 6 Han 1996). O desenvolvimento de modelos fuzzy em sistemas especialistas em medicina (Chen et al 1985, Anderson et al 1987, Willians et al 1989, Torasso 1991, Shono et al 1992, Kandel 1992, Majumder $\&$ Basu 1995) e sistemas diagnóstico (Sanchez 1979, Esogbue \& Elder 1980, Smets 1981, Vila \& Delgado 1983, Esogbue \& Elder 1983, Norris et al 1987, Roy \& Biswas 1992, Sanchez 1996, Kucheva 65 Steimann 1999, Adlassnig 2000) têm crescido enormemente nas últimas duas décadas, porém os modelos em epidemiologia são particularmente recentes, consistindo em trabalhos de grupos isolados. Esta tese teve por objetivo desvendar algumas possibilidades de aplicação dessa teoria no universo de problemas médicos, dando ênfase aos sistemas epidemiológicos. Não é necessário se aprofundar muito no universo dos médicos, dos epidemiologistas e dos profissionais de saúde pública para percebermos o potencial da lógica fuzzy como ferramenta a ser aplicada nessas áreas. O nosso desafio foi o de estabelecer alguns caminhos e buscar maneiras de realizar uma junção efetiva dessa teoria com as áreas citadas, principalmente a epidemiologia. Com este objetivo percorremos partes dessa teoria propondo modelos que abordassem problemas específicos. As perguntas que desejamos responder são: Esta teoria pode realmente ser útil na solução de problemas da biomedicina? Esta abordagem fornece resultados efetivamente aplicáveis? De que maneiras podemos aplicar a lógica fuzzy em sistemas epidemiológicos? Acreditamos que estas perguntas são respondidas no decorrer da tese e, principalmente, na discussão dos trabalhos em andamento e perspectivas futuras.

\subsection{O que é a lógica fuzzy}

A teoria fuzzy foi apresentada em 1964 por Lotfi A. Zadeh, professor no departamento de engenharia elétrica e ciências da computação da Universidade da Califórnia, em Berkeley, quando ele trabalhava com problemas de classificações de conjuntos que não 
possuíam fronteiras bem definidas (ou seja, a transição entre os conjuntos é suave e não abrupta). É importante, porém, ressaltar que no decurso da ciência outros pesquisadores demonstraram seu desconforto com relação a lógica binária, relatando sua fragilidade para lidar com situações mais realistas 2 .

Em muitos problemas em física e em matemática nós não temos dificuldade em classificar elementos como pertencentes ou não a um dado conjunto clássico. Dessa forma, dado um conjunto $A$ e um elemento $x$ do conjunto universo $U$ conseguimos muitas vezes dizer se $x \in A$ ou se $x \notin A$. Nós, por exemplo, afirmamos sem receio que o número 5 pertence ao conjunto dos números naturais e que o número -5 não pertence a este mesmo conjunto. Este é um caso sobre o qual não temos dúvidas, sendo a lógica booleana devidamente aplicada. No entanto, poderemos discordar quanto ao fato de o número 4,5 pertencer ou não ao conjunto dos números aproximadamente iguais a 5. Neste caso a resposta não é única e objetiva, pertencer ou não poderá depender do tipo de problema que estamos analisando. Pensemos, por exemplo, que 4,5 foi a média de provas de um aluno extremamente aplicado que está passando por sérios problemas de saúde e que, em razão disso, apresentou dificuldades para realizar as últimas provas. O professor nesta situação poderá ponderar sobre a capacidade do aluno, sua dedicação durante o curso e sua realidade optando por aprová-lo, ainda que a média necessária seja 5 . Neste caso o número 4,5 pode ser visto como pertencendo ao conjunto dos números aproximadamente iguais a $53^{3}$. De fato, mesmo a aplicação numérica de notas pode não ser um método totalmente objetivo de avaliação (Law 1996).

Existem inúmeras situações em que a relação de pertinência não é bem definida e, nestes casos, não sabemos dizer se o elemento pertence ou não a um dado conjunto. A intensão de Zadeh foi flexibilizar a pertinência de elementos aos conjuntos criando a idéia de grau de pertinência. Dessa forma, um elemento poderia pertencer parcialmente a um dado conjunto. Esta sua idéia foi publicada em 1965 (Zadeh 1965), sendo este artigo considerado o marco do nascimento da teoria de conjuntos fuzzy.

O termo fuzzy significa nebuloso, difuso, e se refere ao fato de, em muitos casos, não conhecermos completamente os sistemas que estamos analisando. Se desejarmos construir, por exemplo, o conjunto dos números aproximadamente iguais a 5, citado acima, como deveríamos proceder? Será que os números 2 e 10 pertenceriam a este conjunto? Claramente, esta resposta dependerá do contexto. O que Zadeh nos propõe é considerarmos uma função de pertinência que nos forneça o grau de pertinência dos diversos números ao conjunto considerado. Sendo assim, chamando de $\mathbb{F}$ o conjunto dos números aproximadamente iguais a 5 , no universo dos números naturais $\mathbb{N}$, podemos propor por exemplo, uma função de pertinência onde o $10 \in \mathbb{F}$ com grau 0,0

${ }^{2}$ A lógica de três valores proposta por Lukasiewicz, onde 1 é verdadeiro, 0 é falso e $1 / 2$ é possível, foi um trabalho formal que já sinalizava o desenvolvimento de teorias neste sentido (Reznik 1997).

${ }^{3} \mathrm{~A}$ utilização da palavra pertencer neste caso consiste em um abuso de linguagem, pois o elemento não pertence de fato ao conjunto citado. O mais correto seria dizer que o número 4,5 é compatível, com um certo grau, com a afirmação é aproximadamente igual a 5. Todavia, por simplicidade, utilizarei a palavra pertencer para designar esta compatibilidade. 
(o que corresponde a não pertinência clássica), o 2 e o $8 \in \mathbb{F}$ com grau de pertinência 0,25 , o 3 e o $7 \in \mathbb{F}$ com grau 0,5 , os números 4 e $6 \in \mathbb{F}$ com o grau 0,75 e o $5 \in \mathbb{F}$ com grau de pertinência 1,0 (correspondendo a pertinência total). Esta extensão da função característica da lógica clássica para o intervalo $[0,1]$ originou os conjuntos fuzzy e possibilitou, entre outras coisas, a utilização de variáveis lingüísticas, permitindo a exploração do conhecimento humano no desenvolvimento de muitos sistemas. A figura 1.1 apresenta a função de pertinência do conjunto fuzzy que corresponde aos números aproximadamente iguais a 5 proposta. Note que, neste caso a função de pertinência é discreta, mas ela também pode ser contínua, como por exemplo a função de pertinência para exposição à fumaça de cigarro, apresentada na figura 1.2.

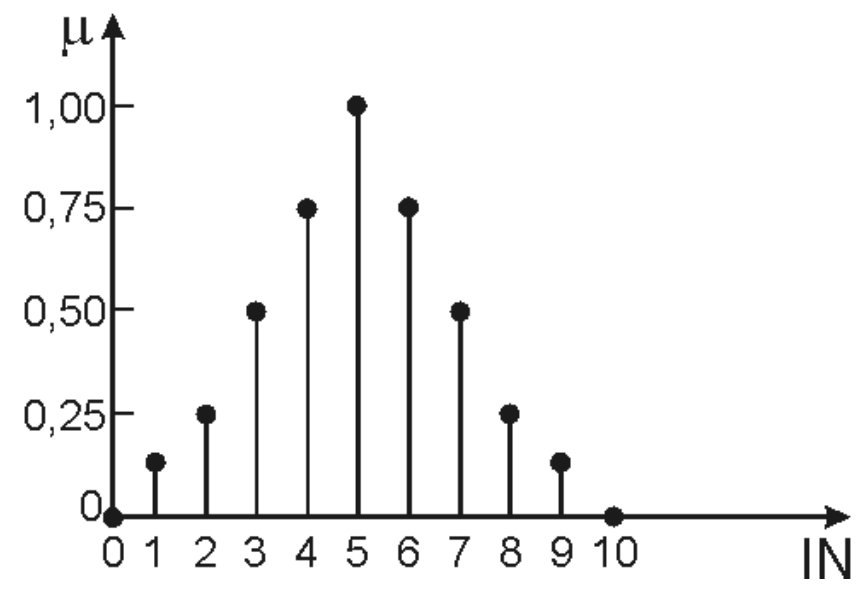

Figura 1.1: Função de pertinência do conjunto fuzzy que corresponde aos números aproximadamente iguais a 5 , no universo dos $\mathbb{N}$.

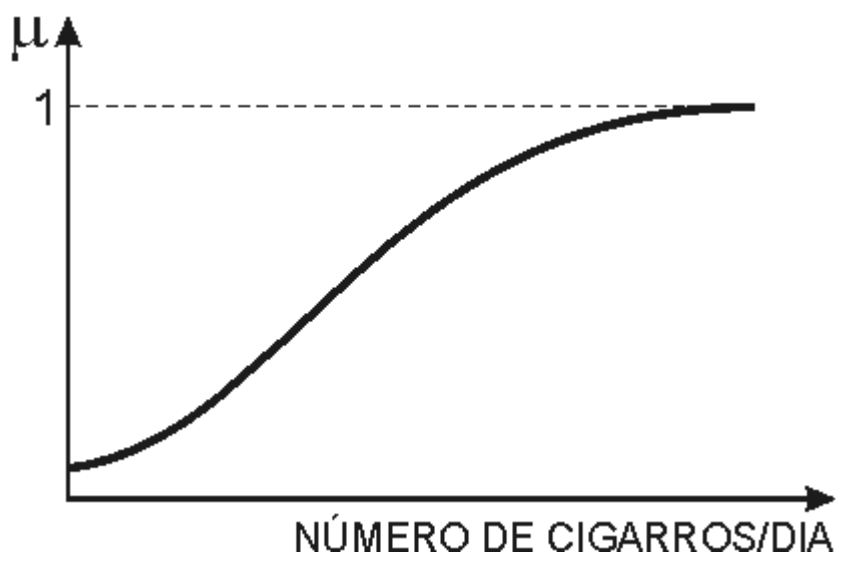

Figura 1.2: Função de pertinência para exposição à fumaça de cigarro.

Dadas as características da teoria da lógica fuzzy, é esperado que suas contribuições para o desenvolvimento da física teórica e seus princípios fundamentais sejam muito tímidas, como discutirei mais adiante. No entanto, em áreas onde é necessário lidar 
com a imprecisão, como a engenharia (Karwowski \& Mital 1986, Yager \& Filev 1994, Kosko 1997, Shaw 83 Simões 1999, Wen 8$\}$ Lee 1999) e a química (Schultz 1999, Fonseca \& Knapp 2000, Russo et al 1998), e com a subjetividade e o desconhecimento, como a biologia ( Luo et al 1995, Sadegh-Zadeh 1999), a medicina, a epidemiologia ( Massad et al 1997, Struchiner et al 1997, Ohayon 1999, Ortega et al 2000, Ortega et al 2001, Massad et al 2001), a ecologia (Giering III \& Kandel 1983, Salski 1992, Bassanezi \&3 Barros 1995, Bai-Lian Li 1996, Barros et al 2000), a economia (OH et al 1990, Tarrazo 83 Gutierrez 2000, Campbell 83 Kelly 1996, Nurmi et al 1996), a psicologia (Saitta $\&$ Torasso 1981, Averkin 83 Tarasov 1987, Theoto et al 1987, Anwar $\mathscr{6}$ Igor 1997), as ciências sociais (Smithson 1988), a educação (Law 1996) e a saúde pública (Massad et al 1999), esta teoria têm demonstrado grande capacidade de aplicação, ajudando estes profissionais a produzir modelos mais de acordo com a suas necessidades e realidades.

A idéia de grau de pertinência da lógica fuzzy nos possibilita agrupar os elementos de maneira diferente da aplicada na lógica clássica, o que nos permite re-interpretar antigos conceitos, elaborados segundo esta lógica. Os conceitos de saúde e doença, por exemplo, são vistos pela comunidade médica como opostos, ou seja, a doença é a ausência de saúde e vice-e-versa. Dessa forma, a existência de saúde e doença em um mesmo indivíduo consiste em uma situação contraditória. No entanto, na abordagem fuzzy os conceitos de doença e saúde são antes complementares do que contraditórios. Sendo assim, um novo conceito de doença e saúde pode ser estabelecido, o que pode provocar transformações em outras construções conceituais da medicina como, por exemplo, a nosologia (Sadegh-Zadeh 1994, Sadegh-Zadeh 1998, Sadegh-Zadeh 1999 ).

\section{$1.2 \quad$ Um breve histórico}

A teoria da lógica fuzzy enfrentou forte resistência por parte da comunidade científica no seu início, principalmente por parte dos estatísticos norte americanos. Entretanto, a despeito de todo preconceito muitos pesquisadores vislumbraram as possibilidades que esta teoria oferecia e trabalhos surgiram em todo o mundo, particularmente no Japão onde a lógica fuzzy encontrou um solo fértil para desenvolver-se rapidamente.

Já na primeira década (1965-1975) os pesquisadores se esforçaram por estender os fundamentos da lógica fuzzy, introduzindo conceitos novos e desenvolvendo outras abordagens da teoria, bem como as relações fuzzy, as variáveis lingüísticas, os processos de decisão fuzzy, a medida fuzzy, sistemas topológicos, álgebra com números fuzzy, fuzzy clustering, etc.. Em 1972 formou-se no Japão o primeiro grupo de pesquisas em sistemas fuzzy, coordenado pelo professor Toshiro Terano, e em 1974 iniciou-se um importante capítulo no desenvolvimento desta teoria com a apresentação do primeiro controlador fuzzy criado por E. Mamdani, no Reino Unido. A partir de então vários foram os pesquisadores que buscaram aplicar a teoria de lógica fuzzy para controlar sistemas em engenharia. Em 1976 temos a primeira aplicação industrial da lógica fuzzy, desenvolvido pelo Circle Cement e SIRA, na Dinamarca, que consistiu de um 
controlador fuzzy que incorporava o conhecimento e a experiência dos operários para controlar os fornos das fábricas (Reznik 1997). Em 1977, Didie Dubois aplicou os conjuntos fuzzy em um estudo sobre condições de tráfego e neste mesmo ano surgiu o primeiro sistema especialista fuzzy (Yen $\mathcal{E}$ Langari 1999).

Em 1985 foi desenvolvido o primeiro chip fuzzy por Masaki Togai e Hiroyuke Watanabe, no laboratório Bell (EUA). Em 1987 foi inaugurado com sucesso o primeiro trem controlado com lógica fuzzy, no sistema do metrô de Sendai, no Japão. Foi também neste ano que a Yamaha desenvolveu seu helicóptero não-tripulado, Yamaha-50, totalmente controlado por um controlador fuzzy, dando origem a era do desenvolvimento tecnológico proporcionado por esta teoria. Em 1988 começou a operar no Yamaichi Fuzzy Fund o primeiro sistema de comércio financeiro fuzzy. Mas foi em 1990 que esta teoria atingiu a popularidade com o lançamento no mercado da primeira máquina de lavar roupas fuzzy, da Matsushita Electric Industrial Co., marcando o início do desenvolvimento de produtos de consumo (Reznik 1997). Hoje é possível encontrar, principalmente no Japão, toda a sorte de eletrodoméstico cujo sistema é baseado em controles fuzzy (televisão, câmera fotográfica, panela para cozimento de arroz, vídeos, etc.) e existem atualmente várias empresas (Siemens, Daimler-Benz, Klockner-Moeller, SGS-Thomson, General Motors, Motorola, Hewlett-Packard, etc.) que possuem laboratórios de pesquisa em lógica fuzzy para desenvolvimento de seus produtos.

O objetivo desse breve histórico é ilustrar quão rápido se deu o desenvolvimento da teoria fuzzy e quão abrangente tem sido suas aplicações. Esta teoria tem mostrado possuir um enorme potencial de desenvolvimento na área de Soft Computing. Em verdade, podemos notar um interesse por esta teoria cada vez mais crescente por profissionais e pesquisadores das mais diversas áreas dada a sua capacidade de explorar variáveis lingüísticas, da possibilidade de desenvolver raciocínios mais próximos do humano, da sua diversidade de operações e da sua potencialidade em aplicações. 


\subsection{Porque aplicar lógica fuzzy em problemas da biomedicina}

Talvez em nenhum outro campo da biociência a necessidade de estruturas matemáticas e computacionais, que possibilitem lidar com as imprecisões e incertezas de forma mais crítica e realista, é tão evidente quanto na medicina e na epidemiologia. O diagnóstico de doenças envolve vários níveis de imprecisão e incerteza, particularmente nos estudos de epidemiologia. Uma única doença pode se manifestar de forma totalmente diferente em diferentes pacientes e com vários graus de severidade. Além disso, um único sintoma pode ser indicativo de várias doenças distintas, e a presença de outras doenças em um mesmo indivíduo pode alterar completamente o padrão sintomático esperado para qualquer uma delas. Estes efeitos costumam ser geradores de muitas incertezas e imprecisões afetando as interpretações dos exames e o diagnóstico. Temos ainda, que as doenças são geralmente descritas com a utilização de termos lingüísticos, que são intrinsecamente vagos, e que muitas são as variáveis qualitativas em medicina, o que apresenta dificuldades na utilização de métodos quantitativos. Um resumo muito bem documentado sobre os diferentes tipos de incertezas inerentes a área médica pode ser obtido em Silva (Silva 2001).

Em epidemiologia a incerteza não se restringe apenas a variações aleatórias. Nessa área podemos agrupar as incertezas em duas classes: a variabilidade, originada da heterogeneidade da população ou da estocacidade; e a ignorância parcial, que resulta de erros sistemáticos de medida ou do desconhecimento de parte do processo considerado (subjetividade). Portanto, variabilidade e ignorância devem ser tratados com métodos diferentes e mais apropriados (Ferson 6 Ginzburg 1996). No caso da variabilidade a Teoria de Probabilidades (estatística) é, em geral, o método mais indicado, porém, ela não consegue na maioria das vezes abordar o problema da ignorância e da subjetividade. Esses últimos podem ser tratados, entre outros métodos, com a Teoria da Lógica Fuzzy 4 .

A Teoria da Lógica Fuzzy tem sido desenvolvida para lidar com o conceito de verdade parcial, ou seja, com valores de verdade entre o completamente verdadeiro e o completamente falso da lógica Booleana. Não é necessário muito esforço para percebermos que poucos são os casos no nosso cotidiano real em que temos total certeza sobre as coisas e os fatos, e que faz parte da atividade humana tomar decisões considerando a verdade parcial existente. Nesse sentido, dificilmente podemos considerar um indivíduo completamente doente (algumas funções, ou a maioria delas, permanecem perfeitas), da mesma forma poucas vezes podemos nos considerar completamente saudáveis, principalmente quando moramos em grandes centros como São Paulo, onde estamos quase sempre resfriados, gripados, estressados ou mal alimentados. Quando realizamos tarefas "simples" como estacionar um carro estamos utilizando este conceito de verdade parcial, pois estacionamos o carro mais ou menos próximo a guia, quase

\footnotetext{
${ }^{4}$ É importante salientar que a palavra imprecisão neste texto não se refere a incerteza estatística, mas sim a dificuldade na classificação dos elementos.
} 
paralelamente a ela, e, digamos, quase corretamente. Na verdade, necessitamos de muito poucas informações para realizarmos esta tarefa. No entanto, se desejássemos que um computador Booleano estacionasse o nosso carro, seria necessário um programa sofisticado de controle e um enorme conjunto de informações que alimentassem o sistema, o que poderia resultar em uma tarefa muito sofisticada para este tipo de computador. É neste sentido que a lógica fuzzy difere da lógica convencional, pois ela nos permite considerar afirmações com valores entre Falso e Verdadeiro, nos possibilitando inclusive trabalhar com variáveis lingüísticas. Ela pode ser considerada como uma das ferramentas matemáticas mais poderosas para lidar com incertezas, imprecisões e verdades parciais, permitindo a tratabilidade de problemas do mundo-real muitas vezes com soluções de baixo custo.

Considerando o que foi exposto acima, vemos que a lógica fuzzy pode ser uma ferramenta realmente útil na abordagem de problemas em biomedicina. De fato, a aplicação dessa teoria na área médica tem demonstrado a sua capacidade para aprimorar e desenvolver tanto equipamentos quanto modelos nas mais diversas atividades hospitalares e de pesquisa.

\subsection{A lógica fuzzy na física}

A Lógica Fuzzy ainda é uma teoria estranha e desconhecida para a grande maioria dos físicos e são relativamente poucos os trabalhos em física utilizando essa teoria. Todavia, a junção das teorias físicas com a lógica fuzzy me parece bastante promissora, principalmente com o advento crescente de pesquisas interdisciplinares, onde a intensão de se abordar problemas complexos e mais realistas exige a colaboração de profissionais de diversas áreas e uma mistura de teorias.

Como era de se esperar, a lógica fuzzy adentra o mundo da física pelo seu lado menos determinístico e onde a incerteza é inerente ao processo, qual seja a Mecânica Quântica. A motivação para estudos desse tipo surge do fato reconhecido de que as medidas físicas estão sujeitas a erros e que muitas vezes esses erros não são controláveis. Assumir a atitude de que a imprecisão experimental envolvida nos processos de medida é, em si mesma, um fato da realidade física impulsionou alguns pesquisadores a buscar a incorporação dessas incertezas as teorias físicas (Twareque Ali $\mathscr{G}$ Doebner 1976). Claramente, essa atitude resulta na reformulação de muitas questões de caráter matemático e físico, dando ensejo ao aparecimento de outros trabalhos (Prugovecki 1976a, 1976b, 1976c).

Foi com este espírito que Prugovecki, em 1974, propõs a utilização de conjuntos fuzzy na teoria de medidas de observáveis incompatíveis (Prugovecki 1974), onde ele introduziu a noção de evento fuzzy na teoria de medida da mecânica quântica, indicando em que sentido as medidas poderiam ser consideradas como conjuntos fuzzy 5. Em 1975 ele propôs as medidas em mecânica quântica como processos estocásticos

\footnotetext{
${ }^{5}$ Vale ressaltar que este é o trabalho mais antigo sobre lógica fuzzy em física que obtive, mas isto não significa que ele seja o primeiro.
} 
sobre o espaço de eventos fuzzy (Prugovecki 1975), investigando a possibilidade de formulação da teoria quântica na qual a medida de qualquer número de observáveis são vistos como processos estocásticos sobre espaços de pontos fuzzy. Em 1976, Twareque Ali \& Doebner, estimulados por esses trabalhos, estudaram a mecânica quântica não relativística baseada em espaços de configuração fuzzy ( Twareque Ali $\&$ Doebner 1976 ) e no ano seguinte Twareque Ali \& Prugovecki proposeram representações da mecânica quântica sobre espaços de fase fuzzy (Twareque Ali \& Prugovecki 197ry).

Outros trabalhos de lógica fuzzy em mecânica quântica foram propostos, entre eles o de Pykacz onde, apoiado em trabalhos de Giles (Giles 1976 e 1977) e Guz (Guz 1984 e 1985), ele sugere a possibilidade de substituir a intepretação probabilística da mecânica quântica por outra baseada na lógica de valores infinitos e na teoria de conjuntos fuzzy (Pykacz 1992). Pickacz estudou também a interação entre a lógica fuzzy e a lógica quântica (Pykacz 198\%a, 198\%b, 1988, 1990). A lógica fuzzy na mecânica quântica também foi explorada por Cattaneo \& Laudisa (Cattaneo $\&$ Laudisa 1994) e Granik \& Caulfield (Granik \& Caulfield 1996). Uma discussão mais geral sobre a teoria da lógica fuzzy em física é obtida em Castillo-Mussot \& Dias (Castillo-Mussot E) Dias 1993).

Talvez a área da física que mais tenha explorado a teoria de conjuntos fuzzy seja a área de física nuclear. Entre os trabalhos mais conhecidos nessa área constam os de Onisawa e colaboradores, onde eles abordam o acidente de Chernobil considerando análises de confiança fuzzy em sistemas homem-máquina (Onisawa 1988, Onisawa 6 Nishiwaki 1988). A influência crescente da lógica fuzzy nas áreas de física e engenharia nucleares torna-se evidente quando consultamos uma biblioteca virtual, onde podemos verificar o registro de algumas centenas de artigos utilizando a logica fuzzy nessas áreas. Esses trabalhos abordam principalmente proteção radiológica, experimentos com reatores nucleares, segurança nuclear e controle de reatores nucleares (Cheng et al 1992, Han \& Lee 1994, Holbert et al 1994, Matsuoka 1991).

Em 1993 o 5o. congresso mundial do International Fuzzy Systems Association (IFSA'93, Seul) $)^{6}$ organizou, juntamente com a International Atomic Energy Agency (IAEA), um workshop internacional sobre aplicações de lógica fuzzy nas áreas de engenharia nuclear e segurança (Ruan 1995). A criação desse espaço nesse congresso evidencia a importância e o interesse por parte dos pesquisadores das duas áreas sobre a potencialidade da teoria da lógica fuzzy na solução de problemas nucleares. Neste workshop 8 trabalhos, advindos da Áustria, Coréia, Bélgica e EUA, foram apresentados. Em 1994, na 3a. conferência internacional sobre lógica fuzzy, redes neurais e soft computing (IIZZKA'94, Fukuka) foi organizado outro workshop sobre aplicações de lógica fuzzy em energia nuclear. Neste ano foram apresentados cerca de 20 trabalhos e várias atividades foram propostas visando a ampliação de projetos nessas áreas. Estes workshops foram a semente embrionária do primeiro encontro internacional sobre lógica fuzzy e tecnologias inteligentes em ciências nucleares, a FLINS, organizado ainda em 1994 na Bélgica, onde 70 trabalhos, advindos de vários países,

\footnotetext{
${ }^{6}$ Os congressos organizados pela IFSA estão entre os mais importantes e relevantes da área de lógica fuzzy, contendo em seu comitê científico nomes significativos no desenvolvimento dessa teoria.
} 
foram submetidos (Ruan 1995). Sem dúvida, o sucesso dessas reuniões evidenciam o crescimento do interesse por aplicações de ferramentas de soft computing em ciencias nucleares?

A lógica fuzzy também tem adentrado o mundo da física estatística, na medida em que surgem trabalhos sobre conjuntos fuzzy em termodinâmica (Singer 1992), irreversibilidade (Bobylev 1990), processos estocásticos (Wang \&3 Zhang 1992, Friedman ES Sandler 1997), teoria de probabilidades (Boswell \&3 Taylor 1987, Heilpern 1993), autômatos celulares (Ahmed 1996 e 1997, Cattaneo et al 1997, Flocchini et al 2000) e entropia (Meisels et al 1989, Dumitrescu 1995). Mais recentemente, Friedman e Sandler propuseram o uso de sistemas dinâmicos fuzzy como uma alternativa à mecânica estatística (Friedman e Sandler 1999). Também é possível encontrar trabalhos onde a lógica fuzzy é utilizada para auxiliar experiências em física (Battiston et al 1998, Kasa et al 2000 ). A física molecular (ou química quântica) é, talvez, a área da física na qual as aplicações da lógica fuzzy são mais recentes (Mezey 1998, Sordo 1999).

Vale a pena ressaltar que não faz parte do escopo dessa tese o estudo aprofundado de trabalhos sobre lógica fuzzy em física, até porque muitos dos trabalhos citados são extremamente complexos e demandariam um projeto específico de pesquisa. A minha intenção aqui é apenas a de ilustrar como e de que maneiras essa teoria tem se desenvolvido junto aos problemas físicos. Dado o desconhecimento por parte dos físicos a respeito dessa teoria, podemos ser conduzidos ao pensamento de que ela não seria útil em física e que não há trabalhos nessa área. No entanto, penso que o esboço delineado acima nos ilustra uma realidade diferente.

\subsection{A teoria de conjuntos fuzzy e a teoria de pro- babilidade}

É muito comum quando somos apresentados à teoria de conjuntos fuzzy confundirmos esta com a teoria de probabilidades. Freqüentemente trocamos grau de pertinência por probabilidade e pensamos na função de pertinência como sendo uma função de distribuição estatística. Esta confusão surge por haver uma estreita relação entre as duas teorias e, sob certos aspectos a teoria fuzzy se apresenta muito similar a teoria de probabilidades. De fato, a teoria de medidas nos indica que a medida de probabilidade é um caso particular de medida fuzzy, onde esta possui a propriedade de $\sigma$-aditividade (Barros 1992, Klir $\&$ Yuan 1995, Pedrycz $\&$ Gomide 1998). É importante, no entanto, perceber a diferença entre as duas teorias para melhor compreendermos como elas podem ser complementares, resultando em uma ferramenta bastante interessante.

A teoria de probabilidades e a teoria de conjuntos fuzzy lidam, em geral, com tipos de incertezas distintos. Na teoria de probabilidades temos o evento muito bem definido e a dúvida paira sobre a ocorrência do evento. No entanto, uma vez que o evento ocorreu não existirá mais dúvida alguma. Podemos calcular qual a probabilidade de,

\footnotetext{
${ }^{7}$ Basta uma pesquisa rápida no INSPEC para percebermos o volume de trabalhos que têm sido produzidos com lógica fuzzy em ciências nucleares.
} 
em uma urna contendo $n_{b}$ bolas brancas e $n_{v}$ bolas vermelhas, sortearmos uma bola vermelha. Todavia, uma vez sorteada a bola não há nada mais a fazer, a bola será branca ou vermelha, e a incerteza desaparecerá. No entanto, supomos que haja em uma urna várias bolas com diversos tons de rosa, variando do vermelho ao branco. Neste caso não poderemos simplesmente perguntar qual a chance de sortearmos uma bola branca, pois teríamos dificuldades para decidir sobre as bolas rosas. Na verdade, não poderemos fazer uma pergunta de caráter 'puramente estatístico' pois o evento não está bem definido, existirão bolas quase vermelhas, bolas quase brancas e bolas com diversos tons de rosa (o que configura uma situação de imprecisão). Precisamos saber nestes casos qual é a pergunta a ser realizada e como respondê-la.

Um outro aspecto que diferencia as duas teorias é o fato da teoria de probabilidades não considerar subjetividades, como por exemplo características psicológicas dos indivíduos. É muito comum as pessoas jogarem na Loto ou na Sena, inclusive profissionais da área de estatística. É conhecido também que raramente as pessoas apostam um conjunto de números seqüenciados como 1,2,3,4,5 e 6 . As pessoas, de uma forma geral, têm a sensação de que um jogo assim é muito menos provável de acontecer do que um conjunto de números sortidos. E estranhamente elas têm razão em sentir-se assim, uma vez que este evento dificilmente é verificado (quase nunca ocorre um sorteio de números seqüenciados). No entanto, sabemos que a probabilidade de ocorrer qualquer combinação de números é a mesma. E se perguntarmos a um estatístico que joga na Sena ou na Loto que tipo de jogo ele faz dificilmente obteremos uma seqüência ordenada de números! Ou seja, mesmo sabendo que a probabilidade deste jogo é a mesma que a de qualquer outro ele não se sente confortável em jogá-lo, ainda que se jogasse teria grande chance de ganhar sozinho! Desejo com este exemplo apenas ilustrar que as pessoas não são meramente estatísticas, elas são também estatísticas. Sendo assim, a depender do objeto que estamos analisando a teoria de probabilidades pode não ser suficiente, havendo a necessidade de utilizarmos outras técnicas para abordar as incertezas envolvidas no processo. Vale ressaltar que a estatística Bayesiana costuma lidar bem com os exemplos citados acima, todavia, a principal diferença consiste na habilidade da lógica fuzzy em tratar incertezas nãoestatísticas.

Para citar novamente o sistema diagnóstico, temos que o raciocínio médico parece estar muito mais baseado em graus de possibilidade do que de probabilidade, uma vez que seria humanamente impossível para o médico guardar todas as informações exatas sobre as freqüências dos sintomas nas doenças, tanto quanto a prevalência das doenças em uma dada população. A probabilidade está associada a chance de um determinado evento ocorrer, enquanto a possibilidade está relacionada com o quão razoável é um dado evento (Zadeh 1978). Os médicos raramente expressam suas impressões com valores numéricos, utilizando termos lingüísticos tanto para se expressar quanto para associar cognitivamente os sintomas/doenças. Além disso, sabemos que um paciente ao procurar um médico não deseja saber "qual a chance" de que ele tenha uma determinada doença, ele quer saber "qual" doença ele tem. O médico, a partir de em exame clínico, lista as possíveis patologias e segue um estudo mais profundo 
(com exames laboratoriais, por exemplo) a partir de graus de possibilidade, ou seja, do que é mais razoável.

Não obstante a rejeição inicial, as teorias de probabilidade e possibilidade, como também a lógica fuzzy, têm se demonstrado muito mais complementares do que concorrentes (Zadeh 1995). Muitos são os trabalhos sobre probabilidades fuzzy (Zadeh 1984, Stein 1985, Piasecki 1985, Piasecki 1986, Bordley 1989), medidas e métricas fuzzy e probabilidades (Campos et al 1990, Campos Ibañez \&3 Carmona 1989, Wu 83 Ma 1990, Guerra et al 1996), possibilidade e probabilidade (Natvig 1983, Delgado 83 Moral 1987, Sudkamp 1992, Gupta 1993, Heilpern 1993, Drakopoulos 1995), bem como o desenvolvimento de testes estatísticos utilizando a lógica fuzzy (Casals et al 1986, Féron \&3 Féron 1988, Watanabe $\mathcal{E}$ Imaizumi 1993, Römer $\mathcal{E}$ Kandel 1995, Biswas 1995, Chang ES Lee 1996, Ralescu 1997).

\subsection{Sistemas dinâmicos contínuos fuzzy}

Sistemas epidemiológicos são essencialmente dinâmicos (em particular a epidemiologia das doenças transmissíveis) e, assim sendo, estudar a aplicação da lógica fuzzy a estes sistemas consiste em estudarmos os sistemas dinâmicos fuzzy. No entanto, sistemas dinâmicos fuzzy são uma área relativamente recente de pesquisa, não havendo ainda tratamentos matemáticos completamente estabelecidos sobre esses sistemas, principalmente sistemas não lineares e acoplados, que é o caso dos sistemas epidemiológicos.

Em 1987 Kaleva e Seikalla estudaram o problema da equação diferencial com condição inicial fuzzy, baseados nos trabalhos de Dubois \& Prade e Puri \& Ralescu (Dubois \& Prade 1982a, 1982b, 1982c, Puri \& Ralescu 1983). Em seu trabalho Kaleva estudou propriedades de diferenciabilidade e integrabilidade de uma certa classe de mapeamentos a valores fuzzy e provou o teorema de existência e unicidade para a solução da equação diferencial do tipo $x^{\prime}(t)=f(t, x(t))$ com a condição inicial $x(0)=x_{0}$ fuzzy (Kaleva 1987). Seikalla propôs a solução para este tipo de equação (Seikalla 1987). No seu trabalho a abordagem matemática consiste em buscar as soluções da equação diferencial fuzzy baseando-se na solução das equações diferenciais em cada nível $\alpha$, o que consiste em soluções clássicas. (O nível $\alpha$ de um conjunto fuzzy é um tipo de projeção de um dado nível (veja o capítulo 2). A união de todos os $\alpha$-níveis recompõem o conjunto fuzzy). Estes trabalhos impulsionaram muitos outros, entre eles Pearson que, em 1997, propôs uma estrutura de solução para um conjunto de equações diferenciais lineares também baseada nos $\alpha$ - nivveis ( Pearson 1997a, 1997b, 1997c). Todavia, um dos problemas dessa abordagem é que ao resolver a solução nos níveis $\alpha$, o que significa resolver equações diferenciais classicamente, é necessário garantir que ao "compor" as soluções no espaço dos conjuntos fuzzy estas produzam um conjunto fuzzy de fato. Esta exigência sobre as soluções $\alpha$ - níveis implica em que o suporte do conjunto fuzzy solução sempre cresça com o passar do tempo, tendendo ao infinito. Esta característica desse tipo de abordagem é claramen- 
te indesejável, pois significa que o nosso desconhecimento sobre o sistema aumentará com o passar do tempo. Uma outra forma de abordar as equações diferenciais fuzzy seria construir sua solução no próprio espaço dos conjuntos fuzzy, não utilizando o recurso dos $\alpha$-níveis. No entanto esta abordagem exige uma elevada sofisticação matemática e ainda não se tem notícias desse tipo de desenvolvimento. Um outro recurso, que me parece mais possível, é abordar sistemas dinâmicos fuzzy com inclusão diferencial (Baidosov 1990, Diamond 1999, Pearson 2000). Todavia os estudos nessa área ainda são muito incipientes. Um outro entrave para o desenvolvimento de sistemas epidemiológicos fuzzy dinâmicos contínuos se deve ao fato desses sistemas serem fortemente não lineares e acoplados, não sendo ainda contemplado matematicamente esse tipo de sistema.

Uma possibilidade para considerar a subjetividade nos sistemas dinâmicos consiste na utilização do Valor Esperado Fuzzy (FEV). Barros propôs em sua dissertação de mestrado a utilização do FEV para tratar equações diferenciais com parâmetros subjetivos em modelos ecológicos (Barros 1992, Barros \& Bassanezi 1995). Recentemente, Barros e colaboradores têm desenvolvido trabalhos utilizando esse método para o estudo de modelos epidemiológicos do tipo SIS e SIR ${ }^{8}$. Os resultados obtidos têm sido muito interessantes, produzindo interpretações distintas ao valor de reprodutibilidade da infecção, $R_{0}$, que é um dos parâmetros mais importantes em epidemiologia ( $A n$ derson \& May 1991). Esses trabalhos são bastante recentes e revelam, a meu ver, uma linha próspera de pesquisa. Todavia, ainda se faz necessário compreender o que de fato ganhamos quando consideramos o FEV e não o valor esperado clássico, da mesma forma, outras questões interpretativas também precisam ser aprofundadas.

Considerando as dificuldades para tratar os sistemas dinâmicos contínuos, uma opção para a solução de problemas epidêmicos fuzzy é desenvolver modelos dinâmicos lingüísticos fuzzy em tempo discreto. Nessa tese apresentamos três trabalhos onde este tipo de dinâmica foi analizada.

\subsection{O trabalho de tese}

Nesta tese apresento oito trabalhos onde aplicamos aspectos da teoria da lógica fuzzy em sistemas diagnósticos e, principalmente, epidemiologia. A tese está dividida em duas partes. Na primeira, abordo a motivação do trabalho, com um panorama geral sobre a teoria, as perguntas que estamos tentando responder e os conceitos básicos da teoria de conjuntos fuzzy que foram utilizados na tese. Na segunda parte, apresentarei cada trabalho desenvolvido em detalhe, assim como nossas perspectivas de trabalhos atuais e futuros, seguido da discussão final.

Os trabalhos desenvolvidos foram: um estimador de risco epidemiológico fuzzy, onde propomos a fuzificação do conceito de risco epidemiológico clássico; uma pro-

\footnotetext{
${ }^{8}$ Estes modelos consistem de sistemas compartimentalizados, onde o SIS descreve uma dinâmica do tipo Susceptível-Infectado-Suscetível e os modelos do tipo SIR descrevem uma dinâmica do tipo Suscetível-Infectado-Recuperado.
} 
posta para escolher uma estratégia para a campanha de vacinação contra o sarampo, proposta que foi acolhida pela Secretaria de Saúde Pública e implementada em todo o estado de São Paulo; uma aplicação da teoria de probabilidade fuzzy, onde buscamos responder a duas perguntas de cunho epidemiológico; o modelo para inferência da progressão clínica para a AIDS de indivíduos HIV-soropositivos e uma estimativa do risco de morte neonatal considerando o peso e a idade gestacional do recém nascido, sendo estes modelos lingüísticos estáticos (sem evolução temporal); o modelo lingüístico dinâmico para a raiva canina na cidade de São Paulo, onde comparamos os resultados do modelo com dados experimentais; o modelo lingüistico dinâmico para uma epidemia tipo SIR, considerando parâmetros típicos para uma epidemia de sarampo; e uma aplicação do princípio de extensão na elaboração de regras fuzzy, onde utilizamos um método para extrair as regras de forma menos dependente do especialista.

O papel do especialista na elaboração de modelos fuzzy em epidemiologia e sistemas diagnósticos será uma discussão que permeará toda a tese, uma vez que ele assume um papel fundamental nessa nossa abordagem.

Em alguns trabalhos escritos em português o termo fuzzy costuma ser traduzido por nebuloso ou difuso. Confesso que nenhuma dessas palavras me satisfaz quanto ao significado do termo fuzzy, quando inserido no universo da teoria da lógica fuzzy. Sendo assim, optei por não usar essas traduções e manter o termo em inglês, que a meu ver expressa uma gama de caraterísticas maior do que as palavras em português. 


\section{Capítulo 2}

\section{Alguns conceitos da teoria de conjuntos fuzzy}

A teoria de conjuntos fuzzy tem sido estendida a diversas abordagens, sendo o termo lógica fuzzy usado em dois sentidos distintos: um sentido mais restrito que se refere a um sistema lógico que generaliza a lógica clássica para uma mais flexível (teoria de conjuntos, implicações lógicas, verdades parciais, etc.) e um sentido mais amplo, que engloba o sentido mais restrito, que se refere a todas as teorias e tecnologias onde se aplicam conjuntos fuzzy (processos de decisão fuzzy, fuzzy clustering, relações fuzzy, modelos híbridos, etc.). Todavia, a grande maioria das teorias e técnicas abrangidas pelo sentido mais amplo da lógica fuzzy estão baseadas em quatro conceitos básicos: conjuntos fuzzy, variáveis lingüísticas, distribuição de possibilidades e regras Se-Então fuzzy. Neste capítulo discutirei esses conceitos, bem como outros que foram utilizados nos trabalhos desenvolvidos na tese.

\subsection{Teoria de medida fuzzy}

O conceito de medida fuzzy foi introduzido por Sugeno em 1974 (Sugeno 1974), e consiste numa forma natural para se avaliar graus de incertezas, principalmente quando tais valores dependem da subjetividade de quem está realizando a medida (Barros 1992). Um exemplo de medida subjetiva é a avaliação de uma jóia, do valor de uma obra de arte, do valor de alguma mercadoria, do valor da remuneração de um trabalho, da avaliação de pobreza de uma dada região, etc.. Todavia, apesar da subjetividade envolvida existem certas características na qual somos unânimes em concordar. Por exemplo, nós concodaremos que uma jóia $A$, maior e de melhor qualidade que uma jóia $B, B \subset A$, deve ter maior avaliação do seu valor do que a jóia $\mathrm{B}$. Assim, é de se esperar que se $\mathrm{B}$ é um subconjunto de $\mathrm{A}$, então $\mu(B) \leq \mu(A)$ sendo $\mu$ uma medida subjetiva ou não (Barros 1992).

Antes de apresentarmos a definição de medida fuzzy é necessário introduzirmos o conceito de espaço mensurável e de medida. O espaço mensurável é descrito pelo par 
$(\Omega, \mathbb{A})$ que consiste de um universo $\Omega$ e de uma $\sigma$ - algebra de conjuntos mensuráveis de $\Omega$ (Pedrycz $\&$ Gomide 1998).

- Definição 2.1 Dizemos que $\mathbb{A}$ é uma $\sigma$-algebra, com $\mathbb{A} \neq \emptyset$, se são satisfeitas:

1. $A \in \mathbb{A} \Rightarrow \bar{A} \in \mathbb{A}$, onde $\bar{A}$ é o complemento de $A$.

2. $A_{k} \in \mathbb{A}, k \in \mathbb{N} \Rightarrow \bigcup_{k \in \mathbb{N}} A_{k} \in \mathbb{A}$.

- Definição 2.2 Uma medida $\mu$ é uma função definida em um espaço mensurável $(\Omega, \mathbb{A})$ que não assume valores negativos e que satisfaz os seguintes postulados:

1. $\mu(\emptyset)=0$.

2. $\mu$ é $\sigma-$ aditiva, ou seja, para uma família de pares de conjuntos disjuntos, $A_{i} \in \Omega, A_{i} \cap A_{j}=\emptyset, i=1,2, \ldots, i \neq j$, a medida da união dos $A_{i} s$ é dada por:

$$
\mu\left(\bigcup_{i=1}^{\infty} A_{i}\right)=\sum_{i=1}^{\infty} \mu\left(A_{i}\right)
$$

3. Se $\left\{A_{n}\right\}, n=1,2, \ldots$ é uma seqüência crescente de conjuntos mensuráveis, então

$$
\lim _{n \rightarrow \infty} \mu\left(A_{n}\right)=\mu\left(\lim _{n \rightarrow \infty} A_{n}\right)
$$

A medida $\mu$ descrita acima é chamada de medida clássica $(\sigma-$ aditiva $)$ e apresenta algumas propriedades:

1. Se $A \subseteq B$, então $\mu(A) \leq \mu(B)$.

2. $\mu(\bar{A})=1-\mu(A)$.

3. $\mu(\Omega)=1$.

Uma das medidas $\sigma-$ aditiva mais comumente usada é a medida de probabilidade, na qual a $\sigma-$ aditividade é expressa por:

$$
P\left(\bigcup_{i=1}^{\infty} A_{i}\right)=\sum_{i=1}^{\infty} P\left(A_{i}\right)=\sum_{i=1}^{\infty} p_{i}
$$

onde os $A_{i} s$ são conjuntos disjuntos e $p_{i}=P\left(A_{i}\right)$.

A medida fuzzy generaliza a medida $\sigma-$ aditiva definida acima através da substituição da propriedade de $\sigma$-aditividade pela propriedade de monotonicidade (Pedrycz 
$\mathscr{G}$ Gomide 1998) 17. Embora as medidas $\sigma$ - aditivas sejam úteis para um grande número de aplicações, algumas vezes estamos interessados em avaliar objetos onde esta propriedade não se verifica (Barros 1992). Nestes casos a aplicação de uma medida não aditiva, como a medida fuzzy por exemplo, pode ser mais conveniente.

- Definição 2.3 Uma função $\mu: \mathbb{A} \rightarrow[0,1]$ é uma medida fuzzy se ela satisfaz:

1. $\mu(\emptyset)=0$ e $\mu(\Omega)=1^{2}$.

2. $\mu(A) \leq \mu(B)$ se $A \subseteq B, \forall A, B \in \mathbb{A}$.

3. Para qualquer seqüência crescente de conjuntos mensuráveis $\left\{A_{n}\right\}$, com $n=$ $1,2, \ldots$, é verificado que:

$$
\lim _{n \rightarrow \infty} \mu\left(A_{n}\right)=\mu\left(\lim _{n \rightarrow \infty} A_{n}\right)
$$

A tripla $(\Omega, \mathbb{A}, \mu)$ é comumente chamada de espaço de medida fuzzy. Dadas as características acima não é difícil perceber que a medida de probabilidade é um caso particular damedida fuzzy, quando esta apresenta a $\sigma$ - aditividade. Sendo assim, temos que todo o espaço de probabilidade $(\Omega, \mathbb{A}, P)$ é um espaço de medida fuzzy (Barros 1992). Note que a medida fuzzy atua sobre espaços de conjuntos clássicos e é importante não confundi-la com os próprios conjuntos fuzzy. É importante ressaltar também que, além da medida fuzzy, existem outros tipos de medida subjetiva, como a medida de possibilidade, a medida de plausabilidade, a medida de crença, a medida de compatibilidade, etc. (Klir $\&$ Yuan 1995, Pedrycz $\&$ Gomide 1998).

\subsection{Conjuntos fuzzy}

Os conjuntos fuzzy são conjuntos que não possuem fronteiras bem definidas e que foram introduzidos devido ao fato de os conjuntos clássicos apresentarem limitações para lidar com problemas onde as transições de uma classe para outra acontecem de forma suave. Sua definição, propriedades e operações são obtidas da generalização da teoria de conjuntos clássicos, recaindo esta em um caso particular da teoria de conjuntos fuzzy.

A teoria de conjuntos clássicos está baseada na função característica clássica, dada por

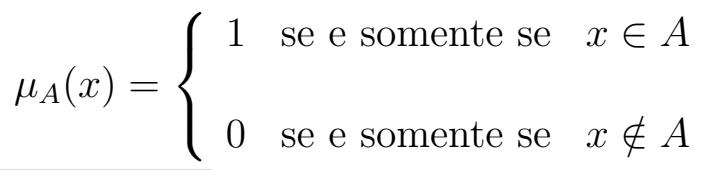

\footnotetext{
${ }^{1}$ Vale ressaltar que anteriormente ao surgimento da teoria fuzzy outros pesquisadores já haviam desenvolvido medidas não $\sigma$-aditivas (De Finetti 1939 e 1970).

${ }^{2}$ De maneira geral, não há necessidade de que $\mu(\Omega)=1$ seja satisfeito, e sim que $\mu: \mathbb{A} \rightarrow[0, \infty)$.
} 
2 Alguns conceitos da teoria de conjuntos fuzzy

onde $U$ é o conjunto Universo, $A$ é um subconjunto de $U$ e $x$ é um elemento de $U$, ou seja, a função característica é um mapeamento do conjunto universo no conjunto $\{0,1\}$. Essa função característica discrimina entre todos os elementos de $U$ aqueles que, segundo algum critério, pertencem ou não ao subconjunto $A$, dividindo o conjunto universo em duas partes com fronteira bem definida. As operações básicas dos conjuntos clássicos são a união, a intersecção e o complemento e eles podem ser expressos através da função característica. Seja $A$ e $B$ subconjuntos de $U$, então, temos respectivamente:

$$
\begin{gathered}
\mu_{A \cup B}(x)=\max \left(\mu_{A}(x), \mu_{B}(x)\right), \\
\mu_{A \cap B}(x)=\min \left(\mu_{A}(x), \mu_{B}(x)\right)
\end{gathered}
$$

e

$$
\mu_{\bar{A}}(x)=1-\mu_{A}(x) .
$$

Note que a escolha dos operadores união e interseç̧ão é arbitrária. A única propriedade que a a operação intersecção deve satisfazer é retornar 1 quando ambos os argumentos são 1 e zero quando algum dos argumentos é 0. Da mesma forma, a operação união exige apenas que o operador retorne 1 se pelo menos um dos argumentos é 1 e zero caso contrário. Para obtermos os conjuntos fuzzy e suas operações basta generalizarmos a função característica da lógica clássica para o intervalo $[0,1]$, ou seja, $\mu_{A}(x): U \rightarrow[0,1]$, o que implica em considerarmos um contínuo de valores de pertinência e não apenas pertence e não-pertence. O elemento $x$ pertencerá ao subconjunto $A$ com um grau de pertinência que é um valor no intervalo $[0,1]$.

- Definição 2.4 Um conjunto fuzzy A em um conjunto universo U é um conjunto de pares ordenados de um elemento genérico $x$ e seu grau de pertinência $\mu_{A}(x)$ da forma

$$
A=\left\{\left(x, \mu_{A}(x) \mid x \in U\right\} .\right.
$$

Em última análise, um conjunto fuzzy é caracterizado por uma função de pertinência, e o grau de pertinência pode ser considerado como uma medida que expressa a possibilidade de que um dado elemento seja membro de um conjunto fuzzy.

Quanto à representação de um conjunto fuzzy temos que, se ele é discreto podemos simplesmente enumerar os seus elementos juntamente com seus graus de pertinência, na forma:

$$
A=\sum_{i} \mu_{A}\left(x_{i}\right) / x_{i}
$$


onde a somatória se refere a operação união (disjunção) e a notação $\mu_{A}\left(x_{i}\right) / x_{i}$ se refere ao elemento $x_{i}$ que pertence ao conjunto fuzzy $A$ com grau $\mu_{A}\left(x_{i}\right)$. Em geral, por simplicidade, somente é listado no conjunto $A$ aqueles elementos cujo grau de pertinência é diferente de zero.

- Exemplo 2.1: Considere o conjunto universo de discurso discreto composto pelos indivíduos com idade entre 1 e 24 anos, $U=\{1,2, \ldots, 23,24\}$, e os conjuntos fuzzy $A$ e $B$ abaixo que designa, respectivamente, as crianças e os adolescentes:

$$
\begin{aligned}
& A=0,4 / 2+0,6 / 3+0,8 / 4+1,0 / 5+1,0 / 6+1,0 / 7+0,8 / 8+0,6 / 9+0,4 / 10 \\
& B=0,1 / 7+0,2 / 8+0,4 / 9+0,6 / 10+0,8 / 11+0,9 / 12+1,0 / 13+1,0 / 14 .
\end{aligned}
$$

A figura 2.1 apresenta graficamente estes conjuntos.

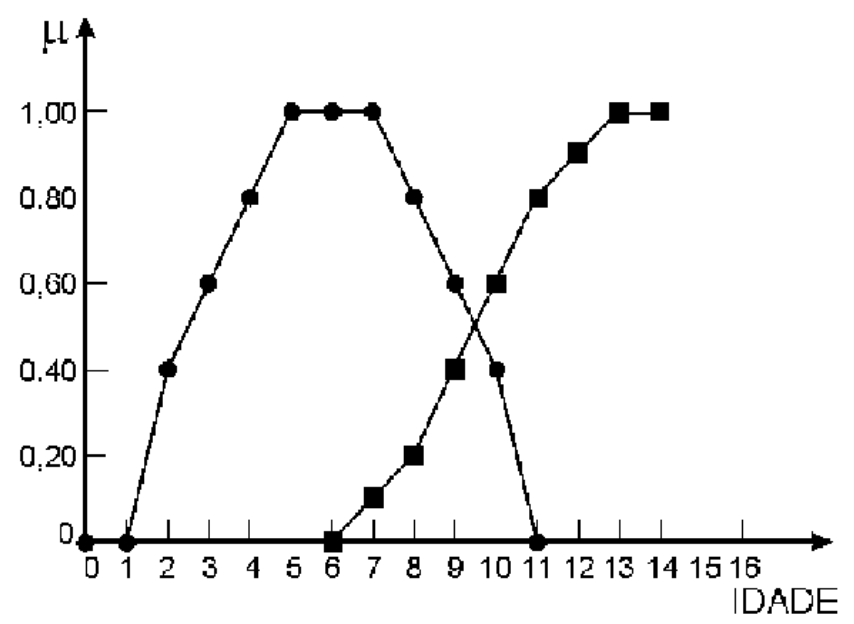

Figura 2.1: Conjuntos fuzzy para crianças e adolescentes.

Quando os conjuntos fuzzy são contínuos sua representação é a própria função de pertinência. As formas para as funções de pertinência são totalmente arbitrárias. Todavia, as funções mais utilizadas são:

- linear por partes (triangular ou trapezoidal);

- quadrática;

- gaussiana;

- ou alguma outra função especial. 
As funções lineares por partes são as mais populares devido a simplicidade dessas funções e ao fato de que o custo computacional adicional exigido pelos outros tipos de função não refletem, em geral, em uma melhoria significativa na qualidade dos valores de saída dos sistemas (Yen $\mathscr{E}$ Langari 1999). No entanto, o problema da escolha das funções de pertinência não foi ainda resolvido teoricamente e elas permanecem sendo escolhidas a depender da aplicação e do contexto do problema abordado (Reznik 1997). As figuras 2.2 e 2.3 apresentam alguns exemplos de funções de pertinência linear por partes e gaussiana, respectivamente.

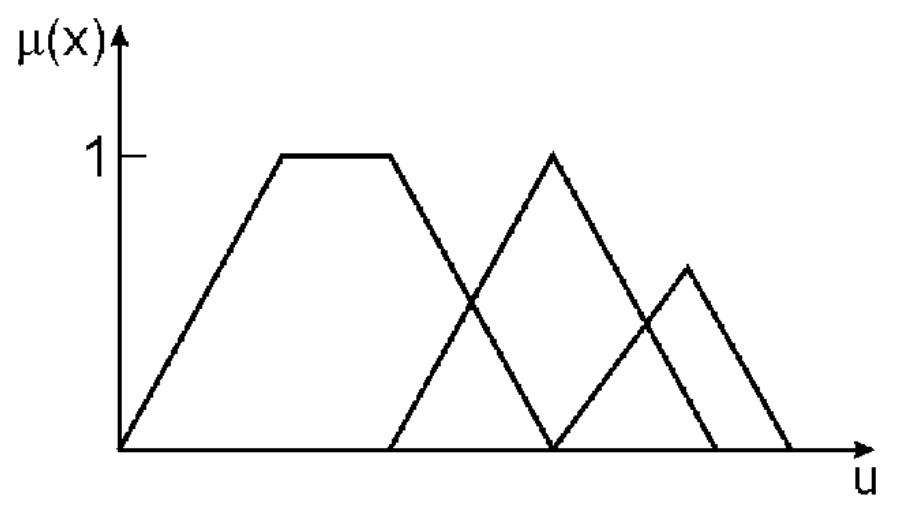

Figura 2.2: Exemplo de função de pertinência do tipo linear por partes.

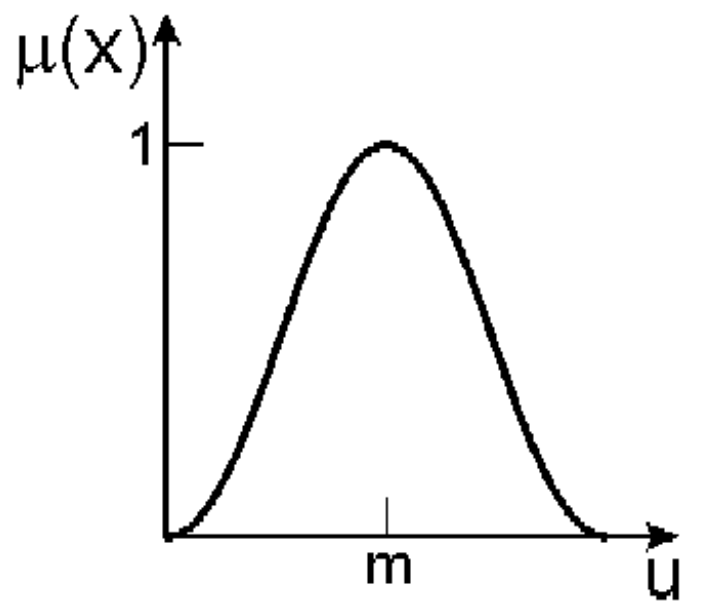

Figura 2.3: Exemplos de funções de pertinência do tipo gaussiana.

As três operações básicas (2.5), 2.6) e (2.7) são idênticas para a teoria de conjuntos fuzzy, a diferença estando na generalização da função característica. Como na lógica clássica, os operadores de intersecção e união correspondem respectivamente aos operadores lógicos de conjunção (E) e disjunção (OU ). Aqui também existem muitas formalizações matemáticas possíveis para esses operadores e a relação dual entre eles também se mantem, ou seja, a escolha de um operador conjunção "define" 
qual será o operador disjunção, e vice e versa. O par de operadores mais amplamente utilizado nas técnicas fuzzy são o operador mim (mínimo) para a conjunção e o max (máximo) para a disjunção fuzzy. As figuras 2.4, 2.5 e 2.6 ilustram exemplos de união, intersecção e complemento de conjuntos fuzzy.

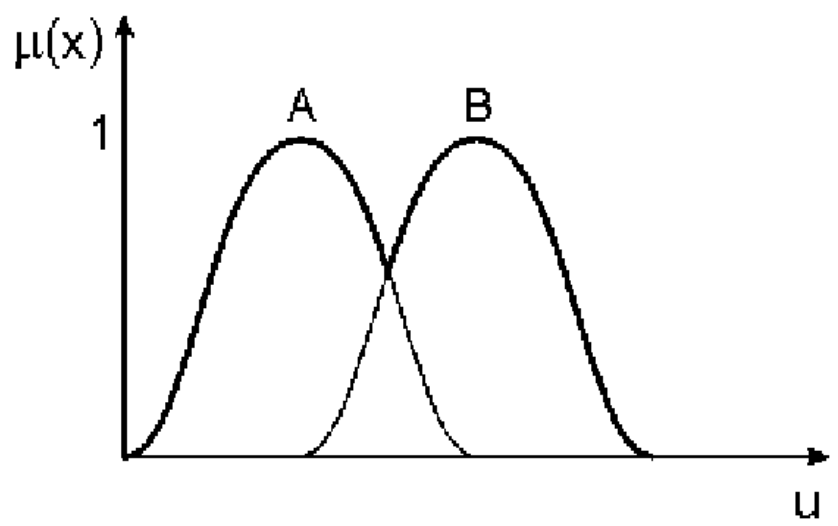

Figura 2.4: Exemplo de União entre conjuntos fuzzy.

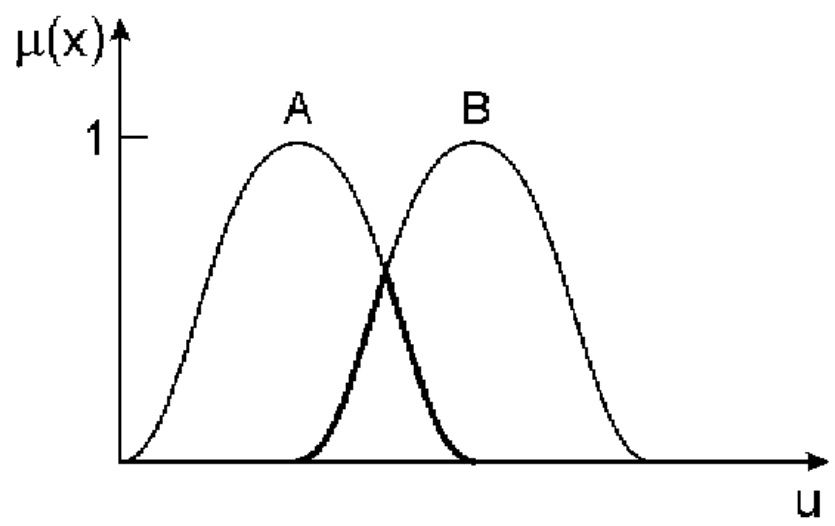

Figura 2.5: Exemplo de Intersecção entre conjuntos fuzzy.

Uma das conseqüências interessantes da definição de conjuntos fuzzy em contraste com os conjuntos clássicos é a Lei do Meio Excluído e a Lei da Contradição. Classicamente temos que $A \cup \bar{A}=U$ e $A \cap \bar{A}=\emptyset$. Todavia, devido a flexibilidade da função característica isso não ocorre com os conjuntos fuzzy. Podemos ver nas figuras 2.7 e 2.8 que $A \cup \bar{A} \neq U$ e $A \cap \bar{A} \neq \emptyset$, isto se deve ao fato de existirem incertezas não estatísticas e imprecisões no processo. Outra conseqüência da definição, é que, em franco contraste com a teoria de probabilidades, os valores de pertinência de um mesmo elemento $a$ nos diversos conjuntos fuzzy não precisam somar 1 . 


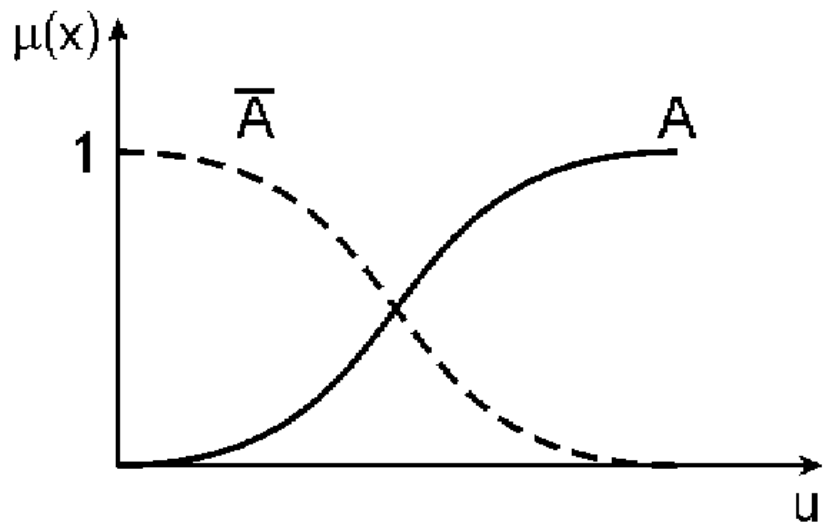

Figura 2.6: Exemplo do complemento de um conjunto fuzzy.
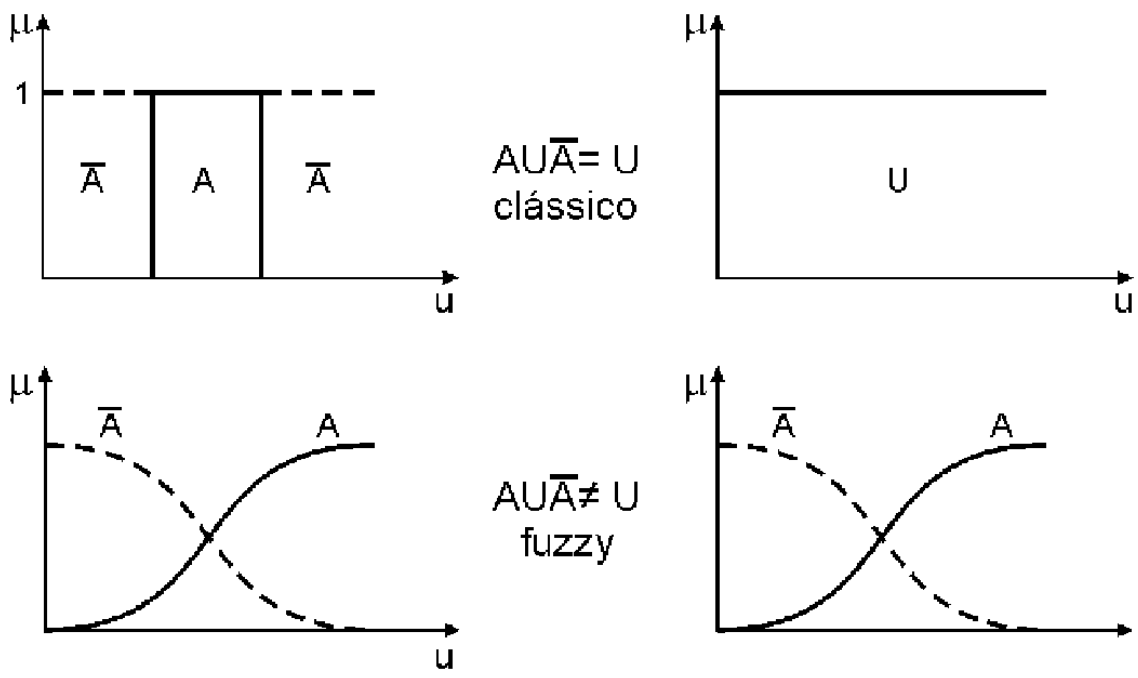

Figura 2.7: Lei do Meio Excluído.

Outro conceito importante na teoria de conjuntos fuzzy é o suporte e o conjunto $\alpha$-nível.

- Definição 2.5 O suporte $S(A)$ de um conjunto fuzzy A é o conjunto clássico de todos os elementos $x \in U$ cuja função de pertinência tem valor diferente de zero.

$$
S(A)=\left\{x \in U \mid \mu_{A}(x)>0\right\}
$$

- Definição 2.6 O conjunto de elementos que pertencem a um conjunto fuzzy $A$ pelo menos com um grau $\alpha$ é chamado conjunto $\alpha$-nível ou conjunto $\alpha-$ cut.

$$
A_{\alpha}=\left\{x \in U \mid \mu_{A}(x)>\alpha\right\}
$$




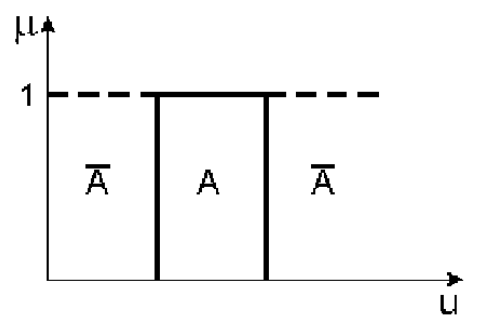

$\mu^{\wedge}$
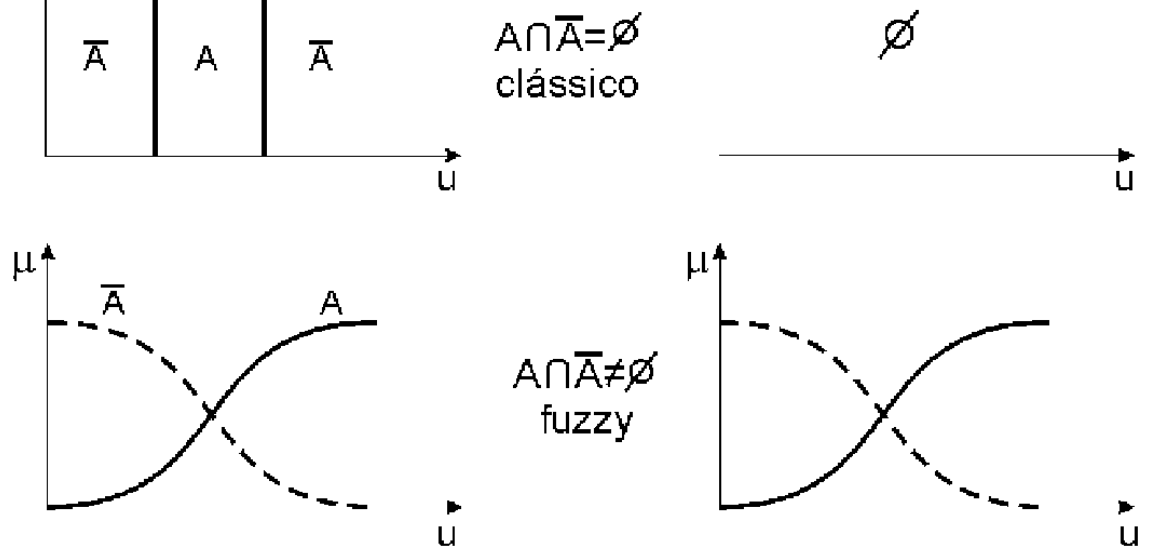

Figura 2.8: Lei da Contradição.

Esta definição é importante pois fornece uma outra maneira de se considerar um conjunto fuzzy. Uma vez que a função de pertinência determina completamente um conjunto fuzzy, e que seus valores pertencem ao intervalo $[0,1]$, então um conjunto fuzzy A pode ser descrito pela união de todos os conjuntos $\alpha$ - níveis: $A=\cup_{\alpha} A_{\alpha}$, $\alpha \in[0,1]$. A importância dos conjuntos $\alpha$-níveis vem do fato deles serem conjuntos clássicos e, assim sendo, muito do formalismo matemático da teoria de conjuntos fuzzy pode ser desenvolvido no espaço dos conjuntos clássicos, aproveitando inclusive resultados (teoremas, lemas etc.) já desenvolvidos na teoria clássica. Os estudos de diferenciabilidade e integrabilidade desenvolvidos por Dubois \& Prade, Kaleva, Ralescu, Seikkala e outros se baseam no conceito de conjuntos $\alpha$ - nível (ver seção 1.6). Um exemplo de conjunto $\alpha-$ nível é apresentado na figura 2.9.

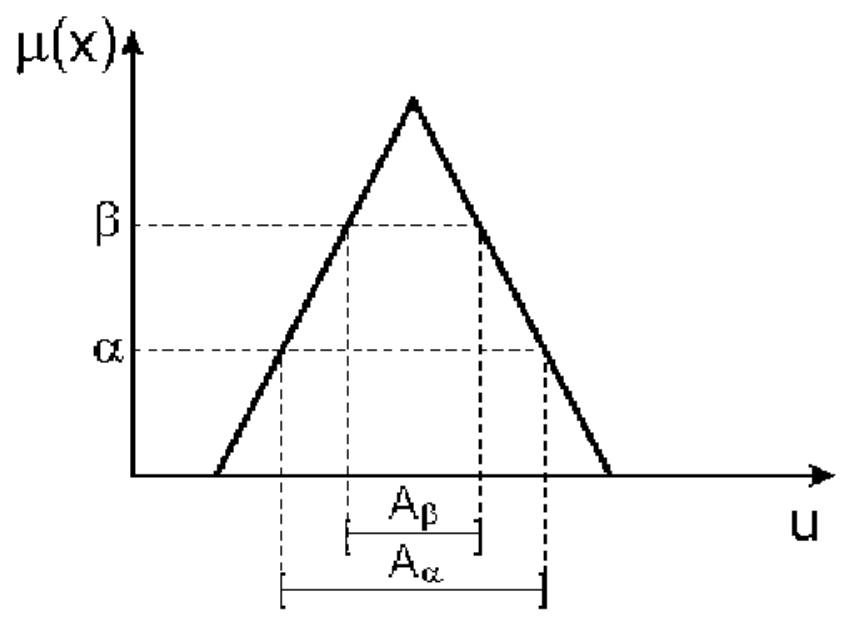

Figura 2.9: Exemplo de $\alpha-$ nível. 
2 Alguns conceitos da teoria de conjuntos fuzzy

Outros conceitos importantes de conjuntos fuzzy diz respeito a cardinalidade e altura desses conjuntos. A cardinalidade de um conjunto é o número total de elementos no conjunto. Uma vez que os elementos podem pertencer parcialmente a um conjunto fuzzy, uma generalização natural da noção clássica de cardinalidade consiste em pesar cada elemento pelo seu grau de pertinência. Sendo assim, a cardinalidade de um conjunto fuzzy é definida por:

$$
\operatorname{Card}(A)=\sum_{x_{i}} \mu_{A}\left(x_{i}\right)
$$

onde $A$ é um conjunto fuzzy e os $x_{i} s$ são os elementos do conjunto Universo.

Para exemplificar consideremos a cardinalidade dos conjuntos crianças e adolescentes da figura 2.1, temos que

$$
\operatorname{Card}(\text { crianças })=0,4+0,6+0,8+1+1+1+0,8+0,6+0,4=6,6
$$

e

$$
\operatorname{Card}(\text { adolescentes })=0,1+0,2+0,4+0,6+0,8+0,9+1+1=5,0 .
$$

O conceito de cardinalidade torna-se importante quando estamos interessados no tamanho dos conjuntos, como acontece em sistemas de informação e análise de banco de dados fuzzy, e quando precisamos definir fatores de normalização para os conjuntos fuzzy, como acontece em alguns processos de defuzificação (Yen $\mathscr{E}$ Langari 1999).

A altura de um conjunto fuzzy é o maior valor de pertinência da sua função de pertinência:

$$
h g t(A)=\max _{x_{i}} \mu_{A}\left(x_{i}\right)
$$

Os conjuntos fuzzy com altura igual a 1 são chamados normais e aqueles cuja altura é inferior a 1 são chamados subnormais. Os conjuntos fuzzy da figura 2.1 são conjuntos normais e na figura 2.2 temos um exemplo de função de pertinência triangular subnormal.

\subsection{Variáveis lingüísticas}

Uma variável lingüística fuzzy é uma variável cujo valor é expresso qualitativamente por um termo lingüístico (que fornece um conceito à variável) e quantitativamente por uma função de pertinência. De fato, uma variável lingüística é caracterizada por $\{n, T, X, m(n)\}$ onde $n$ é o nome da variável (por exemplo, temperatura, pressão, febre, etc.), $T$ é o conjunto de termos lingüísticos de $n$ (elevado, baixo, pouco, extenso, etc.), $X$ é o domínio (Universo) de valores de $n$ sobre o qual o significado do termo 
lingüístico é determinado (a febre pode estar, por exemplo, entre 35 e $40^{\circ} \mathrm{C}$ ) e $m(t)$ é uma função semântica que assinala para cada termo lingüístico $t \in T$ o seu significado, que é um conjunto fuzzy em $X$ (ou seja, $m: T \rightarrow(X)$ onde $(X)$ é o espaço dos conjuntos fuzzy).

A figura 2.10 mostra um exemplo de variável lingüística. O nome $(n)$ da variável é Febre. Os termos lingüísticos $t \in T$ que atribuem um significado semi-quantitativo a Febre são: baixa, média e alta. O domínio $(X)$ da variável é o intervalo [36, 40]. Cada termo lingüístico tem a ele associado um conjunto fuzzy $m(t)$ que o caracteriza. Note que, na formulação clássica, os termos lingüísticos atribuídos para Febre são: presente e ausente.
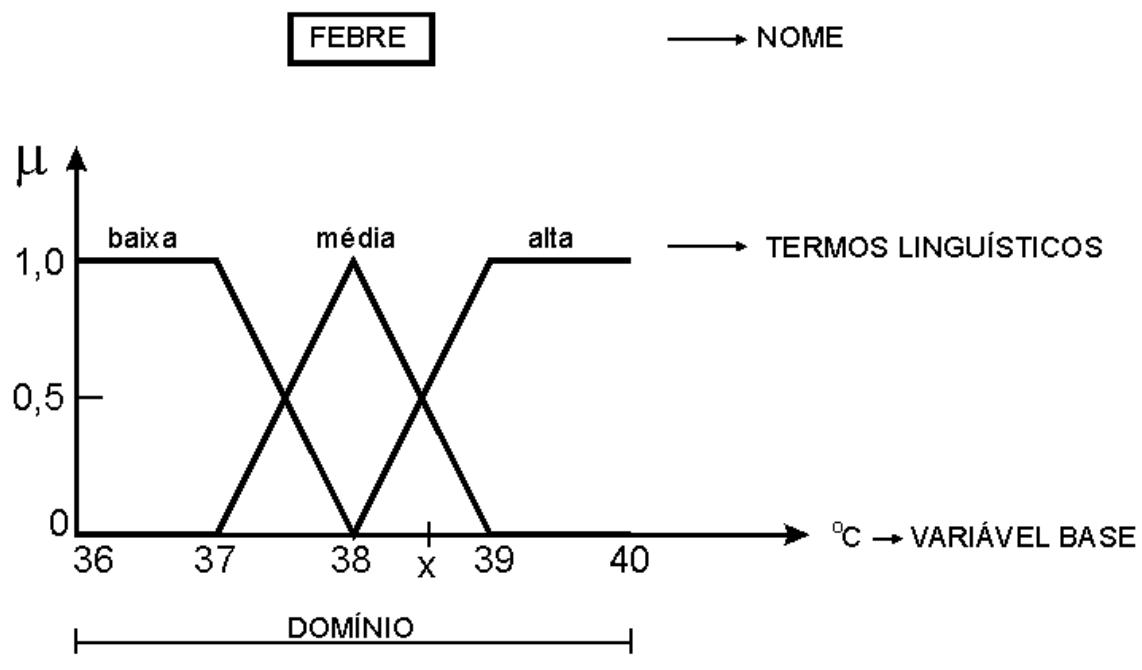

Figura 2.10: Exemplo de variável lingüística.

É importante notar que a variável lingüística é expressa em termos de uma variável básica, que denota a sua medida. No exemplo acima Febre é medida em graus centígrados (temperatura). Esta medida pode ser quantitativa, no caso em que é possível o uso de aparelhos de medida, ou pode ser expressa de forma qualitativa, como no caso do uso de cruzes em exames clínicos.

Os termos lingüísticos são usados para expressar conceitos e conhecimentos na comunicação humana, e em muitas áreas eles são a forma mais importante (quando não a única) de quantificar os dados/informações. O uso de termos lingüísticos é freqüênte no nosso cotidiano, dizemos que o "Dia está muito quente", "O ônibus estava lotado", "Tal pessoa é alta, magra", etc.. Todos estes termos possuem um significado e transmitem informação. No universo médico o uso de termos lingüísticos permeia todas as áreas, inclusive exames laboratoriais. São frenqüentes os termos normalidade, levemente aumentado/diminuído, debilitado, bom estado, etc. A figura 2.11 é um exemplo de variável lingüística utilizada pelos pneumologistas para expressar graus de desconforto respiratório. 


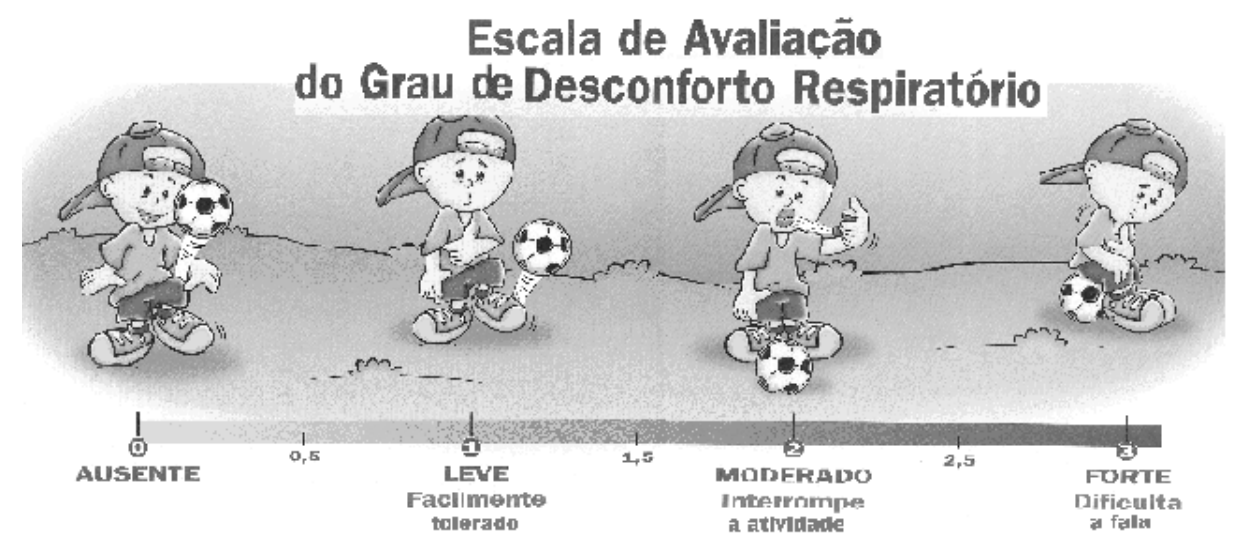

Figura 2.11: Exemplo de variável lingüística utilizada por pneumologistas para designar o grau de desconforto respiratório.

As variáveis linguísticas são expressas dentro de um certo domínio de valores. Em geral é o especialista que define esse domínio e realiza sua partição fuzzy. Nesse contexto, o papel do especialista torna-se fundamental na modelagem fuzzy, particularmente em alguns modelos de epidemiologia e sistemas diagnóstico.

As variáveis numéricas expressam o seu valor e utilidade e são amplamente empregada nas ciências exatas (engenharia, física, matemática, etc), porém, as variáveis simbólicas têm conquistado cada vez maior importância devido ao desenvolvimento das áreas de inteligência artificial e processos de decisão. A capacidade de combinar variáveis simbólicas (lingüísticas) e numéricas é uma das principais razões do sucesso das aplicações da lógica fuzzy em sistemas inteligentes, tanto na engenharia quanto em muitas outras áreas que lidam com domínios contínuos.

\subsection{Distribuição de possibilidades}

Assim como ocorre com os conjuntos clássicos, quando uma variável lingüística é definida ela é restrita a um conjunto de valores. A diferença entre as duas abordagens é justamente a noção de valores possíveis e impossíveis, que na lógica fuzzy é expressa por diferentes graus. Suponha, por exemplo, que alguém esteja interessado em conseguir um namorado (a) em algum site da internet. Algumas características desejadas no suposto candidato costumam ser solicitadas, como por exemplo cor dos olhos, altura, cor dos cabelos, profissão, idade, etc.. A idade, por exemplo, pode ser expressa em um intervalo de interesse do tipo, Idade (candidato $)=[20,30]$. Este intervalo limita a idade do candidato, ou seja, candidatos com idade 20,21, 22,..., ou 30 são possíveis. Por outro lado, não será aceitável candidatos com 19 ou 31 anos, assim como qualquer outra idade que esteja fora do intervalo $[20,30]$. Dessa forma, o intervalo acima define qual é o conjunto de valores impossiveeis de ocorrer. Os conjuntos fuzzy, porém, generalizam a distinção binária entre possível e impossível, gerando vários graus de possibilidade. Assim, no nosso exemplo, poderia ser solicitado apenas que o candidato 
fosse jovem, e uma função de pertinência para a idade forneceria a distribuição de possibilidades de cada candidato. Dessa forma, a possibilidade de um candidato com 18 anos poderia ser 0.7 e a de um outro candidato com 24 anos poderia ser 1 . Vemos, portanto, que a distribuição de possibilidades é a própria função de pertinência. Neste caso,

$$
\pi_{\text {idade }}(x)=\mu_{\text {jovem }}(x), \operatorname{hgt}\left(\mu_{\text {jovem }}\right)=1
$$

onde $\pi$ denota a distribuição de possibilidade da idade do candidato, $x$ é uma variável que representa a idade da pessoa e $\mu_{\text {jovem }}$ é um conjunto fuzzy normal.

Novamente, convêm esclarecer que a distribuição de possibilidades é diferente da distribuição de probabilidades, elas lidam com diferentes tipos de incertezas. De fato, a medida de probabilidade é uma forma da medida de possibilidade (Klir 1995, Barros 1992). Contudo, embora possibilidade e probabilidade sejam medidas distintas, elas apresentam uma relação entre elas pois, se é impossível para uma variável $x$ assumir um certo valor $x_{i}$ é também de se esperar que seja improvável que $x$ apresente o valor $x_{i}$, ou seja,

$$
\pi_{X}\left(x_{i}\right)=0 \Longrightarrow P_{X}\left(x_{i}\right)=0 .
$$

De uma forma geral, a possibilidade pode ser vista como um limite superior para a probabilidade: $P_{X}\left(x_{i}\right) \leq \pi_{X}\left(x_{i}\right)$ (Klir 1995, Yen \& Langari 1999).

\subsection{Regras fuzzy}

As regras fuzzy são estruturas vastamente utilizadas em várias abordagens da teoria fuzzy. Ela pode ser entendida de diversas maneiras. Conceitualmente, as regras fuzzy descrevem situações específicas que podem ser submetidas a análise de um painel de especialistas, e cuja inferência nos conduz a algum resultado desejado. A inferência baseada em regras fuzzy pode também ser compreendida como um funcional que mapeia um conjunto de entradas do sistema para um conjunto de saídas (como em um esquema de interpolação).

A regra fuzzy é uma unidade capaz de capturar algum conhecimento específico, e um conjunto de regras é capaz de descrever um sistema em suas várias possibilidades. Cada regra fuzzy, da mesma forma que uma afirmação clássica, é composta por uma parte antecedente (a parte $S e$ ) e uma parte conseqüente (a parte Então), resultando em uma estrutura do tipo

$$
\text { Se \{antecedentes\} Então \{conseqüentes\}. }
$$

Os antecedentes descrevem uma condição (premissas), enquanto a parte conseqüente descreve uma conclusão ou uma ação que pode ser esboçada quando as premissas se verificam. A diferença entre os antecedentes de uma regra fuzzy e uma regra 
2 Alguns conceitos da teoria de conjuntos fuzzy

clássica é que os primeiros descrevem uma condição elástica, ou seja, uma condição que pode ser parcialmente satisfeita, enquanto os últimos descrevem uma condição rígida (a regra não funciona se os antecedentes não são completamente satisfeitos).

Os antecedentes definem uma região fuzzy no espaço das variáveis de entrada do sistema. Já os conseqüentes descrevem uma região no espaço das variáveis de saída do sistema, qual seja a sua conclusão/ação. Sendo assim, a construção dos antecedentes muitas vezes resulta em um trabalho de classificação, enquanto a elaboração dos conseqüentes exige um conhecimento, ainda que empírico, sobre a dinâmica do sistema. Podemos esperar, então, que a elaboração dos conseqüentes de uma regra seja mais complexa do que a dos antecedentes.

Uma vez construído o conjunto de regras fuzzy necessitaremos de uma "máquina de inferência" para extrair dela a resposta final. Existem vários métodos de inferência possíveis e a escolha por um deles depende do sistema que está sendo analisado. No entanto, a inferência mais comum, e amplamente utilizada no controle de sistemas, é o Método de Mamdani.

As regras são processadas em paralelo, ou seja, todas as regras (circunstâncias) são consideradas ao mesmo tempo, e ao final obtemos uma resposta que pode ser tanto um valor numérico clássico, quanto um conjunto fuzzy ou um funcional, a depender do tipo de conseqüente utilizado. Às vezes é necessário que a saída do sistema seja um número, o que é muito comum em controladores fuzzy, pois o sistema precisa ser re-alimentado. Nestes casos se a saída do sistema for um conjunto fuzzy, então se faz necessário um processo de defuzificação para se obter um número apropriado. No capítulo 3 são discutidos os métodos de inferência e de defuzificação no contexto dos modelos fuzzy.

\subsection{Relações fuzzy}

As relações fuzzy são, assim como os conjuntos fuzzy, uma generalização das relações clássicas. Uma relação clássica descreve a inter-relação entre dois ou mais objetos. Uma inter-relação entre dois objetos é uma relação binária, entre três objetos é uma relação ternária, e assim por diante. A inter-relação entre um pai e seu filho pode ser representado por uma relação binária: (pai, filho).

Uma relação clássica segue a função característica clássica. Sendo assim, uma relação de amizade entre duas pessoas, por exemplo, designada como "amigos" considera que nas relações humanas ou alguém é seu amigo ou não o é, o que é uma simplificação da realidade. Por outro lado, uma relação de "amizade"fuzzy entre duas pessoas pode considerar o grau de amizade entre elas. Sendo assim, dois ou mais indivíduos podem se relacionar com diferentes graus de amizade, desde 1 (são certamente amigos) até 0 (não são amigos). Uma relação binária sobre as variáveis $x$ e $y$, cujos domínios são respectivamente $X$ e $Y$, pode ser definida como um conjunto de pares ordenados em $X \times Y$. Por exemplo, a relação "maior que" entre dois números reais pode ser formalmente definida por 


$$
R=\{(x, y) \mid x>y ; x, y \in \mathbb{R}\} .
$$

De uma forma geral, temos que uma relação sobre $n$ objetos $x_{1}, x_{2}, \ldots, x_{n}$ cujos domínios são $X_{1}, X_{2}, \ldots, X_{n}$ é um subconjunto do espaço $X_{1} \times X_{2} \times \ldots \times X_{n}(Y e n \mathscr{G}$ Langari 1999).

Uma relação binária $R$ entre duas variáveis, $x \in X$ e $y \in Y$, por exemplo, pode ser representada como uma função que mapeia um par ordenado $(x, y)$ em $X \times Y$ para 0 (quando a relação não se aplica) ou 1 (quando a relação se aplica), ou seja, $R: X \times Y \rightarrow\{0,1\}$. Uma relação fuzzy entre duas variáveis $x \in X$ e $y \in Y$ é definida, então, como uma função que mapeia os pares ordenados em $X \times Y$ para o seu grau na relação, que é um número no intervalo [0,1], ou seja, $R: X \times Y \rightarrow[0,1]$.

Uma relação fuzzy $R$ sobre $n$ objetos $x_{1}, x_{2}, \ldots, x_{n}$, cujos domínios são $X_{1}, X_{2}, \ldots, X_{n}$ respectivamente, é definida por uma função que mapeia o ponto $\left(x_{1}, x_{2}, \ldots, x_{n}\right)$ em $X_{1} \times X_{2} \times \ldots \times X_{n}$ para um número no intervalo [0,1], ou seja, $R: X_{1} \times X_{2} \times \ldots \times X_{n} \times \rightarrow$ $[0,1]$. Este mapeamento é equivalente a uma função de pertinência de um conjunto fuzzy multidimensional.

Se os valores de $x$ e $y$ são discretos, então, podemos expressar uma relação fuzzy em uma forma matricial. Suponhamos, por exemplo, que desejemos expressar a relação fuzzy de um sistema diagnóstico em termos dos sintomas e das doenças. Suponha que o conjunto de sintomas seja \{cefaléia, tosse, febre\} e o conjunto das doenças seja \{Endocardite, Pneumonia, Coqueluche, Turbeculose, Gripe Comum\}. Podemos solicitar a algum especialista que estabeleça o grau de relação entre cada sintoma com cada doença, elaborando assim uma matriz de relação fuzzy onde as colunas são as doenças consideradas, as linhas são os sintomas e os valores são o grau com que os sintomas se relacionam com as doenças:

$\begin{array}{cccccc} & \text { End. } & \text { Pn. } & \text { Coq. } & \text { Tb. } & \text { G.C. } \\ \text { cefaléia } & 0.0 & 0.0 & 0.3 & 0.0 & 0.8 \\ \text { febre } & 0.9 & 1.0 & 0.3 & 1.0 & 0.2 \\ \text { tosse } & 0.2 & 0.4 & 0.7 & 1.0 & 0.1\end{array}$

Assim, o grau de relação entre cefaléia e Pneumonia é zero , ou seja, segundo a matriz de relações proposta não existe correlação direta entre cefaléia e Pneumonia. No entanto, a relação entre febre e Pneumonia é um, segundo esta mesma matriz relacional. Alguém poderia sugerir que a relação entre sintomas e doenças depende da idade, o que seria razoável para um grande número de patologias. Para agregarmos a informação idade precisaríamos considerar mais uma dimensão na matriz de relações e teríamos uma relação fuzzy ternária (idade, sintoma, doença).

Consideremos agora o caso de um paciente que apresenta um certo grau de tosse, febre e cefaléia. Um médico desejará saber qual a possibilidade de que este paciente possua alguma das doenças consideradas acima. A pergunta consiste em como agregar as características desse paciente com as informações contidas na matriz relacional 
2 Alguns conceitos da teoria de conjuntos fuzzy

sintoma/doença. Para responder ao médico podemos utilizar um dos recursos mais preciosos das relações fuzzy, qual seja a Composição de Relações Fuzzy.

\subsubsection{Composição de Relações Fuzzy}

Seja $X$ e $Y$ o universo de discurso para as variáveis $x$ e $y$, respectivamente, e $x_{i}$ e $y_{i}$ os elementos de $X$ e $Y$. Considere $R$ a relação fuzzy que mapeia $X \times Y$ em [0,1] e a distribuição de possibilidade de $X, \pi_{x}\left(x_{i}\right)$, então a distribuição de possibilidades de $Y$ é dada por:

$$
\pi_{Y}\left(y_{j}\right)=\oplus_{x_{i}}\left[\pi_{X}\left(x_{i}\right) \otimes \pi_{R}\left(x_{i}, y_{j}\right)\right]
$$

onde o símbolo $\oplus$ denota um operador qualquer de disjunção fuzzy e o $\otimes$ denota um operador qualquer de conjunção fuzzy. Considerando a expressão 2.12 podemos re-escrever a equação 2.14 em termos das funções de pertinência de $X$ e $Y$, obtendo:

$$
\mu_{Y}(y)=\oplus\left[\mu_{X}(x) \otimes \mu_{R}(x, y)\right]
$$

O procedimento para calcular a regra de composição é semelhante a usada para multiplicar matrizes. Os operadores de conjunção e disjunção fuzzy acima correspondem, respectivamente, aos passos de multiplicação e soma na multiplicação de matrizes.

A regra composicional não é única, uma vez que diferentes escolhas podem ser feitas com respeito aos operadores de conjunção e disjunção. Na prática as duas mais utilizadas são a composição max-min e a composição max-produto. Considerando estas duas possibilidades a equação 2.15 fornece:

$$
\mu_{Y}(y)=\max _{x_{i}}\left[\min \left(\mu_{X}\left(x_{i}\right), \mu_{R}\left(x_{i}, y_{i}\right)\right)\right]
$$

para a composição max-mim, e

$$
\mu_{Y}(y)=\max _{x_{i}}\left[\mu_{X}\left(x_{i}\right) \cdot \mu_{R}\left(x_{i}, y_{i}\right)\right]
$$

para a composição max-produto.

Sendo assim, considere $A=\{$ cefaléia,febre,tosse $\}$ o conjunto de sintomas, $s, B=$ \{Endocardite, Pneumonia, Coqueluche, Tuberculose, Gripe Comum\} o conjunto de doenças, $d$, e $R(s, d)$ a matriz de relação sintomas/doenças citada anteriormente. Considere um paciente cuja pertinência em $A$ é dado por $[0,0 ; 0,7 ; 1,0]$, ou seja, seu grau de cefaléia é zero, o de febre é 0,7 e o de tosse é 1,0 (o paciente tosse muito). Então, se desejamos saber qual o grau de pertinência deste paciente no conjunto de doenças, dado que existe uma relação entre os sintomas e as doenças descrita em $R$, precisamos fazer a composição de $A \operatorname{com} B$ :

$$
\mu_{B}(d)=\max \left[\min \left(\mu_{A}(s), \mu_{R}(s, d)\right]\right.
$$


cujo cálculo nos fornece

$$
[0,7 ; 0,7 ; 0,7 ; 1,0 ; 0,2],
$$

ou seja, a possibilidade de que o paciente tenha Endocardite, Pneumonia ou Coqueluche é 0,7 ; a possibilidade de que ele tenha Tuberculose é 1,0 e a possibilidade de que seja uma Gripe Comum é 0, 2 .

Note que a resposta da composição é também um conjunto fuzzy, ou seja, ela não responde qual doença possui o paciente. O que ela fornece é a distribuição de possibilidades do paciente no conjunto doenças, dado que ele apresenta uma certa distribuição de possibilidades no conjunto sintomas. No entanto, baseado na resposta obtida o médico pode tomar decisões, optar por exemplo por exames laboratoriais mais detalhados, investigando com mais afinco a possibilidade de ser uma Tuberculose e descartando a possibilidade de uma Gripe Comum.

\subsection{Princípio de extensão}

O Princípio de Extensão permite mapeiar conjuntos fuzzy de um domínio em conjuntos fuzzy de outro domínio a partir de uma função clássica. Este princípio surge da necessidade de aplicarmos uma função clássica a argumentos imprecisos. Neste sentido, se temos uma função $f$ e precisamos aplicar esta função a argumentos fuzzy, então, nós precisamos recorrer ao princípio de extensão.

Um argumento fuzzy descreve a distribuição de possibilidade do argumento da função $f$. Assim, para cada possível valor que a variável da função pode assumir, o funcional produz sua possível imagem fornecendo também a distribuição de possibilidade dessa imagem. Dependendo da função pode ocorrer que diferentes valores de entrada sejam mapeados no mesmo valor de saída, como acontece com funções nãoinjetoras. Neste caso, é preciso determinar a possibilidade de cada um dos valores de saída, através da combinação dos graus de pertinência de todos os valores de entrada que mapeiam o mesmo valor de saída, o que pode ser feito usando o operador sup. A figura 2.12 apresenta um exemplo de mapeamento de uma distribuição de possibilidade para uma função monotônica, onde $A$ e $B$ são conjuntos fuzzy e o mapeamento é obtido com o operador:

$$
B(y)=\sup _{x \in X, y=f(x)} \mu_{A}(x)
$$

As características descritas acima introduzem os dois conceitos mais importantes do princípio de extensão:

- A possibilidade de um valor de entrada é propagado diretamente para a possibilidade de sua imagem.

- Quando a combinação de múltiplas entradas mapeam o mesmo valor de saída, a possibilidade da saída é obtida pela combinação das possibilidades dessas entradas através do operador sup. 


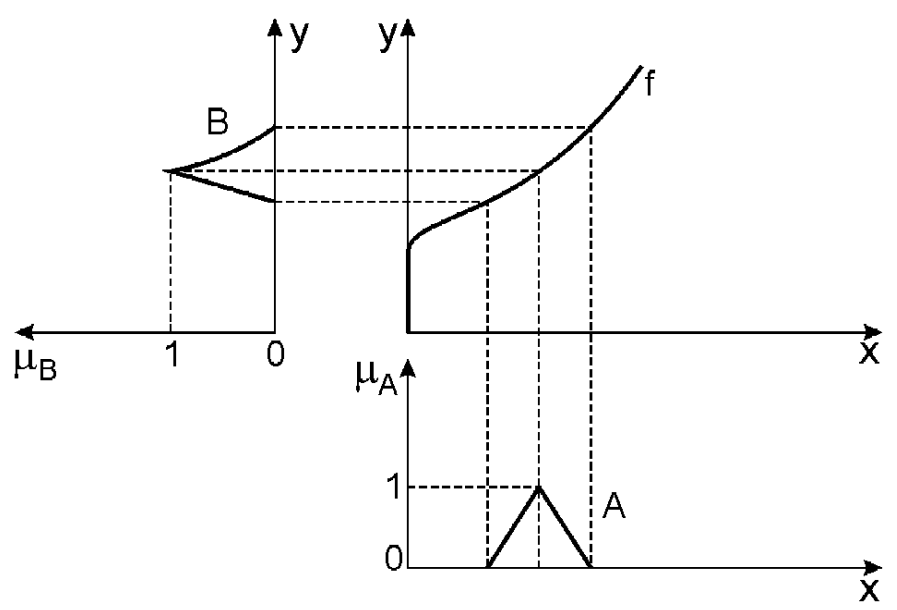

Figura 2.12: Exemplo de Extensão de uma função monotônica.

Pode ocorrer também de, ao fim do processo, obtermos diferentes distribuições de possibilidades para cada argumento $\left(x_{1}, x_{2}, \ldots, x_{n}\right)$ da função $f$. Neste caso, é necessário aplicar um operador de conjunção fuzzy para decidir qual será o grau de possibilidade da imagem. Mais precisamente, considere uma função clássica

$$
f: X_{1} \times X_{2} \times \ldots \times X_{n} \rightarrow Y
$$

e $A_{1}, A_{2}, \ldots A_{n}$, subconjuntos fuzzy de $X_{1}, X_{2}, \ldots, X_{n}$, respectivamente. O princípio de extensão produz um conjunto $B=f\left(A_{1}, A_{2}, \ldots A_{n}\right)$ que é um subconjunto fuzzy de $Y$, cuja função de pertinência é dada por:

$$
\mu_{B}(y)=\left\{\begin{array}{lll}
\sup _{\left(x_{1}, x_{2}, \ldots, x_{n}\right) \in f^{-1}(y)}\left[\min \left(\mu_{A_{1}}\left(x_{1}\right), \ldots, \mu_{A_{n}}\left(x_{n}\right)\right)\right] & \text { se } & f^{-1}(y) \neq \emptyset \\
0 & \text { se } & f^{-1}(y)=\emptyset
\end{array}\right.
$$

onde $f^{-1}(y)=\left\{\left(x_{1}, x_{2}, \ldots, x_{n}\right) \in X_{1} \times X_{2} \times \ldots \times X_{n}\right.$, tal que $\left.f\left(x_{1}, x_{2}, \ldots, x_{n}\right)=y\right\}$.

A função $\widehat{f}$, que caracteriza o conjunto fuzzy $B$, induzida por este método apresenta muitas propriedades (Klir \& Yuan 1995, Yen \& Langari 1999), das quais uma das mais importantes é que a $\widehat{f}$, de fato, recupera os valores clássicos, no sentido que a $\widehat{f}\left(\widehat{x}_{1}, \widehat{x}_{2}, \ldots, \widehat{x}_{n}\right)=f\left(x_{1}, x_{2}, \ldots, x_{n}\right)$ para todo $\left(x_{1}, x_{2}, \ldots, x_{n}\right) \in X_{1} \times X_{2} \times \ldots \times X_{n}$ onde $\widehat{x}_{i}(t)=\left\{\begin{array}{lll}1 & \text { se } & t=x_{i} \\ 0 & \text { se } & t \neq x_{i}\end{array}\right.$.

Portanto, o princípio de extensão nos permite obter a distribuição de possibilidade da imagem de uma função cujos argumentos são conjuntos fuzzy, consistindo em uma técnica extremamente útil na investigação sobre a ação de uma função clássica sobre 
argumentos imprecisos. No capítulo 10 discutirei como nós utilizamos este princípio na elaboração dos conseqüentes de um conjunto de regras fuzzy em um modelo lingüístico.

Ao aplicarmos o princípio de extensão à operações aritméticas (tais como adição e subtração) é possível obter as operações aritméticas fuzzy. Considere $x$ e $y$ os argumentos, $z$ o resultado da operação, $A$ e $B$ os conjuntos fuzzy para as variáveis $x$ e $y$, respectivamente, $\oplus$ um operador de disjunção fuzzy e $\otimes$ um operador de conjunção fuzzy. Então, as operações de adição e subtração fuzzy são dadas por:

$$
\mu_{A+B}(z)=\oplus_{x, y \mid x+y=z}\left(\mu_{A}(x) \otimes \mu_{B}(y)\right)
$$

e

$$
\mu_{A-B}(z)=\oplus_{x, y \mid x-y=z}\left(\mu_{A}(x) \otimes \mu_{B}(y)\right)
$$

- Exemplo 2.3: Seja $A$ e $B$ os seguintes conjuntos fuzzy

$$
\begin{aligned}
& A(x)=0,4 / 1+0,6 / 2+0,8 / 3+1 / 4+0,7 / 5+0,1 / 6 \\
& B(y)=0,5 / 3+0,8 / 4+1 / 5+0,2 / 6
\end{aligned}
$$

Então, a soma desses dois conjuntos fuzzy pode ser obtida pela equação 2.21 considerando os operadores mim e max para a conjunção e a disjunção, respectivamente. Analisando todas as combinações $(x, y)$ dos conjuntos fuzzy e o operador mim obtemos:

$$
\begin{aligned}
f(A+B) & =0,4 / 4+0,4 / 5+0,4 / 6+0,2 / 7 \\
+ & 0,5 / 5+0,6 / 6+0,6 / 7+0,2 / 8 \\
& +0,5 / 6+0,8 / 7+0,8 / 8+0,2 / 9 \\
& +0,5 / 7+0,8 / 8+1 / 9+0,2 / 10 \\
& +0,5 / 8+0,7 / 9+0,7 / 10+0,2 / 11 \\
& +0,1 / 9+0,1 / 10+0,1 / 11+0,1 / 12
\end{aligned}
$$

Aplicando o operador max sobre os valores duplicados obtemos o resultado final:

$$
\begin{aligned}
A+B= & 0,4 / 4+0,5 / 5+0,6 / 6+0,8 / 7+0,8 / 8 \\
& +1 / 9+0,7 / 10+0,2 / 11+0,1 / 12
\end{aligned}
$$

Podemos notar do exemplo acima, que o suporte do conjunto fuzzy resultante da soma de dois outros conjuntos fuzzy é maior do que os suportes dos conjuntos argumentos. 


\subsection{Processos de decisão fuzzy}

Tomar decisões é uma das atividades mais fundamentais dos seres humanos e muitos estudos têm sido desenvolvidos a cerca desse assunto. O objeto de análise de um processo de decisão é justamente o estudo de quais estratégias utilizar e como escolhê-las de forma melhor ou mais eficientemente. Estudos desse tipo têm sido amplamente aplicados em áreas de gerenciamento, onde o processo de decisão assume um papel fundamental, tais como controle, investimentos, desenvolvimento de novos produtos e alocação de recursos, entre outros. Entretanto, em geral, os processos de decisão incluem qualquer situação onde uma escolha ou seleção de alternativas se faz necessária, abrangendo desde as ciências tidas como exatas até as humanas.

A aplicação da teoria de conjuntos fuzzy em processos de decisão consiste basicamente na fuzificação da teoria de decisão clássica. Enquanto o processo de decisão sobre condições de risco têm sido modelado com teorias de decisão probabilística e teoria de jogos, a teoria de decisão fuzzy procura lidar com as formulações vagas e imprecisas, inerentemente humanas, quanto à preferências, limitações e objetivos. Um processo de decisão é dito sobre condições de certeza quando o resultado de cada ação pode ser determinado com precisão. Ele é dito sobre condições de risco quando o conhecimento disponível a cerca do resultado consiste apenas da distribuição de probabilidade condicional, relativo a cada ação. Por outro lado, quando os resultados devido a cada ação são caracterizados apenas aproximadamente, então, o processo de decisão é dito sobre condições de imprecisão. Este é o caso dos processos de decisão fuzzy (Klir \& Yuan 1995).

Os conjuntos fuzzy podem ser introduzidos na teoria de tomada de decisão de diversas formas. Bellmam e Zadeh sugeriram um modelo fuzzy de tomada de decisão no qual os objetivos e restrições relevantes são expressos em termos de conjuntos fuzzy, e a decisão é determinada a partir de um tipo de agregação apropriada desses conjuntos (Bellmam e Zadeh 1970). Um processo de decisão nesse tipo de modelo é caracterizado pelos seguintes componentes:

- um conjunto $A$ de possíveis ações ou estratégias;

- um conjunto de metas $G_{i}(i \in \mathbb{N})$, cada uma das quais expressa em termos de um conjunto fuzzy definido sobre $A$;

- um conjunto de restrições $C_{j}(j \in \mathbb{N})$, cada um também sendo expresso em termos de um conjunto fuzzy definido sobre $A$;

Então, dada uma situação de decisão caracterizada pelos conjuntos fuzzy $A, G_{i}$ $(i \in \mathbb{N})$ e $C_{j}(j \in \mathbb{N})$, a decisão fuzzy $D$, é definida como um conjunto fuzzy sobre $A$ que satisfaz simultaneamente as metas e as restrições, ou seja,

$$
D(a)=\min \left[\inf _{i \in \mathbb{N}} G_{i}(a), \inf _{j \in \mathbb{N}} C_{j}(a)\right]
$$

para qualquer $a \in A$. 
- Exemplo 2.4: Suponha que um estudante deseja escolher entre três possíveis faculdades $a_{1}, a_{2}, a_{3}$ para seguir seu curso superior. Seu objetivo é escolher uma faculdade que ofereça o melhor curso sob a condição (restrição) de que ela não seja muito cara e nem muito longe de sua residência. Neste caso, $A=\left\{a_{1}, a_{2}, a_{3}\right\}$ e os conjuntos fuzzy envolvidos representam os conceitos curso alto nível, preço razoável e próximo de casa. Note que estes conceitos são bastante subjetivos e dependem de um contexto e portanto, eles devem ser definidos pelo próprio indivíduo interessado. O objetivo $G_{i}$ pode ser expresso em termos de uma nota entre 0 e 10 dada a cada faculdade a depender da sua avaliação no Provão, por exemplo. Vamos supor que os valores $g_{i}^{\prime} s$ das notas atribuídas sejam:

$g\left(a_{1}\right)=10$

$g\left(a_{2}\right)=7$

$g\left(a_{3}\right)=2$

Então o conjunto fuzzy $G_{i}$ de curso alto nível, expressos sobre $A$, pode ser determinado pela normalização dessas notas para o intervalo $[0,1]$ :

$$
G_{i}=1 / a_{1}+0,7 / a_{2}+0,2 / a_{3}
$$

O conjunto fuzzy $C_{1}$ sobre $A$, que expressa a restrição quanto ao preço da faculdade, pode ser definido em termos monetários a depender do valor do pagamento mensal. Digamos que os valores $c_{1 i}^{\prime} s$ sejam:

$c_{1}\left(a_{1}\right)=R \$ 1.000,00$

$c_{1}\left(a_{2}\right)=R \$ 600,00$

$c_{1}\left(a_{3}\right)=R \$ 500,00$

Então, segundo um certo contexto, podemos dizer que a pertinência destas instituições no conjunto preços razoáveis é:

$$
C_{1}=0,2 / a_{1}+0,6 / a_{2}+0,7 / a_{3}
$$

A segunda restrição, $C_{2}$, que requer que a distância entre a faculdade e a sua residência não seja muito grande, pode ser expresso em termos de uma medida de distância, $k m$. Digamos que os valores $c_{2 i}^{\prime} s$ são:

$c\left(a_{1}\right)=10 \mathrm{~km}$

$c\left(a_{2}\right)=7,5 \mathrm{~km}$

$c\left(a_{3}\right)=2,5 \mathrm{~km}$

e o conjunto $C_{2}$ expresso em termos do conjunto $A$ é dado por:

$$
C_{2}=0,4 / a_{1}+0,6 / a_{2}+1 / a_{3} .
$$


2 Alguns conceitos da teoria de conjuntos fuzzy

Então, aplicando a equação 2.23 nós obtemos o conjunto decisão fuzzy

$$
D=0,2 / a_{1}+0,6 / a_{2}+0,2 / a_{3} .
$$

que representa uma caracterização fuzzy do conceito de faculdade desejável. A instituição a ser escolhida é a $a_{2}$ uma vez que ela é a mais desejável entre as três candidatas, pois é a que tem a maior pertinência no conjunto decisão, dado o objetivo e as restrições consideradas.

No capítulo 5 é apresentado um modelo onde utilizamos os conceitos expostos para escolhermos a melhor estratégia de vacinação contra o sarampo. Esta estratégia determinou a campanha de vacinação que foi aplicada em todo o Estado de São Paulo para combater o surto da doença em 1997. Um outro conceito da teoria de lógica fuzzy que aplicamos em problemas de epidemiologia foi o de Probabilidade de um Evento Fuzzy.

\subsection{Probabilidade de eventos fuzzy}

Uma maneira de unir a teoria de probabilidades e a lógica fuzzy é considerarmos a probabilidade de um evento fuzzy. Um evento é um subconjunto do espaço amostral cujos elementos compartilham uma característica comum, sobre a qual estamos interessados. Lançar dez moedas e verificar quantas caras e coroas obtivemos é um evento, dentre todas as possibilidades entre nenhuma cara e nenhuma coroa que descrevem o espaço amostral. Como foi discutido anteriormente, existem casos em que o evento não é bem definido, estes eventos são chamados de eventos fuzzy. No exemplo do lançamento das dez moedas um evento fuzzy poderia ser "existem muito mais caras do que coroas", onde o quanto é muito mais não é bem definido, podendo depender da situação ( Yen É Langari 1999). Formalmente, um evento fuzzy é um subconjunto fuzzy do espaço amostral.

A probabilidade de um evento fuzzy é obtida pela generalização da teoria de probabilidade. No caso de o espaço amostral $X$ ser contínuo temos que a probabilidade $P(A)$ de um evento fuzzy $A$ é dada por:

$$
P(A)=\int \mu_{A}(x) \otimes P_{X}(x) d x
$$

onde $P_{X}$ denota a distribuição de probabilidades de $X, \mu_{A}$ é a função de pertinência do evento $A$ e o operador $\otimes$ é um operador fuzzy de intersecção, como por exemplo o operador multiplicação. Para o caso em que $X$ é discreto teremos:

$$
P(A)=\sum_{i} \mu_{A}\left(x_{i}\right) \otimes P_{X}\left(x_{i}\right) .
$$




\subsubsection{Probabilidade condicional de eventos fuzzy}

Muitas vezes estamos interessados em avaliar a probabilidade condicional entre dois eventos. Considere dois eventos $A$ e $B$ de um espaço amostral, a probabilidade condicional de $A$ dado $B$ é definida pela teoria de probabilidades como

$$
P(A / B)=\frac{P(A \cap B)}{P(B)} .
$$

Temos ainda que a soma da probabilidade condicional de $A$ dado $B$ com a probabilidade condicional de $n \tilde{a} o$ A dado $B$ é 1:

$$
P(A / B)+P\left(A^{c} / B\right)=1
$$

A probabilidade condicional de eventos fuzzy pode ser definida de forma similar a apresentada na equação 2.26. No entanto, a expressão 2.27 continuará valendo apenas se escolhermos a multiplicação como operador de intersecção (conjunção). Utilizaremos, então, os operadores soma e produto algébrico para designar, respectivamente, a união e a intersecção dos eventos fuzzy.

Ademais, se $A$ e $B$ são dois eventos fuzzy quaisquer de um espaço amostral $S$, a probabilidade de ocorrer ambos os eventos fuzzy é definida como (Yen $\mathscr{G}$ Langari 1999):

$$
P(A \cap B)=\sum_{x \in S} \mu_{A}(x) \cdot \mu_{B}(x) \cdot P(x)
$$

onde $\mu_{A}(x)$ e $\mu_{B}(x)$ são as funções de pertinência dos conjuntos $A$ e $B$, respectivamente, e $P(x)$ é a distribuição de probabilidades de $x$. Com isso, é possível definir formalmente a probabilidade condicional de eventos fuzzy (Yen $\&$ Langari 1999).

- Definição 2.7: $S e A$ e $B$ são dois eventos fuzzy quaisquer em um espaço amostral $S$ e $P(B) \neq 0$, então, a probabilidade condicional de $A$ dado $B$ é expressa por

$$
P(A / B)=\frac{P(A \cap B)}{P(B)} .
$$

Dessa definição obtemos que

$$
P(A \cap B)=P(A / B) \cdot P(B) .
$$




\subsubsection{Eventos fuzzy independentes}

Na teoria de probabilidades, dois eventos $A$ e $B$ são independentes se a ocorrência de um não afeta a ocorrência do outro, ou seja, se $P(A / B)=P(A)$ e $P(B / A)=P(B)$. Se substituirmos $P(A / B)$ por $P(A)$ na equação 2.30 nós temos que $P(A \cap B)=$ $P(A) \times P(B)$, o que nos fornece uma definição formal para a independência de eventos fuzzy.

- Definição 2.8: Dois eventos fuzzy $A$ e $B$ são independentes se, e somente se,

$$
P(A \cap B)=P(A) \cdot P(B)
$$

No capítulo 5 utilizamos estes conceitos de probabilidade de eventos fuzzy para respondermos duas questões de cunho epidemiológico. 


\section{Capítulo 3}

\section{Modelos lingüísticos fuzzy}

Os sistemas fuzzy são, em geral, o resultado de uma generalização dos sistemas clássicos, ou seja, nessa abordagem os conceitos nebulosos (vagos) são incorporados a esses sistemas. Os modelos fuzzy são também uma extensão do significado clássico de modelos, qual seja, uma representação das características essenciais de um sistema através da estrutura da teoria de conjuntos fuzzy. Uma característica central dos sitemas fuzzy é que eles são baseados no conceito de partição fuzzy das informações. A utilização de conjuntos fuzzy permite uma generalização da informação, que está associada com a introdução da imprecisão, do desconhecimento dos fenômenos. Em essência, a representação da informação nos sistemas fuzzy procura imitar o processo de raciocínio humano, considerando conhecimentos heurísticos e cruzando informações desconectadas a priori.

Os modelos fuzzy podem, em geral, ser agrupados em duas categorias que diferem fundamentalmente em suas habilidades para representar diferentes tipos de informação. O primeiro grupo é constituído pelos Modelos Lingüisticos (MLs), cuja base é um conjunto de regras do tipo Se-Então, cujos predicados são vagos. Neste tipo de modelo as quantidades estão associadas a termos lingüísticos, sendo o modelo fuzzy essencialmente uma expressão qualitativa do sistema. Esse tipo de modelagem é baseada na utilização da linguagem natural para descrever o comportamento dos sistemas.

A outra categoria de modelos fuzzy está baseada no método de modelagem de Takagi-Sugeno-Kang (TSK), que foi proposta por Sugeno e seus colaboradores e que é essencialmente uma combinação de conceitos fuzzy e não-fuzzy. Os conceitos fuzzy baseados nesse método integram a habilidade dos modelos lingüísticos, na representação de conhecimentos qualitativos, com um efetivo potencial para uma expressão quantitativa dos sistemas. Os modelos TSK são compostos por proposições condicionais cujos antecedentes são variáveis lingüísticas e cujos conseqüentes são funções.

Tanto os Modelos Lingüísticos quanto os Modelos TSK apresentam soluções alternativas à abordagem de sistemas dinâmicos. 


\subsection{Modelos lingüísticos (MLs)}

Nos modelos lingüísticos as equações diferenciais, que normalmente caracterizam os sistemas dinâmicos, são substituídas por um conjunto de regras cuja construção abrange predicados vagos e, muitas vezes, conhecimentos heurísticos. Estes modelos são estruturados sobre uma base de conhecimentos e seu poder de decisão depende da elaboração das regras e dos mecanismos de raciocínio fuzzy.

Na teoria de sistemas, os modelos são classificados de acordo com algumas características que o conjunto de equações diferenciais, que é quem estabelece as relações entre as entradas e saídas do sistema, apresentam; como por exemplo, linearidade, não-linearidade, dinâmica, estática, etc. Nos modelos fuzzy quem assume este papel são as famílias de regras. Assim, os diferentes modelos resultam de distintas interpretações dos conhecimentos contidos nas regras e dos mecanismos de raciocínio adotados. Existem diversos tipos de inferência para relacionar as entradas e saídas do conjunto de regras. Eles diferem pelo tipo de operador utilizado e pelos tipos de antecedentes e conseqüentes. As regras podem, por exemplo, ser constituídas por uma única entrada e um única saída, esse é o caso dos sistema "Single-Input/Single-Output" (SISO). Por outro lado, o sistema pode ser caracterizado por regras com múltiplos valores de entrada e múltiplos valores de saída, o que consiste em uma generalização do caso anterior (MIMO). Os modelos lingüísticos fuzzy para sistemas dinâmicos são também muito interessantes e amplamente aplicados. Nesses modelos a dinâmica do sistema é obtida através de um conjunto de regras iterativas, onde a evolução temporal é obtida pela iteração da saída do passo de tempo anterior como entrada do passo posterior.

Nos sistemas SISO o conhecimento é expresso através de um conjunto de regras que possui a seguinte estrutura:

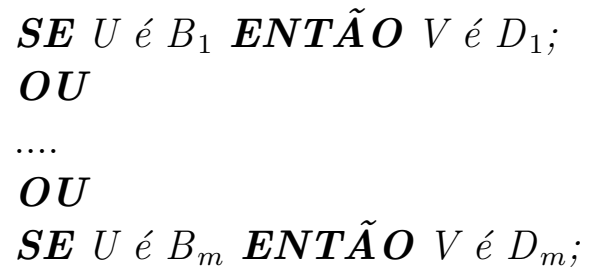

onde $U$ é a variável lingüísticas de entrada (antecedentes) com domínio $X, V$ é a variável lingüísticas de saída (conseqüentes) com domínio $Y$, e $B_{i}$ e $D_{i}$ são subconjutos fuzzy dos conjuntos $X$ e $Y$. Normalmente os conjuntos fuzzy $B_{i}$ e $D_{i}$ estão associados a algum termo lingüístico, tais como, pequeno, médio, muito alto, baixo, rápido, lento , etc. Esta é a estrutura básica do conjunto de regras nos modelos lingüísticos.

Os MLs podem ser entendidos como sistemas especialistas que descrevem lingüisticamente um determinado objeto complexo. Os seus conjuntos fuzzy, $B_{i}$ e $D_{i}$, são os parâmetros do modelo e o número de regras determina a sua estrutura. A idéia aqui é subdividir o espaço das variáveis de entrada e de saída em regiões fuzzy e associar 
cada subconjunto do espaço de entrada com o conveniente subconjunto do espaço de saída.

O método de inferência determina a forma operacional do modelo lingüístico. Ele é um mapeamento que define uma transformação do valor fuzzy de entrada em um valor de saída. Existem diversos métodos de inferência, devemos portanto, escolher aquele que melhor de adapta ao sistema que estamos modelando. Um dos métodos mais divulgados, pela sua simplicidade e por se adaptar muito bem aos controladores fuzzy, é o método de Mamdani.

\subsection{Modelos lingüísticos tipo Mamdani}

Trata-se de modelos lingüísticos cuja saída é construída pela superposição dos conseqüentes das regras individuais. Nesta abordagem cada regra,

$\boldsymbol{S E} U$ é $B_{i} \boldsymbol{E N T} \tilde{\boldsymbol{A}} \boldsymbol{O} V$ é $D_{i}$;

é expressa como uma relação fuzzy $R_{i}$ que é interpretada como o produto cartesiano dos conjuntos fuzzy $B_{i}$ e $D_{i}$,

$$
R_{i}=B_{i} \times D_{i}
$$

isto é, $R_{i}$ é um subconjunto de $X \times Y$, e cuja função de pertinência é

$$
R_{i}(x, y)=B_{i}(x) \wedge D_{i}(y) .
$$

onde $\wedge$ é o operador de conjunção fuzzy, min.

Logo, podemos perceber da expressão acima que a relação $R_{i}$ ocupa uma região no espaço do produto cartesiano $X \times Y$, como mostra a figura 3.1, com distribuição de possibilidade dada por (3.4).

Neste modelo, a agregação do conjunto de regras (o operador OU em 3.1) é realizada através do operador união sobre todas as relações individuais, o que caracteriza o caráter construtivo desse tipo de modelo. Assim,

$$
R=\bigcup_{i=1}^{m} R_{i},
$$

e a função de pertinência $R(x, y)$ da relação fuzzy $R$ é

$$
R(x, y)=\vee_{i} R_{i}(x, y)=\vee_{i=1}^{m}\left(B_{i}(x) \wedge D_{i}(y)\right) .
$$

onde $\vee$ é um operador de disjunção fuzzy, $\max$.

Assim, para um dado conjunto fuzzy $A$ de entrada, o conjunto fuzzy de saída $F$ será obtido através da regra de inferência max-min e a função de pertinência será 


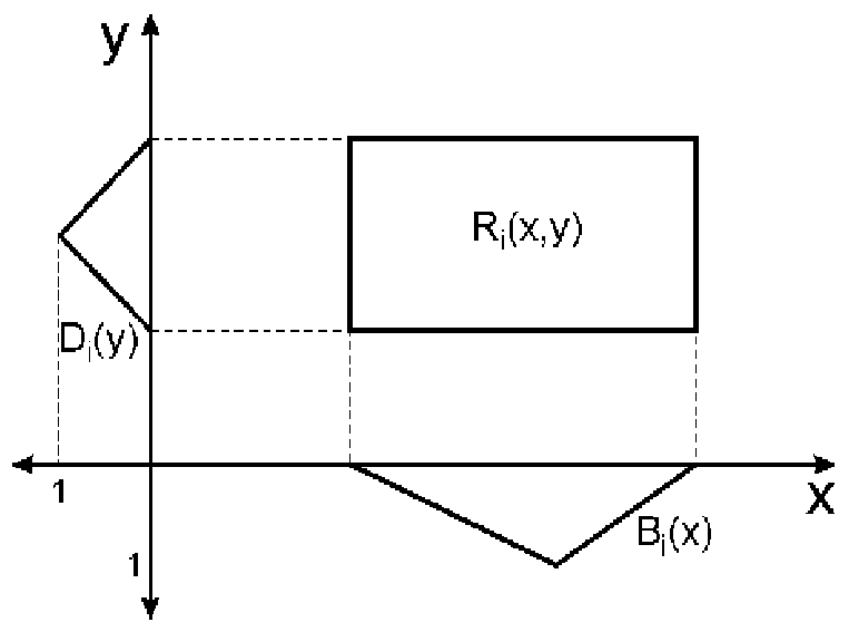

Figura 3.1: Exemplo de relação fuzzy para um sistema de uma variável de entrada e uma de saída.

$$
\begin{aligned}
F(y) & =\vee_{x}[A(x) \wedge R(x, y)]=\vee_{x}\left[\bigvee_{i=1}^{m}\left(A(x) \wedge R_{i}(x, y)\right)\right] \\
& =\vee_{i=1}^{m}\left[\left(\vee_{x}\left[A(x) \wedge B_{i}(x)\right]\right) \wedge D_{i}(y)\right]=\vee_{i=1}^{m}\left[\tau_{i} \wedge D_{i}(y)\right]
\end{aligned}
$$

onde $\tau_{i}$ é o grau de ativação da i-ésima regra, chamado dof (degree of firing), que denota a possibilidade de $B_{i}$ dado $A$ (Yager \& Filev 1994).

$$
\tau_{i}=\operatorname{Poss}\left[B_{i} \mid A\right]=\vee_{x}\left[B_{i}(x) \wedge A(x)\right] .
$$

No caso em que o valor de entrada é um número $x^{*}$, ou seja, a função de pertinência de $A$ é:

$$
A(x)=\left\{\begin{array}{lll}
0 & \text { se } & x \neq x^{*} \\
1 & \text { se } & x=x^{*}
\end{array}\right.
$$

então, o grau de ativação dof torna-se

$$
\tau_{i}=\operatorname{Poss}\left[B_{i} \mid A\right]=B_{i}\left(x^{*}\right) .
$$

Em resumo, o algoritmo usado para calcular a saída de um modelo lingüístico através do modelo de Mamdani, considerando uma entrada $U=A$ ou $U=x^{*}$, é o seguinte:

1. Para cada regra do MLs:

a) calcula-se o dof, $\tau_{i}$, da regra:

$\tau_{i}=\vee_{x}\left[B_{i}(x) \wedge A(x)\right]$ se a entrada é um conjunto fuzzy.

$\tau_{i}=B_{i}\left(x^{*}\right)$ se a entrada é um número $x^{*}$.

b) Obter o conjunto fuzzy $F_{i}$ referente a $i$-ésima regra:

$F_{i}(y)=\tau_{i} \wedge D_{i}(y)$

2. Agregar os conjuntos fuzzy $F_{i}$ de saída utilizando a operação união, ou o max: 
$F(y)=\vee_{i=1}^{m} F_{i}(y)$.

A figura 3.2 apresenta de forma gráfica um exemplo de aplicação do método de inferência de Mamdani de um ML tipo SISO, com duas regras, quando a entrada é um conjunto fuzzy .

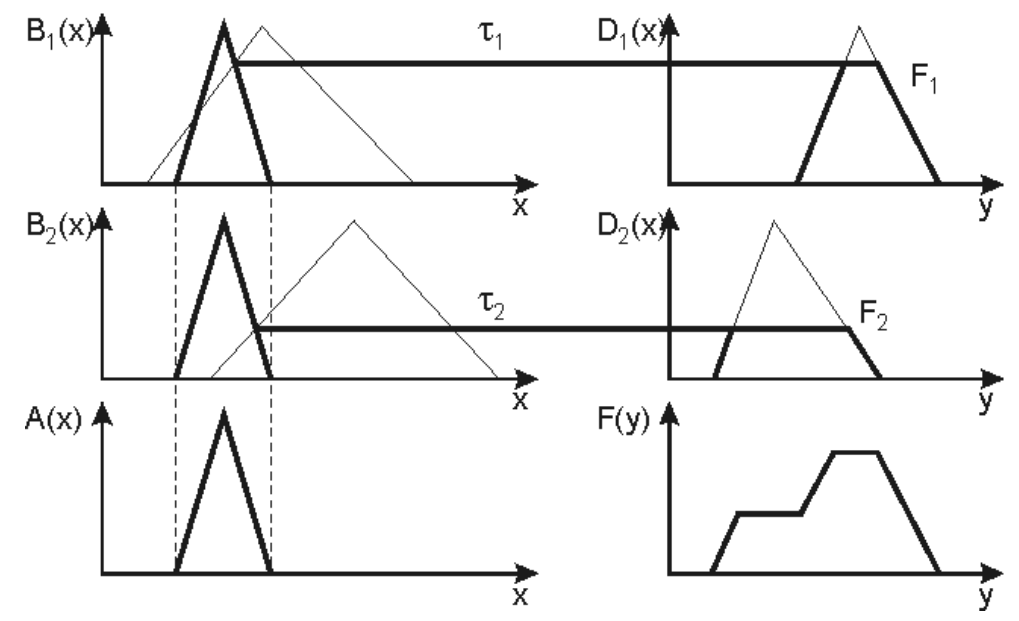

Figura 3.2: Exemplo do Método de inferência de Mamdani.

\subsection{Modelos lingüísticos com múltiplas variáveis}

Estes modelos podem ser de dois tipos: múltiplas variáveis fuzzy de entrada e uma única variável fuzzy de saída (MISO) ou múltiplas variáveis fuzzy de entrada e de saída (MIMO). No primeiro caso as regras têm a forma

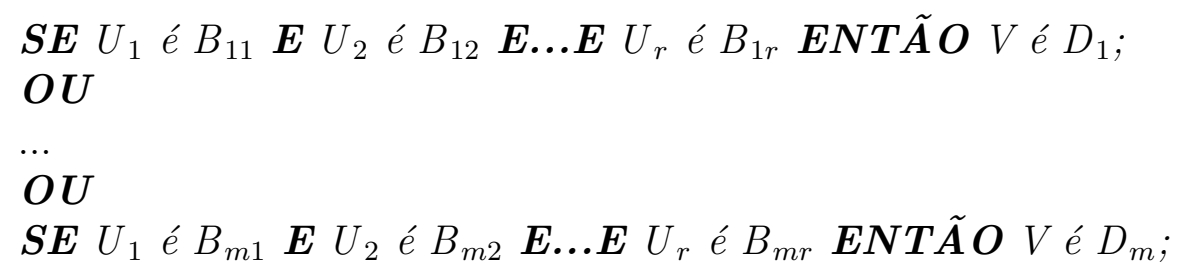

onde $U_{1}, \ldots, U_{r}$ são as variáveis lingüísticas de entrada e $V$ é a variável de saída do ML. $B_{i j}$ e $D_{i}(i=1 \ldots m$ e $j=1 \ldots r)$, são os subconjuntos fuzzy dos universos $X_{1}, X_{2} \ldots, X_{r}$ e $Y$ de $U_{1}, \ldots, U_{r}$ e $V$. Assim como no modelo anterior (SISO), cada regra está associada a uma relação fuzzy $R_{i}$, que é tratada como uma relação fuzzy:

$$
R_{i}=B_{i 1} \times B_{i 2} \times \ldots \times B_{i r} \times D_{i} .
$$

A relação fuzzy $R_{i}$ é definida no espaço gerado pelo produto cartesiano $X_{1} \times X_{2} \times$ $\ldots \times X_{r} \times Y$ e sua função de pertinência é 


$$
R_{i}\left(x_{1}, \ldots, x_{r}, y\right)=B_{i 1}\left(x_{1}\right) \wedge \ldots \wedge B_{i 1}\left(x_{r}\right) \wedge D_{i}(y) .
$$

Assim, a relação fuzzy $R$ associada a este modelo é obtida através do operador união fuzzy $(\max )$ sobre todas as relações individuais, ou seja,

$$
R=\cup R_{i}
$$

ou, equivalentemente em termos de função de pertinência:

$$
R\left(x_{1}, \ldots, x_{r}, y\right)=\vee_{i=1}^{m} R_{i}\left(x_{1}, \ldots, x_{r}, y\right)=\vee_{i=1}^{m} B_{i 1}\left(x_{1}\right) \wedge \ldots \wedge B_{i r}\left(x_{r}\right) \wedge D_{i}(y) .
$$

A saída fuzzy $F$ desse modelo, para um dado conjunto de variáveis de entrada fuzzy $A_{1}, \ldots, A_{r}$ é obtido através da inferência max-mim,

$$
F(y)=\vee_{i=1}^{m} \tau_{i} \wedge D_{i}(y),
$$

onde $\tau_{i}(i=1 \ldots m)$ denota o dof da $i$-ésima regra:

$$
\begin{aligned}
\tau_{i} & =\operatorname{Poss}\left[B_{i 1} \mid A_{1}\right] \wedge \ldots \wedge \operatorname{Poss}\left[B_{i r} \mid A_{r}\right] \\
& =\left(\vee_{x_{1}}\left[B_{i 1}\left(x_{1}\right) \wedge A_{1}\left(x_{1}\right)\right]\right) \wedge \ldots \wedge\left(\vee_{x_{r}}\left[B_{i r}\left(x_{r}\right) \wedge A_{r}\left(x_{r}\right)\right]\right) .
\end{aligned}
$$

No caso especial em que as entradas são números $x_{1}^{*}, \ldots, x_{r}^{*}$, o dof torna-se

$$
\tau_{i}=B_{i 1}\left(x_{1}^{*}\right) \wedge \ldots \wedge B_{i r}\left(x_{r}^{*}\right) .
$$

Nos modelos com múltiplas variáveis fuzzy de entrada e de saída as regras possuem a forma

$\boldsymbol{S E} U_{1}$ é $B_{11} \boldsymbol{E} U_{2}$ é $B_{12} \boldsymbol{E} \ldots \boldsymbol{E} U_{r}$ é $B_{1 r}$

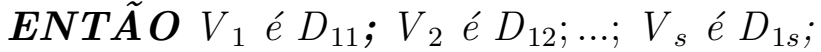

$O U$

...

$O U$

$\boldsymbol{S E} U_{1}$ é $B_{m 1} \boldsymbol{E} U_{2}$ é $B_{m 2} \boldsymbol{E} \ldots \boldsymbol{E} U_{r}$ é $B_{m r}$

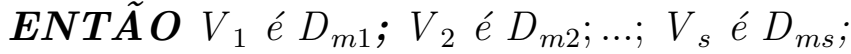

onde as variáveis lingüísticas de entrada $U_{1}, \ldots, U_{r}$ e os termos lingüísticos $B_{i j}(i=$ $1 \ldots m ; j=1 \ldots r)$ são definidos como no modelo MISO, $V_{1}, \ldots, V_{s}$ são as variáveis de saída e $D_{i j}(i=1 \ldots m ; j=1 \ldots s)$ são os subconjuntos fuzzy, definidos no universo de discurso $Y_{1}, Y_{2}, \ldots, Y_{s}$ das variáveis de saída.

Os modelos lingüísticos fuzzy fornecem uma saída para o sistema que é também um conjunto fuzzy. Todavia, muitas vezes estamos interessados em obter um número como resposta, ou seja, desejamos obter um resultado clássico a partir da saída fuzzy obtida. Este objetivo pode ser alcançado através dos métodos de defuzificação. 


\subsection{Métodos de defuzificação}

A defuzificação é um procedimento que nos permite interpretar a distribuição de possibilidades da saída de um modelo lingüístico fuzzy de forma quantitativa, ou seja, ele nos fornece um valor numérico representativo que captura o significado essencial dessa distribuição de possibilidades. Existem muitas técnicas de defuzificação e entre as mais utilizadas estão:

- Média dos Máximos;

- Centro de Área;

- Método das Alturas.

\subsubsection{Média dos Máximos}

O método de defuzificação da Média dos Máximos (MM) calcula a média de todos os valores de saída que tenham os maiores graus de possibilidade. Suponha que " $y$ é $A$ " é uma conclusão fuzzy que deve ser defuzificada. O método de defuzificação MM pode ser expresso da seguinte forma (Klir $\& 6$ Yuan 1995, Yen $\&$ Langari 1999):

$$
y_{0}=\frac{\sum_{y^{*} \in P} y^{*}}{|P|}
$$

onde $P$ é o conjunto de todos os valores de saída com máximos grau de possibilidade em A, ou seja,

$$
P=\left\{y^{*} \mid \mu_{A}\left(y^{*}\right)=\sup _{y} \mu_{A}(y)\right\} .
$$

e $|P|$ é a cardinalidade do conjunto $P$, ou seja, o número de elementos de $P$. A figura 3.3 apresenta um exemplo desse método. Note que, se $P$ é um intervalo, então, a técnica MM de defuzificação fornece o ponto médio desse intervalo.

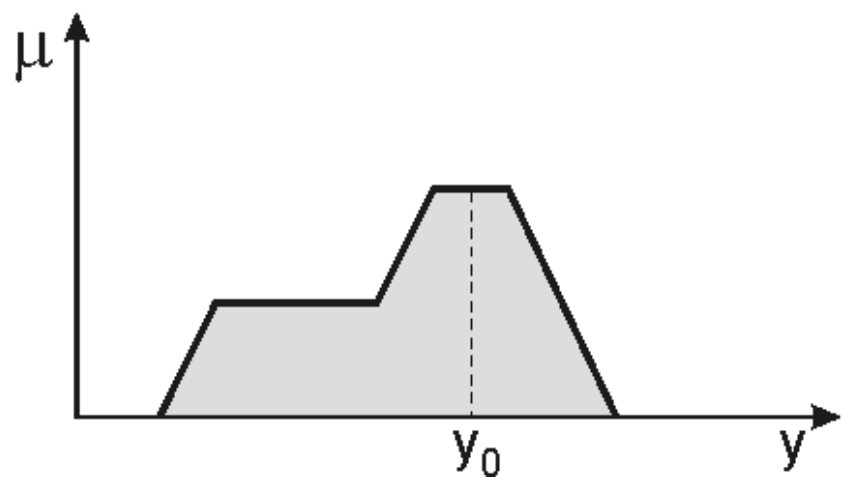

Figura 3.3: Exemplo do método de defuzificação MM. 
A principal limitação do método de defuzificação MM é que ele não considera a forma total do conjunto fuzzy de saída. Sendo assim, duas distribuições de possibilidades que apresentem diferentes formas, porém o mesmo conjunto de valores com grau de pertinência máximo, quando defuzificados com esta técnica fornecerá o mesmo valor clássico, o que é contra-intuitivo. A figura 3.4 mostra um exemplo onde isso ocorre.
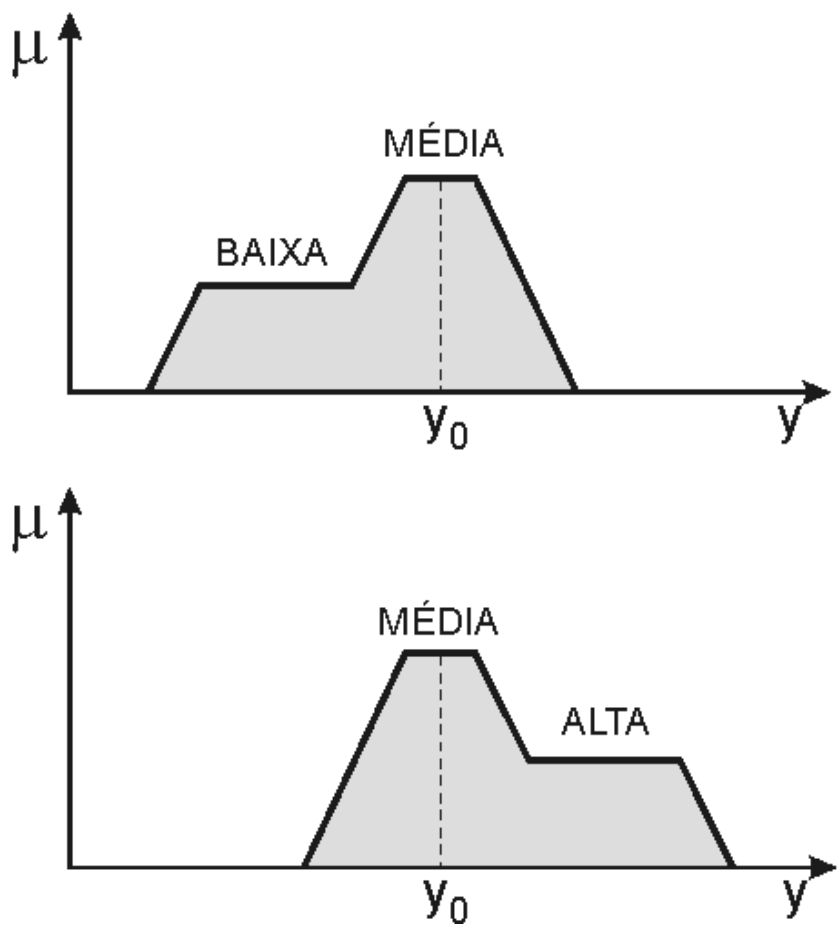

Figura 3.4: Exemplo de problemas que o método de defuzificação MM pode causar.

\subsubsection{Centro de Área}

O método do Centro de Área $(\mathrm{CA})$ é a técnica de defuzificação mais comumente usada. Ele também é citado na literatura como método do Centro de Gravidade ou do Centróide (Klir \& Yuan 1995, Yen \& Langari 1999). Diferentemente do MM, a técnica do Centro de Área para calcular o valor clássico representativo considera toda a distribuição de possibilidade de saída do modelo. O procedimento é similar ao usado para calcular o centro de gravidade em física, se consideramos a função de pertinência $\mu_{A}(x)$ como a densidade de massa de $x$. Por outro lado, o método do Centro de Área pode ser compreendido como uma média ponderada, onde $\mu_{A}(x)$ funciona como o peso do valor $x$. Se $x$ é discreto, então a defuzificação da conclusão fuzzy $A$ é dada por:

$$
y_{0}=\frac{\sum_{x} \mu_{A}(x) \cdot x}{\sum_{x} \mu_{A}(x)} .
$$


Da mesma forma, se x é contínuo, então,

$$
y_{0}=\frac{\int \mu_{A}(x) x d x}{\int \mu_{A}(x) d x} .
$$

A figura 3.5 exemplifica o método de defuzificação do CA. A Principal desvantagem desse método é o seu custo computacional, principalmente no caso em que $x$ é contínuo.

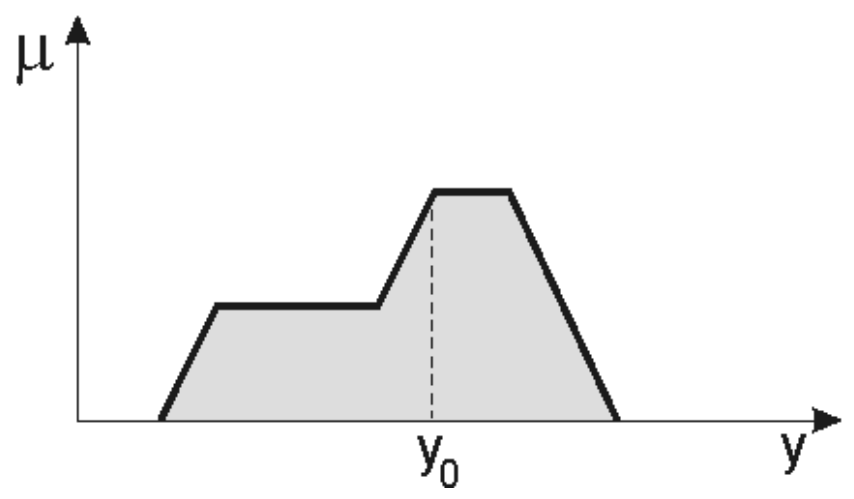

Figura 3.5: Exemplo do método de defuzificação CA.

\subsubsection{Método das Alturas}

O método de defuzificação das Alturas (MA) pode ser visto como uma aproximação do método do Centro de Área. Ele é realizado em dois passos. Primeiro, nós convertemos as funções de pertinência $C_{i}$, os conseqüentes das regras, em conseqüentes clássicos $y=c_{i}$ onde $c_{i}$ é o centro de gravidade de $C_{i}$. A defuzificação do centróide é então aplicada para as regras com os conseqüentes clássicos através da expressão (Klir $\mathscr{G}$ Yuan 1995, Yen \& Langari 1999):

$$
y_{0}=\frac{\sum_{i=1}^{m} w_{i} c_{i}}{\sum_{i=1}^{m} w_{i}}
$$

onde $w_{i}$ é o dof (que denota o grau de ativação da regra) da $i$-ésima regra e $m$ é o número de regras fuzzy do modelo. Uma vez definidas as regras os valores $c_{i}$ estarão determinados e se manterão fixos durante toda a inferência, o que simplifica muito o cálculo do valor clássico representativo, reduzindo o custo computacional. A figura 3.6 ilustra um exemplo desse método de defuzificação.

\subsection{Modelos lingüísticos dinâmicos fuzzy}

Um sistema dinâmico determinístico e discreto pode, em geral, ser representado por um conjunto de equações de estado: 


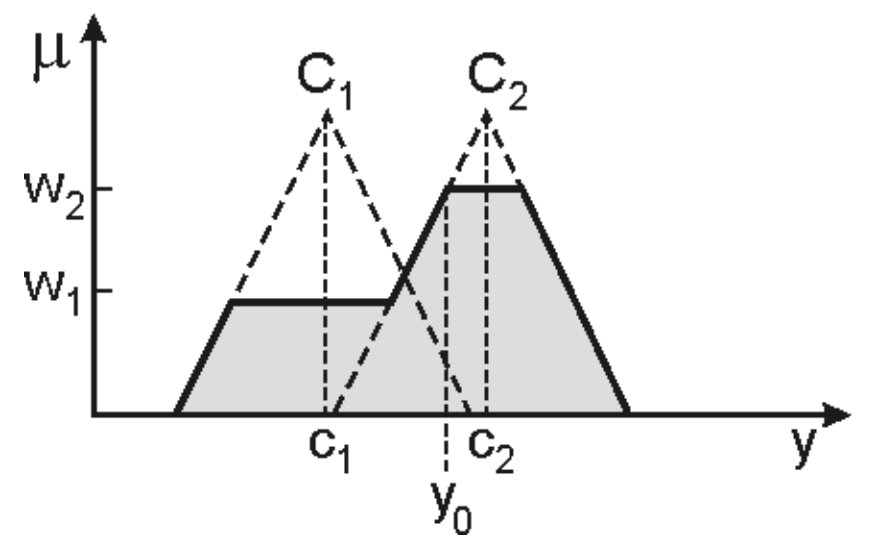

Figura 3.6: Exemplo do método de defuzificação MA.

$$
w(k+1)=f(w(k), u(k))
$$

e

$$
y(k)=g(w(k), u(k)),
$$

onde $u(k)$ e $y(k)$ são as variáveis de entrada e saída do sistema, e $w(k)=\left[w_{1}(k), w_{2}(k), \ldots, w_{n}(k)\right]^{T}$ é o vetor de variáveis de estado no instante $k$. Assim, o valor do estado $w(k+1)$ e a saída $y(k)$ são completamente determinados pelos valores de $w(k)$ e $u(k)$, se conhecermos as funções $f$ e $g$. Em geral, as variáveis de estado possuem um certo significado físico, como por exemplo, velocidade, força, temperatura, concentração, etc. Os mapeamentos $f$ e $g$ descrevem analiticamente as relações entre as variáveis de estado, de entrada e de saída, baseado em algum conhecimento específico: química, física, economia, medicina e outras áreas. No entanto, muitas são as vezes que não temos disponível o conhecimento e/ou a precisão adequados para descrevermos bem os fenômenos. Além disso, algumas variáveis de estado não são mensuráveis 11 ou são difíceis de estimar, como no caso de alguns modelos epidemiológicos. Nestes casos, uma alternativa possível é apresentar as variáveis de estado usando termos lingüísticos, expressados por conjuntos fuzzy, para denotar seus valores prototípicos. O passo seguinte é transformar os mapeamentos $f$ e $g$ em regras lógicas que operam com estes termos lingüísticos, construíndo, desse modo, um sistema fuzzy discreto, onde a não linearidade do sistema dinâmico é descrito pelo uso de valores fuzzy para as variáveis de estado, $w(k+1)$, e de saída, $y(k)$. Então, podemos utilizar a estrutura dos Modelos Lingüísticos para formular uma alternativa lingüística para as equações 3.25 e (3.26) e definir uma interpretação fuzzy para os mapeamentos $f$ e $g$. Portanto, o objetivo é propor um modelo lingüístico, com um raciocínio especifico, como uma alternativa aos modelos de sistemas dinâmicos não-lineares clássicos.

\footnotetext{
${ }^{1}$ A palavra mensurável neste texto significa que é possível de se obter uma medida através de aparelhos.
} 
A idéia principal neste tipo de modelo consiste em supôr que a dinâmica do sistema possa ser descrita por um conjunto de regras atualizadas iterativamente ( Yager $\mathscr{G}$ Filev 1994). Em cada regra as variáveis de entrada dos antecedentes e de saída dos conseqüentes são conjuntos fuzzy e/ou funções. A partir do conhecimento empírico e da experiência do especialista elabora-se a classificação das variáveis em um conjunto de termos lingüísticos convenientes, bem como a construção dos antecedentes e conseqüentes das regras. Sendo assim, o modelo é constituído por este conjunto de regras e por um sistema de inferência adequado. Um exemplo de um conjunto de regras fuzzy é ilustrado a seguir:

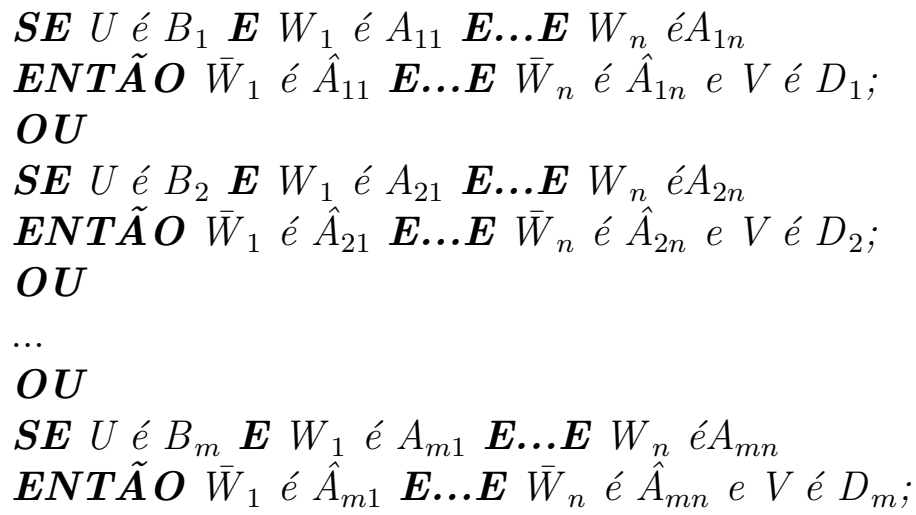

onde $U$ é a variável lingüística de entrada e $W_{i}$ são as variáveis lingüísticas de estado do sistema; $V$ e $\bar{W}_{i}$ são, respectivamente, a saída e as variáveis de estado atualizadas; $B_{i}$ e $A_{i j}$ são os conjuntos fuzzy das variáveis de entrada e $D_{i}$ e $\hat{A}_{i j}$ são os conjuntos fuzzy das variáveis de saída. Assim, escolhendo-se um método de inferência e um método de defuzificação (quando necessário), ao percorrer todas as regras obtêm-se o valor atualizado para as variáveis dos conseqüentes que passarão, no passo seguinte, a ser as variáveis de entrada do sistema, compondo a evolução do sistema de forma iterativa. Segue que,

$$
U(l+1)=V(l)
$$

e

$$
W_{i}(l+1)=\bar{W}_{i}(l)
$$

onde $l+1$ é o passo posterior ao passo $l$, e $U(l+1)$ e $W_{i}(l+1)$ podem ser conjuntos fuzzy ou números a depender da utilização ou não de métodos de defuzificação.

O modelo lingüístico para descrever sistemas dinâmicos apresentado é constituído por um conjunto de regras, com cada uma delas descrevendo diferentes estratégias para lidar com diferentes situações. Cada situação estratégica (por exemplo, a premissa de uma única regra) é caracterizada pela combinação de variáveis lingüísticas $B_{i}$, 
3 Modelos lingüísticos fuzzy

$A_{i 1}, \ldots, A_{i n}$. Os conseqüentes das regras descrevem o desenvolvimento das variáveis de estado independentes para uma determinada situação particular.

$\mathrm{Na}$ formulação do modelo descrito é assumido que as regras individuais (e as respectivas relações fuzzy) não possuem dependência temporal, ou seja, elas são construídas pela invariância temporal dos conjuntos fuzzy de referência. Todavia, estes conjuntos fuzzy podem se transfomar com o passar do tempo, o que caracteriza uma situação não-estacionária e, portanto, uma abordagem mais complexa.

\subsection{Modelos fuzzy tipo Takagi-Sugeno-Kang (TSK)}

Uma disvantagem dos modelos lingüísticos é que eles não contém de uma forma explícita os conhecimentos objetivos a cerca do sistema. Em muitas áreas de atuação, como por exemplo a engenharia, freqüentemente estão disponíveis informações funcionais sobre a estrutura dos sistemas, como por exemplo conservação de energia ou a equação de balanceamento de massa, no caso de sistemas físicos. Procurando contornar este problema Sugeno e colaboradores propuseram um modelo alternativo denominado Modelo de Takagi-Sugeno-Kang (TSK). O método de raciocínio do TSK está associado a um conjunto de regras, que tem a característica especial de possuirem funcionais nos conseqüentes, ao invés dos conjuntos fuzzy usados nos Modelos lingüísticos discutidos anteriormente. Então, um possível conjunto de regras nesse modelo é:

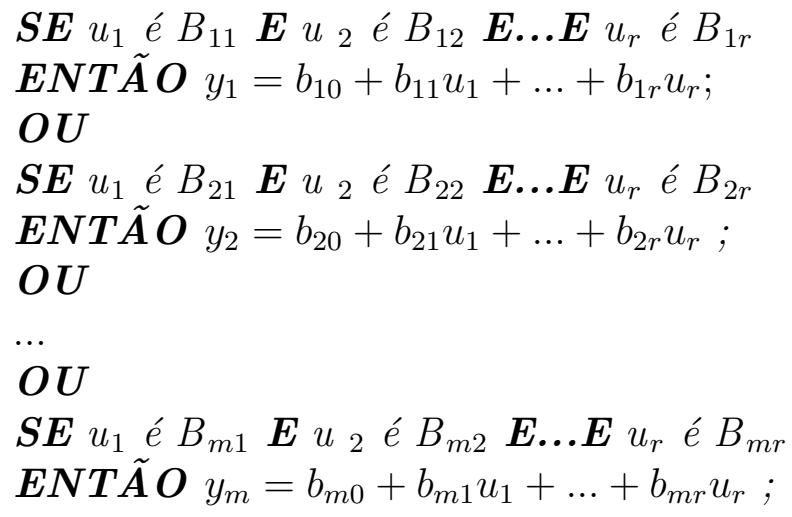

onde $B_{i j}(i=1, \ldots, m ; j=1, \ldots, r)$ são termos lingüísticos, definidos como conjuntos fuzzy de referência, sobre os espaços de entrada $X_{1}, X_{2}, \ldots, X_{r}$ de um sistema MISO; $u_{1}, \ldots, u_{r}$ são as variáveis de entrada. Cada uma das funções lineares nos conseqüentes das regras pode ser entendida como um modelo linear com entradas clássicas $u_{1}, \ldots, u_{r}$, e os parâmetros $b_{i j}(i=1, \ldots, m ; j=0, \ldots, r)$ são valores reais.

A inferência realizada pelo modelo TSK é uma interpolação de modelos. O grau de relevância de um modelo linear é determinado pelo grau de pertinência do valor de entrada ao subespaço fuzzy associado ao modelo linear. No caso de vários valores 
de entrada o grau de relevância é determinado pelo dof da regra. Estes graus de relevância funcionam como um peso no processo de interpolação.

A saída total do modelo, $y$, é definida pela média ponderada das saídas $y_{i}$ de cada subsistema linear individual, $R_{i}$, de forma semelhante a realizada no modelo de Mamdani:

$$
y=\frac{\sum_{i=1}^{m} \tau_{i} y_{i}}{\sum_{j=1}^{m} \tau_{j}}=\frac{\sum_{i=1}^{m} \tau_{i}\left(b_{i 0}+b_{i 1} u_{1}+\ldots+b_{i r} u_{r}\right)}{\sum_{j=1}^{m} \tau_{j}}
$$

onde $\tau_{i}$ é o dof da $i$-ésima regra, dado por

$$
\tau_{i}=B_{i 1}\left(u_{1}\right) \wedge \ldots \wedge B_{i r}\left(u_{r}\right) .
$$

Geometricamente, as regras do método de raciocínio TSK (3.29) corresponde aproximadamente a um mapeamento $X_{1} \times X_{2} \times \ldots \times X_{r} \rightarrow Y$ por uma função linear por partes. De uma forma geral, podemos trocar as funções lineares nos conseqüentes das regras por funções não-lineares. Desse modo, o modelo TSK torna-se uma coleção de regras cuja estrutura é

SE $u_{1}$ é $B_{i 1} \boldsymbol{E} u_{2}$ é $B_{i 2} \boldsymbol{E} \ldots \boldsymbol{E} u_{r}$ é $B_{i r}$

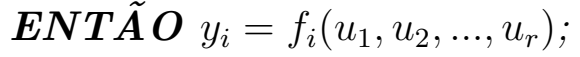

onde as saídas dos subsistemas não-lineares são combinações análogas ao caso linear, através da expressão (3.29).

A arquitetura dos modelos TSK é definida por um conjunto de regras que determinam uma partição do espaço de variáveis de entrada e que depende da estrutura dos subsistemas individuais. A grande vantagem desse modelo consiste no seu poder de representação, especialmente para descrever processos tecnológicos. Ele permite a decomposição de um sistema complexo em um conjunto de subsistemas mais simples. Em situações realísticas, a decomposição dos sistemas em subsistemas clássicos é praticamente impossível, devido a ausência natural de fronteiras bem delimitadas para os sistemas e do conhecimento disponível ser fragmentado. Todavia, o modelo TSK nos permite realizar decomposições fuzzy dos sistemas, o que permite a realização de modelos mais realísticos para a descrição dos fenômenos. É possível elaborar modelos dinâmicos do tipo TSK da mesma forma que nos modelos tipo Mamdani (lingüísticos) através da iteração das regras, ou seja, a saída das regras do passo anterior alimenta a entrada do conjunto de regras no passo seguinte.

No capítulo 7 são apresentados dois trabalhos onde utilizamos modelos lingüísticos tipo Mamdani. Já no capítulo 8 é apresentado um sistema fuzzy dinâmico para modelar a estrutura etária de cães soropositivos a raiva canina onde utilizamos a estrutura dos MLs (Mamdani) e do TSK. No capítulo 9 é apresentado um trabalho onde o modelo lingüístico foi gerado a partir do princípio de extensão. 


\section{Parte II}

\section{Os trabalhos desenvolvidos}




\section{Capítulo 4}

\section{Uma proposta de estimador de risco fuzzy em epidemiologia}

O conceito de risco assume um papel fundamental na epidemiologia moderna (Rothman 1986). A pesquisa causal em epidemiologia requer que duas distinções fundamentais sejam feitas. A primeira é entre os que realmente são submetidos, e aqueles que não o são, aos fatores de risco que estão sendo estudados, enquanto que a segunda distinção é entre aqueles que realmente têm e não têm a doença a ser estudada. Essas distinções são, em geral, complexas e estão sujeitas a erros, vieses e subjetividades.

A pesquisa epidemiológica também pode se mostrar complicada devido à necessidade de analisar muitas variáveis independentes ao mesmo tempo, incluindo como elas interagem, além da necessidade de medir diferentes graus de força da exposição ao fator de risco, duração da exposição ao fator de risco, ou ambos. Ocorre, por e- xemplo, que a freqüência da hipertensão está relacionada com a idade e o sexo e que essas variáveis interagem entre si: antes da idade 50 anos os homens são mais propensos a hipertensão, todavia, depois dos 50 anos as mulheres são mais propensas (Jekel et al 1996). Além disso, a depender do fator de risco pode ser difícil determinar a época do início a exposiçexposição ao fator de risco. Isto é verdade, por exemplo, para fatores de risco como sedentarismo e excesso de ingestão de gorduras na dieta. Existem ainda outras dificuldades para determinar a exposição a uma determinada causa a depender da medida utilizada para estimar a exposição. Por exemplo, o grau de exposição a fumaça de cigarro de um indivíduo pode ser estimado a partir do consumo de cigarros pelo indivíduo fumante, aqueles que consomem um número maior de cigarros/dia estarão mais expostos do que aqueles que consomem menos. No entanto, o não tabagista é considerado não exposto segundo esta medida, o que na realidade não é verdade. O não fumante não é necessariamente não exposto a fumaça do cigarro, o seu grau de exposição dependerá de um certo contexto. Uma outra complicação surge quando se faz necessário medir níveis diferentes de gravidade da doença estudada (Jekel et al $1996)$.

Considerando essas dificuldades, vemos que o tratamento dicotômico Booleano das 
variáveis epidemiológicas (exposto/não-exposto e doente/não-doente) na análise de risco pode muitas vezes não retratar a realidade existente. Neste trabalho é proposta uma nova abordagem para os estudos de causa e efeito através da aplicação dos conceitos de conjuntos fuzzy e da resposta potencial individual. Os indivíduos são considerados expostos a algum fator de risco de acordo comuma certa função de pertinência e sua resposta (doente/não-doente) é também categorizada de acordo com outra funçãode pertinência. A análise de risco pode então ser realizada através da aplicação da teoria de conjuntos fuzzy, permitindo o cálculo da Razão de Risco Fuzzy (FRR) e da Razão de Chances Fuzzy (FOR).

\subsection{Estimadores de risco fuzzy}

A definição do conceito de risco é dada no nível individual, enquanto o estimador do risco é definido no nível populacional. Na epidemiologia clássica, um tipo de estimador de risco é a Razão de Risco (ou risco relativo), $\mathrm{RR}$, que consiste na razão entre o risco em uma grupo exposto e o risco em um grupo não-exposto. Se os riscos no grupo exposto e não-exposto são os mesmos, então o RR será igual a 1. Se os riscos nos dois grupos não são os mesmos, então o cálculo do RR fornecerá uma maneira direta de mostrar, em termos relativos, quão diferentes (maiores ou menores) os riscos são para o grupo exposto, estabelecendo assim, uma associação entre os aspectos estudados.

Vale lembrar que existem vários tipos de exposição. Ela pode estar relacionada a um fator nutricional (uma dieta rica em gorduras), um fator ambiental (radiação, por exemplo), uma característica fisiológica (um alto nível de colesterol no sangue), um fator comportamental (tabagismo, alcoolismo), uma intervenção médica (antibiótico) ou uma intervenção de saúde pública (vacina). Sendo assim, a exposição pode ser um fator prejudicial, como no caso do tabagismo, e então o risco para a doença em um grupo exposto será maior $(R R>1)$, ou a exposição pode ser um fator de proteção, como no caso da vacina, e o risco para a doença no grupo exposto será menor $(R R<1)$.

Classicamente, a razão de risco é definida como a razão entre a probabilidade condicional de que alguém desenvolva a doença dado que tenha sido exposto aos fatores de risco, $p(D \mid E)$, e a probabilidade condicional de que alguém desenvolva a doença dado que não tenha sido exposto aos fatores de risco, $p(D \mid \bar{E})$, ou seja,

$$
R R=\frac{p(D \mid E)}{p(D \mid \bar{E})}
$$

Todavia, se do ponto de vista clássico a razão de risco é definida em termos de probabilidades condicionais, nossa proposta é que a razão de risco fuzzy seja definida em termos da possibilidade relativa, onde a classificação dos indivíduos quanto a exposição e a sua resposta (doença) seja fuzzy.

A distribuição de possibilidade $\pi(x)$ associada a um conjunto $A$ de um universo $X$, como vimos no capítulo 2 , é numericamente igual à sua função de pertinência $\mu_{A}(x)$, 
da forma:

$$
\pi(x)=\mu_{A}(x) \text { para todo } x \in X,
$$

considerando que

$$
\operatorname{hgt}\left(\mu_{A}(x)\right)=1 \Longrightarrow \sup _{x \in X}\left(\mu_{A}(x)\right)=1
$$

cuja medida, $r(A)$, é dada por:

$$
r(A)=\sup _{x \in A} \pi(x) .
$$

Temos que o estimador Razão de Risco Fuzzy pode ser definido em termos da possibilidade relativa, sendo esperado que ele seja proporcional a razão entre a possibilidade relativa de desenvolver uma doença dado que se tenha sido exposto a um certo fator de risco, $\operatorname{poss}(D \mid E)$, e a possibilidade relativa de se desenvolver a doença dado que não se tenha sido exposto aos fatores de risco, $\operatorname{poss}(D \mid \bar{E})$. Assim, a definição do FRR é baseada na equação (4.1):

$$
F R R=\frac{\operatorname{poss}(D \mid E)}{\operatorname{poss}(D \mid \bar{E})} .
$$

O estimador de risco RR, e conseqüentemente o FRR, avalia a relação causal considerando apenas o grupo de doentes. Todavia, uma situação mais geral é proposta por Greenland (Greenland 1987), que considerou a possibilidade teórica de quatro tipos de indivíduos. Nesta proposta, temos os indivíduos que são fadados a desenvolverem uma certa doença, independentemente de serem expostos ou não aos fatores de risco, existem também os indivíduos resistentes que nunca desenvolverão a doença, indepententemente de serem ou não expostos, há aqueles que são protegidos, ou seja, eles desenvolvem a doença se não são expostos as causas suspeitas, e, finalmente, existem os indivíduos sob risco, que são aqueles que somente desenvolverão a doença se forem submetidos aos fatores suspeitos. Esta classificação assume um alto nível de heterogeneidade na população e envolve várias incertezas na definição de cada classe, tornando-se por estas razões uma proposta mais interessante. A tabela abaixo mostra os quatro tipos de indivíduos e suas respectivas categorias. 
Tabela 1.1: Heterogeneidade nas classes de risco.

$$
\begin{aligned}
& \bar{E} \\
& D|\bar{E} \quad \bar{D}| \bar{E} \\
& E \quad D \mid E \text { fadado sob risco } \\
& \bar{D} \mid E \text { protegido resistente }
\end{aligned}
$$

O estimador de risco que considera as heterogeneidades descritas é a Razão de Chances (OR), que é definido em termos das probabilidades condicionais:

$$
O R=\frac{p(D \mid E) \cdot p(\bar{D} \mid \bar{E})}{p(D \mid \bar{E}) \cdot p(\bar{D} \mid E)} .
$$

Uma abordagem fuzzy para o OR deve considerar graus de pertinência para os indivíduos em cada um dos subconjuntos fuzzy (expostos e doentes). O próximo pas so é considerar a possibilidade relativa, no lugar da probabilidade condicional, para cada um dos subconjuntos fuzzy. Sendo assim, o estimador de risco Razão de Chances Fuzzy (FOR) pode ser definido da seguinte forma:

$$
F O R=\frac{\operatorname{poss}(\bar{D} \mid \bar{E}) \Lambda \operatorname{poss}(D \mid E)}{\operatorname{poss}(D \mid \bar{E}) \Lambda \operatorname{poss}(\bar{D} \mid E)}
$$

onde o símbolo $\Lambda$ indica um operador de conjunção $(\mathbf{E})$.

O raciocínio envolvido na expressão 4.7) é o seguinte: os indivíduos que não desenvolvem a doença se não expostos $\mathbf{E}$ que desenvolvem a doença se expostos, são classificados como indivíduos sob risco. Aqueles que desenvolvem a doença se não expostos E não desenvolvem a doença se expostos são classificados como protegidos. Os indivíduos fadados e resistentes não contribuem com informação alguma sobre a relação causal. Assim, a razão entre os indivíduos sob risco e protegidos deve fornecer um bom estimador de risco.

Considerando as incertezas relatadas quanto aos critérios de classificação e a heterogeneidade da população, a abordagem fuzzy proposta definirá uma associação entre causa e efeito a dependerse o valor da razão expressa pela equação (4.7) for maior (no caso uma associação positiva) ou menor (uma associação negativa) que 1.

\subsection{Simulação do modelo}

No sentido de verificar se a proposta do estimador de risco FOR é razoável simulamos o cenário teórico descrito acima. Os graus de pertinência dos indivíduos no subconjunto fuzzy exposto, $\mu_{E}(x)$, foram gerados como uma distribuição uniforme. A função de pertinência para o subconjunto fuzzy doença, $\mu_{D}(x)$, foi associado a exposição segundo o modelo logístico: 


$$
\mu_{D}(x)=\frac{\exp \left(\beta \mu_{E}(x)\right)}{1+\exp \left(\beta \mu_{E}(x)\right)}
$$

onde $\beta$ é um parâmetro cujo sinal e magnitude indica a direção e a intensidade da associação causal. As possibilidadesrelativas foram definidas de acordo com a regra:

$$
\operatorname{poss}(a \mid b)=\max _{x \in X}\left[\min \left(\mu_{a}(x), \mu_{b}(x)\right)\right]
$$

onde $x$ diz respeito aos indivíduos classificados e o operador min é aplicado no nível individual, enquanto o operador max é aplicado no nível populacional.

Sendo assim, foram criados 1000 indivíduos cujos graus de pertinência ao conjunto fuzzy exposto foi gerado aleatoriamente, o grau no conjunto não exposto foi obtido com o operador complemento, $\mu_{\bar{E}}(x)=1-\mu_{E}(x)$, o grau de pertinência no conjunto fuzzy doente foi obtido pela equação 4.8 e o grau de pertinência no conjunto fuzzy não doente foi obtido pelo complemento do conjunto doente, $\mu_{\bar{D}}(x)=1-\mu_{D}(x)$. Cada possibilidade condicional foi calculada através da equação (4.9) e o FOR foi obtido pela equação (4.7) para cada valor fixo do parâmetro $\beta$. Os resultados dessa simulação são apresentados na figura 4.1.

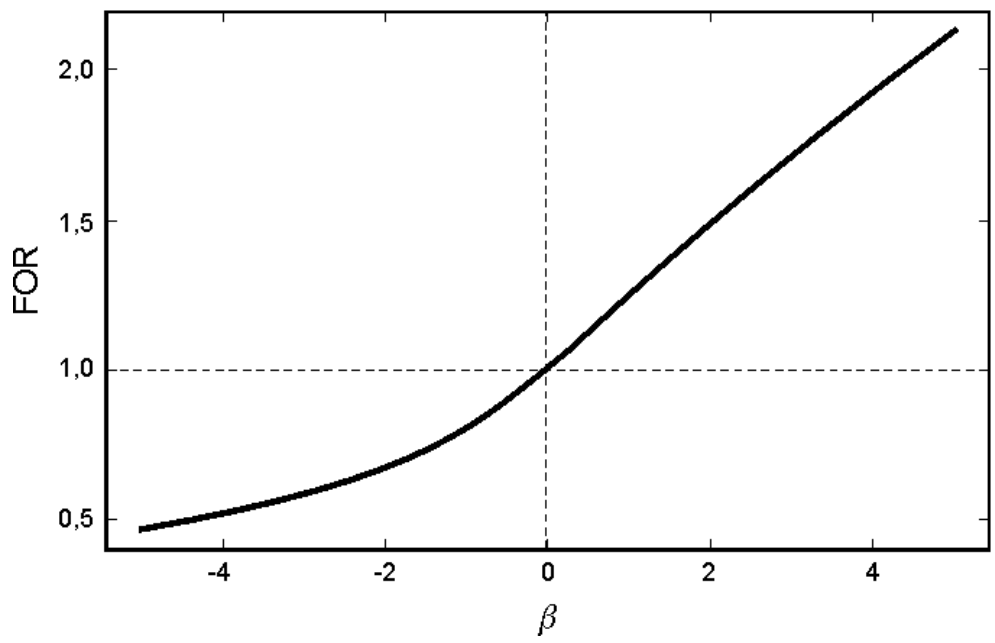

Figura 4.1: Estimador de risco fuzzy FOR em função de $\beta$.

Podemos ver da figura que quando $\beta$ é menor que zero a razão de risco fuzzy, FOR, é menor que um, indicando o efeito de proteção da exposição. Por outro lado, quando $\beta$ é maior que zero, o FOR é maior que um, indicando o efeito de risco à exposição. Temos ainda que, quando $\beta$ é igual a zero o FOR é igual a um, indicando a ausência de associação entre exposição e doença. Podemos notar também que o FOR apresenta uma relação não linear com o parâmentro $\beta$. 


\subsection{Discussão}

Os resultados da simulação mostraram que o estimador de risco proposto é bastante plausível, uma vez que eles confirmaram as situações esperadas quanto a análise causal dos valores do FOR. Podemos ainda conjecturar que o grau de não linearidade da função apresentada na figura 1 está, em um certo nível, relacionada com as incertezas no processo de classificação dos indivíduos nos conjuntos fuzzy do modelo. No entanto, o estudo aqui analisado não nos capacita a verificar tal conjectura, outros trabalhos precisam ser desenvolvidos com este objetivo. Todavia, tendo este sido o primeiro trabalho realizado nesse projeto, nos sinaliza que a teoria de lógicafuzzy pode ser útil também no desenvolvimento e generalização de conceitos epidemiológicos, sendo esta a contribuição mais expressiva desse trabalho. 


\section{Capítulo 5}

\section{Probabilidades de eventos epidemiológicos fuzzy}

Neste trabalho a probabilidade de eventos fuzzy, apresentada na seção 2.8, foi aplicada a casos epidemiológicos. Esta teoria torna-se interessante no tratamento de questões de cunho epidemiológico do tipo "Qual é a probabilidade de que em uma amostra da população seja obtido muito mais indivíduos apresentando uma determinada característica do que indivíduos apresentando uma outra?" ou "Qual é a probabilidade de que um indivíduo que tenha sido muito exposto a uma determinada causa desenvolva uma dada doença muito rapidamente?". Questões deste tipo podem ser respondidas utilizando a teoria de probabilidade de eventos fuzzy e probabilidade condicional de eventos fuzzy. A nossa intenção com este trabalho é o de demonstrar como estas questões poderiam ser respondidas e qual poderia ser o interesse dessa abordagem em epidemiologia. Para isso tratamos duas questões de caráter epidemiológico cujo evento é fuzzy.

\subsection{A primeira questão epidemiológica}

Para exemplificar como podemos trabalhar com a probabilidade de eventos fuzzy vamos imaginar que $X$ é uma variável aleatória que mede a contagem total de HIV (o agente causador da AIDS) entre indivíduos soropositivos em uma amostra de 100 indivíduos escolhidos em uma população usuária de drogas injetáveis com soroprevalência de $50 \%$ (ou seja, metade desta população tem o vírus da AIDS ou apresenta anticorpos específicos). A probabilidade do evento fuzzy que estamos interessados pode ser expressa pela questão "Qual a probabilidade de que nesta amostra de 100 pessoas tenhamos muito mais indivíduosHIV soropositivos do que soronegativos?". Este evento fuzzy pode ser caracterizado pela seguinte função de pertinência:

$$
\mu_{A}(x)= \begin{cases}0 & \text { se } 0 \leq x \leq 50 \\ (x-50) / 30 & \text { se } 50 \leq x \leq 80 \\ 1 & \text { se } x \geq 80\end{cases}
$$


que está representada na figura 5.1. O evento fuzzy $A$ para muito mais HIV soropositivos do que soronegativos é caracterizado pela função de pertinência $\mu_{A}\left(x_{i}\right)$ em função da porcentagem de soropositivos ao HIV, ou seja, até $50 \%$ não é configurado o evento (não posso dizer que existem mais soropostivos na amostra), acima de $80 \%$ o evento com certeza se configura (existem muito mais soropositivos na amostra, com pertinência 1), e entre $50 \%$ e $80 \%$ temos uma transição suave entre esses dois extremos.

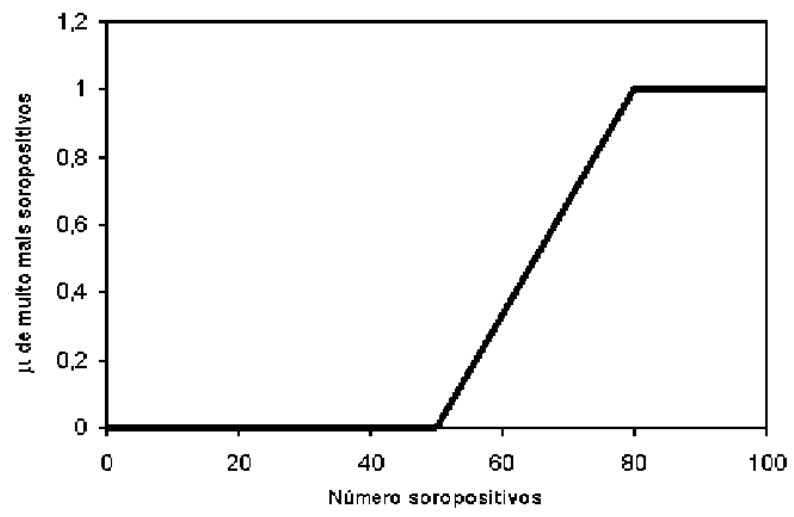

Figura 5.1: Função de pertinência $\mu_{A}(x)$ como porcentagem de soropositivos ao HIV.

Em uma população com 50\% de soroprevalência ao HIV, a função distribuição de probabilidade é descrita pela distribuição binomial onde $p=q=0,5$, que para uma amostra de 100 indivíduos oferece:

$$
P_{X}\left(x_{i}\right)=\frac{100 !}{i !(100-i) !} 0,5^{i} 0,5^{100-i} .
$$

Portanto, a probabilidade de se obter o evento fuzzy "muito mais pessoas soropositivas do que soronegativas nessa amostra de 100 indivíduos" é dada pela equação:

$$
P(A)=\sum_{i} \mu_{A}\left(x_{i}\right) P_{X}\left(x_{i}\right)
$$

o que nos fornece o valor 0,067 ou 6,7\%. Ou seja, a probabilidade de em uma amostra de 100 indivíduos, pertencentes a população de usuários de drogas injetáveis cuja soroprevalência ao HIV é de $50 \%$, seja obtido muito mais HIV soropositivos do que soronegativos é de $6,7 \%$, o que segundo os especialistas é uma estimativa razoável.

\subsection{A segunda questão epidemiológica}

Consideremos, agora, a seguinte questão de cunho epidemiológico: "Qual é a probabilidade de que um indivíduo muito ativo sexualmente (ou seja, com muitos parceiros) 
possa desenvolver AIDS muito rapidamente?" devemos calcular qual a probabilidade condicional fuzzy de que um indivíduo possa desenvolver a AIDS com certa rapidez dado que ele está sujeito a um certo risco devido ao seu nível de atividade sexual. Considere que o tempo em anos necessário para o completo desenvolvimento da AIDS seja uma variável cujo evento fuzzy "desenvolver AIDS muito rapidamente" seja descrito pela seguinte função de pertinência:

$$
\mu_{B}(x)= \begin{cases}1 & \text { se } x \leq 5 \text { anos } \\ (10-x) / 5 & \text { se } 5 \leq x \leq 10 \text { anos } \\ 0 & \text { se } x \geq 10 \text { anos }\end{cases}
$$

ou seja, o evento fuzzy $B$ para desenvolver AIDS muito rapidamente é caracterizado pela função de pertinência $\mu_{B}(x)$ em função do tempo em anos necessários para atingir a doença AIDS, ou seja, até 5 anos o evento é configurado (a progressão para doença é considerada muito rápida com pertinência 1), acima de 10 anos o evento não se configura (não é mais possível considerar esta progressão como sendo muito rápida), e entre 5 e 10 anos temos uma transição suave entre os extremos. Esta função de pertinência é apresentada na figura 5.2.

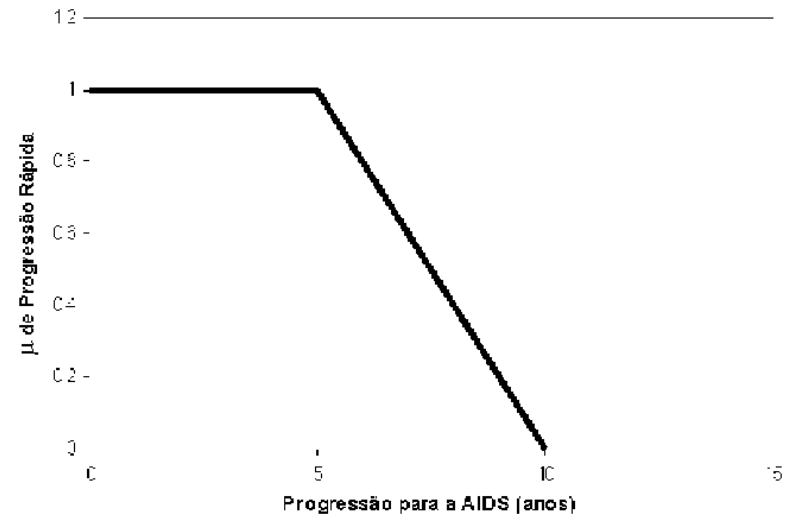

Figura 5.2: Função de pertinência $\mu_{B}(x)$ em função do tempo em anos necessário para atingir a doença AIDS.

Por outro lado, o período de incubação para a AIDS, descrito pelo perfil de prevalência apresentado na figura 5.3, pode ser considerado como a distribuição de probabilidades para a progressão da AIDS, $P_{B}$.

Considere também que a atividade sexual, expressa pela taxa anual de novos parceiros, é uma variável cujo evento fuzzy "muito ativo sexualmente" seja descrito pela seguinte função de pertinência:

$$
\mu_{C}(x)= \begin{cases}0 & \text { se } x \leq 3 \operatorname{anos}^{-1} \\ (x-3) / 8 & \text { se } 3 \leq x \leq 11 \operatorname{anos}^{-1} \\ 1 & \text { se } x \geq 11 \operatorname{anos}^{-1}\end{cases}
$$




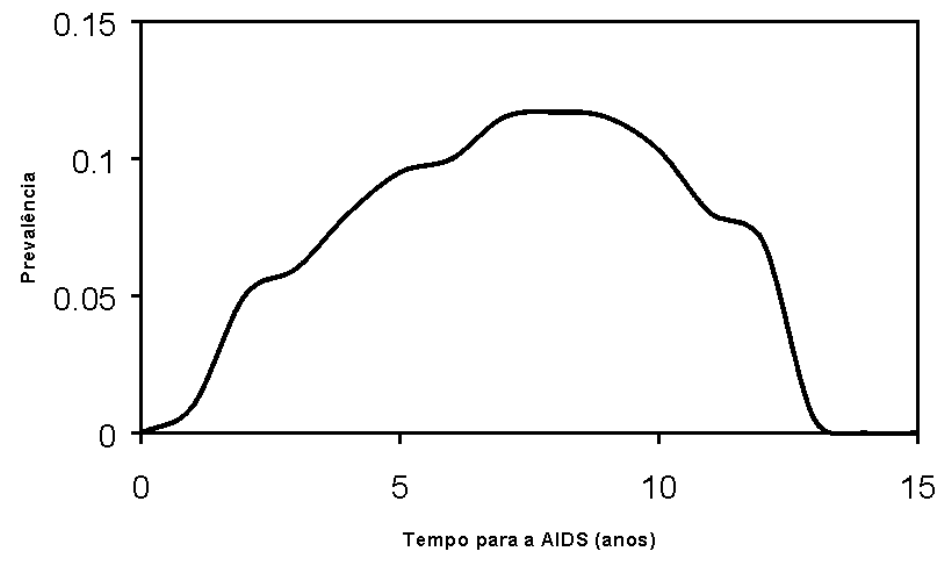

Figura 5.3: Período de incubação para a AIDS.

que é representada na figura 5.4. Segundo esta função de pertinência, os indivíduos com menos de 3 parceiros ao ano não pertencem ao grupo de risco, ou seja, não possuem muitos parceiros sexuais por ano, já os indivíduos com 11 parceiros ou mais pertencem com certeza ao grupo de risco (eles possuem muitos parceiros ao ano), e os indivíduos que possuem entre 3 e 11 parceiros sexuais por ano pertencem parcialmente a esse grupo.

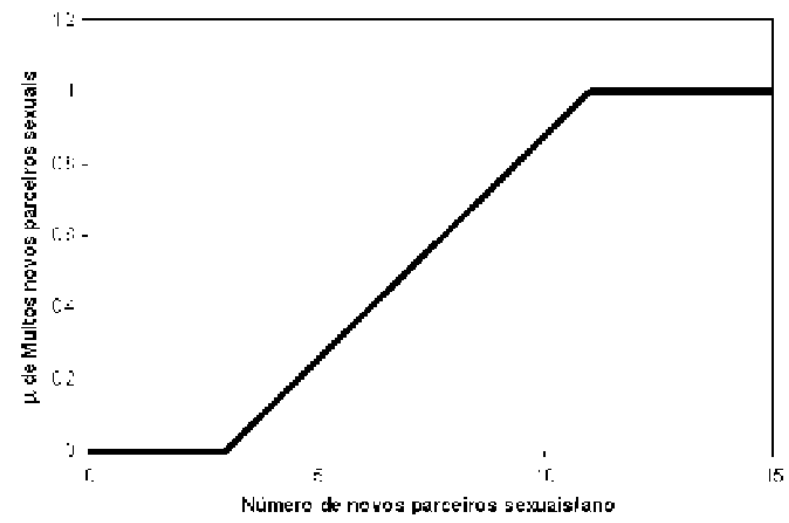

Figura 5.4: Função de pertinência $\mu_{C}(x)$ do número de novos parceiros sexuais/ano.

Temos também, que a distribuição de novos parceiros sexuais por ano, $P_{C}$, é apresentada na figura 5.5.

Considerando as condições acima, podemos responder a questão "Qual é a probabilidade de que um indivíduo muito ativo sexualmente possa desenvolver AIDS muito rapidamente?" utilizando as equações 2.25), 2.28 e 2.29), apresentadas na seção 2.8, e definindo a seguinte probabilidade condicional: 


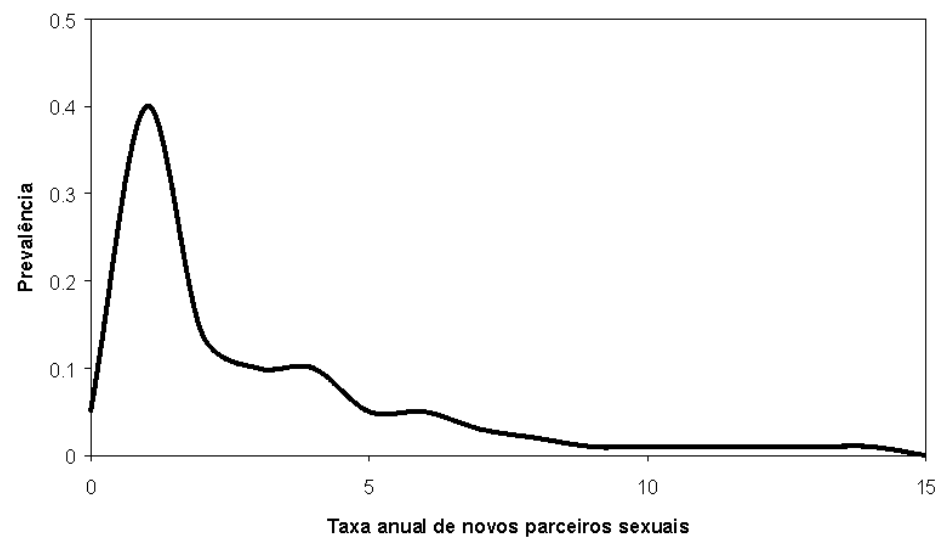

Figura 5.5: Distribuição de novos parceiros sexuais por ano.

$$
P(B / C)=\frac{\sum_{i} \mu_{B} \cdot \mu_{C} \cdot P(B)}{\sum_{i} \mu_{C} \cdot P_{C}}
$$

onde $P(B / C)$ é a probabilidade condicional de que um indivíduo possa desenvolver AIDS rapidamente dado que ele é muito ativo sexualmente, e $P(B)=\mu_{B} \cdot P_{B}$ é a probabilidade de ocorrência do evento fuzzy $B$. A equação (5.6) fornece o valor 0,734 , ou seja, a probabilidade de que um indivíduo desenvolva a AIDS muito rapidamente dado que ele é muito ativo sexualmente é $73,4 \%$, segundo esta abordagem.

É sabido da literatura que a virulência do vírus HIV aumenta com a atividade sexual do indivíduo, ou seja, indivíduos sexualmente muito ativos tendem a selecionar cepas virais mais virulentas, o que acarretaria em um desenvolvimento mais rápido para a doença (Coutinho et al 1999). Sendo assim, é esperado que quanto mais sexualmente ativo o indivíduo for, maior a chance de que ele desenvolva a AIDS mais rapidamente. Temos, portanto, que o resultado apresentado, assim como a definição para probabilidade condicional utilizada, é bastante razoável, uma vez que ele ilustra esta tendência.

\subsection{Discussão}

O objetivo principal desse trabalho foi o de demonstrar como a união da teoria de probabilidades com a teoria de lógica fuzzy pode vir a ser útil na análise de problemas em epidemiologia, podendo fornecer estimadores interessantes. Todavia, esta ainda é uma área extremamente incipiente, sendo a teoria de probabilidades fuzzy muito pouco explorada na literatura. De fato, é praticamente inexistente a proposta de aplicações utilizando esta técnica. Sendo assim, o trabalho apresentado é, a meu ver, uma contribuição importante, uma vez que sinaliza o desenvolvimento de possíveis aplicações dessa teoria, e que os resultados obtidos foram coerentes. 


\section{Capítulo 6}

\section{Processo de decisão fuzzy para escolher uma estratégia de vacinação para o sarampo no Estado de São Paulo}

Desde o final dos anos 60 que os progressos em imunologia têm resultado em vacinas efetivas contra muitas doenças de transmissão direta, tais como o sarampo, a rubéola, a caxumba, alguns sorotipos de menigites, entre outras.

No Brasil algumas dessas vacinas já fazem parte do calendário de imunização, em particular, a vacina contra o sarampo. Devido a sua morbidade e mortalidade o sarampo sempre foi considerado um dos principais problemas de saúde pública em todo o mundo, principalmente em centros urbanos e áreas com altas densidades demográficas, como a cidade de São Paulo.

O sarampo é uma doença contagiosa cuja infecção tem se mantido sob controle no Estado de São Paulo, devido à introdução dessa doença no calendário de vacinação. Desde 1973 as autoridades em saúde pública vêm vacinando gratuitamente as crianças de São Paulo. Todavia, apesar dos esforços realizados no sentido de controlar a incidência de sarampo, até 1986 essa epidemia se mantinha recorrente devido às dificuldades na cobertura da vacinação, mudanças no calendário de imunização e ou- tros problemas diversos. Sendo assim, as autoridades em saúde pública adotaram uma outra estratégia complementar: entre Maio e Junho de 1987 as crianças com menos de 15 anos receberam uma dose de vacina contra o sarampo independentemente de terem sido ou não já vacinadas anteriormente. Esta campanha de vacinação em massa, juntamente com a vacinação de rotina e do sistema de vigilância, resultou em uma redução de $90 \%$ na incidência de casos de sarampo no Estado de São Paulo logo após as medidas tomadas. No entanto, nos últimos anos, deficiências na cobertura da vacinação de rotina levou à um acúmulo de suscetíveis ao sarampo que cuminou em uma epidemia de quase 24.000 casos no ano de 1997. Com a intensão de controlar esta epidemia, as autoridades de saúde pública do Estado de São Paulo decidiram 
6 Processo de decisão fuzzy para escolher uma estratégia de vacinação para o

sarampo no Estado de São Paulo

implementar uma nova campanha de vacinação em massa.

Neste trabalho nós descrevemos a aplicação dos conceitos de lógica fuzzy para escolher a melhor estratégia de vacinação entre um conjunto de oito estratégias consideradas. Até onde temos conhecimento, esta é a primeira vez que os conceitos da lógica fuzzy são utilizados neste tipo de aplicação.

\subsection{Elaborando a estratégia de vacinação}

Tomar decisões é uma tarefa particularmente importante nas questões de saúde pública, uma vez que essas decisões atingem milhares de pessoas. No que diz respeito às estratégias de vacinação as decisões devem contemplar qual a faixa da população que deverá ser imunizada, a proporção de suscetíveis a ser vacinada, a idade ótima para imunização das crianças e a natureza da estratégia, por exemplo se seletiva ou indiscriminada. Estas são variáveis que devem ser otimizadas, sujeitas a um conjunto de restrições.

Como discutido no capítulo 2, o objetivo do Processo de Decisão Fuzzy é estudar como as decisões são de fato realizadas e como realizá-las de uma maneira melhor, de modo a atingir os objetivos com sucesso. Os modelos de tomada de decisão humana incluem, em geral, critérios de agregação ou de restrição. Nos casos em que estes critérios de agregação e/ou restrição não são bem definidos, ou seja, não são determinadamente especificados, não convém modelarmos os problemas classicamente e, nestes casos, a modelagem fuzzy tem apresentado resultados significativos. Esta é a situação dos processos de decisão quanto a uma campanha de vacinação. Sendo assim, nós utilizamos a proposta de Bellman e Zadeh (Bellmam e Zadeh 1970), apresentada na seção 2.7, para modelar o processo de decisão para escolher a campanha de vacinação mais adequada.

Foi considerado como objetivo da campanha de vacinação a redução da infecção de sarampo entre as crianças com menos de 14 anos de idade, por ser este o intervalo de idade onde o vírus do sarampo apresenta maior circulação. Esta decisão é baseada em trabalhos anteriores que mostram que a força de infecção do vírus do sarampo tem uma forte dependência etária, apresentando um pico em torno dos dois anos de idade na ausência de vacinação (Portanto, apesar da alta proporçãode casos na faixa de 20 a 39 anos de idade, durante momentos epidêmicos,o coeficiente de incidência mais alto ocorre entre criaças menoresde 5 anos de idade. Além disso, modelos de contato sugerem que os casos de adultos são resultados de contatos infectivos entre indivíduos suscetíveis e crianças que possuem até 14 anos (Massad et al 1994), que corresponde ao intervalo de idade de interesse para a campanha de vacinação. Toda a análise subseqüente deste trabalho está baseada nas hipóteses acima.

Foram consideradas 8 possibilidades de estratégia para a campanha, compostas pela combinação de vacinação Seletiva, $S_{i}$, que considera apenas as crianças sem registro anterior de vacinação, e vacinação Indiscriminada, $I_{j}$, onde todas as crianças são vacinadas independentemente de históricos anteriores ( $i$ e $j$ caracterizam a faixa 
etária). Além disso, consideramos a possibilidade de Unidades Móveis, $U M$, que são locais de vacinação fora dos postos de saúde ou mesmo veículos preparados para este fim visando atingir locais de difícil acesso, e Unidades Fixas, UF, que consiste na vacinação em postos da rede pública de saúde. A tabela 1 apresenta as várias estratégias de vacinação consideradas. A estratégia 1 , por exemplo, considera a vacinação seletiva nas crianças com idade entre 9 meses e 6 anos e indiscriminada nas crianças com idade entre 6 e 14 anos, utilizando unidades de vacinação móveis e fixas.

$$
\begin{array}{ll}
\text { 1. } & S_{9 m-6 a}-I_{6 a-14 a}, U M+U F \\
\text { 2. } & S_{9 m-6 a}-I_{6 a-14 a}, U F \\
\text { 3. } & S_{9 m-14 a}, U M+U F \\
\text { 4. } & S_{6 a-14 a}-I_{9 m-6 a}, U M+U F \\
\text { 5. } & I_{9 m-14 a}, U M+U F \\
\text { 6. } & S_{9 m-6 a}, U F \\
\text { 7. } & S_{9 m-6 a}, U M+U F \\
\text { 8. } & I_{9 m-6 a}, U M+U F
\end{array}
$$

O número total de crianças, assim como a proporção estimada e o número de crianças suscetíveis (considerando o perfil soroepidemiológico de 1994 e a falha na cobertura da vacinação de rotina contra o sarampo, discutida anteriormente) para cada intervalo de idade, no Estado de São Paulo, é apresentada na tabela 2.

Tabela 2: Número de crianças, proporção estimada e número de crianças suscetíveis, em cada faxa etária.

\begin{tabular}{clll} 
idade & \#crianças* & prop. suscetíveis & \#suscetíveis \\
$9 \mathrm{~m}$ & 49.500 & 0.65 & 32.175 \\
$10 \mathrm{~m}$ & 49.500 & 0.50 & 24.750 \\
$11 \mathrm{~m}$ & 49.500 & 0.50 & 24.750 \\
$12 \mathrm{~m}$ & 49.500 & 0.50 & 24.750 \\
$1-2 \mathrm{y}$ & 640.609 & 0.10 & 64.061 \\
$3-5 \mathrm{y}$ & 2.515 .711 & 0.05 & 125.786 \\
$6-14 \mathrm{y}$ & 5.920 .000 & 0.05 & 296.000 \\
Total & 9.274 .331 & - & 592.272 \\
\multicolumn{4}{c}{ *estimado a partir de dados oficiais } \\
+estimado a partir de modelo dinâmico (Massad et al 1994)
\end{tabular}

A última coluna da tabela 2 é o número teórico (estimado) de crianças que devem ser vacinadas, em cada faixa etária, para que a epidemia pare de crescer. A estratégia ótima, portanto, é aquela que maximiza o número de crianças suscetíveis vacinadas em cada intervalo de idade, sem desperdício de recursos por vacinar crianças já imunizadas. 
6 Processo de decisão fuzzy para escolher uma estratégia de vacinação para o sarampo no Estado de São Paulo

O passo seguinte consistiu em convidar um número de especialistas da Secretaria de Saúde Pública do Estado de São Paulo com grande experiência em campanhas de vacinação para que, através dos seus julgamentos, obtivéssemos uma escala de eficiência e/ou restrições para cada uma das possíveis estratégias consideradas. As variáveis escolhidas pelo grupo de especialistas foram:

- adesão pela população, ou seja, a proporção da população que espera-se que venha a aderir à campanha para cadaestratégia;

- recursos humanos, uma escala relativa de habilidades necessárias (incluindo treinamento) para a implementação de cada campanha;

- transporte, uma escala relativa de dificuldades de transporte de pessoas e materiais para cada estratégia;

- divulgação, uma escala relativa de dificuldades para explicar para a população como se realizará cada campanha.

O valor mínimo de cada uma das variáveis será aquele que determinará o sucesso da estratégia. A opinião dos especialistasquanto as variáveis acima é apresentada na tabela 3 . 


\begin{tabular}{cccccc}
\multicolumn{5}{c}{ Tabela 3: Variavéis que determinarão o sucesso das respectivas estratégias. } \\
estratégia & adesão & recur. humanos. & transporte & divulgação & min \\
1 & 0.30 & 0.30 & 0.20 & 0.30 & 0.20 \\
2 & 0.45 & 0.60 & 1.00 & 0.50 & 0.45 \\
3 & 0.70 & 0.50 & 0.30 & 0.40 & 0.30 \\
4 & 0.40 & 0.40 & 0.30 & 0.40 & 0.30 \\
5 & 0.80 & 0.20 & 0.20 & 0.80 & 0.20 \\
6 & 0.60 & 1.00 & 1.00 & 0.70 & 0.60 \\
7 & 0.50 & 0.60 & 0.60 & 0.60 & 0.50 \\
8 & 1.00 & 0.70 & 0.40 & 1.00 & 0.40
\end{tabular}

Os valores fornecidos pelos especialistas podem ser entendidos como uma proporção do sucesso esperado para cada estratégia ou como o grau de pertinência dessas variáveis aos conjuntos fuzzy de sucesso das estratégias. Em ambos os casos o operador min é o que determina o resultado esperado de cada estratégia (veja a última coluna da tabela 3). E assim, se considerarmos as variáveis apresentadas na tabela 3 como sendo o conjunto de restrições das estratégias consideradas, então, o operador max pode ser utilizado para decidir qual estratégia maximiza o sucesso da campanha, o que no caso seria a estratégia número 6 (aquela que minimizando as restrições oferece o máximo de eficiência).

O valor do operador min apresentado na tabela 3 nos permite estimar o número esperado de crianças, em cada faixa etária, que seriam vacinados em cada uma das possíveis estratégias. Assim, a estratégia número 1, por exemplo, tem como fator limitante o transporte de pessoas e materiais e cobriria, portanto, apenas $20 \%$ da população a ser vacinada. Como esta estratégia se propõe a vacinar seletivamente crianças com idade entre 9 meses até 6 anos e indiscriminadamente crianças de 6 anos até 14 anos, somente $20 \%$ dos suscetíveis com menos de 6 anos e $20 \%$ de todas as crianças entre 6 e 14 anos receberiam a vacina, o que neste caso resultaria em 1.243.254 crianças vacinadas em todo o Estado. Uma medida da eficácia de cada estratégia, de acordo com a definição de estratégia ótima apresentada anteriormente, pode ser obtida através da diferença entre o número de crianças que deveriam receber a vacina e o número de crianças que potencialmente receberão a vacina de fato, em cada faixa etária. Assim, consideramos a distância euclidiana como estimador de eficácia para cada estratégia, normalizando os valores através da estratégia mais eficaz que recebeu o valor 1. Os valores estimados para a eficácia das estratégias são apresentados na tabela 4 .

Ainda na tabela 4 apresentamos os valores de custo econômico de cada estratégia. Este valores de custos foram calculados considerando um custo unitário de $U S \$ 0,25$ para cada dose de vacina de sarampo, $U S \$ 1,40$ para cada dose de sarampo-caxumbarubéola (aplicada somente em crianças com mais de um ano de idade) e um custo unitário de $U S \$ 0,75$ para a aplicação das vacinas. A coluna 4 da tabela 3 apresenta o custo econômico para cada estratégia e a coluna 5 apresenta o custo relativo, considerando que a estratégia com custo mais elevado assume o valor 1. 
6 Processo de decisão fuzzy para escolher uma estratégia de vacinação para o sarampo no Estado de São Paulo

\begin{tabular}{lllll} 
& \multicolumn{5}{c}{ Tabela 4: Eficiência e custo econômico das estratégias. } \\
estratégia & \#vacinados & eficiência relativa & custo econômico & custo relativo \\
1 & 1.243 .254 & 0,01 & $3.178 .223^{*}$ & 0,533 \\
2 & 2.797 .322 & 0,02 & 5.959 .168 & 1,000 \\
3 & 177.682 & 0,26 & $414.359^{*}$ & 0,070 \\
4 & 1.095 .099 & 0,03 & $2.743 .384^{*}$ & 0,460 \\
5 & 1.854 .866 & 0,01 & $4.730 .907^{*}$ & 0,794 \\
6 & 177.763 & 1,00 & 308.758 & 0,052 \\
7 & 148.136 & 0,80 & $370.509^{*}$ & 0,062 \\
8 & 1.341 .732 & 0,04 & $3.352 .374^{*}$ & 0,563 \\
\multicolumn{5}{c}{} \\
* custo adicional de 20\% pelas unidades móveis
\end{tabular}

Agrupando todas as variáveis técnicas (adesão, recursos humanos, transporte e divugação) em uma única variável, restrições técnicas, o próximo passo nessa análise é comparar os dois fatores limitantes para determinar o sucesso da estratégia, ou seja, as restricões técnicas e os custos relativos. Para compararmos essas variáveis tomamos o mínimo entre os valores estabelecidos pelos especialistas para as variáveis técnicas (última coluna da tabela 3) e o complemento do custo relativo (1-custo relativo) da última coluna da tabela 4, estando assim ambas as escalas na mesma direção. Então, os valores mínimos dessas variáveis representam o limitante máximo para as retrições de cada estratégia, como apresentado na tabela 5:

Tabela 5 : Varíaveis que representam as restrições de cada estratégia.

$\begin{array}{llll}\text { estratégia } & \text { restrições técnicas } & \text { restrições de custo } & \text { min } \\ 1 & 0,20 & 0,467 & 0,20 \\ 2 & 0,45 & 0,000 & 0,00 \\ 3 & 0,30 & 0,930 & 0,30 \\ 4 & 0,30 & 0,540 & 0,30 \\ 5 & 0,20 & 0,206 & 0,20 \\ 6 & 0,60 & 0,948 & 0,60 \\ 7 & 0,50 & 0,938 & 0,50 \\ 8 & 0,40 & 0,437 & 0,40\end{array}$

Neste ponto temos todos os componentes necessários ao modelo de decisões fuzzy apresentado no capítulo 2 (Klir \& Yuan 1995, Bellman 83 Zadeh 1970):

- um conjunto $A$ de possíveis ações: as oito possíveis estratégias;

- um conjunto de objetivos, $G_{i}(i \in \mathbb{N})$, definido em $A$ : a eficiência relativa de cada possível estratégia (terceira coluna da tabela 4); 
- um conjunto de restrições, $C_{j}(j \in \mathbb{N})$, definido em $A$ : o mínimo entre as restrições técnicas e os custos (última coluna da tabela 5 ).

A decisão fuzzy, $D$, que satisfaz simultaneamente os objetivos, $G_{i}$, e as restrições, $C_{i}$, é dada por:

$$
D(a)=\min \left[G_{i}(a), C_{j}(a)\right]
$$

para todo $a \in A$, cujos valores estão expressos na tabela 6 .

$\begin{array}{clll}\text { Tabela 6: Conjunto de decisão fuzzy. } \\ \text { estratégia } & G_{i}(a) & C_{j}(a) & D(a) \\ 1 & 0,01 & 0,20 & 0,01 \\ 2 & 0,02 & 0,00 & 0,00 \\ 3 & 0,26 & 0,30 & 0,26 \\ 4 & 0,03 & 0,30 & 0,03 \\ 5 & 0,01 & 0,20 & 0,01 \\ 6 & 1,00 & 0,60 & 0,60 \\ 7 & 0,80 & 0,50 & 0,50 \\ 8 & 0,04 & 0,40 & 0,04\end{array}$

Portanto, a estratégia que tem o máximo grau de pertinência no conjunto de decisão é aquela que vacina seletivamente as crianças com idade entre 9 meses e 6 anos em unidades fixas, ou seja, a estratégia 6 (grau de pertinência 0,6).

\subsection{A epidemia de sarampo em São Paulo}

No Estado de São Paulo a rotina de vacinação contra o sarampo iniciou-se em 1973. Todavia, apesar dessa rotina de vacinação, epidemias periódicas continuaram a ocorrer até 1987 , quando a primeira campanha de vacinação em massa contra o sarampo foi realizada. Esta campanha reduziu a incidência média para cerca de 0,1 por 100.000 habitantes; um nível que persistiu até o final de setembro de 1996, quando o número de casos de sarampo notificados pelas autoridades de saúde de São Paulo começou a crescer. Em Março de 1997, o número de novos casos começou a crescer exponencialmente, caracterizando o início de uma nova epidemia, atingindo um total de 23.195 casos confirmados após um ano, com 23 mortes. Com relação ao perfil etário da epidemia, é notável que $47 \%$ ocorreram entre adultos jovens com idade entre 20 e 29 anos. O outro grupo mais atingido foi o de crianças com menos de um ano de idade (15\%), que apresentaram a mais alta taxa de incidência por 100.000 habitantes. A tabela 7 apresenta os valores da taxa de incidência do sarampo por 100.000 habitantes no Estado de São Paulo. 
6 Processo de decisão fuzzy para escolher uma estratégia de vacinação para o sarampo no Estado de São Paulo

Tabela 7: Taxa de incidência do sarampo em São Paulo por 100.000 habitantes.

$\begin{array}{cccc}\text { Idade (anos) } & \text { Área Metropolitana } & \text { Interior } & \text { Total } \\ <1 & 871,50 & 94,17 & 482,84 \\ 1-4 & 115,99 & 15,32 & 65,65 \\ 5-9 & 61,21 & 13,13 & 37,17 \\ 10-14 & 36,17 & 5,93 & 21,05 \\ 15-19 & 67,27 & 11,34 & 39,31 \\ 20-29 & 314,30 & 29,85 & 172,08 \\ 30-44 & 56,52 & 7,54 & 32,03\end{array}$

A segunda taxa de incidência mais elevada ocorreu entre adultos jovens, atingindo a faixa etária que mais tem contato com as crianças pequenas. Esses adultos representam provavelmente os pais, professores e pajens das crianças que sofreram a mais alta taxa de incidência. A figura 6.1 apresenta a onda epidêmica do sarampo no Estado de São Paulo, no interior do Estado e na cidade de São Paulo, durante o ano de 1997.

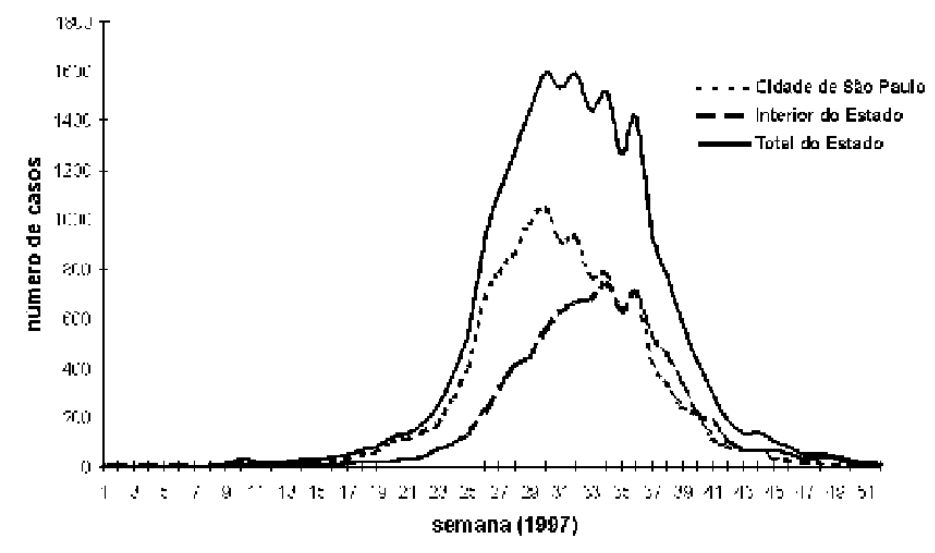

Figura 6.1: Epidemia do sarampo no Estado de São Paulo, no interior do Estado e na cidade de São Paulo, durante o ano de 1997.

\subsection{O impacto da vacinação}

A estratégia de vacinação proposta foi implementada em todo o Estado de São Paulo, em 21 de Junho de 1997. Um total de 213.084 doses foram aplicadas em crianças de 9 meses a 6 anos de idade, o que representa uma cobertura de 6,5\% de toda a população do Estado de São Paulo nesta faixa etária. Na região Metropolitana de São Paulo 7,5\% das crianças na faixa etária considerada foram vacinadas, já no interior do Estado esse valor foi de 5,1\%. Não existe dados oficiais quanto a eficiência do processo de seleção com relação a identificação das crianças já imunizadas, ou seja, não sabemos se a pequena proporção de crianças vacinadas foi aquela de suscetíveis 
ou não. Como o número esperado de crianças suscetíveis que deveriam ser vacinadas, segundo a estratégia proposta, foi de 177.763 (ver tabela 4), nós podemos concluir que a estatística realizada a partir das informações dos especialistas foi bastante coerente com a realidade.

No sentido de estimar o curso natural da epidemia nós primeiramente ajustamos uma função contínua a fase inicial do crescimento epidêmico real, considerando as semanas anteriores a primeira intervenção. Como esperado, o ajuste forneceu uma curva exponencial, com uma taxa de crescimento positivo de 0,25/semana. A figura 6.2 apresenta o resultado desse ajuste.

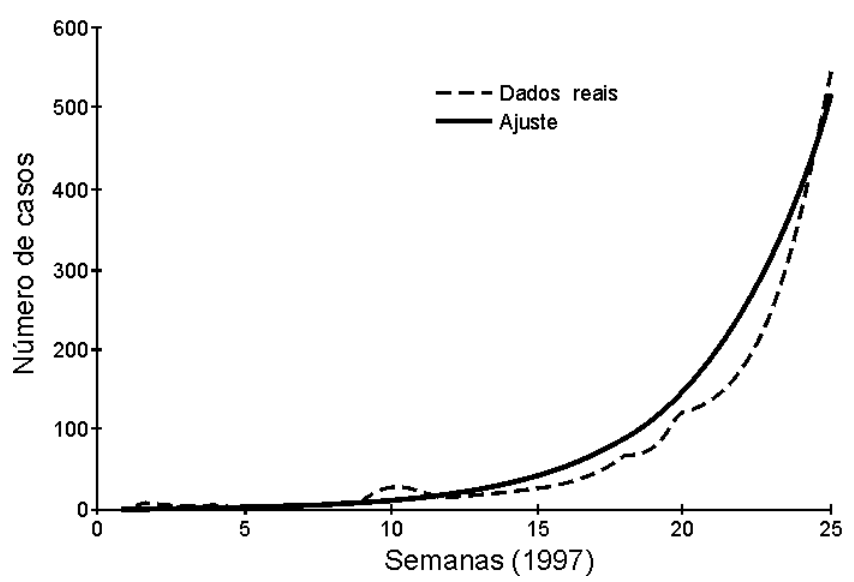

Figura 6.2: Ajuste do crescimento epidêmico na sua fase inicial.

Em seguida, foi calculado a taxa de contato efetivo, $\beta$; uma taxa composta que descreve a probabilidade de contato entre indivíduos suscetíveis e infectados e a probabilidade de que tal contato resulte em um novo caso. Isto foi realizado considerando que o número de novas infecções, $y(t)$, aumenta exponencialmente (como pode ser visto na figura 6.2) de acordo com:

$$
y(t)=y_{0} \exp \{[\beta \bar{x}-(\mu+\gamma)] t\}
$$

onde $y_{0}=y(0), \bar{x}$ é a proporção esperada de suscetíveis, considerado como sendo $10 \%$, $\mu$ é a taxa de mortalidade natural da população, considerado como 0,0003/semana, e $\gamma$ é o inverso do período de infecciosidade do sarampo, considerado para ser igual a uma semana.

Estes parâmetros, então, alimentaram um sistema dinâmico clássico do tipo SIR 1 . com o objetivo de recuperar o curso natural da epidemia na ausência de vacinação. O modelo descrito é composto pelas seguintes equações:

$$
\frac{d x(t)}{d t}=\mu[y(t)+z(t)]-\beta x(t) y(t)
$$

\footnotetext{
${ }^{1} \mathrm{O}$ modelo tipo SIR é um sistema dinâmico que consiste de três compartimentos: suscetível, infectado e recuperado.
} 
6 Processo de decisão fuzzy para escolher uma estratégia de vacinação para o

$$
\begin{aligned}
\frac{d y(t)}{d t} & =\beta x(t) y(t)-(\mu+\gamma) y(t) \\
\frac{d z(t)}{d t} & =\gamma y(t)-\mu z(t)
\end{aligned}
$$

onde $x(t)$ são os indivíduos suscetíveis, $y(t)$ são os indivíduos infectados e $z(t)$ representa os indivíduos recuperados (imunes). O resultado da simulação, com condições iniciais $x(0)=0,1 ; y(0)=10^{-7}$ e $z(0)=0,9$, é apresentado na figura 6.3, onde podemos compará-lo com a curva epidêmica real.

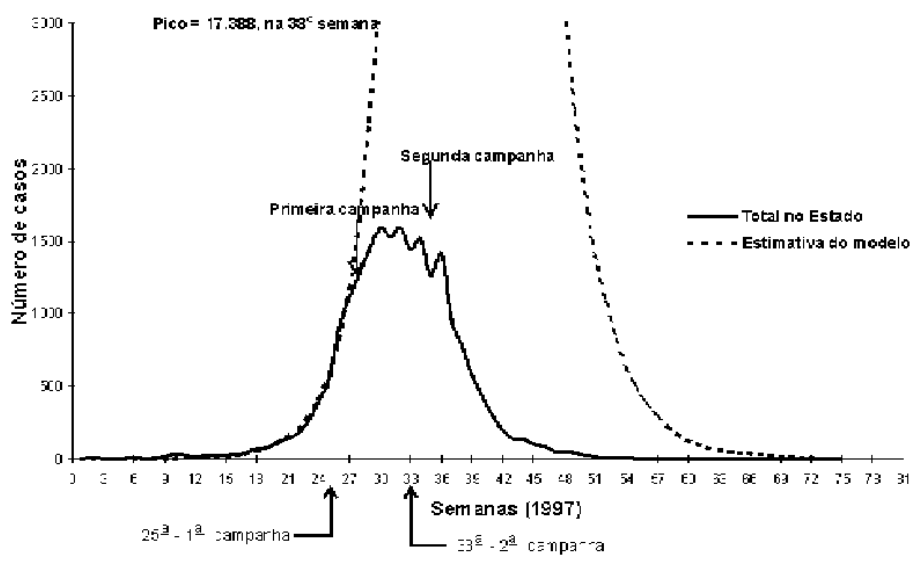

Figura 6.3: Comparação dos resultados do modelo clássico com os valores reais.

Podemos ver da figura que o número esperado de casos, simulado pelo modelo acima, atinge um pico em torno de 17.500 na $38^{a}$ semana, totalizando quase 300.000 casos. Isto representaria uma taxa de incidência que atingiria cerca de $8 \%$ de toda a po- pulação suscetível, uma cifra que é um limite inferior para outras epidemias de sarampo registradas na literatura (Hutchins 83 Markowitz 1990, Weeks et al 1992, Markowitz \&3 Katz 1994, Murray \& Lopez 1996, Nokes 83 Swinton 1997). Vemos também que a concordância entre a curva simulada e os valores reais da onda epidêmica é muito grande até a $25^{a}$ semana. A partir deste ponto ocorre uma deflexão significativa da tendência exponencial da curva epidêmica, o que ocorre logo após a primeira intervenção.

Comparando o número de casos (simulados) com os apresentados pela curva epidêmica real podemos concluir que a estratégia de vacinação poposta (realizada na $25^{a}$ semana) provocou um impacto significativo sobre a epidemia na cidade de São Paulo, diminuindo drasticamente o número de casos nas quatro semanas subseqüêntes a campanha. No entanto, o número de casos no interior do Estado começou a crescer três semanas após a campanha (veja a figura 6.1), apresentando o seu pico aproximadamente dez semanas depois (Uma recente epidemia de sarampo nos Estados Unidos apresentou um fenômeno similar, com um segundo pico algum tempo depois da campanha de vacinação). As autoridades em Saúde Pública, então, decidiram realizar uma segunda campanha de vacinação que difere da primeira por não considerar as restrições de custo econômico. Nestes termos, a estratégia número oito foi a melhor candidata, uma 
vez que apresentava o maior valor de adesão, sendo implementada em 16 de Agosto de 1997 (33 $3^{a}$ semana). O número de casos caiu significativamente em todas as faixas etárias e em todo o Estado logo após a segunda campanha de vacinação, sendo o surto considerado controlado.

\subsection{Discussão}

Embora a vacina contra o sarampo esteja disponível há mais de 25 anos, atingindo 95\% de eficiência, essa doença ainda é um importante problema de saúde pública, matando mais de um milhão de crianças todos os anos em regiões em desenvolvimento e apresentando um valor DALY ${ }^{2}$ maior do que o da malária para essas mesmas regiões (Murray \& Lopez 1996). Sendo uma infecção extremamente transmissível ela exige um alto nível de cobertura na vacinação (cerca de 93\%) para que seja eliminada. No entanto, esses níveis de cobertura raramente são mantidos nos esquemas de rotina para imunização. Portanto, uma estratégia de controle usual, pelo menos em regiões em desenvolvimento, é estabelecer campanhas de vacinação em massa de tempos em tempos. De fato, este procedimento foi adotado no Estado de São Paulo em 1987 e em 1992, causando um impacto significativo na incidência de sarampo.

É comum observarmos uma drástica queda no número de casos logo após uma campanha de vacinação em massa. Com o passar do tempo, no entanto, começa a se acumular na população uma fração de suscetíveis, advindos de pessoas vacinadas que não responderam à vacina (não convertidos) e imigrantes de outras áreas do país. Este fato, aliado a queda nos níveis de cobertura da imunização de rotina, observada nos dois anos anteriores à 1997 no Estado de São Paulo, pode explicar a onda epidêmica do ano de 1997.

Em países populosos como o Brasil, particularmente em regiões como o Estado de São Paulo, onde uma campanha de vacinação em massa deve imunizar milhões de indivíduos, é razoável tentarmos estimar o número mínimo de vacinações necessárias para controlar a epidêmia, podendo, assim, economizar milhões de dolares do dinheiro público. Quando a onda epidêmica foi identificada no Estado de São Paulo e decidiuse por uma campanha de vacinação em massa, poucos dados estavam disponíveis, não permitindo a aplicação de um modelo dinâmico, que é uma abordagem mais estruturada, para elaborar o melhor esquema de vacinação (Massad et al 1994). Além disso, o comportamento do pico de sarampo logo após uma intervenção, como por exemplo uma campanha de vacinação em massa, tem sido pouco documentado na literatura. Sendo assim, é muito complicado prever qual o impacto da intervenção no curso da epidemia. Tinhamos ainda a imposição de uma importante limitação o número total de doses disponíveis foi limitado em 300.000. Este cenário nos levou a optar pelo uso dos conceitos da lógica fuzzy para elaborar qual a campanha de vacinação a ser adotada.

\footnotetext{
${ }^{2}$ DALY (Disability-Adjusted Life-Years), simplificadamente, é uma medida do quanto uma dada doença pode prejudicar a qualidade de vida das pessoas.
} 
6 Processo de decisão fuzzy para escolher uma estratégia de vacinação para o sarampo no Estado de São Paulo

A capacidade do modelo de decisão fuzzy para prever o número de crianças que deveriam ser vacinadas pode ser avaliada pelo contraste deste número (177.763, o que corresponde a $60 \%$ (tabela 3 e 4) dos suscetíveis da população visada) com o número real de crianças que receberam a vacina (213.084, o que corresponde a $72 \%$ dos suscetíveis da população visada). Portanto, o modelo fuzzy de predição do número de crianças que deveriam ser vacinadas apresentou uma acurácia maior que $80 \%$. O resultado da eficiência da estratégia escolhida foi significativa pelo menos na região Metropolitana da cidade de São Paulo, todavia, um impacto muito menor foi observado no resto do Estado.

Uma possível explicação para esse fato pode ser a ausência de uma seleção criteriosa entre as crianças já vacinadas. Um outro fato, não abordado no modelo inicial, foi a decisão das autoridades em Saúde Pública de extender a campanha de sarampo para uma outra mais ampla, onde outras vacinas foram incluídas, sendo elas difteriacoqueluche-tétano (DPT). No entanto, logo após o meio dia do dia 21 de Junho, o estoque de vacinas DPT esgotou-se, o que provavelmente desmobilizou a população. Este último argumento é apenas um exemplo de como fatores não esperados podem influenciar o resultado final de um trabalho complexo, como o de uma campanha de vacinação em massa.

Nós acreditamos que a abordagem da lógica fuzzy utilizada para controlar essa recente epidemia de sarampo em São Paulo foi muito efetiva, uma vez que ela nos permitiu combinar, de forma coerente, as informações intuitivas dos especialistas em Saúde Pública com as restrições de custo econômico. Vale ainda ressaltar que a abordagem proposta teve grande aceitação por parte dos profissionais de saúde, que colaboraram na elaboração do modelo com entusiasmo. Estes profissionais atestaram que o modelo proposto, devido as suas características próprias, auxiliou muito na organização das discussões, uma vez que a partir dele foram ressaltadas as variáveis importantes para a tomada de decisão. Nossos resultados, apesar dos fatores que estiveram fora de controle durante a implementação da estratégia proposta, são muito encorajadores, demonstrando o potêncial de uma nova técnica para auxiliar na elaboração de intervenções em saúde pública. 


\section{Capítulo 7}

\section{Modelos lingüísticos fuzzy estáticos em biomedicina}

Os modelos lingüísticos representam boa parte dos trabalhos realizados com a teoria de lógica fuzzy nas mais diversas áreas. O sucesso desses modelos se deve principalmente a sua ampla aplicabilidade nos controladores fuzzy que, como discutido anteriormente, são os responsáveis pelo rápido desenvolvimento da teoria de lógica fuzzy e da sua inserção na indústria e no aprimoramento de produtos de consumo.

A capacidade em lidar com variáveis lingüísticas, a facilidade na sua compreensão, o baixo custo computacional, e a sua habilidade em incorporar aos sistemas a experiência de especialistas humanos, fazem dessa abordagem uma opção extremamente interessante. Como não poderia deixar de ser, nós procuramos avaliar que possibilidades este tipo de modelagem fuzzy poderia nos oferecer no tratamento de problemas em epidemiologia. Sendo assim, desenvolvemos logo no início desse projeto o modelo para progressão clínica da AIDS em indivíduos HIV soropositivos. Este trabalho foi importante porque a partir dele outros foram desenvolvidos, como os que são apresentados nos capítulos 8 e 9 .

Como é esperado, os modelos lingüísticos estáticos são muito mais simples de serem elaborados do que os modelos dinâmicos, entretanto, eles não são menos úteis. De fato, muitos trabalhos em epidemiologia, e alguns de grande aplicabilidade, podem ser realizados com modelos deste tipo. Um exemplo disso é o modelo para estimar o risco de morte neonatal que realizamos já no final desse projeto e que será ainda aprimorado. Podemos obter uma idéia melhor do quanto estes modelos são potencialmente útéis em epidemiologia na discussão dos trabalhos futuros, onde apresento algumas perspectivas de aplicações que estamos desenvolvendo.

\subsection{Modelo para a inferência da progressão clínica da AIDS em indivíduos HIV soropositivos}

É atualmente aceito que a concentração do vírus de imunodeficiência humana (HIV) 
7 Modelos lingüísticos fuzzy estáticos em biomedicina

na circulação sanguínea influi efetivamente na progressão clínica da infecção. Tem sido demonstrado também que o tempo médio entre a infecção e o desenvolvimento dos primeiros sintomas da Síndrome da Imunodeficiência (AIDS) é cerca de dez anos. No entanto, uma proporção significativa de indivíduos tem progredido para a AIDS cerca de cinco anos ou menos da infecção. Por outro lado, cerca de $12 \%$ dos indivíduos infectados permanecem livres da AIDS por pelo menos vinte anos. Estes diferentes desfechos estão relacionados, entre outras coisas, com o nível de carga viral atingido pelo indivíduo durante o período de incubação do vírus. Outra medida que pode fornecer informações sobre a situação em que se encontra o indivíduo soroconvertido ao HIV quanto á sua perspectiva de progressão clínica é a quantidade de célula CD4 no sangue, que é uma célula do sistema imunológico. A figura 7.1 apresenta o comportamento típico dos indivíduos soroconvertidos, no que diz respeito à carga viral e à quantidade de CD-4 com o tempo.

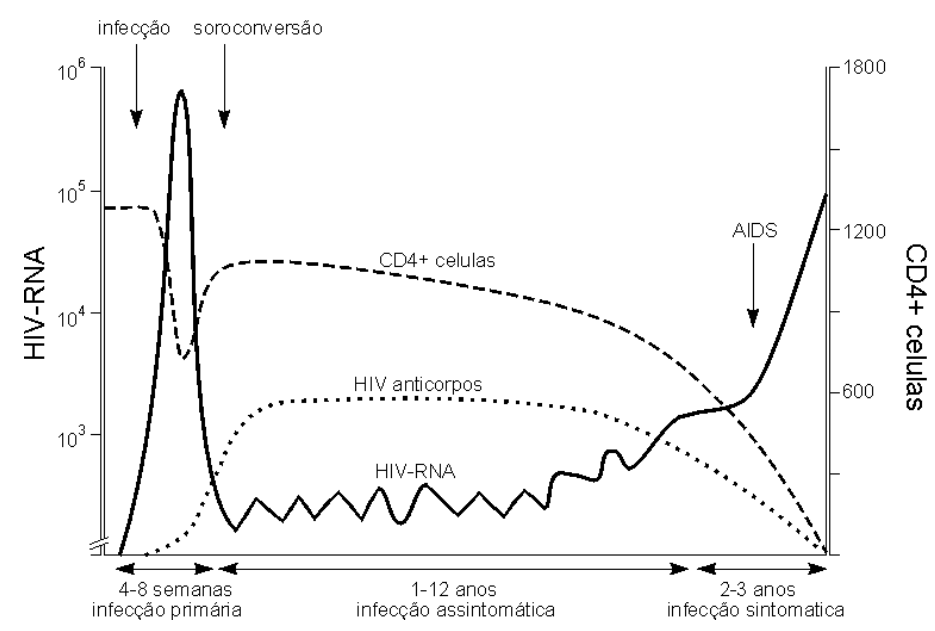

Figura 7.1: Comportamento típico dos indivíduos soroconvertidos ao HIV com relação a progressão clínica.

É verificado que em um primeiro estágio a concentração do vírus na circulação sanguínea cresce rapidamente (primeiro e segundo meses após a infecção) e atinge um máximo, a partir do qual a carga viral começa a diminuir até atingir um nível estacionário, onde o indivíduo permanece por alguns anos. Passado o período de incubação do vírus, a concentração deste na circulação sanguínea volta a crescer e o indivíduo começa a esboçar os primeiros sintomas da AIDS. O processo descrito é chamado progressão clínica. É fato que o indivíduo progredirá para a AIDS mais rapidamente quanto mais alto o nível de carga viral atingido no estágio estacionário assintomático. É de fundamental importância para a escolha do tratamento o conhecimento sobre em que estágio da curva se encontra o indivíduo. Para tanto, além dos exames de concentração do vírus são também realizados exames de concentração de CD-4, que mede a quantidade de linfócito T (antígeno de superfície CD-4) no sangue. Por exemplo, um nível alto de CD-4 pode, a depender do nível de carga viral, estar relacionado com uma progressão clínica lenta. 
A inferência sobre em que estágio da infecção se encontra o paciente consiste em um acompanhamento longitudinal no tempo dos indicadores citados, o que consome alguns meses de análise. Baseado no conhecimento exposto acima, neste trabalho é proposto um modelo lingüístico fuzzyque estabelece relações entre os valores de carga viral e CD-4 com a progressão clínica para AIDS em indivíduos infectados pelo HIV. O objetivo, portanto, é estimar a progressão clínica do indivíduo a partir de uma coleta de exames pontuais no tempo.

O modelo tem uma estrutura em que a carga viral é expressa como o logaritmo da contagem de RNA-HIV no plasma sanguíneo, o valor de CD-4 é expresso como a contagem do linfócito CD-4 e a progressão clínica é expressa como o tempo (em anos) que o indivíduo leva até apresentar os primeiros sintomas da AIDS.

Com o auxílio de um especialista dividimos os valores de carga viral em quatro categorias: muito baixa, baixa, intermediária e alta, e estabelecemos a função de pertinência de $\mathrm{CV}$ à cada categoria.

$$
\begin{array}{ll}
\text { CV muito baixa } & \begin{cases}\mu_{C V m b}(x)=1 & \text { se } x \leq 3 \\
\mu_{C V m b}(x)=4-x \quad \text { se } 3 \leq x<4 \\
\mu_{C V m b}(x)=0 & \text { se } x \geq 4\end{cases} \\
C V \text { baixa } & \begin{cases}\mu_{C V b}(x)=0 & \text { se } x<3,7 \text { ou } x>4,5 \\
\mu_{C V b}(x)=2,0(x-3,7) & \text { se } 3,7 \leq x<4,2 \\
\mu_{C V b}(x)=3, \overline{3}(4,5-x) & \text { se } 4,2 \leq x \leq 4,5\end{cases} \\
\text { CV intermediária } & \left\{\begin{array}{lll}
\mu_{C V i}(x)=0 & \text { se } x<4,0 \text { ou } x>4,8 \\
\mu_{C V i}(x)=2,0(x-4,0) & \text { se } 4,0 \leq x<4,5 \\
\mu_{C V i}(x)=3, \overline{3}(4,8-x) & \text { se } 4,5 \leq x \leq 4,8
\end{array}\right. \\
\text { CV alta } & \left\{\begin{array}{lll}
\mu_{C V a}(x)=0 & \text { se } x<4,7 \\
\mu_{C V a}(x)=3, \overline{3}(x-4,7) & \text { se } 4,7 \leq x<5,0 \\
\mu_{C V a}(x)=1 & \text { se } x \geq 5,0
\end{array}\right.
\end{array}
$$

Os valores de CD-4 foram categorizados em cinco conjuntos fuzzy, com as seguintes funções de pertinência: muito alto, alto, médio, baixo e muito baixo. 


$$
\begin{aligned}
& C D-4 \text { muito alto } \begin{cases}\mu_{C D m a}(x)=0 & \text { se } x<600 \\
\mu_{C D m a}(x)=0,005(x-600) & \text { se } 600 \leq x<800 \\
\mu_{C D m a}(x)=1 & \text { se } x \geq 800\end{cases} \\
& C D-4 \text { alto } \quad \begin{cases}\mu_{C D a}(x)=0 & \text { se } x<400 \text { ou } x>800 \\
\mu_{C D a}(x)=0,005(x-400) & \text { se } 400 \leq x<600 \\
\mu_{C D a}(x)=0,005(800-x) & \text { se } 600 \leq x \leq 800\end{cases} \\
& C D-4 \text { médio } \quad \begin{cases}\mu_{C D m}(x)=0 & \text { se } x<300 \text { ou } x>600 \\
\mu_{C D m}(x)=0,00 \overline{6}(x-300) & \text { se } 300 \leq x<450 \\
\mu_{C D m}(x)=0,00 \overline{6}(600-x) & \text { se } 450<x \leq 600\end{cases} \\
& C D-4 \text { baixo } \quad \begin{cases}\mu_{C D b}(x)=0 & \text { se } x<150 \text { ou } x>350 \\
\mu_{C D b}(x)=0,02(x-150) & \text { se } 150 \leq x<200 \\
\mu_{C D b}(x)=0,00 \overline{6}(350-x) & \text { se } 200 \leq x \leq 350\end{cases} \\
& C D-4 \text { muito baixo } \begin{cases}\mu_{C D m b}(x)=1 & \text { se } x \leq 80 \\
\mu_{C D m b}(x)=0,008 \overline{3}(200-x) & \text { se } 80<x \leq 200 \\
\mu_{C D m b}(x)=0 & \text { se } x>200\end{cases}
\end{aligned}
$$

A progressão clínica também foi dividida em cinco categorias: muito lenta, lenta, média, rápida e muito rápida, cujas funções de pertinência fornecidas pelo especialista foram as seguintes:

$$
\begin{aligned}
& \text { PCmuito lenta } \begin{cases}\mu_{P C m l}(x)=0 & \text { se } x<10 \\
\mu_{P C m l}(x)=0,20(x-10) & \text { se } 10 \leq x<15 \\
\mu_{P C m l}(x)=1 & \text { se } x \geq 15\end{cases}
\end{aligned}
$$

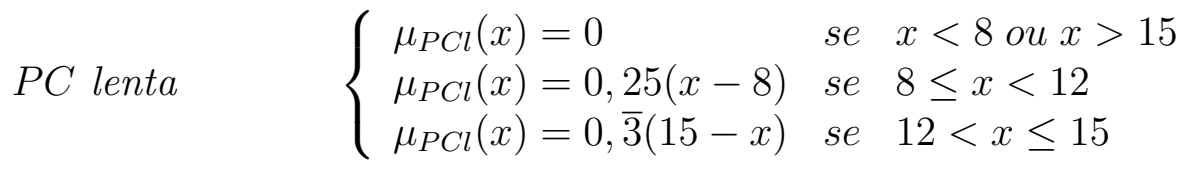

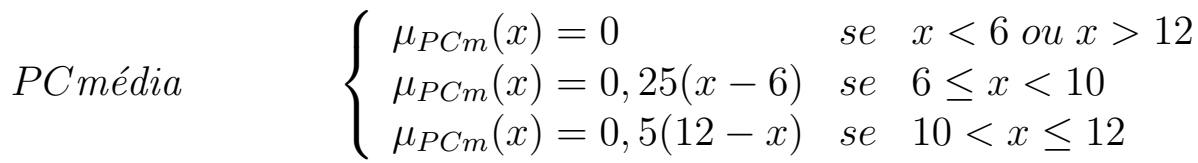

$$
\begin{aligned}
& \text { PCrápida } \quad \begin{cases}\mu_{P C r}(x)=0 & \text { se } x<3 \text { ou } x>7 \\
\mu_{P C r}(x)=0,5(x-3) & \text { se } 3 \leq x<5 \\
\mu_{P C r}(x)=0,5(7-x) & \text { se } 5<x \leq 7\end{cases} \\
& \text { PCmuito rápida } \begin{cases}\mu_{P C m r}(x)=1 & \text { se } x \leq 2 \\
\mu_{P C m r}(x)=0, \overline{3}(5-x) & \text { se } 2<x \leq 5 \\
\mu_{P C m r}(x)=0 & \text { se } x>5\end{cases}
\end{aligned}
$$


As figuras 7.2, 7.3 e 7.4 apresentam os conjuntos fuzzy para as variáveis lingüísticas carga viral, CD-4 e progressão clínica, respectivamente.

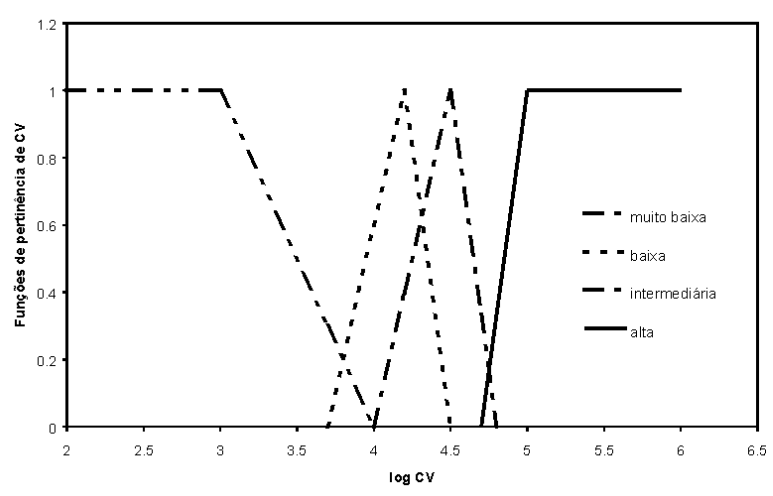

Figura 7.2: Conjuntos fuzzy para a variável lingüística Carga Viral.

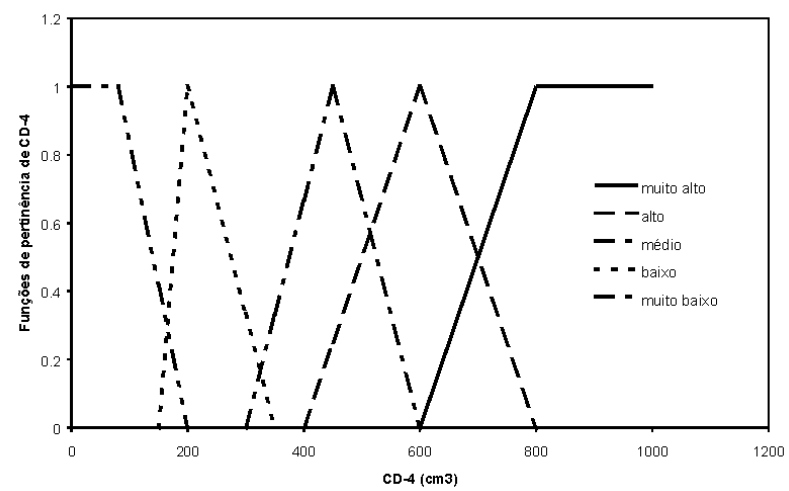

Figura 7.3: Conjuntos fuzzy para a variável lingüística $C D-4$.

Combinando os conjuntos fuzzy de $C V, C D-4$ e $P C$ construímos as regras que relacionam as entradas do sistema $(C V$ e $C D-4)$ com a saída $(P C)$. Assim, das possibilidades geradas foram elaboradas 20 regras, cujo desfexo foi determinado pelo especialista. As regras fuzzy foram as seguintes:

1) SE CV é muito baixa ECD-4 é muito alto ENTÃO PC é muito lenta

2) Se $C V$ é muito baixa $E C D-4$ é alto ENTÃO PC é muito lenta

3) Se $C V$ é muito baixa $E C D-4$ é médio ENTÃO PC é lenta

4) Se CV é muito baixa ECD-4 é baixo ENTÃO PC é lenta

5) Se CV é muito baixa E CD-4 é muito baixo ENTÃO PC é médio

6) Se $C V$ é baixa ECD-4 é muito alto ENTÃO PC é muito lenta

7) Se CV é baixa ECD - 4 é alto ENTÃO PC é lenta

8) Se CV é baixa E CD-4 é médio ENTÃO PC é média 
7 Modelos lingüísticos fuzzy estáticos em biomedicina

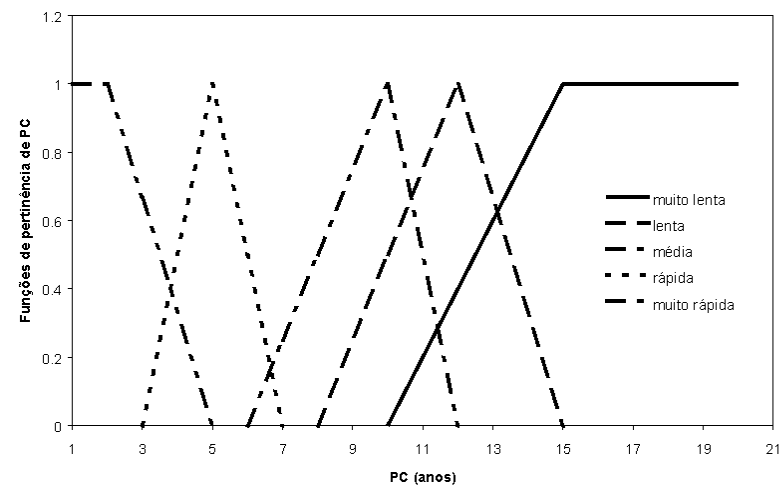

Figura 7.4: Conjuntos fuzzy para a variável lingüística Progressão Clínica.

9) $S e C V$ é baixa $E C D-4$ é baixo ENTÃO PC é média

10) $S e C V$ é baixa $E C D-4$ é muito baixo ENTÃO PC é rápida

11) $S e C V$ é intermediária $E C D-4$ é muito alto ENTÃO PC é média

12) Se $C V$ é intermediária $E C D-4$ é alto ENTÃO PC é média

13) Se $C V$ é intermediária $E C D-4$ é médio ENTÃO PC é média

14) $S e C V$ é intermediária $E C D-4$ é baixo ENTÃO PC é rápida

15) Se $C V$ é intermediária $E C D-4$ é muito baixo ENTÃO PC é muito rápida

16) Se CV é alta $E C D-4$ é muito alto ENTÃO PC é rápida

17) $S e C V$ é alta $E C D-4$ é alto ENTÃO PC é rápida

18) Se $C V$ é alta $E C D-4$ é médio ENTÃO PC é rápida

19) $S e C V$ é alta $E C D-4$ é baixo ENTÃO PC é muito rápida

20) $S e C V$ é alta $E C D-4$ é muito baixo ENTÃO PC é muito rápida

O procedimento do modelo lingǘstico fuzzy consiste em, dado os valores de entrada $C V_{i}$ e $C D-4_{i}$ de um determinado indivíduo, é calculado o grau de pertinência de $C V_{i}$ e $C D-4_{i}$ nos diversos conjuntos fuzzy de carga viral e $C D-4$, respectivamente. A progressão clínica é inferida, a partir das regras estabelecidas, através do Método de Mamdani. Sendo assim, ao final de todo o procedimento teremos um conjunto fuzzy que designa a progressão clínica para aquele paciente. A resposta clássica (não fuzzy) foi obtida através da defuzificação utilizando o Método do Centro de Área (MCA). A figura 7.5 ilustra o conjunto de regras e a figura 7.6 apresenta a superfície obtida pelo mapeamento realizado pelo modelo fuzzy.

Assim, por exemplo, para um indivíduo que apresente um valor para o logaritmo da carga viral igual a 4,3, e um valor de CD-4 igual a $650 \mathrm{cont} / \mathrm{mm}^{3}$, é estimado uma progressão clínica de 12,3 anos. A tabela 7.1 abaixo mostra os valores estimados para a $P C$ considerando alguns pares de valores de $C V$ e $C D-4$. 

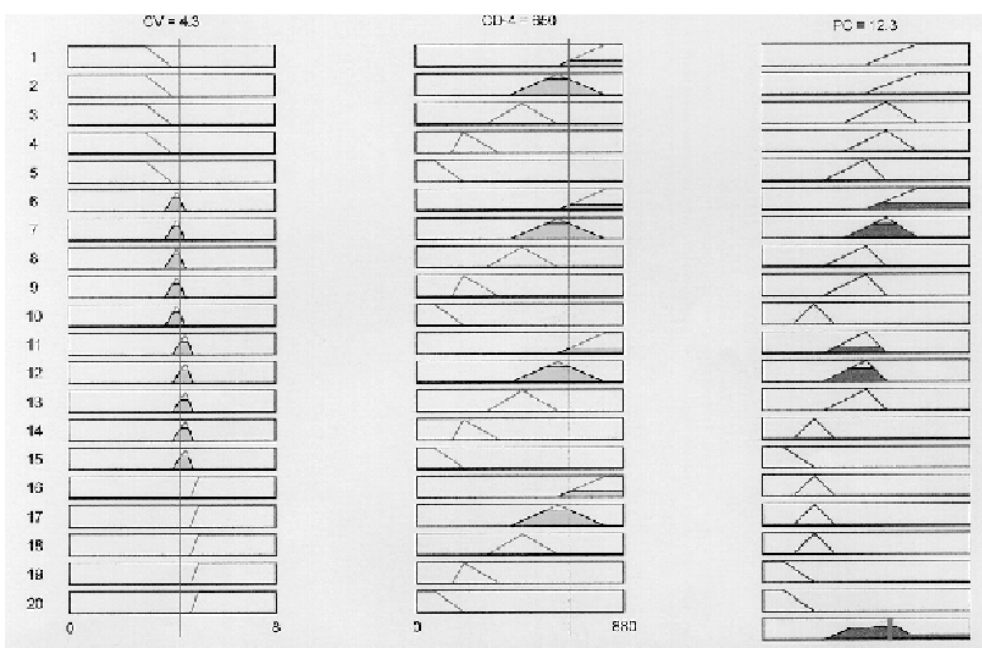

Figura 7.5: Conjunto de regras fuzzy para o Modelo de Progressão Clínica.

Tabela 7.1: Alguns resultados do modelo para valores de $C V$ e $C D-4$.

$\begin{array}{ccc}C V(\log c v) & C D-4\left(\text { cont } / \mathrm{mm}^{3}\right) & P C(\text { anos }) \\ 4,3 & 650 & 12,3 \\ 4,0 & 100 & 5 \\ 6,0 & 200 & 1,8 \\ 2,0 & 350 & 11,6 \\ 4,5 & 400 & 9,28\end{array}$

É importante ressaltar que neste modelo não foi considerada a intervenção no curso natural da doença a partir da utilização de remédios e tratamentos diversos. Sendo assim, o valor de $P C$ estimado pelo modelo serviria apenas para nortear algumas intervenções clínicas iniciais do infectologista, ajudando-o a tomar decisões a partir da identificação da posição do indivíduo na curva apresentada na figura 7.1. Entretanto, uma vez iniciada a utilização dos medicamentos o modelo já não poderá oferecer informações a cerca da progressão clínica do paciente.

O desenvolvimento de medicamentos para o tratamento de soropositivos ao HIV está sempre sendo aperfeiçoado e a realidade do controle sobre a doença AIDS hoje já se apresenta muito diversa da de quando desenvolvemos este trabalho (Abril de 1997). De fato, felizmente, essa doença se encontra hoje razoavelmente sob controle graças ao desenvolvimento dos coquetéis, que têm prolongado ao máximo (e com qualidade de vida) a sobrevivência dos HIV soropositivos.

A não disponibilidade de dados sobre progressão clínica para a AIDS na ausência de medicamentos tornou impossível a validação do modelo com dados experimentais. Portanto, somente nos foi possível comparar os resultados fornecidos pelo modelo com a opinião de um infectologista, sendo o conjunto de dados apresentados consideradosrazoáveis pelo especialista. Sendo assim, consideramos que o método proposto, baseando em uma descrição qualitativa dos conhecimentos disponíveis na época da 


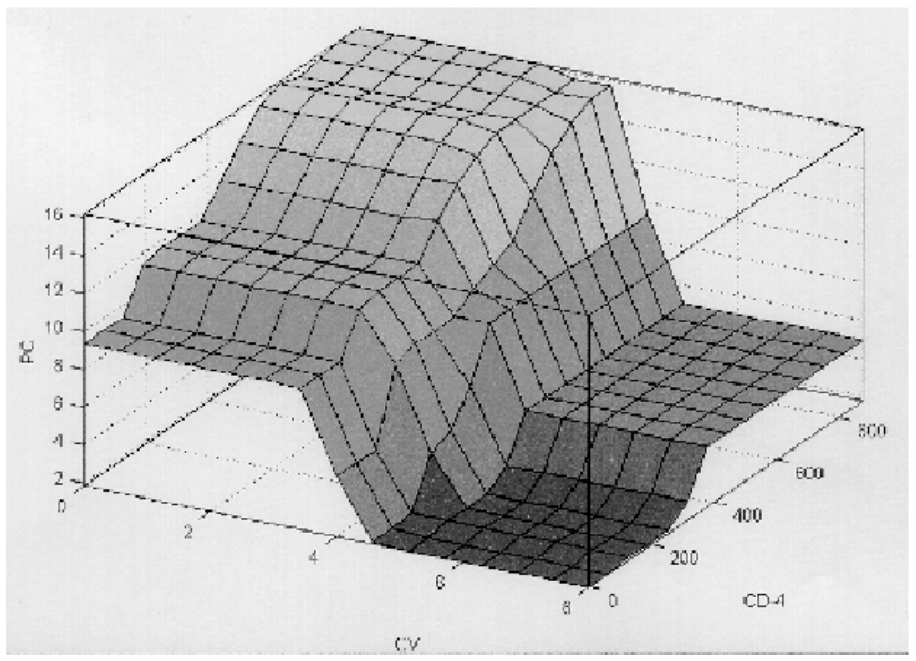

Figura 7.6: Superfície obtida pelo mapeamento realizado pelo modelo fuzzy para a Progressão Clínica.

elaboração do modelo, demonstrou possuir boa capacidade preditiva para a progressão clínica de indivíduos infectados pelo HIV.

\subsection{Modelo para estimativa de risco de morte ne- onatal}

Dentre as principais causas de mortalidade neonatal destacam-se entre outras, o nascimento de crianças com baixo peso (RNBP) e os recém-nascidos pré-termos (RNPT). Existe uma classificação utilizada pelos obstetras para designar as crianças como prétermo e baixo peso. Aquelas cujo peso é inferior a $2500 \mathrm{~g}$ ao nascer são consideradas com baixo peso e dentre estas, aquelas que nascem com um peso inferior a $1500 \mathrm{~g}$ são consideradas muito baixo peso. Da mesma forma, são consideradas pré-termo as crianças que nascem antes de completadas 37 semanas de gestação e pré-termo extremo aquelas que nascem antes de completadas 32 semanas. No Brasil estima-se em torno de $10 \%$ a incidência de RNBP e RNPT. Sendo assim, estimar o risco de morte neonatal pode dar informações importantes ao pediatra e em especial ao intensivista neonatal, quanto à atenção que deve ser dedicada àquele recém-nascido. Todavia, um possível gerador de confusão é a classificação Booleana para RNPT e RNBP descrita acima, pois uma criança que, por exemplo, tenha nascido com 2600 g pode não vir a receber a devida atenção por não ter sido considerada como RNBP, o mesmo podendo acontecer com uma criança que tenha nascido após 38 semanas de gestação. Claramente, os cuidados com o recém-nascido variam a depender do hospital e da região em que ele se encontra (cidades maiores ou menores). É de conhecimento geral que em alguns hospitais mais modestos ocorre muitas vezes de não haver um pediatra no momento do parto, sendo a avaliação do recém-nascido conduzida por outros 
profissionais. É também sabido, que esta avaliação, como a nota de APGAR por exemplo, varia a depender do tipo de especialista que conduz a avaliação. Sendo assim, o desenvolvimento de um programa simples que seja capaz de avaliar o risco de morte neonatal pode vir a ser uma importante ferramenta no auxílio desses profissionais, principalmente quando o neonatologista não está presente.

Neste trabalho é proposto um modelo lingüístico fuzzy para avaliar este risco de morte baseando-se na fuzificação das variáveis peso ao nascer e idade gestacional. O especialista considerou 4 conjuntos fuzzy para a variável peso ao nascer: muito baixo peso (MBP), baixo peso (BP), peso insuficiente (PI) e Normal (PN); e 3 para a variável idade gestacional: muito pré-termo (MPT), pré-termo (PT) e termo $(\mathrm{T})$. Os conjuntos foram os seguintes: 
Peso ao nascer:

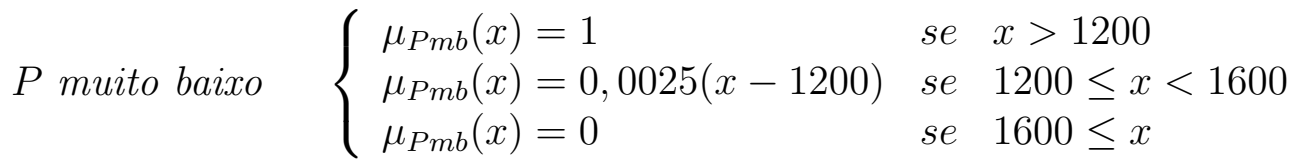

$$
\begin{aligned}
& P \text { baixo } \quad\left\{\begin{array}{ccc}
\mu_{P b}(x)=0 & \text { se } & x<1400 \text { ou } x>2600 \\
\mu_{P b}(x)=0,005(x-1400) & \text { se } & 1400 \leq x<1600 \\
\mu_{P b}(x)=1 & \text { se } & 1600<x \leq 2200 \\
\mu_{P b}(x)=0,0025(2600-x) & \text { se } & 2200<x \leq 2600
\end{array}\right. \\
& P \text { insuficiente }\left\{\begin{array}{ccc}
\mu_{P i}(x)=0 & \text { se } & x<2300 \text { ou } x>3100 \\
\mu_{P i}(x)=0,00 \overline{3}(x-2300) & \text { se } & 2300 \leq x<2600 \\
\mu_{P i}(x)=1 & \text { se } & 2600<x \leq 2900 \\
\mu_{P i}(x)=0,005(3100-x) & \text { se } & 2900<x \leq 3100
\end{array}\right.
\end{aligned}
$$

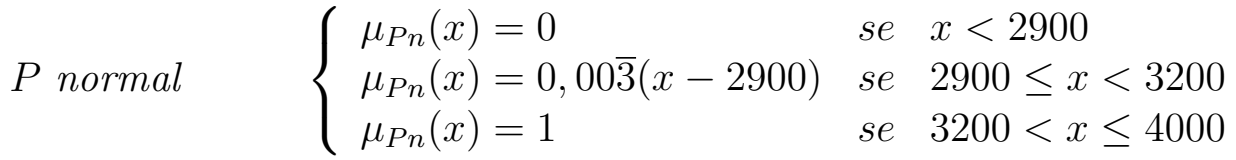


Idade gestacional:

$$
\begin{aligned}
& \text { IG muito pré-termo } \quad\left\{\begin{array}{clc}
\mu_{\text {IGmpt }}(x)=0 & \text { se } & x>32 \\
\mu_{\text {IGmpt }}(x)=0,25(32-x) & \text { se } & 28 \leq x<32 \\
\mu_{\text {IGmpt }}(x)=1 & \text { se } & x \leq 28
\end{array}\right. \\
& \text { IG pré-termo }\left\{\begin{array}{clc}
\mu_{\text {IGpt }}(x)=0 & \text { se } & x<29 \text { ou } x>37,5 \\
\mu_{\text {IGpt }}(x)=0, \overline{3}(x-29) & \text { se } & 29 \leq x<32 \\
\mu_{\text {IGpt }}(x)=1 & \text { se } & 32 \leq x \leq 34 \\
\mu_{\text {IGpt }}(x)=0,286(37,5-x) & \text { se } & 34<x \leq 37,5
\end{array}\right. \\
& I G \text { termo } \quad\left\{\begin{array}{ccc}
\mu_{I G t}(x)=0 & \text { se } & x<36 \\
\mu_{I G t}(x)=0,5(x-36) & \text { se } & 36 \leq x<38 \\
\mu_{I G t}(x)=1 & \text { se } & 38 \leq x \leq 42
\end{array}\right.
\end{aligned}
$$

O conjunto fuzzy de saída do modelo é o risco de morte neonatal, tendo sido considerados 4 conjuntos fuzzy para esta variável: muito baixo, baixo, pouco elevado e elevado.

$$
\begin{aligned}
& R \text { muito baixo } \quad\left\{\begin{array}{clc}
\mu_{R m b}(x)=0 & \text { se } & x<8 \\
\mu_{R m b}(x)=0,25(8-x) & \text { se } & 4 \leq x<8 \\
\mu_{R m b}(x)=1 & \text { se } 0<x \leq 4
\end{array}\right. \\
& R \text { baixo } \quad\left\{\begin{array}{ccc}
\mu_{R b}(x)=0 & \text { se } & x<6 \text { ou } x>22 \\
\mu_{R b}(x)=0,25(x-6) & \text { se } & 6 \leq x<10 \\
\mu_{R b}(x)=1 & \text { se } & 10 \leq x \leq 16 \\
\mu_{R b}(x)=0,1 \overline{6}(22-x) & \text { se } & 16<x \leq 22
\end{array}\right. \\
& R \text { pouco elevado }\left\{\begin{array}{ccc}
\mu_{\text {Rpe }}(x)=0 & \text { se } & x<18 \text { ou } x>55 \\
\mu_{\text {Rpe }}(x)=0,143(x-18) & \text { se } & 18 \leq x<25 \\
\mu_{\text {Rpe }}(x)=1 & \text { se } & 25 \leq x \leq 35 \\
\mu_{\text {Rpe }}(x)=0,05(55-x) & \text { se } & 35<x \leq 55
\end{array}\right. \\
& R \text { elevado } \quad\left\{\begin{array}{ccc}
\mu_{R e}(x)=0 & \text { se } & x<45 \\
\mu_{R e}(x)=0,0 \overline{6}(x-45) & \text { se } & 45 \leq x \leq 60 \\
\mu_{R e}(x)=1 & \text { se } & 60<x \leq 100
\end{array}\right.
\end{aligned}
$$

As figuras 7.7, 7.8 e 7.9 apresentam os conjuntos fuzzy para as variáveis peso, idade gestacional e risco de morte, respectivamente.

O especialista considerou relevantes as seguintes regras:

1) Se Peso é muito baixo E IG é muito pré-termo ENTÃO Risco é elevado

2) Se Peso é baixo E IG é muito pré-termo ENTÃO Risco é elevado 
7 Modelos lingüísticos fuzzy estáticos em biomedicina

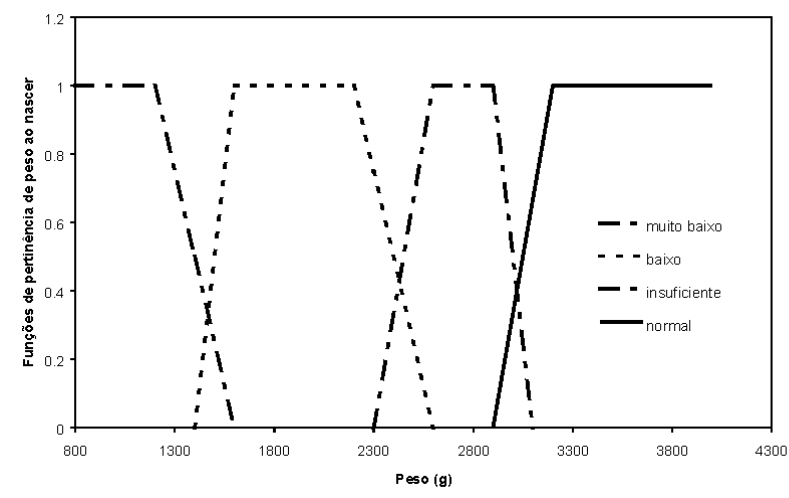

Figura 7.7: Conjuntos fuzzy para a variável lingüística Peso ao nascer.

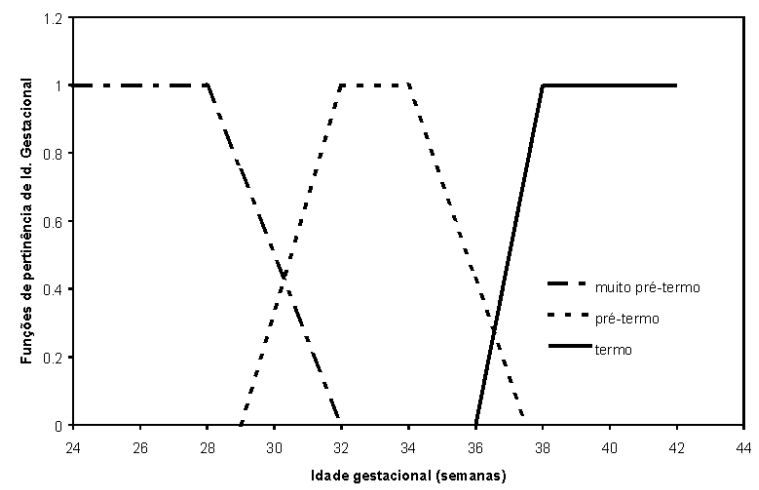

Figura 7.8: Conjuntos fuzzy para a variável lingüística Idade Gestacional.

3) Se Peso é muito baixo E IG é pré-termo ENTÃO Risco é elevado

4) Se Peso é baixo E IG é pré-termo ENTÃO Risco é pouco elevado

5) Se Peso é insuficiente E IG é pré-termo ENTÃO Risco é baixo

6) Se Peso é normal E IG é pré-termo ENTÃO Risco é baixo

7) Se Peso é muito baixo E IG é termo ENTÃO Risco é pouco elevado

8) Se Peso é baixo E IG é termo ENTÃO Risco é baixo

9) Se Peso é insuficiente E IG é termo ENTÃO Risco é muito baixo

10) Se Peso é normal E IG é termo ENTÃO Risco é muito baixo

A inferência utilizada foi o Mínimo de Mamdani e o método de defuzificação utilizado foi o do centro de área (MCA). A figura 7.10 mostra o resultado do mapeamento do sistema.A "região não consistente" nessa figura se refere a região de valores não possíveis ao problema, por exemplo: não é possível que uma criança com nascimento precoce (muito pré termo ou pré termo) apresente peso normal ao nascer.

A tabela 7.2 ilustra alguns dos resultados fornecidos pelo sistema e comparados com a opinião do especialista e a figura 7.11 apresenta a correlação entre esses valores. 


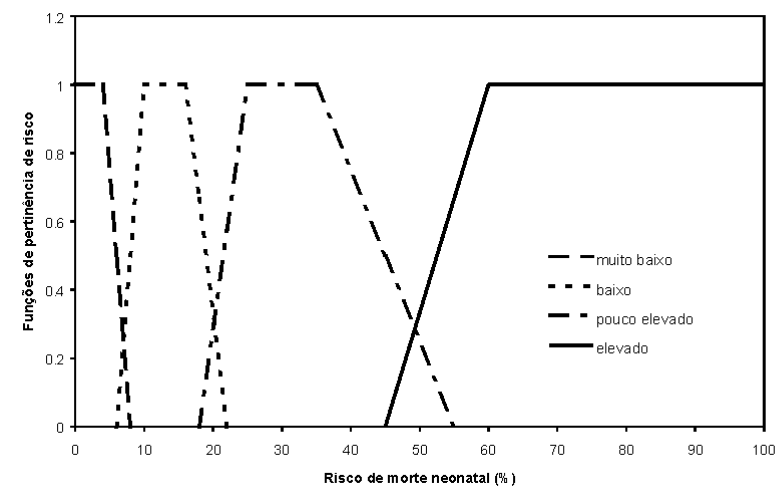

Figura 7.9: Conjuntos fuzzy para a variável lingüística Risco de morte neonatal.

Tabela 7.2: Alguns resultados do modelo para valores de peso e idade gestacional comparados com a opinião do especialista.

$\begin{array}{cccc}\text { Peso }(\mathrm{kg}) & I G \text { (semanas) } & \text { Respecialista (\%) } & \text { Rmodelo (\%) } \\ 1200 & 28 & 80 & 76 \\ 1500 & 30 & 75 & 65 \\ 2000 & 34 & 50 & 33 \\ 1600 & 36 & 50 & 35 \\ 2200 & 36 & 30 & 35 \\ 2000 & 38 & 15 & 13 \\ 2500 & 38 & 10 & 6 \\ 1500 & 36 & 40 & 50 \\ 3000 & 40 & 2 & 3 \\ 2800 & 39 & 4 & 4 \\ 2950 & 37 & 4 & 5 \\ 1500 & 32 & 50 & 47 \\ 2600 & 39 & 8 & 3 \\ 3500 & 40 & 3 & 3 \\ 800 & 29 & 80 & 76\end{array}$

Vemos da tabela que o modelo baseado em apenas duas variáveis mostrou-se robusto na predição da mortalidade neonatal quando compara-se os resultados do modelo e a expectativa dada pelo especialista. De fato, a associação entre os valores do modelo e do especialista foi $r=0,96$.

Este modelo pode ser aprimorado considerando outras variáveis importantes para avaliação do risco de morte neonatal, tais como a nota de apgar da criança, por exemplo. Esta análise de risco de morte neonatal pode ser útil também na estimativa de uso das instalações de UTI nos hospitais, assim como na estimativa do uso de eleitos e medicamentos, o que pode ser do interesse tanto da administração do hospital quanto das seguradoras de saúde. Um refinamento desse modelo objetiva também 


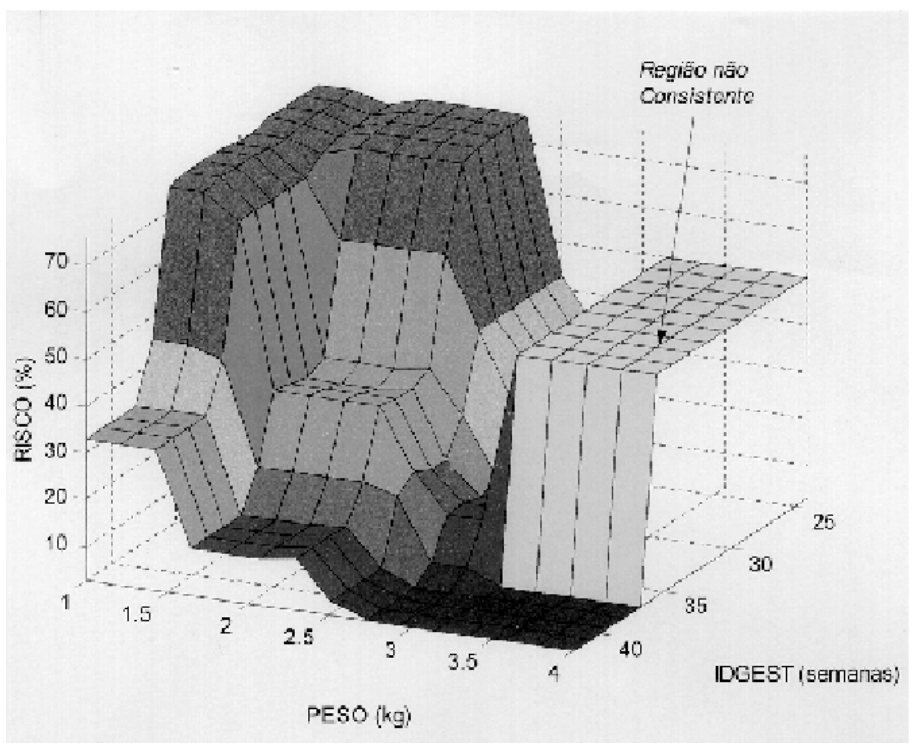

Figura 7.10: Superfície obtida pelo mapeamento realizado pelo modelo fuzzy para a estimativa de Risco de morte neonatal.

incluir variáveis do pré-natal para avaliarmos as chances de complicações no parto e no pós-parto, precavendo a necessidade de cuidados especiais para a mãe e o recémnascido. Outros trabalhos desse tipo serão apresentados no capítulo 10, quando serão discutidos os projetos em andamento efuturos.

\subsection{Discussão}

Embora os modelos aqui apresentados não tenham sido validados com dados experimentais, o que não seria possível no modelo para a progressão clínica para AIDS por questões éticas e humanitárias, nem para o modelo de estimador de risco de morte neonatal por não ser ele uma variável mensurável (vide observação na sessão 3.5), ambos os modelos ilustram a potencialidade dessa ferramenta na solução de problemas em biomedicina. De fato, ao trabalharmos com os especialistas, eles mesmos nos propõem outros caminhos e abordagens, aprimorando os modelos anteriores e buscando respostas a outras situações.

Uma vantagem da estimativa do risco de morte neonatal apresentada é que o valor fornecido pelo modelo não varia com o tempo, o que não acontece com a opinião do especialista. A depender do "estado de humor" do especialista o valor de risco pode ser mais positivo ou negativo, e sua resposta a uma dada circunstância hoje poderá ser diferente da resposta fornecida na semana anterior. Da mesma forma, este modelo evita a variabilidade de análise entre os diversos profissionais de saúde. Sendo o programa muito simples, ele pode ser facilmente implementado em qualquer micro computador sem maiores custos e com grande facilidade de manipulação pelo usuário. 


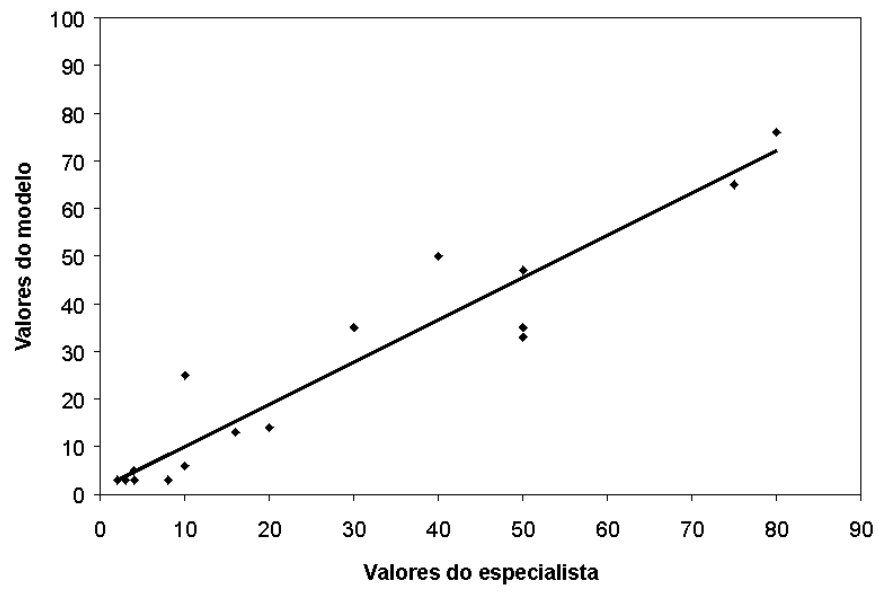

Figura 7.11: Associação entre os valores fornecidos pelo especialista e o modelo fuzzy, para a estimativa de Risco de morte neonatal.

Todavia, como dito anteriormente, este modelo será aprimorado.

Finalmente, os modelos lingüísticos fuzzy são facilmente compreendidos e aceitos pelos especialistas, não exigindo deles conhecimentos complexos nem profundos a cerca da teoria utilizada, o que torna a interdisciplinariedade factível neste caso. Esta é, sem dúvida alguma, uma das principais vantagens oferecidas pela teoria de lógica fuzzy na elaboração de modelos em biomedicina. 


\section{Capítulo 8}

\section{Modelos dinâmicos fuzzy em epidemiologia}

Os modelos dinâmicos convencionais para tratar problemas em epidemiologia são, em geral, modelos compartimentalizados, ou seja, são baseados em um conjunto de equações diferenciais que descrevem a dinâmica do sistema. Todavia, apesar desses modelos produzirem resultados interessantes e algumas vezes aplicáveis, eles não são capazes de lidar com as incertezas inerentes ao sistema quando elas existem, estejam elas relacionadas com as variáveis, as condições de contorno, os estados iniciais ou os valores dos parâmetros. Claramente, todo modelo consiste em uma interpretação e uma simplificação da realidade. Acontece, porém, que em algumas situações os modelos epidemiológicos clássicos figuram uma simplificação demasiada, resultando em dificuldades para serem validados. Portanto, uma abordagem alternativa possível seria combinar as técnicas de lógica fuzzy com as de sistemas dinâmicos não lineares. No entanto, como discutido na seção 1.6, esta área é muito incipiente e enfrenta dificudades teóricas sob vários aspectos, sendo ainda muito difícil produzir resultados práticos.

Neste contexto, os modelos lingüísticos performam uma possibilidade no tratamento da dinâmica de sistemas epidêmicos de forma mais realista. Foi no sentido de investigar esta possibilidade que desenvolvemos os modelos aqui apresentados. O primeiro modelo foi aplicado para descrever a dinâmica etária de cães soropositivos a raiva canina na Cidade de São Paulo. Neste caso, elaboramos duas abordagens de modelos lingüísticos: um modelo tipo TSK (Takagi-Sugeno-Kang) e um tipo Mamdani. O segundo modelo, um pouco mais complexo, buscou descrever a dinâmica de um sistema epidêmico tipo SIR (Suscetível-Infectado-Recuperado). Os resultados fornecidos pelos modelos fuzzy foram comparados com os produzidos a partir de modelos clássicos. 


\subsection{Modelo para raiva canina na cidade de São Paulo}

Um estudo sobre a distribuição de cães soropositivos a raiva canina foi realizado por Paulo Sallum e Eduardo Massad (Sallum et al 2000), na cidade de São Paulo. Neste trabalho foram analisadas as idades e sorologia de cães errantes e de cães da Polícia Militar, sendo a idade dos cães errantes determinada através da observação da dentição dos animais, entre outros fatores. Para avaliar a situação dessa epidemia os autores elaboraram um sistema dinâmico convencional, considerando a estacionariedade temporal e apenas dois estados idade-dependentes: animais soronegativos (não-vacinados ou sororevertidos), denotados por $S^{-}(a)$, e animais soropositivos (vacinados), denotados por $S^{+}(a)$. Sendo a raiva canina uma doença absolutamente letal o modelo considera a ausência de infecção subclínica, ou seja, os animais somente serão soropositivos através do contato vacinal. O sistema é considerado isolado e o modelo compartimentado possui, portanto, dois parâmetros: uma taxa de vacinação idade-dependente $v(a)$, com a qual os animais migram do estado $S^{-}(a)$ para o estado $S^{+}(a)$, e uma taxa idade-independente $\tau$ com a qual eles perdem a imunidade, retornando para o estado $S^{-}(a)$. Esse modelo dinâmico é descrito pelo seguinte sistema de equações diferenciais ordinárias:

$$
\frac{d S^{-}(a)}{d a}=-v(a) S^{-}(a)+\tau S^{+}(a)
$$

$\mathrm{e}$

$$
\frac{d S^{+}(a)}{d a}=v(a) S^{-}(a)-\tau S^{+}(a)
$$

Todavia, sendo o sistema isolado temos que:

$$
S^{+}(a)+S^{-}(a)=1
$$

e resolvendo o sistema de equações acima podemos obter a função que descreve a taxa de vacinação $v(a)$ :

$$
v(a)=\frac{\frac{d S^{+}(a)}{d a}+\tau S^{+}(a)}{1-S^{+}(a)} .
$$

A análise da amostra de cães errantes da Cidade de São Paulo forneceu os seguintes resultados (Sallum et al 2000):

Tabela 8.1: Soroprevalência da amostra de cães errantes. 
8 Modelos dinâmicos fuzzy em epidemiologia

$\begin{array}{ll}\text { Idade (anos) } & \text { Fração de Positivos } \\ 0.5 & 0.09 \\ 1.5 & 0.13 \\ 3.5 & 0.22 \\ 6.0 & 0.32\end{array}$

Cujo ajuste linear forneceu

$$
S^{+}(a)=0,04+0,0486 a,
$$

e a força de vacinação, expressa pela equação (8.4), resulta na expressão

$$
v(a)=\frac{(0,04+0,0486 a) \tau+0,0486}{1-(0,04+0,0486 a)} .
$$

A tabela 8.2 apresenta os resultados para os cães da polícia militar.

Tabela 8.2: Soroprevalência da amostra de cães da polícia militar.

$\begin{array}{ll}\text { Idade (anos) } & \text { Fração de Positivos } \\ 0.5 & 0.57 \\ 1.5 & 0.80 \\ 3.5 & 0.80 \\ 6.0 & 0.90\end{array}$

Cujo ajuste resultou na seguinte equação

$$
S^{+}(a)=0,9(1-\exp (-0,95 a)),
$$

onde a força de vacinação é expressa, a partir da equação (8.4), por:

$$
v(a)=\frac{0,86 \exp (-0,95 a)+0,9(1-\exp (-0,95 a)) \tau}{1-0,9(1-\exp (-0,95 a))} .
$$

A figura 8.1 mostra os dados experimentais para as amostras de cães errantes e de cães dapolícia militar.

O modelo fuzzy proposto é constituído por um conjunto de regras que busca reconstruir a dinâmica do sistema de forma a considerar a subjetividade das grandezas envolvidas. A construção das regras e os conjuntos fuzzy foram obtidos com o auxílio e o conhecimento empírico de um especialista.

A seguir é apresentado o primeiro modelo fuzzy para raiva canina que avaliamos. Trata-se de um modelo tipo TSK construído a partir de informações obtidas no modelo dinâmico clássico anterior e de um grande grau de subjetividade na escolha da função que desempenha o conseqüente das regras. Na sessão seguinte é apresentada uma outra abordagem deste mesmo problema, porém, considerando um modelo do tipo MISO, onde as saídas são agora conjuntos fuzzy. 


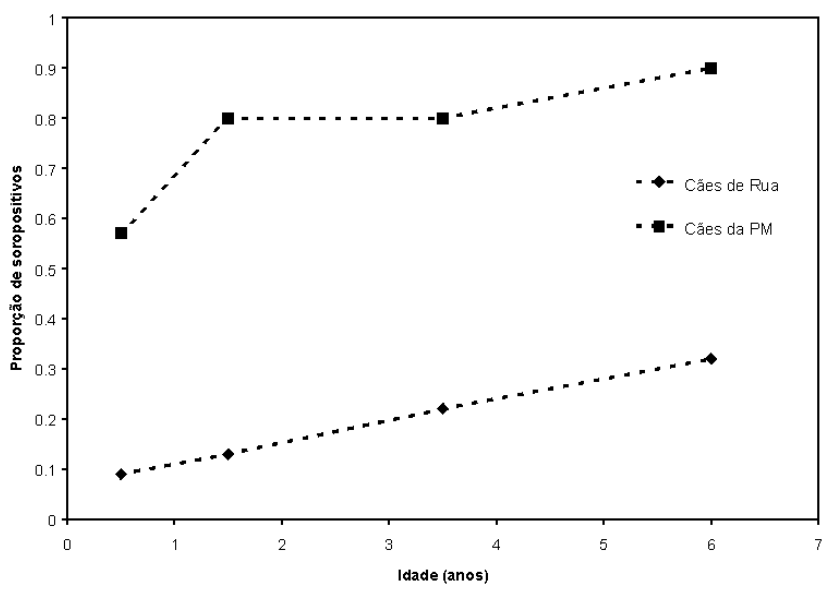

Figura 8.1: Dados experimentais para as amostras de cães errantes e de cães da polícia militar.

\section{Modelo dinâmico fuzzy tipo TSK}

Neste modelo consideramos três variáveis lingüísticas de entrada: $S$, que se refere aos animais soropositivoł 1 , que é a força de vacinação e $\Gamma$ que é dado pelo inverso do tempo de permanência no compartimento $S$. Cada variável lingüística é caracterizada por três conjuntos fuzzy, como apresentado abaixo:

\footnotetext{
${ }^{1}$ Daqui em diante, utilizaremos as letras maiúsculas para designar as variáveis lingüísticas fuzzy e as minúsculas para designar as variáveis clássicas. Assim, $S$ é a variável lingüística para a proporção de soropositivos e $s$ é o valor clássico dessa proporção. Ainda por simplicidade, denominaremos os soropositivos apenas por $s(a)$ e não mais por $s^{+}(a)$.
} 
$S(s)$ (proporção de animais soropositivos)

$$
\begin{array}{ll}
S \text { baixo } & \begin{cases}\mu_{S b}(x)=5 x & \text { se } 0 \leq x \leq 0.2 \\
\mu_{S b}(x)=-5(x-0.4) & \text { se } 0.2<x \leq 0.4 \\
\mu_{S b}(x)=0 & \text { se } x>0.4\end{cases} \\
S \text { médio } & \left\{\begin{array}{lll}
\mu_{S m}(x)=5(x-0.3) & \text { se } 0.3 \leq x \leq 0.5 \\
\mu_{S m}(x)=-5(x-0.7) & \text { se } 0.5<x \leq 0.7 \\
\mu_{S m}(x)=0 & \text { se } x<0.3, x>0.7
\end{array}\right. \\
S \text { grande } & \left\{\begin{array}{lll}
\mu_{S g}(x)=5(x-0.6) & \text { se } 0.6 \leq x \leq 0.8 \\
\mu_{S g}(x)=5(x-1.0) & \text { se } 0.8<x \leq 1.0 \\
\mu_{S g}(x)=0 & \text { se } x<0.3, x>0.7
\end{array}\right.
\end{array}
$$


$V(\nu)$ (força de vacinação)

$$
\begin{array}{ll}
V \text { fraco } & \begin{cases}\mu_{V f}(x)=2.2 \overline{2}(x-0.05) & \text { se } 0.05 \leq x \leq 0.5 \\
\mu_{V f}(x)=-3 . \overline{3}(x-0.8) & \text { se } 0.5<x \leq 0.8 \\
\mu_{V f}(x)=0 & \text { se } x>0.4\end{cases} \\
V \text { médio } & \begin{cases}\mu_{V m}(x)=1.6 \overline{6}(x-0.6) & \text { se } 0.6 \leq x \leq 1.2 \\
\mu_{V m}(x)=-1.25(x-2.0) & \text { se } 1.2<x \leq 2.0 \\
\mu_{V m}(x)=0 & \text { se } x<6.0, x>1.2\end{cases} \\
V \text { forte } & \left\{\begin{array}{lll}
\mu_{V f o}(x)=x-1.0 & \text { se } 1.0 \leq x \leq 2.0 \\
\mu_{V f o}(x)=-1(x-3.0) & \text { se } 2.0<x \leq 3.0 \\
\mu_{V f o}(x)=0 & \text { se } x<1.0, x>3.0
\end{array}\right.
\end{array}
$$

$\Gamma(\tau)$ ( inverso do tempo de permanência como soropositivo)

$$
\begin{array}{ll}
\text { Г curto } & \left\{\begin{array}{lll}
\mu_{\Gamma c}(x)=10(x-0.3) & \text { se } 0.3 \leq x \leq 0.4 \\
\mu_{\Gamma c}(x)=-10(x-0.5) & \text { se } 0.4<x \leq 0.5 \\
\mu_{\Gamma c}(x)=0 & \text { se } x<0.3, x>0.5
\end{array}\right. \\
\Gamma \text { médio } & \left\{\begin{array}{lll}
\mu_{\Gamma m}(x)=3.3 \overline{3}(x-0.4) & \text { se } 0.4 \leq x \leq 0.7 \\
\mu_{\Gamma m}(x)=-3.3 \overline{3}(x-1.0) & \text { se } 0.7<x \leq 1.0 \\
\mu_{\Gamma m}(x)=0 & \text { se } x<0.4, x>1.0
\end{array}\right. \\
\Gamma \text { longo } & \left\{\begin{array}{lll}
\mu_{\Gamma l}(x)=1.43(x-0.5) \\
\mu_{\Gamma l}(x)=-1.25(x-2.0) \\
\mu_{\Gamma l}(x)=0 & \text { se } 0.5 \leq x \leq 1.2
\end{array}\right.
\end{array}
$$

Combinando os diversos conjuntos fuzzy de $S, V$ e $\Gamma$ de forma coerente elaboramos 19 regras cujo conseqüente foi inspirado na discretização da equação (8.2), dada por:

$$
\Delta s=v(a)(1-s(a))-\tau s(a) .
$$

Nestes termos, o conseqüente utilizado para cada regra foi:

$$
\Delta s_{i}=\mu_{V_{i}}(\nu) v(a)\left[1-\mu_{S_{i}}(s) s(a)\right]-\mu_{\Gamma_{i}}(\tau) \tau \mu_{S_{i}}(s) s(a),
$$

onde $\mu_{V_{i}}(\nu)$ é o grau de pertinência no conjunto fuzzy da força de vacinação na $i-$ ésima regra, $\mu_{S_{i}}(s)$ é o grau de pertinência no conjunto fuzzy da proporção de cães soropositivos e $\mu_{\Gamma_{i}}(\tau)$ é o grau de pertinência no conjunto fuzzy da taxa de perda de anticorpos. Note que a equação (8.10) proposta para ser o conseqüente da regra é uma inspiração. Na verdade, não existe nenhuma informação funcional sobre como estas variáveis se relacionam entre si. Como será discutido mais adiante, esta ausência de 
informação funcional é o que torna difícil a elaboração de modelos do tipo TSK em epidemiologia.

Considerando o conseqüente proposto, temos que cada regra fuzzy apresenta a seguinte estrutura:

$\mathrm{SE} S$ é baixo $\boldsymbol{E} V$ é fraco $\boldsymbol{E} \Gamma$ é curto

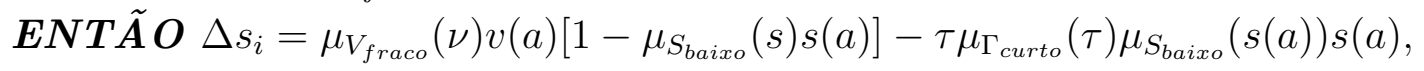

onde $\Delta s_{i}$ é o incremento de $s$ de acordo com a regra $i$. É importante perceber que $\Delta s_{i}$ é, neste caso, um número e não um conjunto fuzzy.

O conjunto de regras considerado foi:

1) $S$ grande, $\Gamma$ curto, $V$ médio;

2) $S$ grande, $\Gamma$ médio, $V$ médio;

3) $S$ grande, $\Gamma$ longo, $V$ forte;

4) $S$ grande, $\Gamma$ curto, $V$ forte;

5) $S$ médio, $\Gamma$ curto; $V$ médio;

6) $S$ médio, $\Gamma$ curto; $V$ fraco;

7) $S$ médio, $\Gamma$ médio; $V$ médio;

8) $S$ médio, $\Gamma$ longo; $V$ médio;

9) $S$ médio, $\Gamma$ longo; $V$ forte;

10) $S$ médio, $\Gamma$ longo; $V$ fraco;

11) $S$ médio, $\Gamma$ curto; $V$ forte;

12) $S$ pequeno, $\Gamma$ longo; $V$ fraco;

13) $S$ pequeno, $\Gamma$ curto; $V$ fraco;

14) $S$ pequeno, $\Gamma$ curto; $V$ forte;

15) $S$ pequeno, $\Gamma$ médio; $V$ fraco;

16) $S$ pequeno, $\Gamma$ médio; $V$ médio;

17) $S$ pequeno, $\Gamma$ longo; $V$ médio;

18) $S$ pequeno, $\Gamma$ longo; $V$ forte;

19) $S$ pequeno, $\Gamma$ curto; $V$ médio;

Após o sistema percorrer todas as regras o valor numérico final de $\Delta s$ é dado por uma ponderação dos valores $\Delta s_{i}$ pelo $d o f_{i}$, que é uma medida da importância da i-ésima regra, como segue:

$$
\Delta s=\frac{\sum_{i=1}^{19} d o f_{i} \Delta s_{i}}{\sum_{i=1}^{19} d o f_{i}}
$$

e, finalmente, temos que

$$
s(a+1)=s(a)+\Delta s .
$$

A força de vacinação foi atualizada a partir de um ajuste linear dos dados experimentais, ou seja, $v(a)$ foi calculado para diferentes idades utilizando-se a equação 
obtida com o ajuste, sendo o sistema alimentado com estes valores. Os resultados fornecidos pelo modelo para o caso dos cães errantes e dos cães da PM, considerando $\tau=0,33$ em ambos os casos, são apresentados nas figura 8.2 e 8.3, respectivamente.

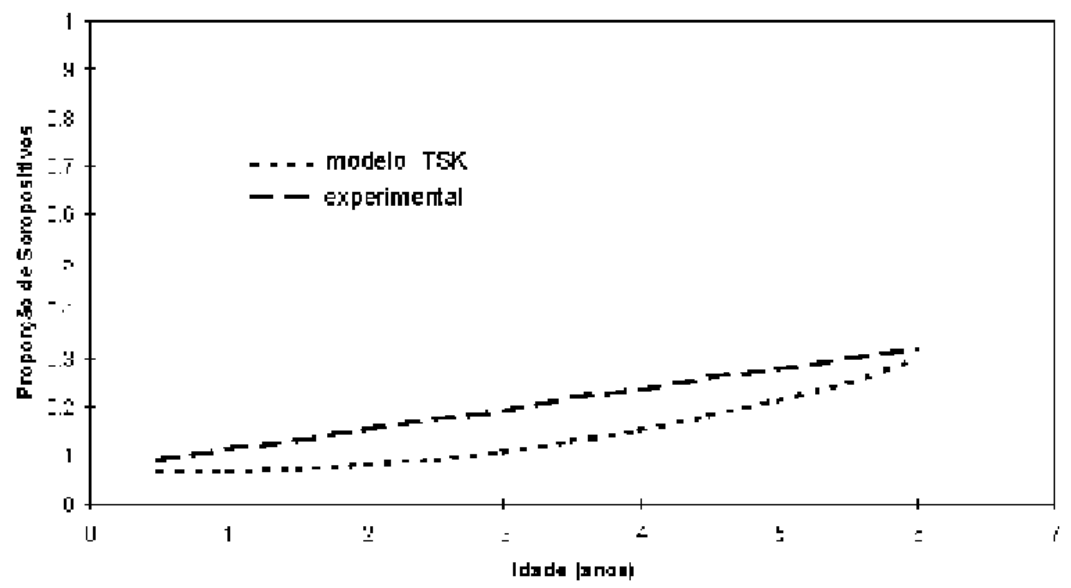

Figura 8.2: Resultados fornecidos pelo modelo TSK para o caso dos cães errantes, considerando $\tau=0,33$.

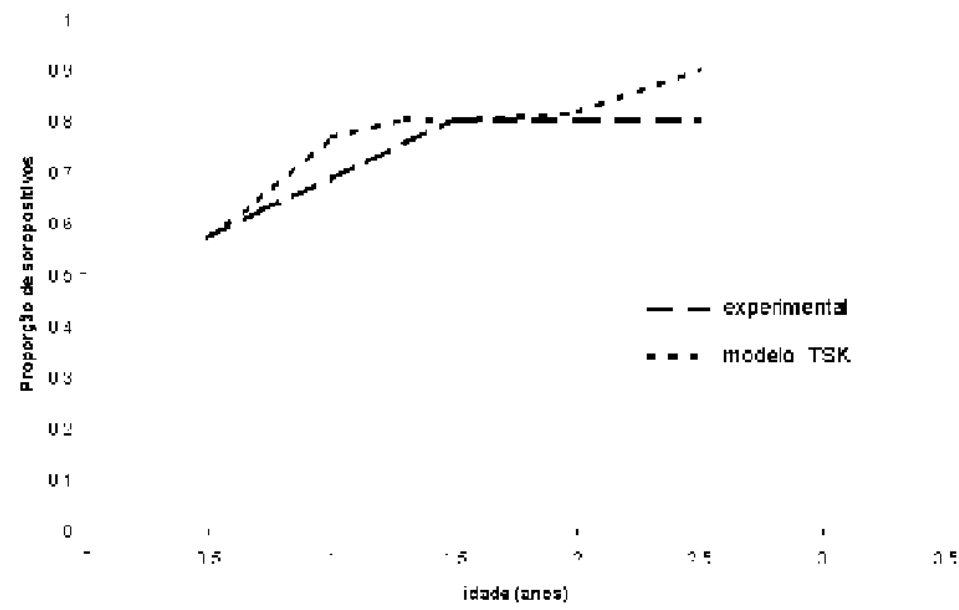

Figura 8.3: Resultados fornecidos pelo modelo TSK para o caso dos cães da Polícia Miitar, considerando $\tau=0,33$.

Os valores obtidos pelo modelo para o caso dos cães errantes foram bastante razoáveis, na verdade animadores. No entanto, não podemos dizer o mesmo para o caso dos cães da PM. De fato, um ajuste linear dos valores experimentais, neste caso, não é uma forma adequada para se obter informação sobre a atualização de $v(a)$, uma vez que os dados são claramente não lineares. Todavia, outras tentativas foram realizadas, inclusive considerando a equação fornecida pelo modelo clássico, e todas apresentaram resultados piores do que os obtidos com o ajuste linear. Além disso, o modelo 
8 Modelos dinâmicos fuzzy em epidemiologia

não se mostrou robusto para o caso dos cães da PM, ou seja, dois ajustes lineares muito semelhantes forneceram comportamentos dinâmicos completamente distintos, caracterizando a inadequabilidade da função proposta como conseqüente das regras. Concluímos, então, que a equação (8.10) proposta para o $\Delta s$ não é conveniente para descrever a dinâmica do sistema.

É importante ressaltar que toda a nossa dificuldade para elaboração de modelos desse tipo consiste no fato de não termos meios de equacionar $\Delta s$, pois não temos informações sobre a evolução do sistema (seus funcionais, suas leis naturais). Neste sentido as aplicações de lógica fuzzy em epidemiologia que desejamos realizar é muito diferente das aplicações fuzzy mais usuais, como em sistemas de controle, nas quais o pequisador sabe qual é o produto final que pretende obter e, a partir das informações que possui, procura "calibrar" o modelo como num processo de refinamento, até obter o "produto" desejado. De fato, uma carcaterística importante dos modelos fuzzy é que, em geral, eles são elaborados através de tentativa e erro.

Os modelos do tipo TSK são muito interessantes na medida em que podemos agregar ao conjunto de regras fuzzy o conhecimento existente sobre a dinâmica do sistema, sendo o modelo menos dependente das informações fornecidas pelo especialista. Todavia, este conhecimento à priori sobre o comportamento do sistema é pouco comum em problemas de epidemiologia, o que torna os nossos modelos completamente baseados no conhecimento dos especialistas. Por estas razões, decidimos elaborar um modelo do tipo MISO, que consiste numa proposta menos audaciosa, cujos conseqüentes são também estruturados como conjuntos fuzzy.

\section{Modelo Dinâmico Fuzzy tipo MISO}

Neste modelo associamos à cada situação abordada pelas regras um conseqüente $\Delta S$ que o especialista julgava adequado, sempre pensando no $\Delta S$ como sendo uma proporção do número de soropositivos. Sendo assim, tomemos como exemplo a situação descrita na regra (1) dada na sessão anterior:

$$
S \text { grande, } \Gamma \text { curto, } V \text { médio. }
$$

Neste caso dizemos que a variação de animais no grupo de soropositivos esperada é muito pequena, ou seja, o especialista não espera que dadas as condições descritas na regra acima a proporção de animais soropositivos na próxima idade considerada, 6 meses neste caso, cresça consideravelmente. Assim, analisando as situações descritas pelas regras construimos uma variável lingüística caracterizada por cinco termos lingüísticos que expressam a sensibilidade do especialista para os valores de $\Delta S$. Os conjuntos fuzzy considerados foram: 
$\Delta$ Smuito pequeno $\quad \begin{cases}\mu_{\Delta S m p}(x)=20 x & \text { se } 0 \leq x \leq 0.05 \\ \mu_{\Delta S m p}(x)=-20(x-0.1) & \text { se } 0.05<x \leq 0.1 \\ \mu_{\Delta S m p}(x)=0 & \text { se } x>0.1\end{cases}$

$\Delta$ Spequeno

$$
\begin{cases}\mu_{\Delta S p}(x)=20(x-0.05) & \text { se } 0.05 \leq x \leq 0.1 \\ \mu_{\Delta S p}(x)=-20(x-0.15) & \text { se } 0.1<x \leq 0.15 \\ \mu_{\Delta S p}(x)=0 & \text { se } x<0.05, x>0.15\end{cases}
$$

$\Delta$ Snulo

$$
\left\{\begin{array}{lll}
\mu_{\Delta S n}(x)=1 & \text { se } & x=0 \\
\mu_{\Delta S n}(x)=0 & \text { se } & x \neq 0
\end{array}\right.
$$

$\Delta S m e ́ d i o$

$$
\begin{cases}\mu_{\Delta S m}(x)=20(x-0.12) & \text { se } 0.12 \leq x \leq 0.17 \\ \mu_{\Delta S m}(x)=-12.5(x-0.25) & \text { se } 0.17<x \leq 0.25 \\ \mu_{\Delta S m}(x)=0 & \text { se } x<0.12, x>0.25\end{cases}
$$

$\Delta$ Sgrande

$$
\begin{cases}\mu_{\Delta S m p}(x)=14.29(x-0.2) & \text { se } 0.2 \leq x \leq 0.27 \\ \mu_{\Delta S m p}(x)=1 & \text { se } 0.27<x \leq 0.32 \\ \mu_{\Delta S m p}(x)=0 & \text { se } x<0.2, x>0.32\end{cases}
$$

Note que a diferença básica entre os modelos TSK e MISO é que no segundo caso a saída da regra é também um conjunto fuzzy. O método de inferência utilizado foi o Mínimo de Mamdani, que fornece um conjunto fuzzy como resposta final. A saída clássica foi obtida através da defuzificação desse conjunto fuzzy de saída através do método das alturas (MA) de defuzificação, apresentado na seção 3.4.

O conjunto de regras fuzzy utilizado neste modelo foi:

1) SE $S$ grande, $\Gamma$ curto, $V$ médio ENTÃO $\triangle S$ é Muito Pequeno

2) $S E S$ grande, $\Gamma$ médio, $V$ médio ENTÃO $\Delta S$ é Muito Pequeno;

3) $S E S$ grande, $\Gamma$ longo, $V$ forte ENTÃO $\Delta S$ é Nulo;

4) $S E S$ grande, $\Gamma$ curto, $V$ forte ENTÃO $\triangle S$ é Nulo;

5) $S E S$ médio, $\Gamma$ curto; $V$ médio ENTÃO $\Delta S$ é Pequeno;

6) $S E S$ médio, $\Gamma$ curto; $V$ fraco ENTÃO $\Delta S$ é Pequeno;

7) $S E S$ médio, $\Gamma$ médio; $V$ médio ENTÃO $\Delta S$ é Pequeno;

8) $S E S$ médio, $\Gamma$ longo; $V$ médio ENTÃO $\Delta S$ é Muito Pequeno;

9) $S E S$ médio, $\Gamma$ longo; $V$ forte ENTÃO $\triangle S$ é Nulo;

10) SE $S$ médio, $\Gamma$ longo; $V$ fraco ENTÃO $\Delta S$ é Muito Pequeno;

11) SE $S$ médio, $\Gamma$ curto; $V$ forte ENTÃO $\Delta S$ é Médio;

12) $S E S$ pequeno, $\Gamma$ longo; $V$ fraco ENTÃO $\triangle S$ é Nulo;

13) SE $S$ pequeno, $\Gamma$ curto; $V$ fraco ENTÃO $\triangle S$ é Muito Pequeno;

14) $S E S$ pequeno, $\Gamma$ curto; $V$ forte ENTÃO $\Delta S$ é Grande;

15) SE $S$ pequeno, $\Gamma$ médio; $V$ fraco ENTÃO $\triangle S$ é Nulo;

16) $S E S$ pequeno, $\Gamma$ médio; $V$ médio ENTÃO $\Delta S$ é Pequeno;

17) SE $S$ pequeno, $\Gamma$ longo; $V$ médio ENTÃO $\Delta S$ é Muito Pequeno; 
18) SE $S$ pequeno, $\Gamma$ longo; $V$ forte ENTÃO $\Delta S$ é Médio;

19) SE $S$ pequeno, $\Gamma$ curto; $V$ médio ENTÃO $\Delta S$ é Pequeno;

Como no modelo TSK, atualizamos a força de vacinação $v(a)$ de diversas formas mantendo em todas elas o tempo de imunização, $\tau=0,33$, constante. A figura 8.4 apresenta os resultados obtidos, para o caso dos cães errantes, segundo: a) v(a) é atualizado a partir da equação (8.9), b) $v(a)=0,12$ é mantido fixo e c) $v(a)$ é atualizado a partir do ajuste linear dado pela equação (8.6). Podemos notar que esse modelo não é sensível a pequenas alterações nos valores de $v(a)$, isto se deve ao tipo de estrutura do modelo. Uma vez que os diversos procedimentos de atualização de $v(a)$ resultam em valores de $s(a)$ muito semelhantes adotaremos então a força de vacinação como variável idade-independente, $v$.

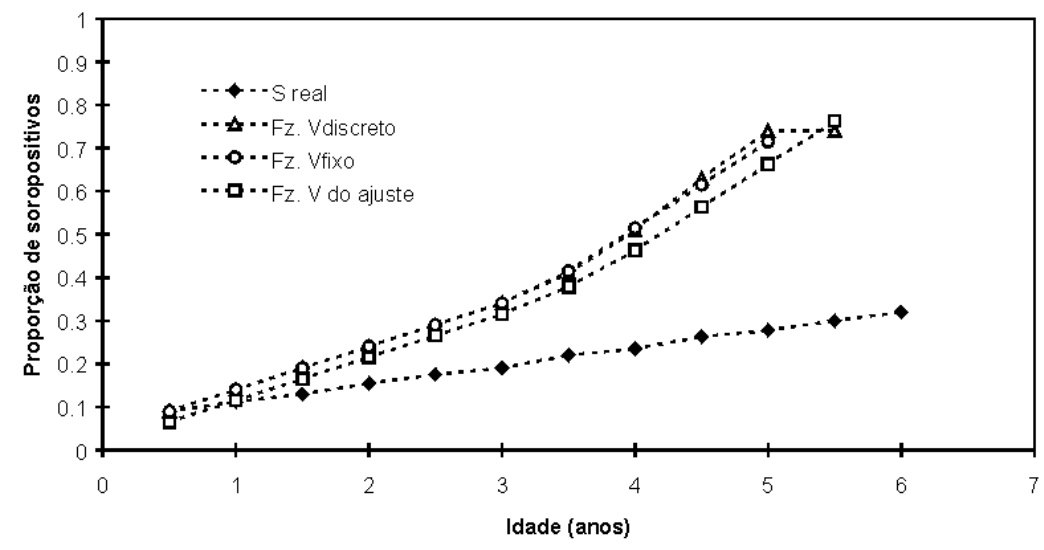

Figura 8.4: Resultados obtidos com o modelo MISO $\operatorname{com} \tau=0,33$ constante e $v(a)$ atualizado por diversos métodos, para o caso dos cães errantes.

Uma vez que os cães errantes são, em geral, imunizados quando alguém coleta o cão e o encaminha para a vacinação (adoção temporária de cães de rua) não é esperado que a força de vacinação, para o caso desses cães, seja forte. Sendo assim, fixamos $v=0,12$, que corresponde nos nossos conjuntos fuzzy a uma força de vacinação fraca e, variamos o valor de $\tau$ objetivando obter o tempo de permanência dos cães errantes enquanto protegidos. A figura 8.5 apresenta os resultados obtidos mostrando-nos que para este modelo o melhor valor de $\tau$ é 0,49 , correspondendo a 2, 04 anos de proteção o que, segundo o conhecimento disponível quanto as vacinas utilizadas nas campanhas contra a raiva canina, é bastante razoável.

Assumindo então que $\tau=0,49$ variamos o valor do parâmetro força de vacinação, procurando obter o melhor valor de $v(a)$. A figura 8.6 mostra-nos que, de fato, a força de vacinação é fraca fornecendo-nos $v(a)=0,12$. 


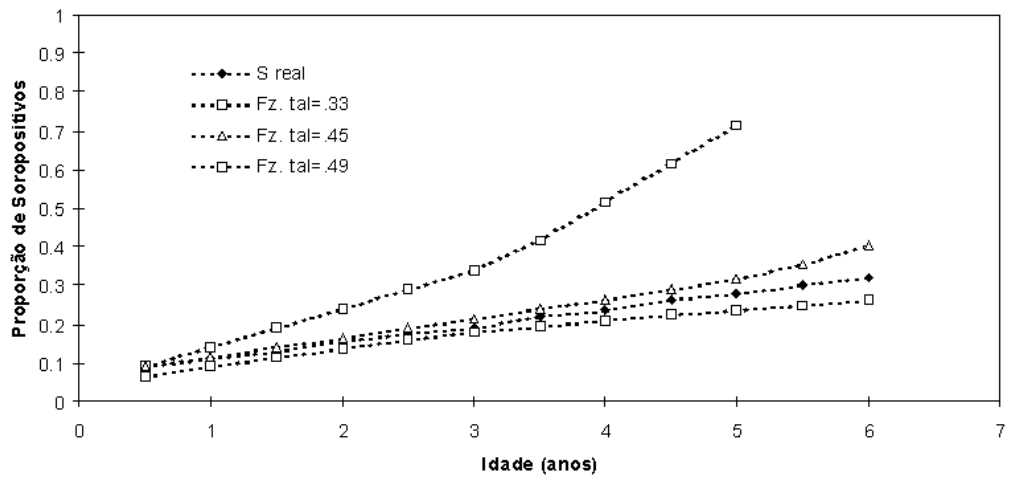

Figura 8.5: Resultados obtidos com o modelo MISO com $v=0,12$ constante e variando o valor de $\tau$, para o caso dos cães errantes.

A figura 8.7 apresenta a correlação entre os resultados obtidos pelo modelo e os dados experimentais, com os valores $\tau=0,49$ e $v=0,12$, onde a reta representa a curva de tendência. Esta figura nos revela que o modelo MISO foi capaz de descrever a dinâmica do sistema satisfatoriamente para o caso dos cães errantes.

A realidade dos cães da Polícia militar é completamente diferente da dos cães de rua. Uma vez que os primeiros são registrados, alimentados adequadamente, cuidados por especialistas e vacinados rotineiramente, é esperado que o tempo com que os cães permanecem protegidos seja razoavelmente longo, da mesma forma que a força de vacinação deve se apresentar forte. Sendo assim, fixamos o valor de $\tau=0,33$, o que corresponde a 3,03 anos de proteção, e variamos o valor de $v$. A figura 8.8 apresenta as curvas obtidas revelando-nos $v=1,2$ como mais adequado.

Como no caso dos cães de rua, fixamos o valor de $v=1,2$ e variamos o valor de $\tau$ para, dessa forma, encontrar o valor desejado. A figura 8.9 apresenta os resultados obtidos mostrando-nos que o tempo de permanência dos cães da PM no grupo dos soropositivos é de 0,31, o que corresponde a 3,23 anos de proteção. Portanto, para este caso, o modelo nos forneceu, após defuzificação, valores clássicos que revelam uma forte força de vacinação e um longo período de proteção, o que é completamente satisfatório na realidade dos cães da Polícia Militar. A figura 8.10 que ilustra a correlação entre os valores gerados pelo modelo e os dados experimentais.

Temos, portanto, que o modelo baseado no especialista foi capaz de descrever de forma satisfatória a dinâmica registrada pelos dados experimentais. As figuras 8.11 e 8.12 apresentam os dados experimentais confrontados com os valores gerados pelo modelo MISO e pelo modelo clássico descrito anteriormente, para os cães errantes e da PM, respectivamente. Podemos notar que, embora neste caso o modelo clássico forneça bons resultados, o modelo MISO se aproxima mais dos valores experimentais, o que pode resultar em um maior poder preditivo.

No sentido de estudar um sistema dinâmico fuzzy mais complexo e compará-lo 


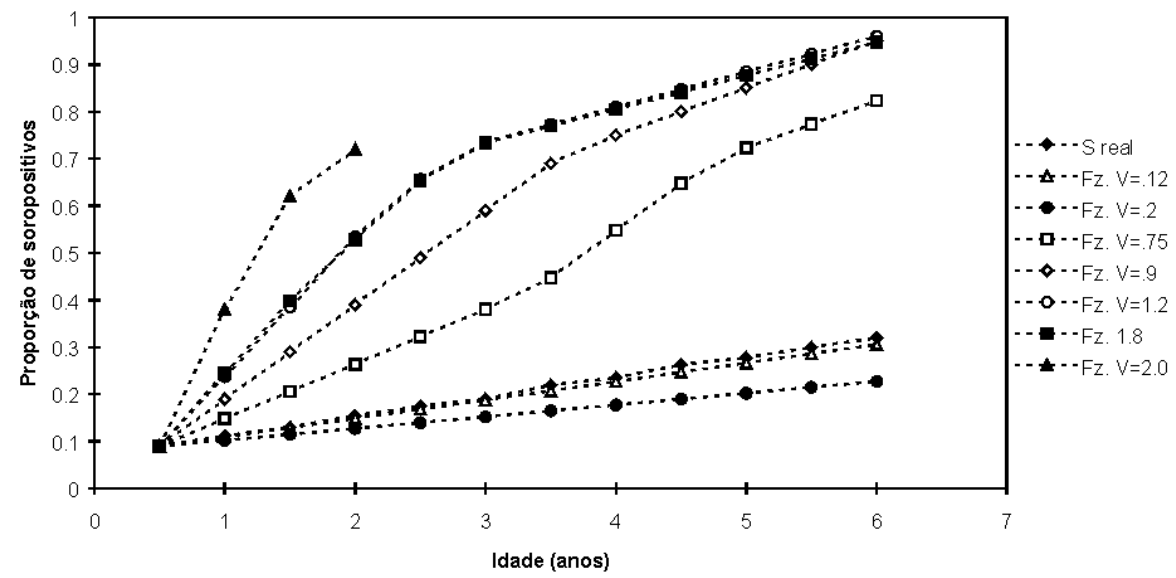

Figura 8.6: Resultados obtidos com o modelo MISO $\operatorname{com} \tau=0,49$ constante e variando o valor de $v$, para o caso dos cães errantes.

com a abordagem clássica, elaboramos um outro modelo linguístico, com múltiplas entradas e múltiplas saídas (MIMO), e comparamos os resultados com um conjunto de três equações diferenciais não lineares.

\subsection{Modelo MIMO para um sistema epidêmico ti- po SIR}

Neste caso nós consideramos o modelo clássico compartimentado do tipo SIR ( $A n$ derson $\&$ May 1991, Massad et al 1995) usado para descrever o desenvolvimento de uma infecção microparasítica típica, assim como o sarampo, quando uma campanha de vacinação é implementada. Este modelo é constituido pelo seguinte conjunto de equações diferenciais não-lineares:

$$
\begin{gathered}
\frac{d s}{d t}=\alpha n-\alpha s-\beta s i-v s \\
\frac{d i}{d t}=-\alpha i+\beta s i-\gamma i \\
\frac{d r}{d t}=\gamma i-\alpha r+v s
\end{gathered}
$$

onde $s$ é a proporção de indivíduos suscetíveis, $i$ é a proporção de indivíduos infectados e $r$ é a proporção de indivíduos recuperados. O modelo tem quatro parâmetros: $\alpha$ é a taxa de mortalidade natural da população, $\beta$ é a taxa de contato infectivo entre indivíduos suscetíveis e infectados, $\nu$ é a força de vacinação e $\gamma$ é a taxa com que os 


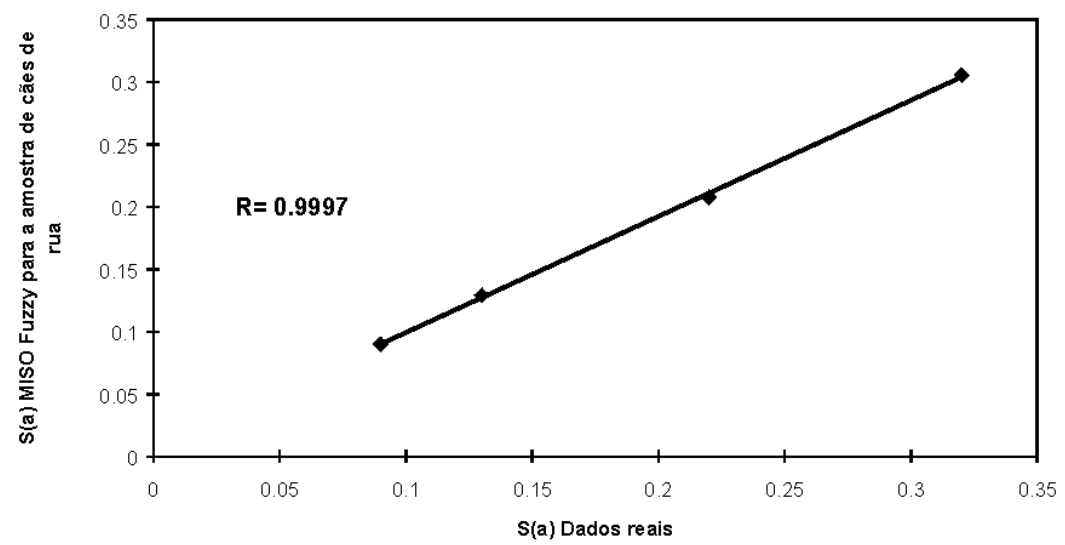

Figura 8.7: Correlação entre os resultados obtidos pelo modelo MISO e os dados experimentais, com os valores $\tau=0,49$ e $v=0,12$, para o caso dos cães errantes.

indivíduos doentes se recuperam. O número total de indivíduos é mantido fixo, ou seja, $n=s+i+r$, o que reduz o conjunto de equações diferenciais acima a duas equações.

No sentido de estudar o comportamento dinâmico deste modelo nós atribuimos va-lores para os parâmetros do modelo baseado na situação real da endemia de sarampo na cidade de São Paulo e simulamos numericamente o conjunto de equações diferenciais acima para vários valores destes parâmetros. Nós analisamos as diversas situações simuladas no modelo clássico para construirmos os nossos conjuntos fuzzy. A figura 8.13 apresenta o comportamento típico das proporções $s, i$ e $r$.

No modelo fuzzy MIMO foi considerado quatro variáveis lingüísticas de entrada e duas variáveis de saída: a taxa de contato infectivo, $B$, a força de vacinação, $V$, a proporção de suscetíveis, $S$, e a proporção de indivíduos infectados, $I$, como antecedentes das regras e a variação da proporção de $S, \Delta S$, e a variação da proporção de $I, \Delta I$, como os conseqüentes. Nós consideramos as seguintes funções de pertinência para os antecedentes: 


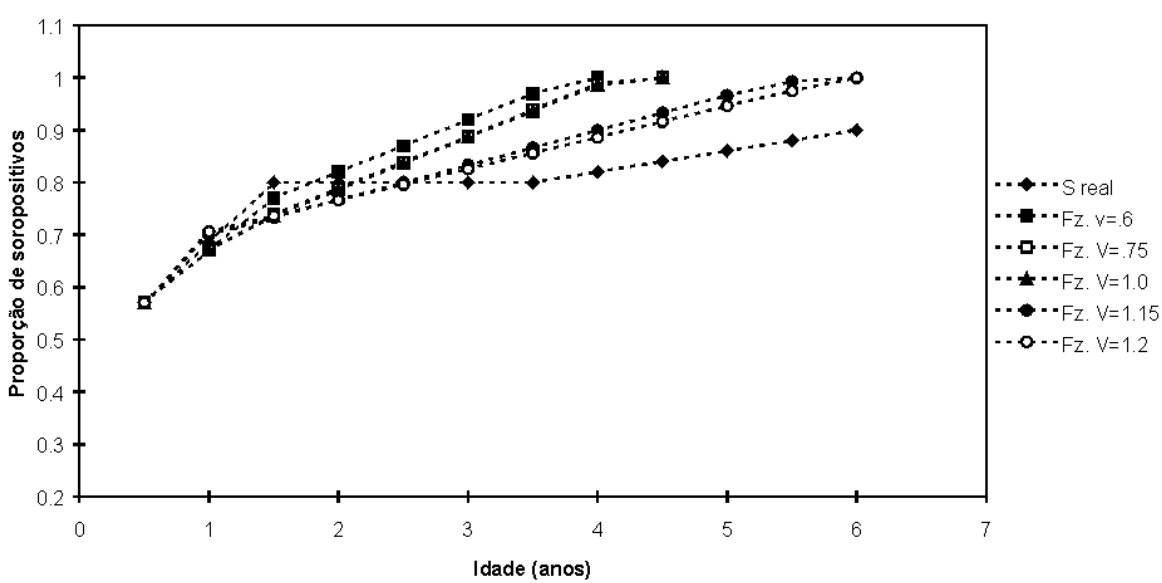

Figura 8.8: Resultados obtidos com o modelo MISO $\operatorname{com} \tau=0,33$ constante e variando o valor de $v$, para o caso dos cães da PM.

$B$ : a taxa de contato infectivo.

$\begin{array}{ll}B \text { pequena } & \begin{cases}\mu_{B p}(x)=1.0 & \text { se } 1.0003 \leq x \leq 2.0 \\ \mu_{B p}(x)=-1.0(x-3.0) & \text { se } 2.0<x \leq 3.0 \\ \mu_{B p}(x)=0 & \text { se } x<1.0003, x>3.0\end{cases} \\ B \text { média } & \begin{cases}\mu_{B m}(x)=0.2(x-2.0) & \text { se } 2.0 \leq x \leq 7.0 \\ \mu_{B m}(x)=-0 . \overline{3}(x-10.0) & \text { se } 7.0<x \leq 10.0 \\ \mu_{B m}(x)=0 & \text { se } x<2.0, x>10.0\end{cases} \\ B \text { grande } & \left\{\begin{array}{lll}\mu_{B g}(x)=0.08 \overline{3}(x-8.0) & \text { se } 8.0 \leq x \leq 20.0 \\ \mu_{B g}(x)=-0.1(x-30.0) & \text { se } 20.0<x \leq 30.0 \\ \mu_{B g}(x)=0 & \text { se } x<8.0, x>30.0\end{array}\right. \\ B \text { muito grande } & \left\{\begin{array}{lll}\mu_{B m g}(x)=0.04(x-25.0) & \text { se } 25.0 \leq x \leq 50.0 \\ \mu_{B m g}(x)=1.0 & \text { se } 50.0<x \leq 100.0 \\ \mu_{B m g}(x)=0 & \text { se } x<25.0, x>100.0\end{array}\right.\end{array}$




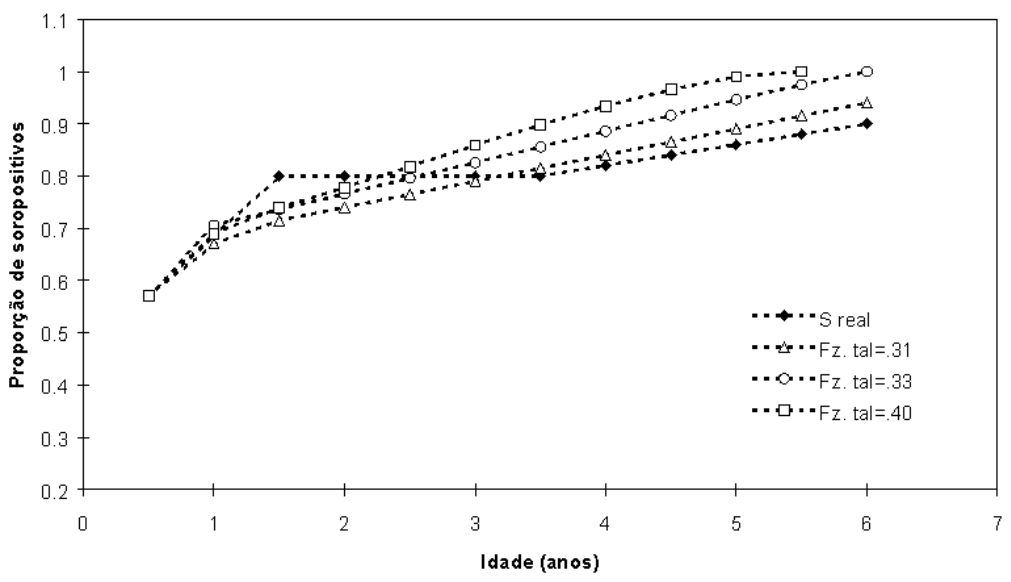

Figura 8.9: Resultados obtidos com o modelo MISO com $v=1,2$ constante e variando o valor de $\tau$, para o caso dos cães da PM.

$V$ : a força de vacinação.

$$
\begin{array}{ll}
V \text { fraca } & \begin{cases}\mu_{V f}(x)=1.0 & \text { se } 0.0 \leq x \leq 0.01 \\
\mu_{V f}(x)=-50.0(x-0.03) & \text { se } 0.01<x \leq 0.03 \\
\mu_{V f}(x)=0 & \text { se } x>0.03\end{cases} \\
V \text { média } & \begin{cases}\mu_{V m}(x)=20.0(x-0.02) & \text { se } 0.02 \leq x \leq 0.07 \\
\mu_{V m}(x)=-33 . \overline{3}(x-0.10) & \text { se } 0.07<x \leq 0.10 \\
\mu_{V m}(x)=0 & \text { se } x<0.02, x>0.10\end{cases} \\
V \text { forte } & \begin{cases}\mu_{V f o}(x)=4.0(x-0.05) & \text { se } 0.05 \leq x \leq 0.30 \\
\mu_{V f o}(x)=1.0 & \text { se } 0.30<x \leq 1.00 \\
\mu_{V f o}(x)=0 & \text { se } x<0.05, x>1.0\end{cases}
\end{array}
$$




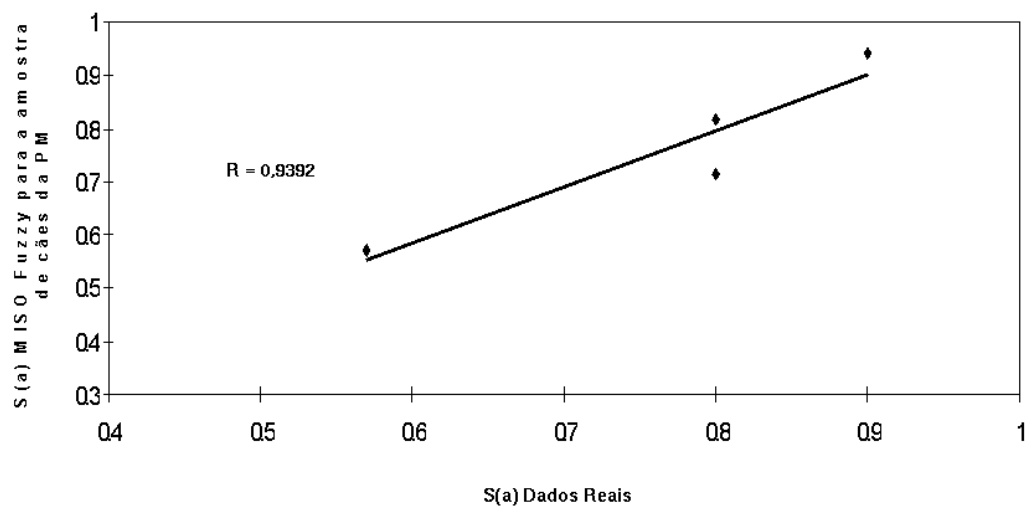

Figura 8.10: Correlação entre os resultados obtidos pelo modelo MISO e os dados experimentais, com os valores $\tau=0,31$ e $v=1,2$, para o caso dos cães da PM.

S : a proporção de suscetíveis.

$S$ muito pequena $\quad \begin{cases}\mu_{S m p}(x)=1.0 & \text { se } 0.0 \leq x \leq 0.10 \\ \mu_{S m p}(x)=-10.0(x-0.20) & \text { se } 0.10<x \leq 0.20 \\ \mu_{S m, p}(x)=0 & \text { se } \quad x>0.20\end{cases}$

$S$ pequena $\quad \begin{cases}\mu_{S p}(x)=7.7(x-0.12) & \text { se } 0.12 \leq x \leq 0.25 \\ \mu_{S p}(x)=-6 . \overline{6}(x-0.40) & \text { se } 0.25<x \leq 0.40 \\ \mu_{S p}(x)=0 & \text { se } x<0.12, x>0.40\end{cases}$

$S$ média $\quad \begin{cases}\mu_{S m}(x)=5.0(x-0.30) & \text { se } 0.30 \leq x \leq 0.50 \\ \mu_{S m}(x)=-10(x-0.60) & \text { se } 0.50<x \leq 0.60 \\ \mu_{S m}(x)=0 & \text { se } x<0.30, x>0.60\end{cases}$

$S$ grande $\quad\left\{\begin{array}{lll}\mu_{S g}(x)=5.0(x-0.50) & \text { se } 0.50 \leq x \leq 0.70 \\ \mu_{S g}(x)=-10(x-0.80) & \text { se } 0.70<x \leq 0.80 \\ \mu_{S g}(x)=0 & \text { se } \quad x<0.50, x>0.80\end{array}\right.$

$S$ muito grande $\quad \begin{cases}\mu_{\text {Smg }}(x)=5.0(x-0.70) & \text { se } 0.70 \leq x \leq 0.90 \\ \mu_{\text {Smg }}(x)=1.0 & \text { se } 0.90<x \leq 1.00 \\ \mu_{\text {Smg }}(x)=0 & \text { se } x<0.70\end{cases}$ 


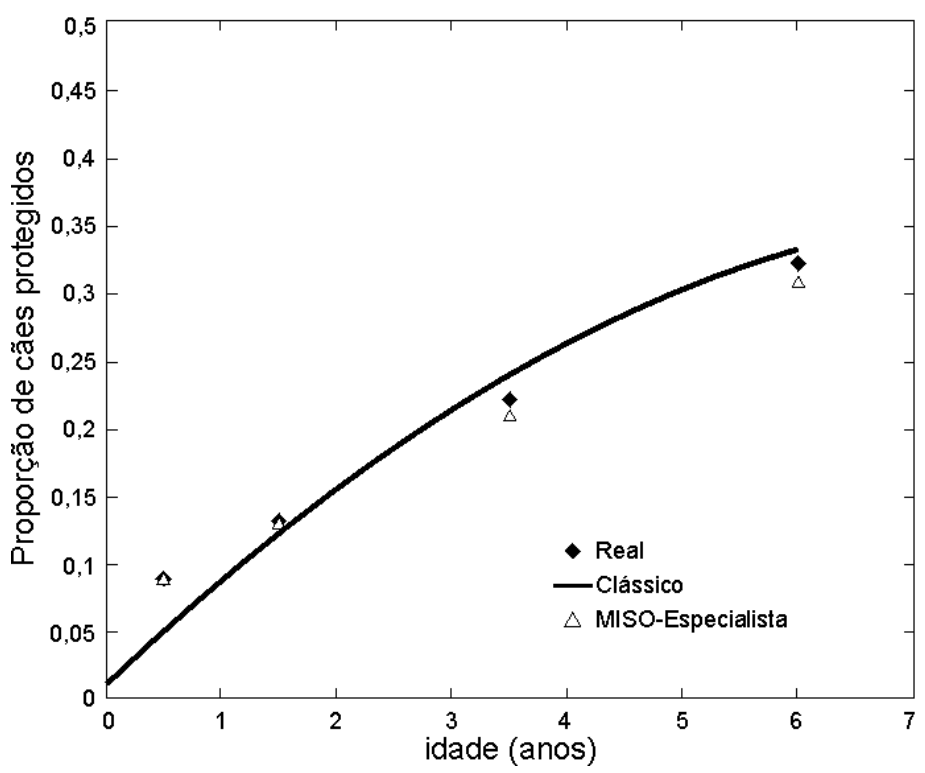

Figura 8.11: Dados experimentais confrontados com os valores gerados pelo modelo MISO e pelo modelo clássico, para o caso dos cães errantes.

$I$ : a proporção de infectados.

I muito pequena $\begin{cases}\mu_{i m p}(x)=1.0 & \text { se } 0.0 \leq x \leq 0.03 \\ \mu_{i m p}(x)=-50.0(x-0.05) & \text { se } 0.03<x \leq 0.05 \\ \mu_{i m p}(x)=0.0 & \text { se } x>0.05\end{cases}$

I pequena

$\begin{cases}\mu_{I p}(x)=25.0(x-0.03) & \text { se } \quad 0.03 \leq x \leq 0.07 \\ \mu_{I p}(x)=-12.5(x-0.15) & \text { se } 0.07<x \leq 0.15 \\ \mu_{I p}(x)=0.0 & \text { se } x<0.03, x>0.15\end{cases}$

I média

$\begin{cases}\mu_{\text {Im }}(x)=5.0(x-0.10) & \text { se } 0.10 \leq x \leq 0.30 \\ \mu_{\text {Im }}(x)=-10(x-0.40) & \text { se } 0.30<x \leq 0.40 \\ \mu_{\text {Im }}(x)=0.0 & \text { se } \quad x<0.10, x>0.40\end{cases}$

I grande

$\begin{cases}\mu_{I g}(x)=10.0(x-0.30) & \text { se } \quad 0.30 \leq x \leq 0.40 \\ \mu_{I g}(x)=-5.0(x-0.60) & \text { se } 0.40<x \leq 0.60 \\ \mu_{I g}(x)=0.0 & \text { se } \quad x<0.30, x>0.60\end{cases}$

I muito grande $\begin{cases}\mu_{i m g}(x)=4.0(x-0.50) & \text { se } 0.50 \leq x \leq 0.75 \\ \mu_{i m g}(x)=1.0 & \text { se } 0.75<x \leq 1.00 \\ \mu_{i m g}(x)=0.0 & \text { se } x<0.50\end{cases}$

A combinação de todos os conjuntos fuzzy acima resultam em 300 regras possiveis. Cada situação foi cuidadosamente analisada, baseado nos resultados da simulação do 


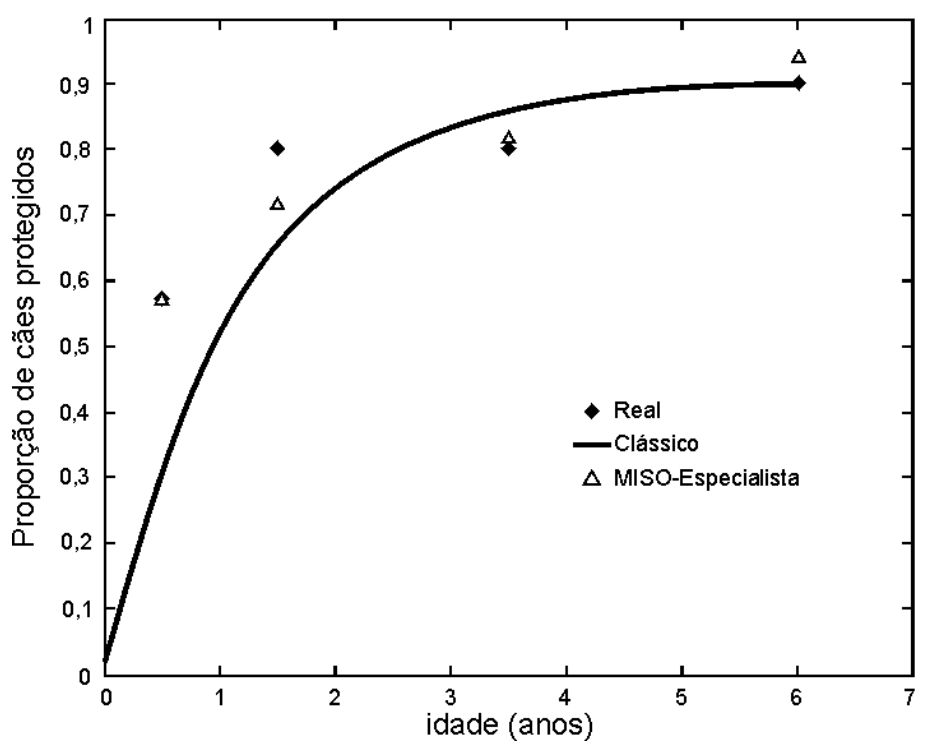

Figura 8.12: Dados experimentais confrontados com os valores gerados pelo modelo MISO e pelo modelo clássico, para o caso dos cães da PM.

modelo clássico, e 157 regras foram consideradas relevantes no contexto do modelo. As funções de pertinência para os conseqüentes $\Delta S$ e $\Delta I$ foram: 


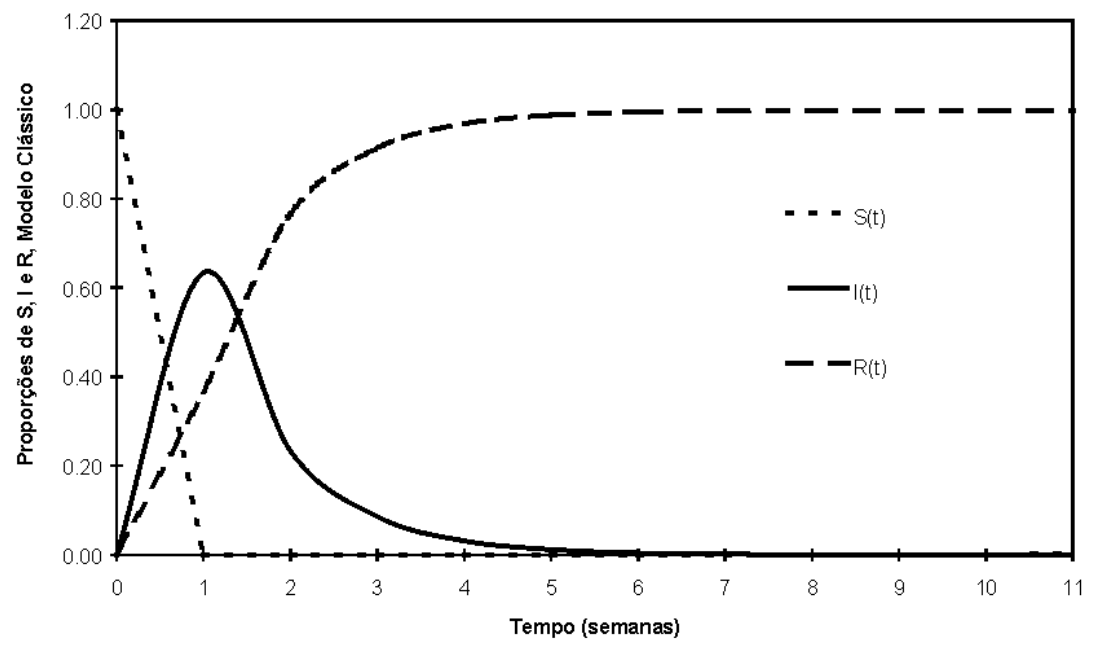

Figura 8.13: Comportamento típico das proporções $s, i$ e $r$ fornecidas pelo modelo clássico.

$\Delta S$ : incremento de $S$ para o modelo MIMO.

$\Delta S$ muito pequeno $\quad \begin{cases}\mu_{\Delta S m p}(x)=1.0 & \text { se } 0 \leq x \leq 0.03 \\ \mu_{\Delta S m p}(x)=-33 . \overline{3}(x-0.06) & \text { se } 0.03<x \leq 0.06 \\ \mu_{\Delta S m p}(x)=0.0 & \text { se } x>0.06\end{cases}$

$\Delta S$ pequeno

$\begin{cases}\mu_{\Delta S p}(x)=20.0(x-0.05) & \text { se } \quad 0.05 \leq x \leq 0.10 \\ \mu_{\Delta S p}(x)=-10.0(x-0.20) & \text { se } 0.10<x \leq 0.20 \\ \mu_{\Delta S p}(x)=0.0 & \text { se } \quad x<0.05, x>0.20\end{cases}$

$\Delta S$ nulo

$\left\{\begin{array}{lll}\mu_{\Delta S n}(x)=1 & \text { se } & x=0 \\ \mu_{\Delta S n}(x)=0 & \text { se } & x \neq 0\end{array}\right.$

$\Delta S$ médio

$\left\{\begin{array}{lll}\mu_{\Delta S m}(x)=20.0(x-0.15) & \text { se } \quad 0.15 \leq x \leq 0.20 \\ \mu_{\Delta S m}(x)=-10.0(x-0.30) & \text { se } \quad 0.20<x \leq 0.30 \\ \mu_{\Delta S m}(x)=0.0 & \text { se } \quad x<0.15, x>0.30\end{array}\right.$

$\Delta S$ grande

$$
\begin{cases}\mu_{\Delta S g}(x)=6 . \overline{6}(x-0.25) & \text { se } 0.25 \leq x \leq 0.40 \\ \mu_{\Delta S g}(x)=1.0 & \text { se } 0.40<x \leq 1.00 \\ \mu_{\Delta S g}(x)=0.0 & \text { se } x<0.25\end{cases}
$$


$\Delta I$ : incremento de I para o modelo MIMO.

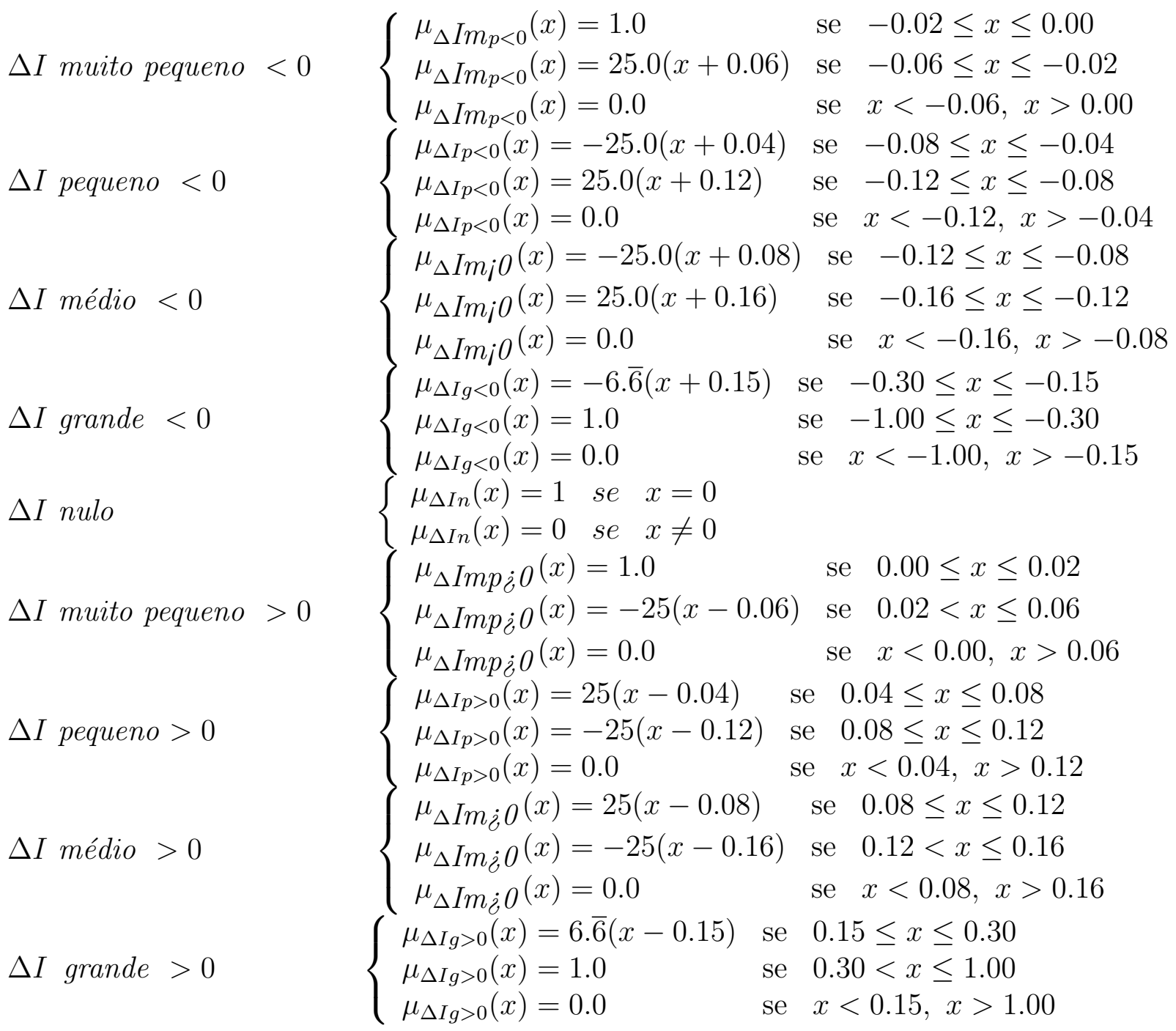

O método de inferência aplicado foi, novamente, o Mínimo de Mamdani e os valores clássicos das saídas foram obtidas com Método das Alturas de defuzificação como no modelo MISO. A figura 8.14 apresenta o comportamento típico das proporções de $S$, $I$ e $R$ para o modelo fuzzy.

Como podemos notar das figuras 8.13 e 8.14, o modelo MIMO foi capaz de reproduzir qualitativamente a dinâmica do sistema de equações diferenciais do modelo SIR, para os mesmo valores de parâmetros. Mesmo quantitativamente os resultados foram razoáveis. Nós simulamos o modelo fuzzy para vários valores dos parâmetros e os resultados se mostraram comparáveis aos do modelo clássico. O modelo fuzzy apresentou um comportamento dinâmico compatível com o apresentado pelo modelo SIR, ou seja, as regras e os conjuntos fuzzy foram capazes de reconstruir qualitativamente a dinâmica do sistema compartimentado. No entanto, a elaboração deste 


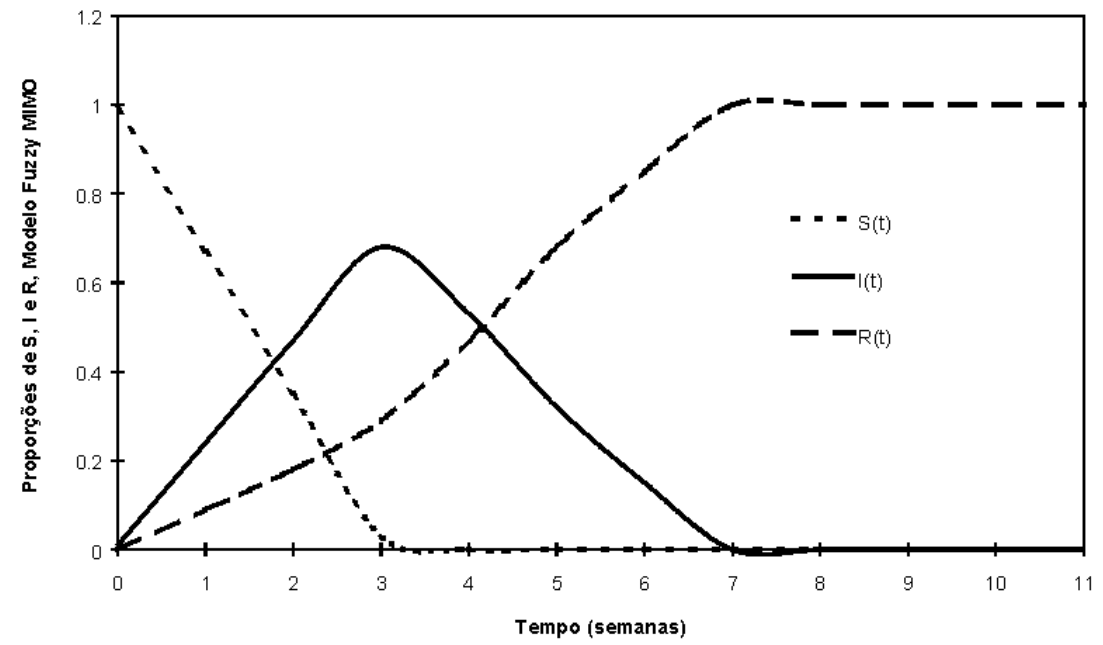

Figura 8.14: Comportamento típico das proporções $s, i$ e $r$ fornecidas pelo modelo fuzzy.

tipo de modelo consiste em um trabalho exaustivo devido ao grande número de conjuntos e, conseqüentemente, de regras possíveis, o que faz deste tipo de modelo uma abordagem com aplicações práticas reduzidas em alguns casos.

\subsection{Discussão}

Este trabalho foi o primeiro modelo dinâmico fuzzy para epidemiologia que desenvolvemos. Os resultados mostram claramente a capacidade potencial que o modelo lingüístico fuzzy apresenta para construir a dinâmica do sistema, através de uma estutura de regras subjetivas.

O modelo TSK possui nas suas características a hipótese de um conhecimento prévio do funcionamento do sistema que, utilizado convenientemente, é capaz de gerar nos conseqüentes das regras a dinâmica do mesmo. Porém, muitas vezes, mesmo não conhecendo os funcionais do sistema somos capazes de elaborar um funcional adequado, a partir de conhecimentos heurísticos que, associado corretamente às regras, também é capaz de reconstruir a dinâmica do sistema. É importante notar que, nestes casos, a construção do funcional adequado se dá de forma absolutamente empírica, consistindo em um método de "adivinhação", ou "chute", do funcional que melhor sintoniza o problema. Este foi o procedimento na nossa primeira abordagem. No entanto, o nosso "chute" não foi muito bom, uma vez que o modelo apresentou comportamentos indesejáveis. Outras formas funcionais foram testadas, porém os resultados obtidos foram ainda piores. Note que, o fato de não termos encontrado um bom funcional não significa que ele não exista. Na verdade, este problema apenas denota a realidade característica da modelagem epidemiológica, onde o pesquisador não possui um conjunto completo de informações a cerca do sistema e sua dinâmica, 
fato esse que reforça a idéia do uso da teoria de conjuntos fuzzy neste tipo de estudo. O modelo MISO possui características tipícas de modelos fuzzy para controle de sistemas, amplamente utilizado nas áreas de engenharia. Modelos com essa estrutura são facilmente manipuláveis pois a subjetividade é expressa apenas na elaboração dos conjuntos fuzzy e na estrutura das regras, o que consiste num grau de dificuldade muito menor que na primeira abordagem. Os resultados obtidos foram bastante satisfatórios. Neste contexto, o modelo MISO pode nos fornecer uma espectativa da proporção de cães soropositivos para as demais idades, mostrando o potencial preditivo deste tipo de modelo.

A quase ausência de conhecimentos a priori em problemas epidemiológicos faz com que modelos do tipo MISO se tornem uma alternativa atraente. No entanto, o estudo realizado com o modelo MIMO nos mostrou o quão complicado pode ser lidar com este tipo de modelo quando temos um número razoável de conjuntos fuzzy, principalmente os conjuntos conseqüentes, e quando as variáveis estão fortemente correlacionadas, como no caso do modelo SIR. Nestes casos, torna-se complicado a implementação da experiência do especialista, devido ao grande número de regras, e os resultados obtidos não são necessariamente melhores do que os obtidos com os modelos clássicos. Nós estamos convencidos de que os modelos do tipo MIMO podem oferecer resultados interessantes desde que o número de conjuntos fuzzy (parâmetros e variáveis de estado a serem controladas) envolvidos seja pequeno, caso contrário esta abordagem pode apresentar pouca utilidade prática.

Temos, portanto, que os modelos do tipo TSK tornam-se atraentes por serem menos dependentes do conhecimento do especialista, mas exigem um conhecimento prévio sobre os funcionais do sistema. Por outro lado, os modelos tipo MIMO são capazes de fornecer a dinâmica do sistema baseando-se apenas na informação dos especialistas, o que o torna altamente dependente. Nos casos em que o modelo possui um número grande de variáveis, sendo elas correlacionadas, o especialista "perde" a capacidade de traduzir o seu conhecimento (e a sua intuição) em conjuntos e regras fuzzy, e esta dependência torna-se então, indesejável. Precisamos, portanto, de uma técnica que nos permita ser menos dependentes do especialista, mas que não nos exija um conhecimento prévio sofisticado a cerca da dinâmica do sistema. No próximo capítulo nós propomos a utilização do princípio de extensão para obtenção dos conseqüentes de modelos lingüísticos fuzzy, sejam eles dinâmicos ou não. 


\section{Capítulo 9}

\section{Aplicação do princípio de extensão em modelos lingüísticos fuzzy}

Como discutido anteriormente, existem vários tipos de modelos lingüísticos fuzzy e a escolha por um determinado modelo dependerá do tipo de informação disponível a respeito do sistema. Existem algumas situações onde conhecemos os funcionais envolvidos e estes modelos tornam-se menos dependentes do especialista, o que em alguns casos consiste em uma vantagem. Outras vezes, além da opinião do especialista, um grande conjunto de dados está disponível. Nestes casos, uma boa opção pode ser a elaboração de modelos híbridos, onde a experiência do especialista pode ser aprimorada a partir da informação dos dados entrada/saída do sistema, o que pode ser realizado com o auxílio de redes neurais ou algoritmos genéticos ( Wang $\&$ Mendel 1992, Jang 1993, Bastian 2000). Este é o caso de muitas aplicações em engenharia, mas não é o caso da maioria dos problemas epidemiológicos. De fato, a disponibilidade de dados epidemiológicos é pouco comum.

Resulta, do exposto acima, que a dependência ao especialista é muito grande na modelagem fuzzy de sistemas epidêmicos, sendo ele quem elabora os conjuntos fuzzy antecedentes e conseqüentes, bem como as regras fuzzy.

\subsection{Extraindo a opinião do especialista}

Elaborar modelos fuzzy com especialistas médicos e epidemiologistas exige uma relação interdisciplinar efetiva. No sentido de extrair o seu conhecimento, é muito importante deixá-los completamente livres para construírem os conjuntos fuzzy, ou na maneira como organizam e traduzem esse conhecimento. De uma forma geral, os conjuntos fuzzy elaborados pelos epidemiologistas e médicos não são conjuntos "bem comportados". Eles costumam elaborar conjuntos assimétricos e irregulares, muito diferente do que é comumente usado em engenharia.

No entanto, como discutido anteriormente, os especialistas podem apresentar sérias dificuldades para traduzir o seu conhecimento quando o modelo é complexo. Ademais, criar os conseqüentes das regras é muito mais difícil do que os antecedentes, porque 
nos primeiros os especialistas precisam considerar a dinâmica do sistema, ponderando todas as influências que podem ocorrer para gerar uma saída específica, e sua correspondente função de pertinência. Por outro lado, para criar os antecedentes o especialista necessita apenas classificar as variáveis em grupos, ou seja, realizar uma partição fuzzy do domínio das variáveis de entrada, elaborando suas funções de pertinência. Portanto, em geral, o especialista tem muito mais facilidade para elaborar os antecedentes do que os conseqüentes das regras fuzzy. Neste sentido, um método que permita construir os conseqüentes das regras implicaria em um importante progresso na modelagem de sistemas que apresentam um grande nível de incerteza.

Considerando as dificuldades apresentadas e com o objetivo de diminuir a dependência ao especialista, propomos neste trabalho a aplicação do princípio de extensão na elaboração dos conseqüentes das regras em modelos lingüísticos fuzzy. Este método foi proposto originalmente por Dubois (Dubois et al 1995) e, para avaliar a sua aplicabilidade, nós elaboramos um modelo lingüístico onde os conseqüentes das regras foram construídos através do princípio de extensão.

\subsection{O método}

O princípio de extensão, como discutido na seção 2.6, é uma operação que mapeia uma função clássica com argumentos fuzzy no espaço das funções fuzzy. Para aplicarmos o método precisamos, portanto, de uma função clássica que descreva de alguma forma a relação entre as variáveis. Contudo, em biomedicina estas funções muitas vezes não estão disponíveis. Nestas circunstâncias, pode acontecer de o modelo clássico nos ajudar a obter uma função, cuja extensão resulte em conjuntos fuzzy que sejam capazes de descrever o sistema de forma mais realista.

Assim, vamos considerar uma função $f(x, y, z)$ e que $X_{i}, Y_{j}$ e $Z_{k}$ sejam conjuntos fuzzy dos argumentos de $f$, cujas funções de pertinência são representadas por $X_{i}(x), Y_{j}(y)$ and $Z_{k}(z)$. Se $i, j, k \in\{1,2\}$ então um modelo lingüístico típico está baseado em oito regras, cujos antecedentes são:

$$
\begin{aligned}
& x \text { é } X_{1} \mathbf{E} \text { y é } Y_{1} \mathbf{E} z \text { é } Z_{1} \\
& \text { x é } X_{2} \mathbf{E} \text { y é } Y_{1} \mathbf{E} z \text { é } Z_{1} \\
& \text { xé } X_{1} \mathbf{E} \text { y é } Y_{2} \mathbf{E} z \text { é } Z_{1} \\
& x \text { é } X_{2} \mathbf{E} \text { y é } Y_{2} \mathbf{E} z \text { é } Z_{2}
\end{aligned}
$$

e os conseqüentes são construídos a partir da extensão de $f(x, y, z)$. O processo consiste de, para cada regra, fixar o valor de $r$ e variar os valores de $x, y$ e $z$ de tal forma que $f(x, y, z)=r$. Então, para cada tripla $(x, y, z)$ nós calculamos o grau de pertinência de $x, y$ e $z$ em seus respectivos conjuntos fuzzy e escolhemos o valor mínimo entre esses graus de pertinência. Depois de obter os valores mínimos de todas as triplas, escolhemos o valor máximo dos graus de pertinência tal que $f(x, y, z)=r$ 
e, aplicamos o operador $\max \left[\min \left(X_{i}(x), Y_{j}(y), Z_{k}(z)\right)\right]$. O resultado será o grau de pertinência de $r$ no conseqüente da $i$ - ésima regra. Variando o valor de $r$, somos capazes de construir o conjunto fuzzy que será o conseqüente dessa regra. Finalmente, executando o método para cada regra, é possível contruir todos os conseqüentes, obtendo o conjunto de regras fuzzy completo do modelo.

No sentido de esclarecer o método, apresentamos um exemplo onde a função clássica tem somente dois argumentos.

- Exemplo 9.1: Seja $f(x, y)=x+y$ uma função clássica e $X=0 / 2+0.2 / 3+$ $0.5 / 4+1 / 5+0.5 / 6+0.2 / 7+0 / 8$ e $Y=0 / 5+0.2 / 6+0.5 / 7+1 / 8+0.5 / 9+0.2 / 10+$ $0 / 11$ são os conjuntos fuzzy dos $\operatorname{argumentos} x$ e $y$, respectivamente. É fácil ver que o domínio do conjunto fuzzy $\widehat{f}(X, Y)$, obtido pela extensão de $f(x, y)$, é um conjunto real. Para um dado valor $r=10$, por exemplo, nós temos os pares $(2,8),(3,7),(4,6)$ e $(5,5)$, cuja imagem de $f$ é $r=10$. O grau de pertinência e a aplicação do operador conjunção fuzzy são apresentados na tabela abaixo:

$\begin{array}{ccc}(x, y) & \text { grau de pertinência } & \min [X(x), Y(y)] \\ (2,8) & X(2)=0 & 0 \\ & Y(8)=1 & \\ (3,7) & X(3)=0.2 & 0,2 \\ & Y(7)=0.5 & \\ (4,6) & X(4)=0.5 & 0,2 \\ & Y(6)=0.2 & \\ (5,5) & X(5)=1 & 0 \\ & Y(5)=0 & \end{array}$

Portanto, o $\max [\min (X(x), Y(y))]$ é 0,2 , o que significa que o grau de pertinência do valor $r=10$ na $\widehat{f}(X, Y)$ é 0,2 . Repetindo este procedimento para todos os possíveis valores do domínio de $\widehat{f}(X, Y)$ nós obtemos o conjunto fuzzy $\widehat{f}(X, Y)$ que será o conseqüente da regra $\boldsymbol{S E} x$ é $X \boldsymbol{E}$ y é $Y \boldsymbol{E} \boldsymbol{N \boldsymbol { T } \tilde { \boldsymbol { A } } \boldsymbol { O }} r$ é $\widehat{f}(X, Y)$, que neste caso é dado por:

$$
\begin{aligned}
\widehat{f}(X, Y)= & 0 / 7+0 / 8+0.2 / 9+0.2 / 10+0.5 / 11+0.5 / 12+1 / 13 \\
& +0.5 / 14+0.5 / 15+0.2 / 16+0.2 / 17+0 / 18+0 / 19 .
\end{aligned}
$$

Note que para $r=13$ o grau de pertinência é 1 , ou seja, existe uma pertinência total como no caso clássico. Esta é uma conseqüência do fato de que os graus de pertinência de $x=5$ e $y=8$ são 1 . Esta característica de recuperar o resultado clássico é uma das propriedades mais importantes do princípio de extensão. 


\subsection{A aplicação}

O método acima descrito foi aplicado ao problema da raiva canina na cidade de São Paulo, apresentado no capítulo anterior. Do modelo clássico temos que a dinâmica desse problema pode ser descrita por uma função do tipo:

$$
\Delta s=f(s(a), v, \tau)
$$

onde $s(a)$ é a proporção de cães soropositivos na idade $a, \nu$ é a força de vacinação, definida como a proporção per capita de indivíduos vacinados, $\tau$ é a taxa de perda de anticorpos na ausência de novas vacinações, e $f$ éuma função crescente com $\nu$ e decrescente $\operatorname{com} \tau$. A função proposta foi a seguinte:

$$
\Delta s=v(1-s(a))-\tau s(a)
$$

onde $(1-s(a))$ é a proporção de cães soronegativos.

A equação (9.2) foi a função clássica que utilizamos para gerar os conseqüentes das regras a partir do princípio de extensão. Os conjuntos fuzzy de entrada do modelo foram os mesmo construídos pelo especialista com a diferença que, para garantirmos que o conseqüente a ser construído fosse uma proporção, ou seja que $0 \leq \Delta s \leq 1$, os conjuntos fuzzy foram normalizados. Os conjuntos fuzzy antecedentes para $S, V$ e $\Gamma$, já normalizados, são apresentados nas figuras 9.1, 9.2 e 9.3, respectivamente.

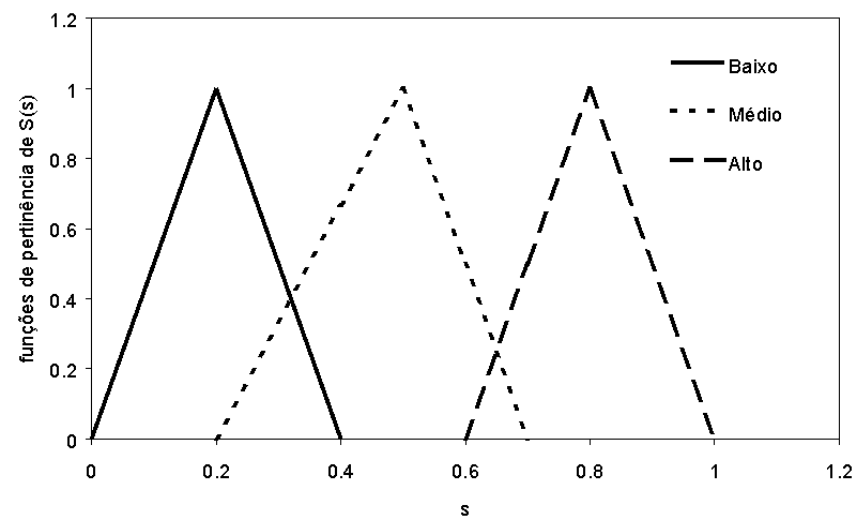

Figura 9.1: Conjuntos fuzzy antecedentes para $S$, já normalizados.

Como desejávamos elaborar o modelo com o máximo de independência, consideramos todas as 27 regras possíveis, não descartando aquelas que foram consideradas irrelevantes pelo especialista. Todos os conjuntos fuzzy conseqüentes obtidos pelo método da extensão foram funções de pertinência triangulares. A figura 9.4 mostra um exemplo das funções obtidas.

O próximo passo consistiu na implementação do modelo MISO dinâmico, denominado $M I S O$-Extensão, cujos antecedentes das regras foram os conjuntos fuzzy $S(s), V(v)$ e $\Gamma(\tau)$ e cujos conseqüentes foram as funções $\widehat{f}(S, V, \Gamma)$ levantadas. O 


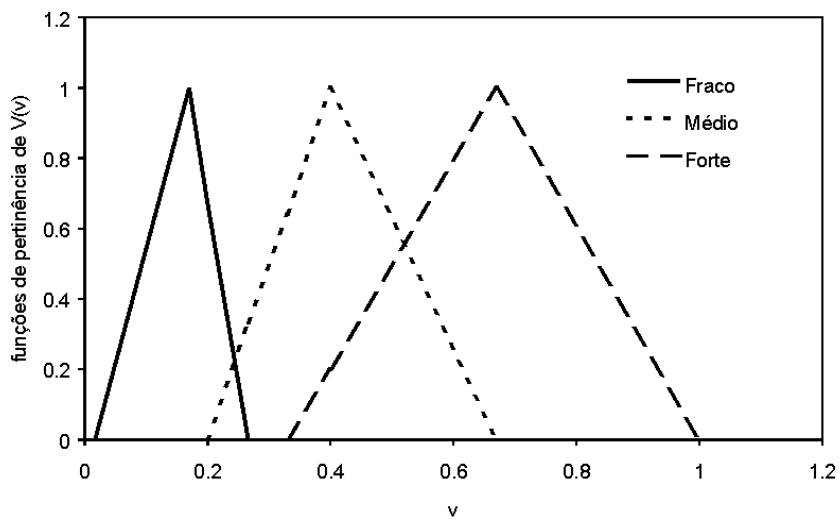

Figura 9.2: Conjuntos fuzzy antecedentes para $V$, já normalizados.

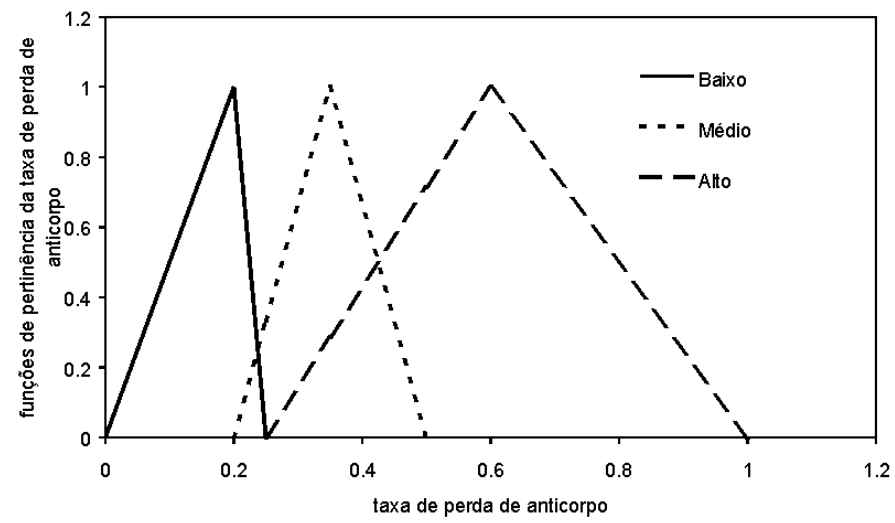

Figura 9.3: Conjuntos fuzzy antecedentes para $\Gamma$, já normalizados.

método de inferência foi o Mínimo de Mamdani e a saída foi defuzificada pelo Método das Alturas. Esses resultados foram comparados com os dados experimentais e com o resultado do modelo MISO-Especialista, que foi totalmente baseado no conhecimento do especialista e discutido no capítulo 8. As figuras 9.5 e 9.6 apresentam os resultados de ambos os modelos para a amostra de cães errantes e de cães da Polícia Militar, respectivamente.

Podemos notar das figuras, que o método proposto forneceu resultados bastante razoáveis em ambos os casos. Os valores dos parâmetros $v$ and $\tau$ estão de acordo com os valores esperados e entre si, ou seja, os parâmetros que melhor ajustaram os dados experimentais foram aproximadamente os mesmos em ambos os modelos, considerando a normalização dos conjuntos fuzzy de entrada. 


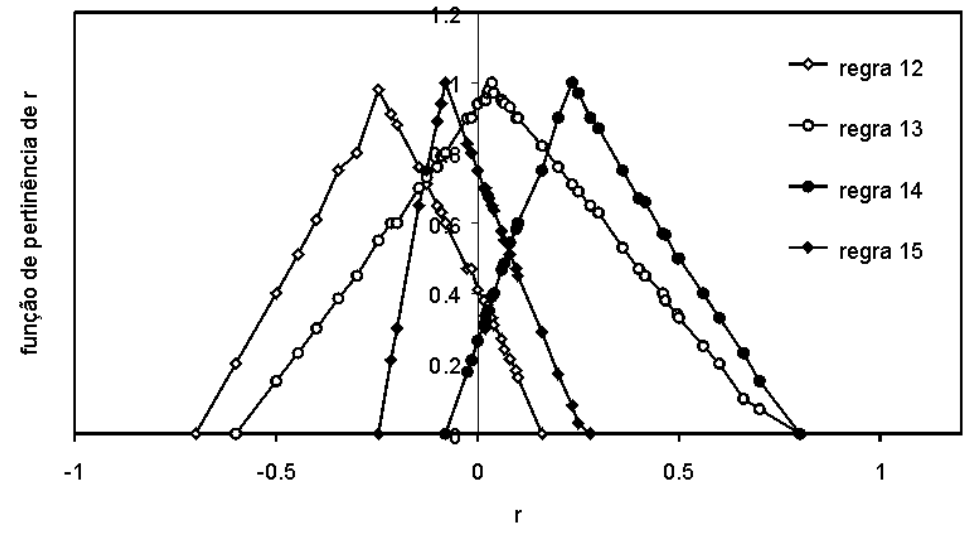

Figura 9.4: Exemplo de conjuntos fuzzy conseqüentes obtidos pela extensão.

\subsection{Discussão}

A utilização do princípio de extensão na construção dos conseqüentes de regras fuzzy mostrou-se bastante efetiva no caso do problema estudado, tendo ajustado os valores experimentais razoavelmente bem, apresentando um poder preditivo assim como o modelo baseado somente no especialista. Na verdade, a capacidade de ajuste do modelo MISO-Extensão mostrou-se quase tão boa quanto a do MISO-Especialista, tendo o especialista "acertado" um pouco mais neste caso. Isto aconteceu porque o problema epidemiológico tratado é razoavelmente simples, logo, o especialista conseguiu traduzir bem o seu conhecimento. Todavia, no caso de um sistema mais complexo, quando o especialista apresenta dificuldades em expressar seu conhecimento, pode acontecer que o modelo baseado no princípio de extensão forneça resultados melhores do que o modelo completamente baseado no especialista. Conjecturamos ainda que este método pode vir também a ser útil quando a opinião do especialista não estiver disponível. Entretanto, sabemos que este método precisa ser aplicado em modelos mais complexos antes de realizarmos qualquer afirmação neste sentido. Finalmente, gostaria de ressaltar que o uso do princípio de extensão na elaboração de regras fuzzy pode ser aplicado tanto a sistemas dinâmicos quanto estáticos. 


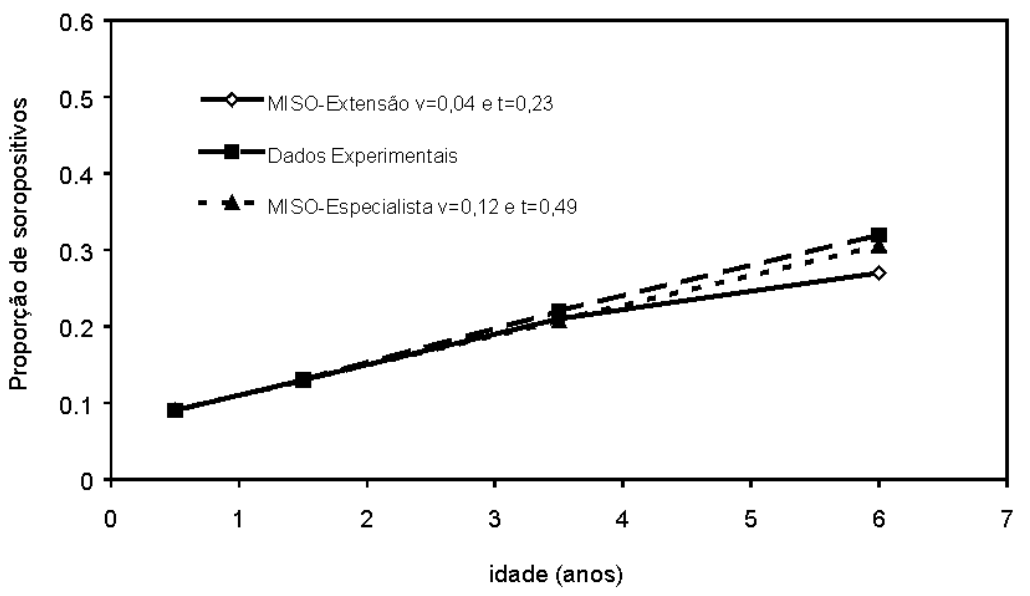

Figura 9.5: Resultado dos modelos MISO-Especialista e MISO-Extensão confrontados com os valores experimentais, para a amostra de cães errantes.

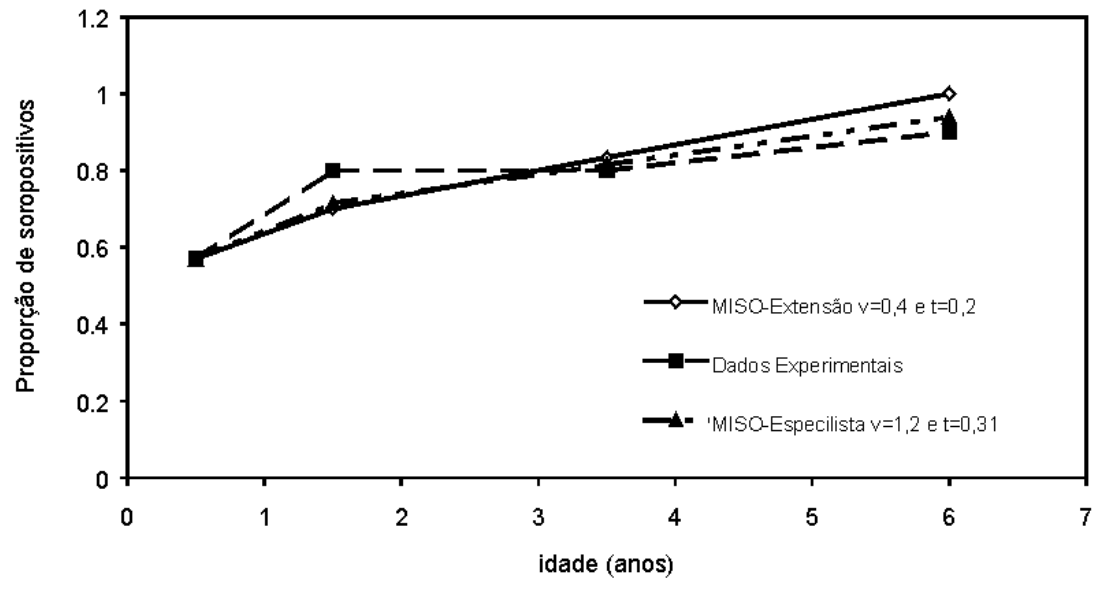

Figura 9.6: Resultado dos modelos MISO-Especialista e MISO-Extensão confrontados com os valores experimentais, para a amostra de cães da Polícia Militar. 


\section{Capítulo 10}

\section{Trabalhos em andamento e perspectivas futuras}

Além dos trabalhos apresentados nesta tese, estou envolvida em outros projetos, alguns já em andamento e outros ainda não iniciados. Com a intensão de ilustrar de que outras formas pode a teoria de conjuntos fuzzy atuar nos problemas da biomedicina é que discutirei a seguir alguns desses projetos.

\subsection{Um modelo para a facilitação social entre espécies de cupins que apresentam canibalismo}

A influência que um indivíduo, ou um grupo de indivíduos, exerce sobre o comportamento de um outro é há muito tempo objeto de estudos da psicologia. As interações entre um conjunto de indivíduos que compõem um grupo social geram comportamentos que não aparecem quando os indivíduos se encontram solitários (Zajonc 1965, Miramontes $\&$ DeSouza 1996). Uma das manifestações mais básicas deste fenômeno é o processo de facilitação social, que consiste de um conjunto de atitudes estimuladas no indivíduo pela convivência em grupo. A facilitação social examina as conseqüências da vivência social dos animais e está relacionada com a capacidade de comunicação de cada espécie, bem como, do número de indivíduos no grupo. O processo de facilitação social é muito comum em um grande número de espécies, assim como invertebrados e insetos. Estudos desse fenômeno consistem, em geral, na observação e comparação de indivíduos solitários e em grupos.

Miramontes e DeSouza (Miramontes \& DeSouza 1996) estudaram o processo de facilitação social entre cupins operários da espécie Nasutitermes investigando o comportamento da curva de sobrevivência como função do tamanho do grupo. Eles coletaram os insetos aleatoriamente de uma única colônia e os separam em grupos de 1, 2, 4, 8 e 16 cupins, com quatro réplicas para cada caso. Os grupos foram confinados em tubos de ensaio que foram mantidos separados, em condições climáticas favoráveis (temperatura e umidade), na posição horizontal e hemerticamente fechados, fican- 
do assim os insetos sem água e comida. O experimento consistiu na observação do tempo de sobrevivência dos indivíduos, contando a cada 12 horas quantos ainda se mantinham vivos, até 24 horas depois de todos os indivíduos solitários terem morrido. Os autores propuseram um autômato celular para simular o decréscimo da atividade dos indivíduos baseado no passeio aleatório dos cupins dentro do tubo de ensaio, no número de primeiros vizinhos de cada cupim, no grau de excitabilidade individual de cada cupim (que eles consideraram igual para todos os cupins) e na habilidade de comunicação característica de cada espécie. Dos seus resultados experimentais podemos observar que a curva de sobrevivência decai mais lentamente quanto mais populoso for o grupo, resultado esse recuperado pelo modelo. Variando os parâmetros do modelo eles investigaram a dependência do tempo de morte dos insetos com a geometria e o tamanho dos recipientes, obtendo como resultado que o tempo de sobrevivência médio dos cupins é maior quanto menor é o recipiente e quanto maior for o número de vizinhos (mudando a geometria da rede), o que denota uma facilitação social mais intensa quanto maior o número de vizinhos (comunicação mais intensa).

Baseado nos trabalhos de DeSouza e Miramontes nós propusemo\$ ${ }^{17}$ um estudo de facilitação social entre os cupins da espécie Coptotermes Havilandi (da família Rhinotermitidae), que é a espécie mais comum nas áreas que abrangem os estados de Rio de Janeiro e São Paulo. Este projeto consistiu de uma parte experimental bastante intensa e de uma parte teórica que descreveremos nas seções seguintes. Esta proposta se diferencia do trabalho citado em diversos aspectos, sendo um dos mais relevantes o fato da espécie que estamos analisando apresentar canibalismo, ou seja, depois de um determinado tempo que os cupins estão sem comida os mais resistentes se alimentam dos mais debilitados. Para evitar o canibalismo é necessário, então, retirar os indivíduos que se apresentem com atividade muito reduzida, caracterizando um julgamento sobre a saúde do cupim analisado, o que é um processo altamente subjetivo. Sendo assim, a partir de uma limitação experimental, surgiu no modelo teórico a necessidade de adicionarmos ao autômato celular a informação subjetiva, o que pretendemos fazer utilizando os recursos da lógica fuzzy.

Neste trabalho, então, os cupins foram submetidos a ausência de água e alimento e a medida experimental consistiu da verificação do tempo médio de sobrevida de um cupim, dado que ele se encontrava em um grupo de certo tamanho. Nosso interesse é estudar a facilitação social nesta espécie de cupins, cujo efeito levaria os grupos mais populados sobreviverem um tempo maior quando comparados com os solitários. A comunicação entre os insetos pode ocorrer de diversas maneiras, no entanto, não estamos considerando neste trabalho nenhum tipo de comunicação sonora e/ou através de cheiros. Portanto, a facilitação social neste caso seria o resultado apenas da trofalaxia entre os cupins (processo pelo qual os cupins se tocam, trocam alimentos, etc). Concentramos nossas observações nos cupins operários, realizando a maior parte do experimento no estudo desta classe. Já no caso dos cupins soldados não é esperado

\footnotetext{
1 A parte teórica deste trabalho está sendo realizada em colaboração com a Professora Aglaé Cristina Navarro de Magalhães, do Centro Brasileiro de Pesquisas Físicas, e a parte experimental foirealizada no Museu de Zoologia da USP, sob a coordenação da pesquisadora Marisa Vianna.
} 
encontrar facilitação social, pois eles não realizam trofalaxia entre si.

\subsubsection{O experimento}

O experimento consistiu em três etapas: obtenção e quebra do ninho; separação dos operários e dos soldados; formação dos grupos e observação do tempo de sobrevivência dos cupins. Todo o experimento foi realizado no laboratório de cupins, do Museu de Zoologia da Universidade de São Paulo. Foram utilizados recipientes de acrílico com áreas e formas geométricas diferentes, com a intensão de verificarmos hipóteses teóricas sobre a influência desses fatores nos tempos de sobrevivência dos cupins. O experimento foi realizado em duas etapas. Na primeira, em 1998, estudamos as curvas de sobrevida de cupins agrupados em grupos de 1, 4, 8, 16 e 32 indivíduos. Esses grupos foram confinados em recipientes de seção retangular cuja área foi mantida constante, porém com perímetro variado. As observações foram feitas em um intervalo de 6 horas. Na segunda etapa, realizada no final de 1999, cupins da mesma espécie foram confinados em recipientes de seção quadrada, cuja área e perímetro variavam, em grupos de 1, 4, 8, 12 e 16 indivíduos. As observações, neste caso, foram realizadas a cada 8 horas. Em ambas as fases experimentais, os cupins foram mantidos no escuro, sendo expostos a luz apenas durante o período de medida, e submetidos a uma temperatura e umidade médias de $26 \pm^{\circ} \mathrm{C}$ e $98 \pm 1 \%$, respectivamente. Para cada grupo foram feitas 10 réplicas, resultando em 3.470 cupins observados. As dimensões das caixas quadradas foram: grupo A $31,5 \times 31,5 \mathrm{~mm}$, grupo B $70 \times 70 \mathrm{~mm}$, grupo C $140 \times 140 \mathrm{~mm}$ e grupo D $175 \times 175 \mathrm{~mm}$, e para as caixas retangulares: grupo E $7 \times 126 \mathrm{~mm}$, grupo G $14 \times 63 \mathrm{~mm}$ e grupo $\mathrm{H} 28 \times 31,5 \mathrm{~mm}$. Foram separados também um grupo de 410 cupins soldados agrupados em conjuntos de 1, 8 e 32 elementos, com 10 réplicas cada conjunto e colocados em vidros de Petri.

Os indivíduos foram classificados em vivos, semi vivos e semi mortos. Os insetos eram considerados vivos até que sua atividade estivesse bastante reduzida, momento em que a grande maioria se mantêm de barriga para cima, semi vivos quando, embora neste estado, eles ainda apresentavam alguma atividade (mechiam as perninhas com vigor) e semi mortos quando apresentavam estado de apatia. Os indivíduos que estavam em grupo quando considerados semi mortos eram imediatamente retirados das caixinhas para, assim, evitarmos o canibalismo. Os elementos solitários foram observados até estarem completamente mortos.

A parte fuzzy do modelo teórico será construído com base na classificação exposta acima, analisando os 80 cupins isolados, bem como na observação da nossa atitude no momento de decidir sobre a retirada do indivíduo. As incertezas envolvidas no processo de decisão se mostraram mais complexas quando na realização do experimento, pois, este dependeu não apenas da classificação da atividade do cupim, como também, da densidade de cupins no grupo e do número de vizinhos do indivíduo. Aconteceu que quanto mais populoso o grupo e, a depender se o cupim analisado estava em um grande amontoado de insetos, mais rígidas fomos na escolha da retirada dos elementos. Todos estes aspectos serão considerados no modelo fuzzy de decisão. 


\subsubsection{O autômato celular}

No nosso modelo a rede é dividida em células cuja dimensão corresponde ao tamanho médio de um cupim, ou seja, cada célula poderá ser ocupada por apenas um indivíduo. Outro aspecto muito importante do comportamento da espécie estudada foi que ela apresentou o fenômeno de saturação, ou seja, os cupins passaram a morrer mais rápido depois de uma certa densidade crítica de cupins no grupo. Este fenômeno de saturação compete com o fenômeno de facilitação social. Sendo assim, o modelo proposto, baseado no autômatocelular móvel, modela a dinâmica da atividade do cupim considerandoos dois fenômenos e é dado por:

$$
a_{k}(t+1)=\operatorname{tgh}\left(a_{k}(t) g_{k}+\lambda g_{k} \sum_{i} a_{i}(t)-\left(\rho(t)-\rho_{c}\right) \Theta\left(\rho(t)-\rho_{c}\right) \sum_{i} a_{i}(t)\right)
$$

onde $a_{k}(t)$ é a atividade do $k$-ésimo cupim no tempo $t, a_{i}(t)$ é a atividade do $i$ ésimo cupim na vizinhança do $k$-ésimo cupim (primeiros e segundos vizinhos na rede retangular), $g_{k}$ é o parâmetro de excitabilidade individual, $\lambda$ é o parâmetro de excitabilidade coletiva (habilidade de comunicação da espécie), $\rho(t)$ é a densidade de cupim na caixa (ou densidade do perímetro), $\rho_{c}$ é a densidade crítica a partir da qual não é esperado que ocorra fenômeno de facilitação social e $\Theta\left(\rho(t)-\rho_{c}\right)$ é a função de Heaviside. Os parâmetros $g_{k}$ foram obtidos experimentalmenteanalisando os cupins isolados. A área da rede foi determinada a partirda medida da área média de um cupim operário e considerando a área dos recipientes. Os cupins são capazes de se movimentar paracelulas adjacentes com diferentes probabilidades, a depender de quãolonge eles estão das bordas da rede. Isto se deve a observaçãoexperimental de que os cupins preferem permanecer próximos as bordas dosrecipientes. É extremamente importante considerarmos este fato, pois ele afeta drasticamente os resultados de facilitação social expressospelo modelo. Todos os $a_{k}^{\prime} s$ são inicializados com o valor 1e decresce segundo a equação acima ate que $a_{k}<a_{k c}$, abaixo do qual a decisão fuzzy é introduzida para decidir se o cupim permanece ou não no grupo. A idéia é elaborar um modelo lingüístico que seja capaz de estimar o valor de $\Delta a_{k}$, considerando asvariáveis subjetivas discutidas na subsessão anterior e usando ovalor de $a_{k}(t)$ fornecido pelo autômato como entrada do sistema. Desse modo, o modelo forneceria um $a_{k}^{\prime}(t+1)$. Se $a_{k}^{\prime}(t+1) \leq 0$ o cupim é retirado da rede, caso contrário ele serámantido e sua atividade, $a_{k}(t)$, atualizada normalmente pelo autômato. O processo se repetirá até que todos os cupins da rede tenhamsido retirados (todos estão mortos) e, assim, obtemos a curva desobrevida do grupo considerado.

O modelo fuzzy têm como antecedentes das regras três variáveis: densidade $(\rho)$, número de vizinhos $(n)$ e atividade $\left(a_{k}\right)$. O conseqüente será a variação da atividade $\left(\Delta a_{k}\right)$. Os conjuntos fuzzy serão construídos como segue:

$\rho$ : alta, média e baixa;

n: muito, médio e pouco;

$a_{k}$ : pequena, média e grande; 
$\Delta a_{k}$ : pequena, média e grande.

Os valores para $g_{k}$ foram gerados a partir de uma distribuição de $g_{k}{ }^{\prime} s$ obtida experimentalmente, a partir dos tempos de sobrevida dos cupins isolados. No caso dos isolados a equação (10.1) se reduz a:

$$
a_{k}(t)=\tanh \left[g_{k} a_{k}(t-1)\right],
$$

sendo assim, conhecendo o tempo $t$ e iterando a função acima obtemos o $g_{k}$ para cada cupim.

\subsubsection{Resultados Experimentais}

Durante o experimento existe a competição de dois fenômenos: o de facilitação social, ou seja, os cupins "gostam" de ficar agrupados, resultando em um tempo de sobrevida maior, e a saturação, que ocorre quando a densidade de cupins é tal que o estresse cresce, fazendo com que os cupins "não gostem" de ficar no grupo, resultando em um tempo de sobrevida menor. Os nossos resultados expressam esta competição. Vale ressaltar que os processos biológicos envolvidos nesses fenômenos são ainda bastante desconhecidos.

No caso das caixas quadradas, a facilitação social foi observada somente quando $\rho_{\text {Área }} \leq \rho_{\text {ÁreaC }}=0,010$, o que inclui todos os casos dosgrupos C e D. Nos grupos A e B não foi observado a facilitaçãosocial. Nossa interpretação é que o fenômeno de saturação foi bastante efetivo nestas caixas, uma vez que as densidades envolvidas são razoavelmente elevadas (as caixas são pequenas). Já nos grupos C e D foi observado o fenômeno de facilitação social, onde os fatores de facilitação são: $f_{D}=<t>_{16 D}$ $/<t>_{1 D}=1,7 \pm 0,2$ e $f_{C}=<t>_{16 C} /<t>_{1 C}=1,51 \pm 0,07$. (No trabalho de Miramontes e DeSouza foi obtido para outra espécie de cupins um fator de facilitação igual 1,88). Nossa interpretação é que nestes casos o fenômeno de facilitação social venceu o de saturação, devido a densidade de cupins ser menor que a densidade crítica.

Devido às caixas dos grupos $\mathrm{H}, \mathrm{G}$ e E serem retangulares e, portanto, acentuarem o comportamento dos cupins de se manterem nas bordas do recipiente, consideramos para estes casos a densidade de cupins no perímetro. No grupo $\mathrm{H}$ não foi observado a facilitação social, e o fenômeno de saturação pareceu dominar a situação, uma vez que o tempo de sobrevida maior ocorreu no grupo dos isolados. No grupo G foi observada uma tendência à facilitação social, porém, o fenômeno de saturação pareceu se expressar quando a densidade do perímetro aumentou. No grupo E, que corresponde a densidade perimetral maior, foi observado um crescimento no tempo de sobrevida médio até o grupo com 8 cupins, passando este a decrescer nos grupos de 16 e 32 cupins (quando o fenômeno de facilitação social "perde" para a saturação). Sendo assim, nós observamos a facilitação social somente quando $\rho_{\text {Perimetro }} \leq \rho_{\text {PerimetroC }}=$ 0,105 (o que inclui os casos 1E, $4 \mathrm{E}, 8 \mathrm{E}, 1 \mathrm{G}, 4 \mathrm{G}$ e $1 \mathrm{H}$ ). Os fatores de facilitação social para os grupos E e G foram: $f_{E}=<t>_{8 E} /<t>_{1 E}=1,4 \pm 0,2$ e $f_{G}=<t>_{4 G} /<$ $t>_{1 G}=1,1 \pm 0,1$. Para todos os valores de $\rho_{\text {Perimetro }}$ nós observamos $t_{E}>t_{G}>t_{H}$. 
As figuras 10.1 e 10.2 apresentam os gráficos dos tempos de sobrevida médios em função das densidades, para os vários grupos. Podemos verificar que existe uma densidade limite a partir da qual é possível observar o fenômeno de facilitação social, qual seja, $\rho_{\text {Área }}=0,010$ para o grupo das caixas quadradas e $\rho_{\text {Perímetro }}=0,105$ para o grupo das caixas retangulares.

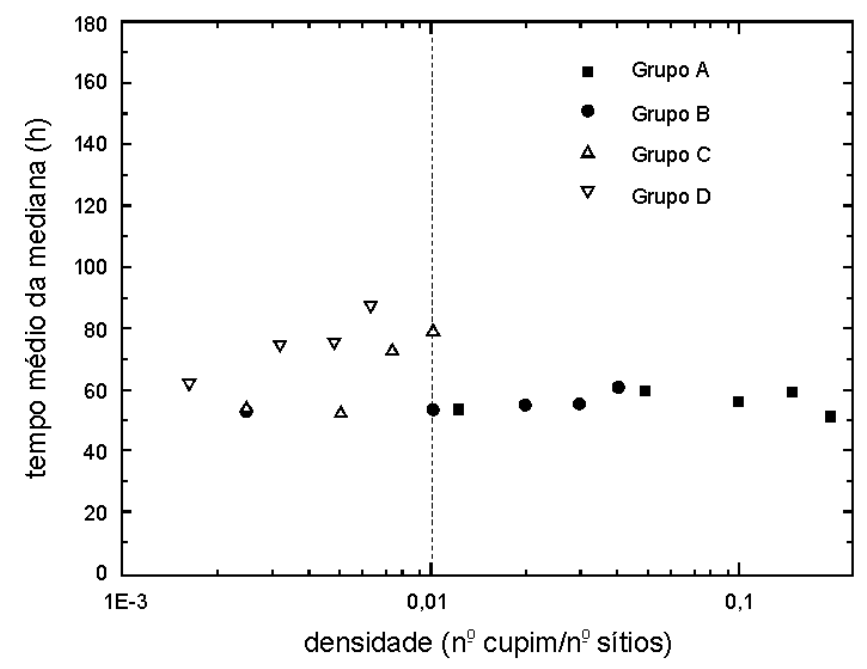

Figura 10.1: Tempos de sobrevida médios dos cupins em função das densidades, para os grupos de caixas quadradas.

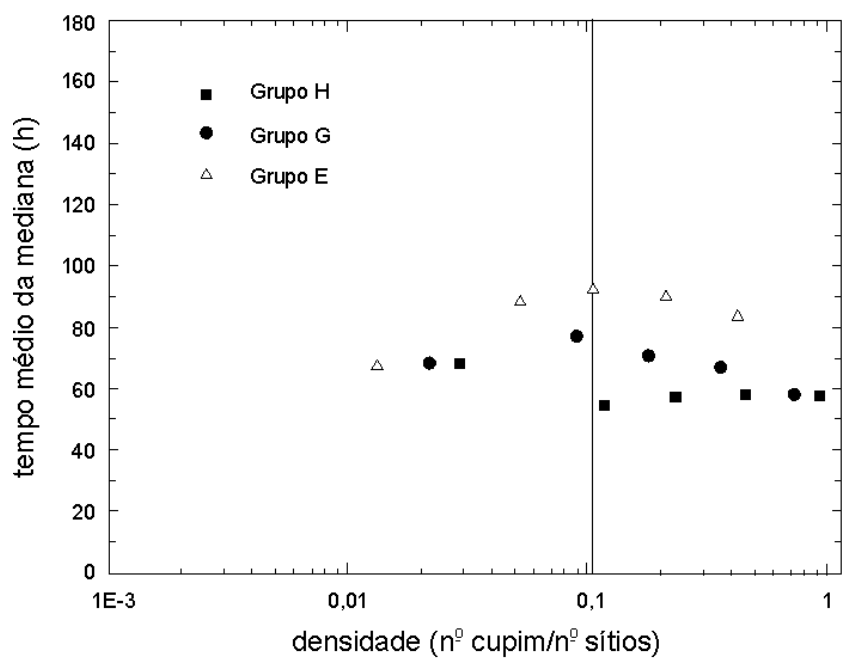

Figura 10.2: Tempos de sobrevida médios dos cupins em função das densidades, para os grupos de caixas retangulares.

Nossos resultados estão consistentes com a hipótese teórica de que o fenômeno de facilitação social cresce com o aumento da taxa de contatos e interações entre os cupins, que supomos consistir basicamente de trofalaxias. No nosso experimento com cupins soldados da mesma espécies não observamos nenhum vestígio do fenômeno de 
facilitaçãosocial, o que corrobora a hipótese acima uma vez que os cupins soldadosnão realizam trofalaxias entre si.

Vale ressaltar que os valores dos fatores de facilitação social apresentados acima estão subestimados, pois a subjetividade nos critérios para retirada dos cupins semimortos afeta mais fortemente as caixas mais densas, ou seja, aquelas com um número maior de cupins. Dessa forma, é esperado que o $<t>_{16}$ real (se o cupim não fosse retirado antes de sua morte completa) seja maior do que o obtido. Por outro lado, os cupins isolados foram observados até sua morte completa, o que significa que o valor de $\left\langle t>_{1}\right.$ é o valor real. A combinação desses fatores implicam em uma diminuição do fator de facilitação social.

\subsubsection{Discussão}

Este modelo ainda se encontra em fase de elaboração devido a algumas dificuldades teóricas que precisam ser ainda resolvidas a respeito da dinâmica descrita pelo autômato celular. Ironicamente, as dificuldades a serem superadas não advêm da parte fuzzy do modelo. Todavia, este trabalho é ao meu ver extremamente interessante por ilustrar uma outra faceta da teoria de conjuntos fuzzy, que pode ser do interesse dos físicos estatísticos, qual seja, auxiliar no tratamento teórico dedados experimentais obtidos a partir de condições subjetivas.

O experimento realizado é intrisicamente subjetivo e, se assim não o fosse, não seria possível realizá-lo. De fato, Miramontes e DeSouza construíram os seus experimentos e escolheram as espécies a serem estudadas de forma que o canibalismo fosse evitado, justamente pela ausência de ferramenta teórica que lhes permitissem agregar ao modelo a subjetividade. Neste processo, o estudo de espécies que apresentam canibalismo torna-se excluído. Todavia, a espécie de cupins que mais nos interessa devido a epidemia existente no eixo Rio-São Paulo apresenta este comportamento, e o modelo proposto é uma alternativa para incluí-los neste tipo de estudo. Sendo assim, ainda que este trabalho não tenha sido concluído a tempo de seus resultados teóricos constarem nesta tese, penso ter sido importante citá-lo.

\subsection{Sistema especialista fuzzy para diagnóstico de doenças pulmonares}

Neste trabalho é proposto um sistema diagnóstico $n$-dimensional, baseado na sugestão de Bellamy (Bellamy 1997). Nesta proposta cada dimensão do espaço diagnóstico representa um sintoma clínico composto por subconjuntos fuzzy que representam diferentes categorias de intensidade. Por exemplo, o sintoma febre pode ser categorizada em ausente, moderada e intensa, sendo cada um desses termos lingüísticos conjuntos fuzzy. Desta forma, um paciente cujo protocolo apresente um conjunto de dados clínicos é representado por um ponto neste espaço $n$-dimensional, cuja região corresponderá ao diagnóstico mais possível. A proposta é utilizar a operação das relações 
fuzzy para inferirmos um conjunto fuzzy de diagnóstico para doenças pulmonares. $\mathrm{O}$ interessante nesta técnica é que ela é facilmente implementada em contraste com os sistemas especialistas clássicos.

Primeiramente, junto ao especialista escolhemos um conjunto de sintomas, constituído por informações do paciente, dados clínicos e exames laboratoriais, que representaremos pela letra $S$. Este conjunto é composto pelos diversos graus de pertinência de cada sintoma nas respectivas categorias de intensidade. Os sintomas considerados até então e os seus termos lingüísticos são apresentados abaixo:

- Sintomas que o paciente comunica:

- dispnéia: ausente, leve, moderada e intensa;

- febre: ausente, moderada e intensa;

- tempo de doença: agudo, sub-agudo e crônico;

- tosse: ausente e presente;

- sudorese: ausente e presente;

- perda de peso: ausente, leve, moderada e intensa;

- expectoração: ausente e presente;

- hemoptise: ausente, leve, moderada e intensa;

- situação socio-econômica: pouco satisfatória, média e satisfatória;

- alcoolismo: ausente e presente;

- antecedentes: presente, ausente e duvidoso;

- sexo: feminino e masculino (conjuntos clássicos);

- idade: criança, jovem adulto, adulto e idoso;

- fumo: ausente, leve, moderada e intensa;

- Sintomas do exame clínico:

- temperatura corporal: ausente, moderada e intensa;

- estado nutricional: desnutrição grau III, desnutrição grau II, desnutrição grau I, eutrófico (normal), sobre-peso e obeso;

- estado geral: mal, regular e bom;

- propedêutica do pulmão: normal, sugestivo e suspeita;

- Sintomas dos exames laboratoriais:

- Raio X: normal, sugestivo e suspeita;

- cultura de escarro: normal, sugestivo e suspeita;

- exame direto: normal, sugestivo e suspeita;

- anátomo patológico: normal, sugestivo e suspeita;

- hemograma: normal, sugestivo e suspeita;

- tomografia computadorizada: normal, sugestivo e suspeita;

- broncoscopia: normal, sugestivo e suspeita;

Sendo assim, para cada paciente podemos elaborar diferentes "estados clínicos", a partir da combinação dos diversos termos lingüísticos. Porém, para inferirmos o 
diagnóstico escolheremos, neste primeiro momento, apenas o estado máximo, ou seja, o mais crítico, onde os graus de pertinência nas diversas etiquetas são máximos. $\mathrm{Na}$ verdade seria interessante analisar todos os estados possíveis, porém, o custo computacional quando comparado com o acréscimo de informação não justifica esta medida. De fato, a operação matemática utilizada é tal que somente os valores máximos são expressos no diagnóstico final, no entanto, uma análise da distribuição dos valores das possibilidade para as diversas doenças, considerando todos os estados, poderia ajudar na discriminação da patologia mais possível, expressando um tipo de medida da confiabilidade do resultado. Este processedimento será analisado num momento posterior. Posteriormente, foram escolhidas sete possíveis diagnósticos que compõem o conjunto de doenças, $D$ :

- pneumonia;

- tuberculose;

- bronquiectasia infectada;

- paracoccidioidomicose infectada;

- histoplasmose;

- câncer do pulmão;

- pneumoconiose.

A etapa seguinte consistiu na elaboração, juntamente com o especialista, de uma matriz de relação entre sintomas e doenças, $R^{\prime}$, que é construída considerando os diferentes termos lingüísticos para cada sintoma e as sete patologias escolhidas. A matriz de relação final, $R$, é construída para cada paciente considerando apenas o caso limite descrito acima.

Uma outra informação importante neste processo de diagnóstico é o quanto cada sintoma é discriminante para cada doença. Por exemplo, o fator febre intensa pode significar muito para o diagnóstico da pneumonia e ser irrelevante para o de câncer do pulmão. Para considerarmos o poder discriminante de cada sintoma com relação a cada patologia elaboramos uma matriz de discriminação, $P$, que nada mais é do que uma matriz que fornece um peso para cadasítio da matriz de relação $R$. Sendo assim, a matriz de relação final $R^{*}$ corresponderá a matriz $R$ ponderada pela matriz $P$. E assim, a relação fuzzy entre os sintomas $(s)$ e as doenças $(d)$ será dado por

$$
D=S \circ R
$$

cujos graus de pertinência são obtidos ela expressão:

$$
\mu_{D}=\max _{s \in S}\left[\min \left(\mu_{S}(s), \mu_{R}(s, d)\right)\right] .
$$

O exemplo que segue ilustra como funciona este tipo de sistema especialista. Seja um conjunto de sintomas dados por $S=$ [tosse, febre, tempo de doença, $R X$ pneumonia, $R X$-tuberculose, $R X$-broquiectasia infectada] e um conjunto de doenças dado por $D=[$ pneumonia, tuberculose, bronquiectasia infectada]. Os conjuntos fuzzy 
que caracterizam os sintomas são: tosse $=$ [ausente, presente], febre $=$ [ausente, moderada, intensa], tempo de doença = [agudo, sub-agudo, crônico] e RX-pneumonia, turberculose, bronquiectasia infectada = [normal, sugestivo, suspeito].

Considere agora um paciente cujos dados clínicos sejam: $3^{+}$de tosse, temperatura corporal $38,7^{\circ} \mathrm{C}, 14$ dias de doença, $0^{+} / 1^{+}$de RX-pneumonia, $1^{+} / 2^{+}$de RXtuberculose e $2^{+}$RX-bronquiectasia infectada. Desses valores resultam que os graus de pertinência nos vários conjuntos fuzzy ${ }^{2}$, para cada sintoma, são: tosse $=[0,0 ; 1,0]$, febre $=[0,0 ; 0,43 ; 0,47]$, tempo de doença $=[0,0 ; 0,9 ; 0,0], R X$-pneumonia $=[1,0 ; 0,25$; $0,0], R X$-turberculose $=[0,0 ; 0,75 ; 0,0]$ e $R X$-bronquiectasia infectada $=[0,0 ; 1,0$; $0,0]$. Escolhendo os valores máximos dos graus de pertinência nos sintomas montamos o estado do paciente citado: $S=[1,0 ; 0,47 ; 0,9 ; 1,0 ; 0,75 ; 1,0]$ correspondendo à $S=$ [tosse presente, febre moderada, tempo de doença sub-agudo, $R X$-Pn normal, $R X-T b$ sugestivo, $R X-B I$ sugestivo]. A matriz $R^{\prime}$ que relaciona os sintomas (linhas) com as doenças (colunas) é dada, neste exemplo didático, por

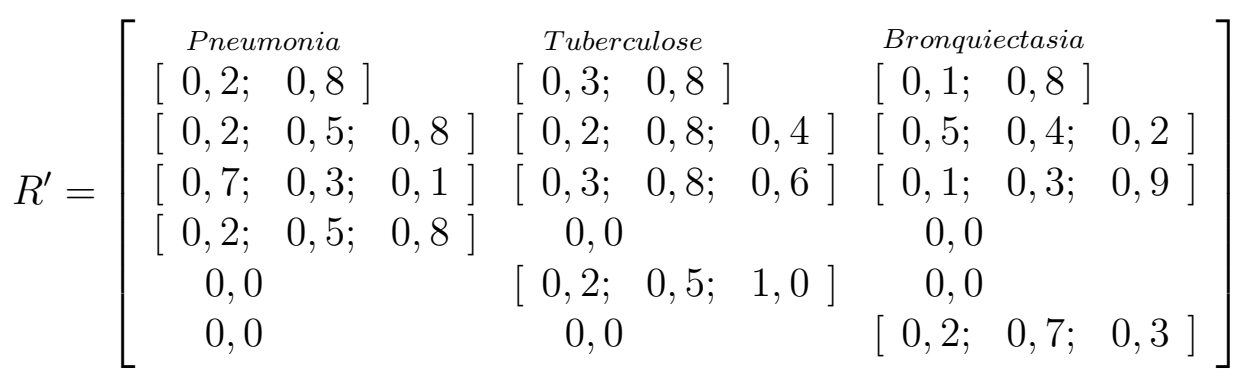

e considerando as etiquetas correspondentes aos valores máximos de graus de pertinência ao conjunto de sintomas construimos a matriz $R$, já característica do paciente:

$$
R=\left[\begin{array}{ccc}
0,8 & 0,8 & 0,8 \\
0,8 & 0,4 & 0,2 \\
0,3 & 0,8 & 0,3 \\
0,2 & 0,0 & 0,0 \\
0,0 & 0,5 & 0,0 \\
0,0 & 0,0 & 0,7
\end{array}\right]
$$

A matriz que considera a importância de cada sintoma na discriminação do dianóstico é:

$$
P=\left[\begin{array}{lll}
0,2 & 0,3 & 0,4 \\
0,8 & 0,7 & 0,3 \\
0,4 & 0,6 & 0,7 \\
0,9 & 0,0 & 0,0 \\
0,0 & 0,7 & 0,0 \\
0,0 & 0,0 & 0,6
\end{array}\right]
$$

\footnotetext{
${ }^{2}$ Estes valores são calculados a partir das funções de pertinência para cada termo lingüístico que por simplicidade não serão citadas. Todas as funções consideradas são triangulares ou trapezoidais.
} 
o que resulta na matriz de relação final,

$$
R^{*}=\left[\begin{array}{lll}
0,16 & 0,24 & 0,32 \\
0,64 & 0,28 & 0,06 \\
0,12 & 0,48 & 0,21 \\
0,18 & 0,0 & 0,0 \\
0,0 & 0,35 & 0,0 \\
0,0 & 0,0 & 0,42
\end{array}\right] .
$$

E finalmente, o conjunto fuzzy das doenças é dado pela relação 10.2 :

$$
D=[1,0 ; 0,47 ; 0,9 ; 1,0 ; 0,75 ; 1,0] \circ\left[\begin{array}{lll}
0,16 & 0,24 & 0,32 \\
0,64 & 0,28 & 0,06 \\
0,12 & 0,48 & 0,21 \\
0,18 & 0,0 & 0,0 \\
0,0 & 0,35 & 0,0 \\
0,0 & 0,0 & 0,42
\end{array}\right]=[0,47 ; 048 ; 0,42]
$$

correspondendo a grau de pertinência 0,47 no grupo pneumonia, 0,48 no grupo tuberculose e 0,42 no grupo bronquiectasia infectada, o que poderia mostrar uma "tendência" ao diagnóstico de tuberculose. No entanto,neste exemplo, o método mostra-se pouco decisivo uma vez que os valoresobtidos são muito semelhantes. Talvez este fosse um caso em que a análise dos outros estados poderia fornecer outras informações queauxiliasse na escolha do diagnóstico. Este trabalho encontra-se ainda nafase inicial dos testes e, portanto, ainda precisa ser refinado. O exemplo acima pretende apenas demonstrar a idéia que estamos desenvolvendo.

O programa para este sistema especialista para doenças pulmonares está completamente pronto e disponível para análise via web na página http://infomed.fm.usp.br:8001. A idéia é que o sistema esteja disponível para ser acessado de qualquer lugar por qualquer profissional da área de saúde, bem como universidades. Considerando que o sistema é composto de 70 sintomas e 7 patologias, é extremamente complicado realizar os ajustes finos apenas com a opinião de um especialista. Têm se revelado, portanto, necessária a elaboração de um painel de especialistas onde cada um fornecerá os seus próprios conjuntos fuzzy, bem como matrizes de relação e discriminação. A partir da composição desse painel obteremos um sistema fuzzy mais adequado e que, consequentemente, acerte mais. Este painel de especialista será de grande ajuda para criarmos bons conjuntos fuzzy e matrizes de relacões/discriminações mães. Porém, acredito que um bom sistema especialista somente será possível depois de refinados todos os parâmetros através de um algoritmo genético.

Uma vez desenvolvido completamente o sistema, um segundo passo seria transformar o sistema especialista em um sistema adaptativo, onde através de outro algoritmo genético outras matrizes de relação e discriminação fossem produzidas como mutações das matrizes mães (do sistema original). Com o tempo as matrizes que apresentassem um maior poder diagnóstico seriam selecionadas e substituiriam as matrizes mães. 
Este procedimento tornaria o sistema especialista adaptável a regiões distintas uma vez que, dependendo de fatores climáticos e ambientais, alterações nas relações sintoma/doença podem ser observadas (uma febre alta pode ter significados levemente distintos no sul ou no norte do nosso pais, por exemplo).

Algoritmos genéticos têm se mostrado de grande utilidade na seleção de conjuntos e regras fuzzy mais adequados à modelagem de sistemas. Eles têm sido empregados com sucesso em problemas de engenharia. Penso que a união do painel de especialistas com a adaptação do sistema, sendo ele "treinado" com um largo banco de dados do HC, nos proporcionará um sistema especialista com grande margem de acertos.

O fato desse sistema ser computacionalmente muito simples permite que sua utilização seja efetiva. Todavia, vale ressaltar que, não temos como saber a princípio se esse sistema especialista apresentará ou não poder discriminativo no diagnóstico, dado a simplicidade do modelo. Os especialistas em pneumologia do HC/FMUSP se mostraram muito interessados no desenvolvimento desse sistema, o que é, a meu ver, um indicativo de que ele poderia ser útil tanto em postos de saúde(onde muitas vezes não há a figura do especialista) quanto no treinamento de residentes.

\subsection{Fuzzy clustering em epidemiologia}

O principal objetivo da classificação não supervisionada é identificar subgrupos naturais baseado na identificação de semelhanças entre pares de objetos. Ela também é motivada pela necessidade de se obter padrões ou agrupamentos de objetos em um dado conjunto de dados. Essas características justificam sua relação profunda com os processos de reconhecimento de padrões e sua vasta aplicação em processamento de imagens médicas.

Uma abordagem alternativa aos modelos dinâmicos não-lineares, que são utilizados para descrever os processos epidêmicos, seria considerar um modelo de agrupamento fuzzy de 3 elementos. Em um agrupamento de 3 elementos as variáveis são classificadas como Objetos, Atributos e Situações, consistindo em uma abordagem de espaço de estados unido a técnicas de otimização. Em um modelo epidêmico de agrupamento fuzzy as variáveis de estado são consideradas como grupos (clusters), os parâmetros são considerados atributos e as situações são a variação temporal de cada indivíduo no grupo. Este tipo de modelo parece ser interessante para tratar pequenas populações, uma vez que ele permite atribuir valores individuais para as variáveis.

Em um modelo de 3 elementos temos que $X(t)=x_{i a}(t)$ é uma matriz que descreve os dados do sistema, com $i=1,2, \ldots, n, a=1,2, \ldots, p$ e $t=1,2, \ldots, T$, onde consideramos $p$ variáveis com respeito a $n$ indivíduos em $T$ passos de tempo. A proposta do agrupamento fuzzy é classificar os $n$ objetos em $K$ grupos. O valor da função de pertinência que designa o grau de pertinência de cada objeto nos grupos é denotado por $U=\mu_{i k}$, onde $\mu_{i k} \geq 0$ e $\sum_{k=1}^{K} \mu_{i k}=1 \mathrm{com} i=1,2, \ldots, n$ e $k=1,2, \ldots K$. O centróide do grupo $K$ no tempo $t$ é $v_{k}^{t}=v_{k a}^{t}$, onde $a=1,2, \ldots, p$ são os atributos em questão 
(Sato et al 1997).

Suponhamos, então, uma situação epidêmica onde três estados são considerados, quais sejam Suscetível, Infectado e Recuperado (modelo tipo SIR). Cada estado pode ser considerado como um grupo fuzzy $(K=S, I$ e $R)$. Assumindo $p$ variáveis diagnóstico, que definirão os indivíduos como pertencentes a um dado grupo (ou a vários), tais como febre, soropositividade aos anticorpos de IgM, ou qualquer outro exame clínico e/ou laboratorial. Os $i$ indivíduos apresentarão valores em todas as $p$ variáveis, que poderão ou não variar com o tempo, $x_{i a}^{t}$. Portanto, é possível definir uma função de pertinência que designe o grau de pertinência do indivíduo $i$ no cluster $K$ dados os valores assumidospara os $p$ parâmetros. Cada cluster possui um centróide que pode evoluir no tempo. A análise dessa evolução temporal pode nos fornecer a dinâmica da epidemia considerada. Sendo assim, a estrutura matemática do fuzzy clustering pode representar uma abordagem alternativa para o tratamento dinâmico de epidemias, onde sejam consideradas as subjetividades reais dos processos. Este tipo de abordagem pode vir a nos fornecer também informações sobre o valor de reprodutibilidade basal, $R_{0}$.

\subsection{Modelos lingüísticos fuzzy}

A parte o aspecto dinâmico da epidemiologia, muitas são as contribuições que a teoria de conjuntos fuzzy pode oferecer aos modelos epidêmicosestáticos, produzindo resultados que podem ajudar os epidemiologistas eos profissionais de saúde de diversas maneiras. Além dos trabalhosapresentados no capítulo 7, tenho desenvolvido colaborações com profissionais de diferentes áreas e muitos são os projetos detrabalhos razoavelmente simples, porém significativos, que podem ser desenvolvidos ainda com modelos lingüísticos. Alguns desses trabalhos são:

- modelo para avaliação do comprometimento do desenvolvimento neuromotor e psicomotor de recém nascidos a partir variáveis do pré-natal, do seu nascimento e do tipo de aleitamento;

- avaliação da possibilidade de parto precoce, ou com complicações, a partir de dados do pré-natal;

- mensuração da qualidade de vida baseada na avaliação da incapacidade (mobilidade, atividade física e social) a partir de uma análise fuzzy das variáveis utilizadas no QWB (Quality of Well being scale) clássico;

- prognóstico de pacientes infectados com HTLV1 com a intenção de verificar quais deles potencialmente desenvolverão alterações neurológicas;

- avaliação de risco a tuberculose considerando indicadores de risco tais como nível de escolaridade da mãe, número de pessoas residentes e número de pontos de água na casa; 
- avaliação de risco de morte e desenvolvimento de crianças recém nascidas com baixo Apgar, em Unidades de Tratamento Intensivo.

Em alguns desses trabalhos teremos a disponibilidade de dados experimentais, o que nos possibilitará o desenvolvimento de modelos híbridos. 


\section{Capítulo 11}

\section{Considerações finais}

O objetivo desta tese foi o de desenvolver aplicações da teoria de lógica fuzzy em problemas da biomedicina. Particularmente em epidemiologia, são muito poucos os trabalhos existentes com lógica fuzzy, sendo esta área ainda muito incipiente. De fato, ousaria dizer que o Brasil é um dos pioneiros nas pesquisas sobre aplicações dessa teoria em epidemiologia. Neste sentido, penso que uma das contribuições importantes dessa tese é a de agregar algum conhecimento às pesquisas realizadas nessa área. Contudo, o trabalho desenvolvido nesta tese está longe de encerrar conclusivamente algumas questões. Na verdade, esses trabalhos desvendam um universo de aplicações e possibilidades que nos animam intensamente a continuar os estudos nessa linha de pesquisa.

Ao longo da tese, várias análises a respeito da contribuição, das dificuldades e dos resultados obtidos com cada trabalho foram apresentadas. Todavia, gostaria de ressaltar algumas considerações e aspectos que julgo mais importantes:

- O estimador de risco fuzzy (FOR) que propomos forneceu resultados qualitativamente coerentes com os conceitos epidemiológicos. Logo, a teoria de conjuntos fuzzy pode ser efetivamente útil no desenvolvimento e generalização de conceitos epidemiológicos clássicos. Vale ressaltar que generalizações desse tipo podem conduzir a interpretações dos fenômenos diversas das estabelecidas, podendo acarretar transformações importantes nas estruturas dos sistemas teóricos em medicina e epidemiologia.

- O especialista de uma forma geral é capaz de traduzir o seu conhecimento empírico e acadêmico, bem como a sua experiência, em conjuntos e regras fuzzy. Entretanto, ele apresenta dificuldades para expressar o seu conhecimento quando o número de variáveis do sistema é razoavelmente grande ou quando as variáveis estão fortemente correlacionadas. No caso dos modelos lingüísticos a dificuldade maior surgiu na elaboração dos conjuntos fuzzy conseqüentes das regras.

- Os modelos lingüísticos forneceram bons resultados e apresentam possibilidades reais de aplicação. Muitas grandezas em medicina e epidemiologia são estimadas por especialistas baseados em julgamentos subjetivos. A estimativa do risco 
de morte neonatal, a nota de APGAR, a avaliação de desenvolvimento neuro e psicomotor, e o valor de QWB são alguns exemplos. Além disso, estimadores baseados em avaliações subjetivas podem variar a depender das condições em que se encontre o especialista no momento da avaliação (cansaço, estresse, desatenção, etc.). Ocorre ainda que, na ausência de um especialista, outros profissionais conduzem estas avaliações, o que em geral produz valores distintos dos fornecidos pelo especialista, podendo conduzir a erros. Neste sentido, um sistema de apoio que possa auxiliar os profissionais de saúde, ou mesmo fazer o papel do especialista na sua ausência, pode vir a ser extremamente útil. Contudo, para que esses sistemas atinjam aos que dele necessitam, qual seja hospitais modestos, postos de saúde, etc., é importante que eles sejam simples, de fácil compreenssão e de baixo custo. Os modelos apresentados no capítulo 7 e os discutidos na seção 10.4 são exemplos de sistemas com essa finalidade, que podem ser facilmente implementados.

- Os modelos lingüísticos dinâmicos forneceram bons resultados, com ressalva feita aos modelos tipo TSK. Todavia, sua implementação pode vir a ser muito trabalhosa e não fornecer resultados satisfatórios a depender da quantidade de variáveis e da correlação entre elas. Isto se deve às dificuldades que o especialista apresenta para traduzir o seu conhecimento, discutidas anteriormente. Nestes casos, a abordagem clássica permanece como uma boa opção e a teoria de conjuntos fuzzy pode ser útil nessa modelagem tratando as grandezas que são intrinsicamente nebulosas e fornecendo valores mais realistas para os parâmetros do modelo clássico.

- A utilização do princípio de extensão na construção das regras fuzzy forneceu bons resultados para o modelo desenvolvido e pode representar uma alternativa aos problemas relatados no item anterior. Todavia, é necessário aplicá-lo a sistemas mais complexos e verificar se ele apresentará sucesso também nesses casos.

- O modelo de decisão fuzzy para escolher a estratégia mais adequada de campanha de vacinação contra o sarampo, que foi implementada no Estado de São Paulo em 1997, é, sem dúvida, um exemplo prático do quanto esta teoria pode ser efetivamente aplicável, e como ela pode ser útil para auxiliar autoridades de Saúde Pública na tomada de decisões. Este trabalho ilustra a capacidade de adesão por parte desses profissionais a modelos desenvolvidos com esta teoria.

- Uma das principais vantagens da teoria de conjuntos fuzzy em relação a outras abordagens de modelagem matemática é a facilidade de sua compreensão por parte de profissionais cuja formação não foi na área de exatas. De fato, muito pouco conhecimento de matemática é necessário para se compreender, basicamente, os conceitos e estruturas dessa teoria. Além disso, a possibilidade de trabalhar com variáveis lingüísticas aproxima a linguagem do modelo com 
a linguagem natural utilizada por esses profissionais, o que faz com que eles se sintam a vontade para expressar o seu conhecimento. Estas características da lógica fuzzy viabilizam a interdisciplinariedade nesses tabalhos.

Além das considerações citadas, gostaria de ressaltar também que a abordagem fuzzy para o estudo de facilitação social entre cupins que apresentam canibalismo surgiu da necessidade de tratar um aspecto subjetivo inerente ao processo experimental. Esta abordagem permitirá esse tipo de estudo em espécies que apresentam esse comportamento. Este trabalho, embora não concluído a tempo para esta tese, sinaliza uma alternativa interessante com a qual outros estudos em biologia poderão ser desenvolvidos, considerando os aspectos subjetivos tão comuns nessa área. Nesse viés, a teoria de conjuntos fuzzy poderá adentrar o mundo dos físicos estatísticos, auxiliando-os a desenvolver modelos mais realistas, a partir de sua combinação com as técnicas de simulação.

Considerando tudo que foi exposto, é possível agora responder as perguntas colocadas no início desse texto, quais sejam: Esta teoria pode realmente ser útil na solução de problemas da biomedicina? Esta abordagem fornece resultados efetivamente aplicáveis? De que maneiras podemos aplicar a lógica fuzzy em sistemas epidemiológicos?. A resposta que esta tese fornece é: Sim, a lógica fuzzy é uma estrutura matemática adequada para abordar problemas de biomedicina. Em particular, na epidemiologia ela se apresenta como uma ferramenta útil e de aplicabilidade real e efetiva. Existem diversas maneiras de se utilizar a lógica fuzzy na solução desses problemas. Escolher entre uma e outra consiste na arte de criar modelos e depende do tipo de resposta desejada e do tipo de informação disponível. Essa tese apresenta algumas dessas possibilidades.

Para concluir, gostaria de relatar que quando apresento essa teoria aos médicos e aos profissionais de saúde, eles se mostram àvidos por conhecê-la porque identificam nela uma ferramenta importante para ajudá-los nos seus problemas. A possibilidade de uma abordagem que lhes seja compreensível e que possa tratar algumas incertezas naturais do seu cotidiano profissional parece animá-los. É assim que muitos trabalhos e idéias nos são apresentados, o que corrobora a importância da continuidade da pesquisa nessa área. 


\section{Referências Bibliográficas}

[1] Adlassnig K. 2000. "Fuzzy Diagnostic and Therapeutic Decision Support". ERUDIT-Workshop, Viena-Austria, editado pela Österreichishe Computer Gesellschaft.

[2] Ahmed E. 1996. "Fuzzy cellular automata models in immunology". Journal of Statistical Physics 85 (1/2), 291-293.

[3] Ahmed E. 1997. "On modelling oral tolerance using cellular automata". Physica A 237, 449-451.

[4] Aminzadeh F. \& Jamshidi M. 1994. Soft Computing: Fuzzy Logic, Neural Networks and Distributed Artificial Intelligence. editora Prentice Hall, USA.

[5] Anderson J., Bandler W., Kohout L.J. e Trayner C. 1987. "A Route-Choosing Medical Diagnostic Technique". Fuzzy Sets and Systems 23, 89-96.

[6] Anderson R. M. \& May R. M.. "Infectious diseases of humans: Dinamics and Control". Oxford University Press, Reino Unido, 1991.

[7] Anwar T. \& Igor B. 1997. "Fuzzy Classification System for Psychiatry". in: Proceedings of Seventh IFSA World Congress, Praga, República Checa.

[8] Averkin A.N. \& Tarasov V.B. 1987. "The fuzzy modelling relation and its application in psychology and artificial intelligence". Fuzzy Sets and Systems 22, 3-24.

[9] Baidosov V. A. 1990. "Fuzzy Differential Inclusions". PMM Journal of Applied Mathematics and Mechanics 54(1), 8-13.

[10] Bai-Lian Li 1996, Special Issue Fuzzy Modelling in Ecology. Ecological Modelling 90, 1996.

[11] Barros L.C. 1992. "Modelos determinísticos com parâmetros subjetivos". Dissertação de Mestrado, Instituto de Matemática, Estatística e Ciência da Computação, Universidade de Campinas, Brasil.

[12] Barros L.C., Bassanezi R.C. e Tonelli P.A. 2000. "Fuzzy modeling in population dynamics". Ecological Modelling 128, 27-33. 
[13] Bassanezi R.C. \& Barros L.C. 1995. "A simple model of life expectancy with subjective parameters". Kybernetes 24 (9), 91-98.

[14] Battiston F.M., Bammerlin M., Loppacher C., Lüthi R., Meyer E., Güntherodt H.J. e Eggimann F. 1998. "Fuzzy controlled feedback applied to a combined scanning tunneling and force microscope". Applied Physics Letters 72 (1), 2527.

[15] Bellamy J.E. 1997. "Medical diagnosis, diagnostic spaces and fuzzy systems". Journal of American Veterinarian Medicine Association 210 (3), 390-396.

[16] Bellman R. \& Zadeh L.A. 1970. "Decision-making in a fuzzy environment". Management Science 17, 141-154.

[17] Bezdek J.C., Hall L.O., Clark M.C., Goldgof D.B. e Clarke L.P. 1997. "Medical image analysis with fuzzy models". Stat. Methods Med. Res. 6 (3), 191-241.

[18] Biswas R. 1995. "An application of fuzzy sets in student's evaluation". Fuzzy Sets and Systems 74, 187-194.

[19] Bobylev V.N. 1990. "A possibilistic argument for irreversibility". Fuzzy Sets and Systems 34, 73-80.

[20] Bordley R. 1989. "Fuzzy set theory, observer bias and probability theory". Fuzzy Sets and Systems 33, 347-354.

[21] Boswell S.B. \& Taylor M.S. 1987. "A central limit theorem for fuzzy random variables". Fuzzy Sets and Systems 24, 331-344.

[22] Buckley J.J. \& Siler W. 1988. "Echocardiogram analysis using fuzzy sets and relations". Fuzzy Sets and Systems 26, 39-48.

[23] Campbell D.E. \& Kelly J.S. 1996. "Social choice trade-offs for an arbitrary measure: with application to uncertain or fuzzy agenda". Economics Letters 50, 99-104.

[24] Campos Ibañez L.M. \& Carmona M. J. B. 1989. "Representations of fuzzy measures through probabilities". Fuzzy Sets and Systems 31, 23-36.

[25] Campos L.M., Lamata M.T. e Moral S. 1990. “ Distances between fuzzy measures through associated probabilities: some applications". Fuzzy Sets and Systems $35,57-68$.

[26] Casals M.R., Gil M.A. e Gil P. 1986. "On the use of Zadeh's probabilistic definition for testing statistical hypotheses from fuzzy information". Fuzzy Sets and Systems 20, 175-190. 
[27] Cattaneo G. \& Laudisa F. 1994. "Axiomatic Unsharp Quantum Theory". Foundations of Physics 24 (5), 631-683.

[28] Cattaneo G., Flocchini P., Mauri G., Quaranta Vogliotti C. e Santoro N. 1997. "Cellular automata in fuzzy backgrounds". Physica D 105, 105-120.

[29] Chang P \& Lee E.S. 1996. "A generalized fuzzy weighted least-squares regression". Fuzzy Sets and Systems 82, 289-298.

[30] Chen W.L., Guo R.J., Shang L.S. e Ji T. 1985. "Fuzzy Match and Floating Threshold Strategy for Expert System in Traditional Chinese Medicine". Fuzzy Sets and Systems 17, 143-151.

[31] Cheng C.K., Chaung L. e Chang C.H. 1992. "Fuzzy logic control of steam generator water level in pressurized water reactors". Nuclear Technology 100, 125134.

[32] Costa N.C.A., Abe J.M., Silva Filho J.I., Murolo A.C. e Leite C.F.S. 1999. Lógica Paraconsistente Aplicada. editora Atlas, São Paulo, Brasil.

[33] Coutinho F.A.B., Massad E., Menezes R.X. e Burattini M.N. 1999. "A theoretical model of the evolution of virulence in sexually transmitted HIV/AIDS". Journal of Public Health 33 (4), 329-33.

[34] De Finetti B. 1939. "Compte rendu critique du colloque de Genève sur la théorie des probabilités". Act. Sci. Ind. 766.

[35] De Finetti B. 1970. Teoria delle Probabilità. editora Einandi, volume I, Torino, Itália.

[36] Degani R. \& Bortolan G. 1987. "Fuzzy numbers in computerized electrocardiography". Fuzzy Sets and Systems 24, 345-362.

[37] Delgado M. \& Moral S. 1987. "On the concept of possibility-probability consistency". Fuzzy Sets and Systems 21, 311-318.

[38] Del Castillo-Mussot M. \& Dias R. C. 1993. "Fuzzy sets and physics". Revista Mexicana de Física 39 (2), 295-303.

[39] Diamond P. 1999. "Time-dependent differential inclusions, cocycle attractors and fuzzy differential equations". IEEE Transactions on Fuzzy Systems 7 (6), 734-740.

[40] Drakopoulos J. A. 1995. "Probabilities, possibilities, and fuzzy sets". Fuzzy Sets and Systems 75, 1-15.

[41] Dubois D. \& Prade H. 1982a. "Towards fuzzy differential calculus Part 1: Integration of fuzzy mappings". Fuzzy Sets and Systems 8, 1-17. 
[42] Dubois D. \& Prade H. 1982b. "Towards fuzzy differential calculus Part 2: Integration of fuzzy intervals". Fuzzy Sets and Systems 8, 105-116.

[43] Dubois D. \& Prade H. 1982c. "Towards fuzzy differential calculus Part 3: Differentiation". Fuzzy Sets and Systems 8, 225-233.

[44] Dumitrescu D. 1995. "Entropy of fuzzy dynamical systems". Fuzzy Sets and Systems 70, 45-57.

[45] Esogbue A.O. \& Elder R. C. 1980. "Fuzzy Sets and the Modelling of Physician Decision Processes, Part II: Fuzzy Diagnosis Decision Models". Fuzzy Sets and Systems 3, 1-9.

[46] Esogbue A.O. \& Elder R. C. 1983. "Measurement and Valuation of a Fuzzy Mathematical Model for Medical Diagnosis". Fuzzy Sets and Systems 10, 223242.

[47] Féron M. \& Féron R. 1988. "Fuzzy especifications and random fuzzy events considered as basic tools for statistical prediction". Fuzzy Sets and Systems 28, 285-293.

[48] Ferson S. \& Ginzburg L.R. 1996. "Different methods are need to propagate ignorance and variability". Reliability Engineering and System Safety 54, 133144.

[49] Flocchini P., Geurts F., Mingarelli A. e Santoro N. 2000. "Convergence and aperiodicity in fuzzy cellular automata: revisiting rule 90". Physica D 142, 20-28.

[50] Fonseca D.J. \& Knapp G. M. 2000. "An expert system for reliability centered maintenance in the chemical industry". Expert Systems with Applications 19, $45-57$.

[51] Friedman Y. \& Sandler U. 1997. "Fuzzy dynamics. A new way for description of uncertainty in complex systems". in: Proceedings of Seventh IFSA World Congress, Praga, Republica Checa.

[52] Friedman Y. \& Sandler U. 1999. "Fuzzy dynamics as an alternative to statistical mechanics". Fuzzy Sets and Systems 106, 61-74.

[53] Giering III \& Kandel A. 1983. "The application of fuzzy set theory to the modeling of competition in ecological systems". Fuzzy Sets and Systems 9, 103127.

[54] Giles R. 1976. "Lukasiewicz logic and fuzzy set theory". International Journal of Man-Machine Studies 8, 315. 
[55] Giles R. 1977. "A non-classical logic for physics". in: Selected Papers on Lukasiewicz Sentential Calculi, R. Wojcicki, Ossolineum, Wroclaw (uma versão reduzida foi publicada no Studia Logica 33, 1974, pp. 397).

[56] Granik A. \& Caulfield J. 1996. "Fuzziness in Quantum Mechanics". Physics Essays 9 (3), 496-505.

[57] Greenland S. 1987. "Interpretation and choice of effect measures in epidemiologic analysis". American Journal of Epidemiology 125, 761-768.

[58] Guerra T.M., Loslever P., Malvache N. e Willaeys D. 1996. "Probabilistic sets and fuzzy reasoning for data analysis problems". Fuzzy Sets and Systems 84, 199-208.

[59] Gupta C.P. 1993. "A note on the transformation of possibilistic information into probabilistic information for investment decisions". Fuzzy Sets and Systems 56, 175-182.

[60] Guz W. 1984. "Stochastic phase space, fuzzy sets, and statistical metric spaces". Foundations of Physics 14, 821.

[61] Guz W. 1985. "Fuzzy $\sigma$-algebras of physics". International Journal of Theoretical Physics 24, 481.

[62] Ham F.M. \& Han S. 1996. "Classification of cardiac arrhythmias using fuzzy ARTMAP". IEEE Trans. Biomed. Eng. 43 (4), 425-430.

[63] Han Y.J. \& Lee B.W. 1994. "Fuzzy power control algorithm for a pressurized water reactor". Nuclear Technology 106, 242-253.

[64] Heilpern S. 1993. "Fuzzy subsets of the space of probability measures and expected value of fuzzy variable". Fuzzy Sets and Systems 54, 301-309.

[65] Holbert K.E., Sharif Heger A. e Alang-Rashid N.K. 1994. "Redundant sensor validation by fuzzy logic". Nuclear Science and Engineering 118, 54-64.

[66] Hutchins S.S., Markowitz L.E., Mead P. et al 1990. "A school-based measles outbreak: the effect of a selective re-vaccination policy and risk factors for vaccine failure". Am. J. Epidemiology 132, 157-168.

[67] Jekel J.F., Elmore J.G. e Katz D.L. 1999. Epidemiologia, Bioestatística e Medicina Preventiva. Artmed, Porto Alegre, Brasil.

[68] Kaleva O. 1987. "Fuzzy differential equations". Fuzzy Sets and Systems 24, 301-317.

[69] Kandel A. 1992. Fuzzy Expert Systems. editora CRC, USA. 
[70] Kasas S., Riederer B.M., Catsicas S., Cappela B. e Dietler G. 2000. "Fuzzy logic algorithm to extract specific interaction forces from atomic force microscopy data". Review of scientific instruments 71 (5), 2082-2086.

[71] Karwowski W. \& Mital A. 1986. "Potential Applications of Fuzzy Sets in Industrial Safety Engineering". Fuzzy Sets and Systems 19, 105-120.

[72] Kerre E.E. \& Nachtegael M. 2000. Fuzzy Techiques in Image Processing. editora Physica-Verlag, Alemanha.

[73] Klir G. \& Yuan B. 1995. Fuzzy Sets and Fuzzy Logic: Theory and Applications. editora Prentice Hall, USA.

[74] Kosko B. 1992. Neural Networks and Fuzzy Systems: A dynamical Systems Approach to Machine Intelligence. editora Prentice Hall, USA.

[75] Kosko B. 1997. Fuzzy Engineering. editora Prentice-Hall, USA.

[76] Kovalerchuk B., Triantaphyllous E., Ruiz J.F. e Clayton J. 1997. "Fuzzy logic in computer-aided breast cancer diagnosis: analysis of lobulation". Artificial Inteligence in Medicine 11 (1), 75-85.

[77] Kuncheva L.I. \& Steimann F. 1999. "Fuzzy diagnosis". Artificial Intelligence in Medicine 16, 121-128.

[78] Law C. 1996. "Using fuzzy numbers in educatinal grading system". Fuzzy Sets and Systems 83, 311-323.

[79] Lin J.S., Cheng K.S. e Mao C.W. 1996. "Segmentation of multispectral magnetic resonance image using penalized fuzzy competitive learning network". Comput. Biomed. Res. 29 (4), 314-326.

[80] Luger G.F. \& Stubblefield W.A. 1997. Artificial Inteligence: Structure and Strategies for Complex Problem Solving. editora Addison Wesley Longman, EUA.

[81] Luo L., Ji F. e Li H. 1995. "Fuzzy Classification of Nucleotide Sequences and Bacterial Evolution". Bulletin of Mathematical Biology 57 (4), 527-537.

[82] Majumder A.B.A.K. \& Basu A. 1995. "A Fuzzy Expert System Approach for Real-Time Monitoring of Endemic Diseases". Information Science 3, 41-53.

[83] Markowitz L.E. \& Katz S.L. 1994. "Measles vaccine". In: Plotkin S.A. \& Mortmer E.A., Vaccines, W.B. Saunders, Filadelfia, EUA, 229-276.

[84] Massad E., Burattini M.N., Azevedo Neto R.S., Yang H.M., Coutinho F.A.B. e Zanetta D.M.T. 1994. "A model-based desing of a vaccination strategy agaisnt rubella in a non-immunized community of São Paulo State". Epidemiol. Infect. 112, 579-594. 
[85] Massad E., Burattini M.N., Coutinho F.A.B. e Struchiner C.J. 1997. "A Fuzzy Model in HIV/AIDS Epidemiology: Predicting the Clinical Course Basing on HIV Viral Load". in: Proceedings of Soft Computing SOCO'97, Nime-France, 58-63.

[86] Massad E., Burattini M.N. e Ortega N.R.S. 1999. "Fuzzy Logic and Measles Vaccination: Designing a Control Strategy". International Journal of Epidemiology 28, 550-557.

[87] Massad E., Ortega N.R.S. e Struchiner C.J. 2001. "Fuzzy Epidemics". Artificial Intelligence in Medicine, a ser publicado.

[88] Matsuoka H. 1991. "A simple fuzzy simulation model for nuclear reactor system dynamics". Nuclear Technology 94, 228-241.

[89] Meisels A., Kandel A. e Gecht G. 1989. "Entropy, and the recognition of fuzzy letters". Fuzzy Sets and Systems 31, 297-309.

[90] Mezey P.G. 1998. "The proof of the metric properties of a fuzzy chirality measure of molecular electron density clouds". Journal of Molecular Structure 455, 183190.

[91] Miramontes O. \& DeSouza O. 1996. "The nonlinear dynamics of survival and social facilitation in termites". Journal of Theoretical Biology 181, 373-380.

[92] Murray C.J.L. \& Lopez A.D.. Global health statistics. The global burden of disease and injury series, Volume II. Harvard University Press, EUA, 1996.

[93] Natvig B. 1983. "Possibility versus probability". Fuzzy Sets and Systems 10, $31-36$.

[94] Nokes D.J. \& Swinton J. 1997. "Vaccination in pulses: a strategy for global eradication of measles and polio?". Trends in Microbiology 5, 14-19.

[95] Norris D., Pilsworth B.W. e Baldwin J.F. 1987. "Medical Diagnosis from Patient Records - A Method Using Fuzzy Discrimination and Connectivity Analyses". Fuzzy Sets and Systems 23, 73-87.

[96] Nurmi H., Kacprzyk J. e Fedrizzi M. 1996. "Probabilistic, fuzzy and rough concepts in social choice". European Journal of Research 95, 264-277.

[97] OH S., Kim W. e Lee J.K. 1990. "An approach to causal modeling in fuzzy environment and its application". Fuzzy sets and systems $\mathbf{3 5}$, 43-55.

[98] Ohayon M.M. 1999. "Improving Decision Making Processes with the Fuzzy Logic Approach in the Epidemiology of Sleep Disorders". Journal of Psychosomatic Research 47 (4), 297-311. 
[99] Onisawa T. 1988. "An approach to human reliability in man-machine systems using error possibility". Fuzzy Sets and Systems 27, 87-103.

[100] Onisawa T. \& Nishiwaki Y. 1988. "Fuzzy human reliability and analysis on the Chernobyl accident". Fuzzy Sets and Systems 28, 115-127.

[101] Ortega N.R.S., Sallum P.C. e Massad E. 2000. "Fuzzy Dynamical System in Epidemic Modelling". Kybernetes 29 (1-2), 201-218.

[102] Ortega N.R.S., Barros L.C. e Massad E. 2001. "An Application of the Extension Principle to Fuzzy Epidemic Models". Fuzzy Sets and Systems, submetido.

[103] Pearson D. W. 1997a. "A property of Linear Fuzzy Differential Equations". Appl. Math. Lett. 10 (3), 99-103.

[104] Pearson D. W. 1997b. "Some Structural Properties of Fuzzy Linear Dynamical Systems".in: Proceedings of Soft Computing SOCO'97, Nime,França, 77-81.

[105] Pearson D. W., Dray G. e Peton N. 1997c. "On Linear Fuzzy Dynamical Systems".in: Proceedings of Soft Computing SOCO'97, Nime,França, 203-209.

[106] Pearson D.W. 2000. "Simplex type differential inclusion". Applied Mathematics Letters 13 (4) 17-21.

[107] Pedrycz W. \& Gomide F. 1998. An Introduction to Fuzzy Sets: Analysis and Design. editora MIT Press, USA.

[108] Piasecki K. 1985. "Probability of fuzzy events defined as denumerable additivity measure". Fuzzy Sets and Systems 17, 271-284.

[109] Piasecki K. 1986. "Fuzzy probability spaces defined by means of the fuzzy relation 'Less Than'”. Fuzzy Sets and Systems 19, 273-289.

[110] Prugovecki E. 1974. "Fuzzy Sets in the Theory of Measurement of Incompatible Observables". Foundations of Physics, 4 (1), 9-18.

[111] Prugovecki E. 1975. "Measurement in Quantum Mechanics as a Stochastic Process on Spaces of Fuzzy Events". Foundations of Physics, 5 (4), 557-571.

[112] Prugovecki E. 1976a. "Probability measures on fuzzy events in phase space". J. Mathematical. Physics. 17 (4), 517-523.

[113] Prugovecki E. 1976b. "Localizability of relativistics particles in fuzzy phase space".J. Physics A. 9 (11), 1851-1859.

[114] Prugovecki E. 1976c. "Quantum 2-particle scattering in fuzzy phase space". J. Mathematical. Physics. 17 (9), 1673-1681. 
[115] Pykacz J. 1987a. "Quantum logics as families of fuzzy subsets of the set of physical states". in preprints of the Second IFSA Congress, Tokyo 2, 437.

[116] Pykacz J. 1987b. "Quantum logics and soft fuzzy probability spaces". Bulletin pour les Sous-Ensembles Flous et leurs Applications 32, 102.

[117] Pykacz J. 1988. "Probability measures in the fuzzy set approach to quantum logics". Bulletin pour les Sous-Ensembles Flous et leurs Applications 37, 81.

[118] Pykacz J. 1990. "Fuzzy quantum logics and the problem of connectives". Bulletin pour les Sous-Ensembles Flous et leurs Applications 43, 49.

[119] Pykacz J. 1992. "Fuzzy sets ideas in quantum logics". International Journal of Theoretical Physics 31 (9), 1767-1783.

[120] Ralescu D.A. 1997. "Fuzzy logic in statistical decision theory". in: Proceedings of Seventh IFSA World Congress, Praga, Republica Checa.

[121] Reznik L. Fuzzy Controllers. Newnes, Reino Unido, 1997.

[122] Römer C. \& Kandel A. 1995. "Statistical tests for fuzzy data". Fuzzy Sets and Systems 72, 1-26.

[123] Rothman K.J. 1986. Modern Epidemiology. Lippincott-Raven, EUA.

[124] Roy M.K. \& Biswas R. 1992. "I-v fuzzy relations and Sanchez's approach for medical diagnosis". Fuzzy Sets and Systems 47, 35-38.

[125] Ruan D. 1995. "Fuzzy logic in the nuclear research world". Fuzzy Sets and Systems 74, 5-13.

[126] Russo M., Santagati N.A. e Lo Pinto E. 1998. "Medicinal Chemistry and Fuzzy Logic". Journal of Information Sciences 105, 299-314.

[127] Sadegh-Zadeh K. 1994. "Fundamentals of clinical methodology: 1. Differential indication". Artificial Intelligence in Medicine 6, 83-102.

[128] Sadegh-Zadeh K. 1998. "Fundamentals of clinical methodology: 2. Etiology". Artificial Intelligence in Medicine 12, 227-270.

[129] Sadegh-Zadeh K. 1999. "Fundamentals of clinical methodology: 3. Nosology". Artificial Intelligence in Medicine 17, 87-108.

[130] Sadegh-Zadeh 2000. "Fuzzy Genomes". Artificial Intelligence in Medicine 18, $1-28$.

[131] Saitta L. \& Torasso P. 1981. "Fuzzy Characterization of Coronary Disease". Fuzzy Sets and Systems 5, 245-258. 
[132] Salski A. 1992. "Fuzzy Knowledge-based models in ecological research". Ecological Modelling 63, 103-112.

[133] Sanchez E. 1979. "Inverse of Fuzzy Relations. Application to Possibility Distributions and Medical Diagnosis". Fuzzy Sets and Systems 2, 75-86.

[134] Sanchez E. 1996. "Truth-qualification and fuzzy relations in natural languages, application to medical diagnosis". Fuzzy Sets and Systems 84, 155-167.

[135] Sanchez E., Shibata T. e Zadeh L.A. 1997. Genetic Algorithms and Fuzzy Logic Systems: Soft Computing Perspectives. editora World Scientific, Singapore.

[136] Sato M., Sato Y. e Jain L.C. 1997. Fuzzy Clustering Models and Applications. Physica-Verlag, Spring-Verlag, Alemanha.

[137] Stein W.E. 1985. "Fuzzy probability vectors". Fuzzy Sets and Systems 15, 263267.

[138] Schulz K., Huwe B. e Peiffer S. 1999. "Parameter uncertainty in chemical equilibrium calculations using fuzzy set theory". Journal of Hydrology 217, 119-134.

[139] Shaw I.S. \& Simões M.G. 1999. Controle e Modelagem Fuzzy. editora Edgard Blücher, Brasil.

[140] Shono H., Oga M., Shimomura K., Yamasaki M., Ito Y., Muro M. e Sugimori H. 1992. "Application of Fuzzy Logic to the Apgar Scoring System". Int. J. Biomed. Comput. 30, 113-123.

[141] Silva R. 2001. "LEPIDUS: Sistema especialista em medicina geral". Tese de Doutorado, Faculdade de Filosofia, Ciências e Letras de Ribeirão Preto, Universidade de São Paulo, Brasil.

[142] Singer D. 1992. "A fuzzy set approach to non-equilibrium thermodynamics". Fuzzy Sets and Systems 47, 39-48.

[143] Smets P. 1981. "Medical Diagnosis: Fuzzy Sets and Degree of Belief". Fuzzy Sets and Systems 5, 259-266.

[144] Smithson M. 1988. "Fuzzy set theory and the social sciences: the scope for applications". Fuzzy Sets and Systems 26, 1-21.

[145] Sordo J.A. 1999. "Using fuzzy set theory to assess basis set quality". Chemical Physics Letters 302, 273-280.

[146] Struchiner C.J., Burattini M.N., Ortega N.R. e Massad E. 1997. "Fuzzy Risk Estimators in Epidemiology". in: Proceedings of Soft Computing SOCO'97, NimeFrance, 64-68. 
[147] Sudkamp T. 1992. "On probability-possibility transformations". Fuzzy Sets and Systems 51, 73-81.

[148] Sugeno M. 1974. "Theory of fuzzy integrals and its applications". Tese de doutorado, Instituto de Tecnologia de Tokio, Tokio, Japão.

[149] Tarrazo M. \& Gutierrez L. 2000. "Economic expectations, fuzzy sets and financial planning". European Journal of Operational Research 126, 89-105.

[150] Theoto M., Santos M.R. e Uchiyama N. 1897. "The Fuzzy Decodings of Educative Texts". Fuzzy Sets and Systems 23, 331-345.

[151] Torasso P. 1991. "Supervising the heuristic learning in a diagnostic expert system". Fuzzy Sets and Systems 44, 357-372.

[152] Twareque Ali S. \& Doebner H. D. 1976. "On the equivalence of nonrelativistic quantm mechanics based upon sharp and fuzzy measurements". J. Math. Phys. 17 (7), 1105-1111.

[153] Twareque Ali S. \& Prugovecki E. 1977. "Systems of imprimitivity and representations of quantum mechanics on fuzzy phase spaces". J. Math. Phys. 18 (2), 219-228.

[154] Vila M.A. \& Delgado M. 1983. "On Medical Diagnosis Using Possibility Measures". Fuzzy Sets and Systems 10, 211-222.

[155] Wang G. \& Zhang Y. 1992. "The theory of fuzzy stochastic processes". Fuzzy Sets and Systems 51, 161-178.

[156] Watanabe N. \& Imaizumi T. 1993. "A fuzzy statistical test of fuzzy hypotheses". Fuzzy Sets and Systems 53, 167-178.

[157] Weeks R.M., Barenzi J.F., Wayira J.R. 1992. "A low-cost, community-based measles outbreak investigation with follow-up action". Bull. WHO 70, 317-321.

[158] Wen C. \& Lee C. 1999. "Development os a cost function for wastewater treatment systems with fuzzy regression". Fuzzy Sets and Systems 106, 143-153.

[159] Williams J.S., Matthewman A. e Brown D. 1989. "An Orthodontic Expert System". Fuzzy Sets and Systems 30, 121-133.

[160] Wu C. \& MA M. 1990. "Fuzzy norms, probabilistic norms and fuzzy metrics". Fuzzy Sets and Systems 36, 137-144.

[161] Yager R.R. \& Filev D.P. 1994.Essential of Fuzzy Modelling and Control. editora John Wiley, USA. 
[162] Yen J. \& Langari R. 1999. Fuzzy Logic: Intelligence, Control, and Information. Prentice Hall, EUA.

[163] Zadeh L.A. 1965. "Fuzzy Sets". Information and Control 8 (3), 338-353.

[164] Zadeh L.A. 1978. "Fuzzy sets as a basis for a theory of possibility". Fuzzy Sets and Systems 1 (1), 3-28.

[165] Zadeh L. A. 1973. "Outline of a New Approach to the Analysis of Complex Systems and Decision Processes". IEEE Transactions on systems, man and cybernetics S1C-3 (1), 28-44.

[166] Zajonc R.B. 1965. "Social facilitation: A solution is suggested for an old unresolved social psychological problem". Science 149, 269-274. 